Universidad de Lima

Facultad de Administración

Carrera de Negocios Internacionales

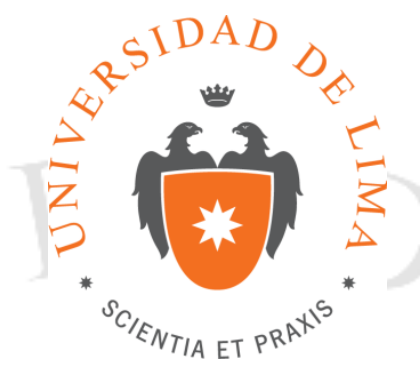

\title{
EXPORTACIÓN DE BODYS PARA BEBÉS ELABORADOS EN BASE DE ALGODÓN ORGÁNICO A BOGOTÁ
}

Trabajo de investigación para optar la licenciatura en Negocios Internacionales

Andrea Gabriela Ovalle Velazco

Código 20090806

\author{
Asesor \\ Renato Peñaflor Guerra
}

Lima - Perú

Junio de 2016 


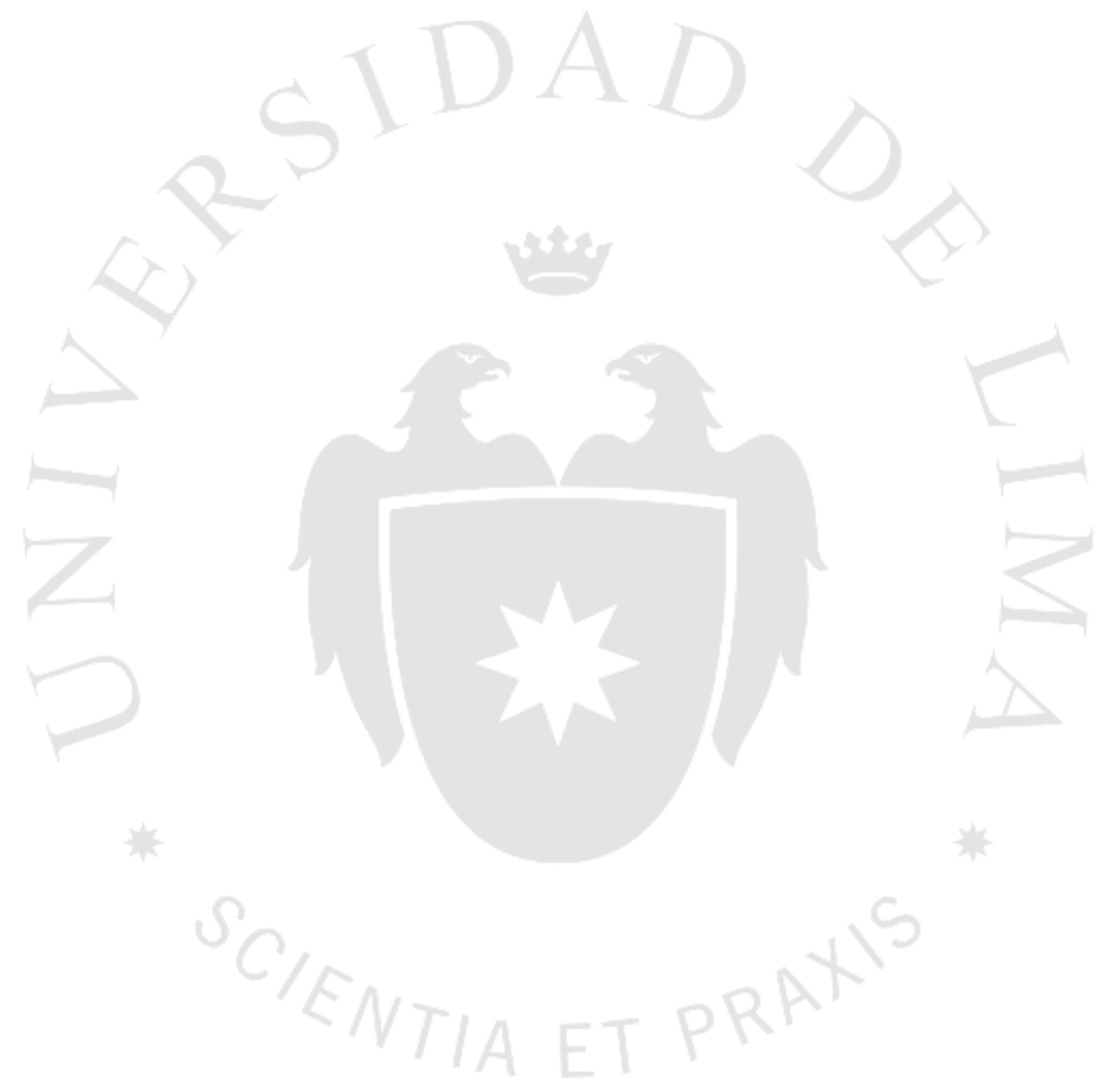




\section{EXPORTACIÓN DE BODYS PARA BEBÉS ELABORADOS EN BASE DE ALGODÓN ORGÁNICO A BOGOTÁ}




\section{ÍNDICE}

RESUMEN EJECUTIVO

CAPÍTULO I: DESCRIPCIÓN DE LA SITUACIÓN ACTUAL DEL

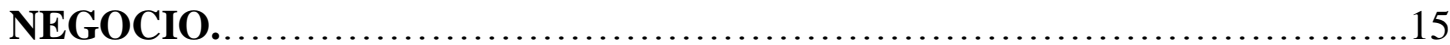

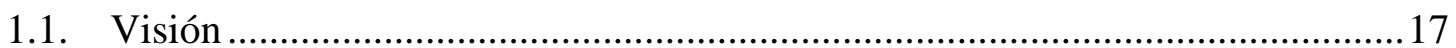

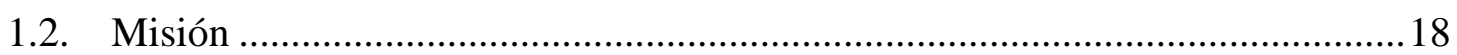

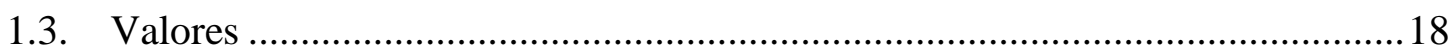

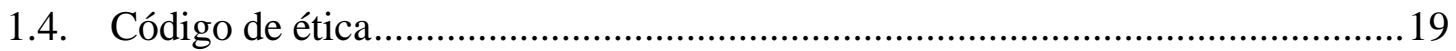

CAPÍTULO II: ANÁLISIS DE LA IDEA, OPORTUNIDAD Y MODELO DE

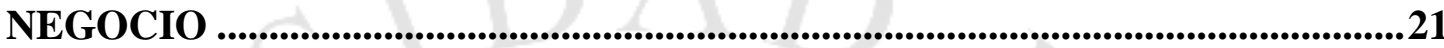

2.1. Identificación y análisis de la problemática actual .............................................21

2.2. Descripción de la idea de negocio como alternativa de solución........................22

2.3. ¿Por qué la idea sería una oportunidad de negocio? ...........................................23

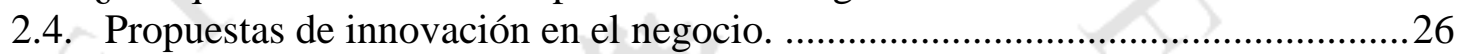

2.5. Diseño del negocio innovador, creativo y estratégico: Modelo Canvas. .............28

2.5.1.- Segmentos de mercado .....................................................................28

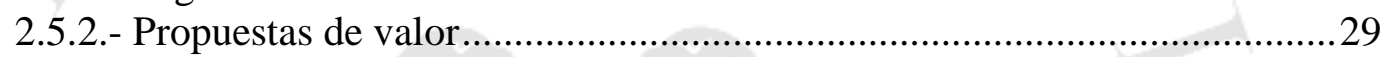

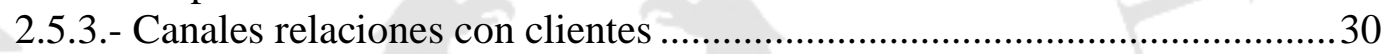

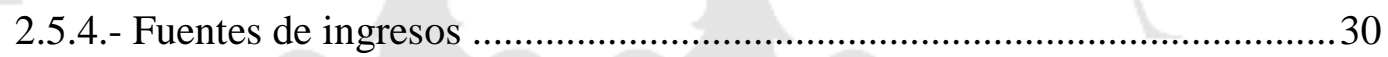

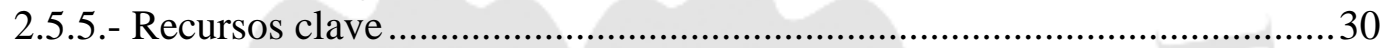

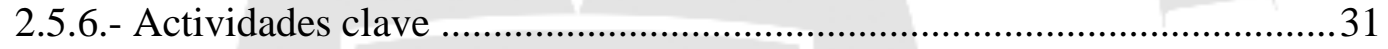

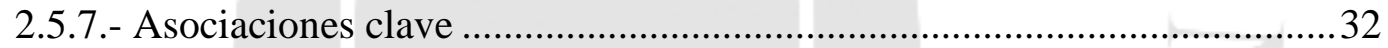

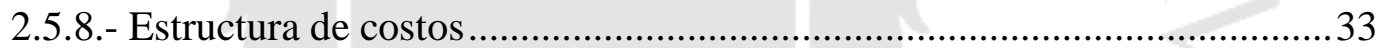

CAPÍTULO III: ESTUDIO DE MERCADO............................................................35

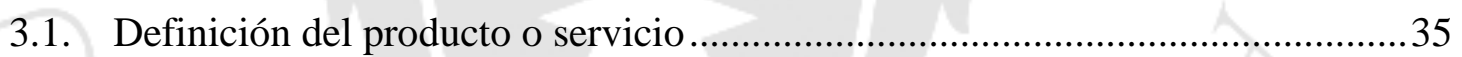

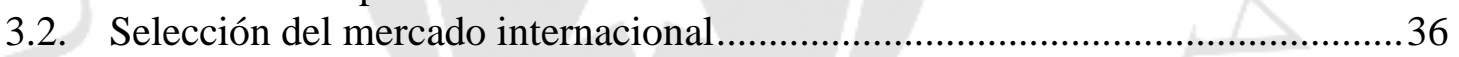

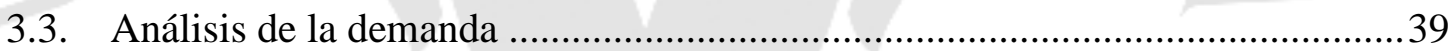

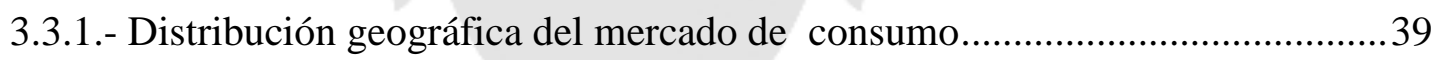

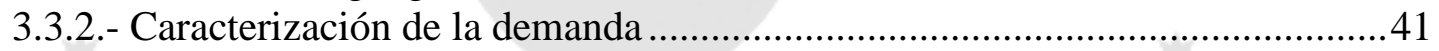

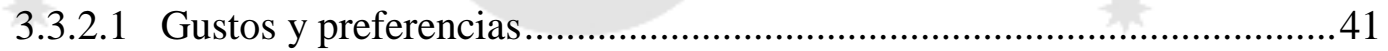

3.3.2.2 Tendencias en el mercado de destino .....................................................4 44

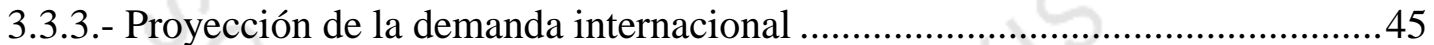

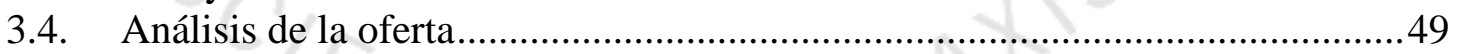

3.4.1.- Características de los principales productores de prendas de vestir ..............49

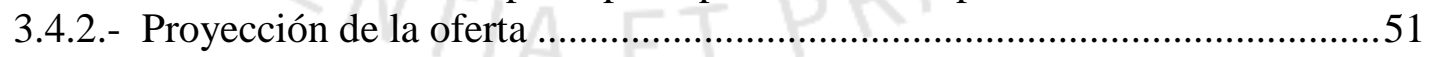

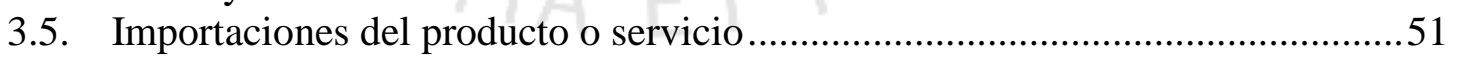

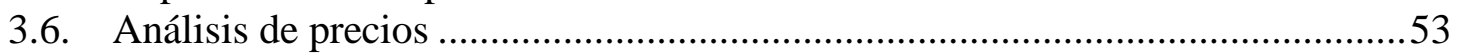

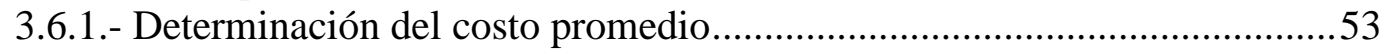

3.6.2.- Análisis histórico y proyección de precios ...............................................54

3.7. Canales de comercialización y distribución del producto ...................................55

CAPÍTULO IV: EVALUACIÓN EXTERNA ............................................................58

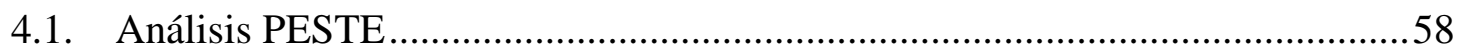

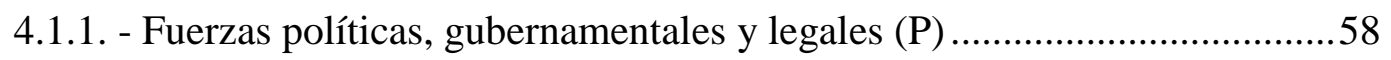

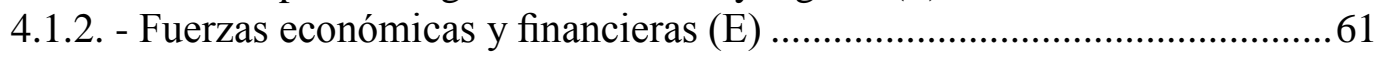

4.1.3. - Fuerzas sociales, culturales y demográficas $(\mathrm{S})$......................................6 65 


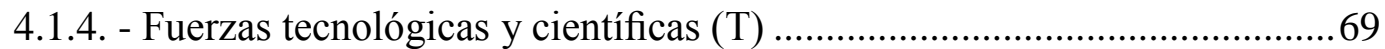

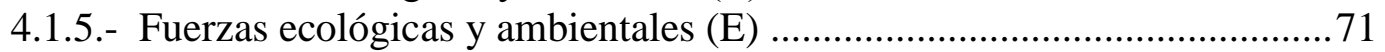

4.2. Matriz de Evaluación de Factores Externos (EFE) ........................................... 73

CAPÍTULO V: ANÁLISIS COMPETITIVO ........................................................76

5.1. Análisis de las 5 fuerzas competitivas de Michael Porter.....................................76

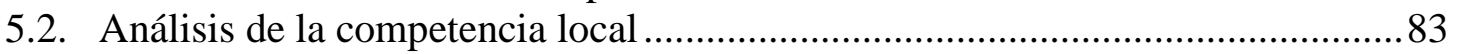

5.3. Principales empresas exportadoras o importadoras peruanas …………………....8 85

5.4. Análisis de la competencia internacional ......................................................... 87

5.5. Principales empresas exportadores internacional................................................8 88

5.6. Barreras arancelarias y no arancelarias .............................................................. 89

5.7. Matriz del Perfil Competitivo (MPC) - Industria Textil ......................................92

\section{CAPÍTULO VI: ELECCIÓN DE OBJETIVOS, ESTRATEGIAS Y POLÍTICAS}

.

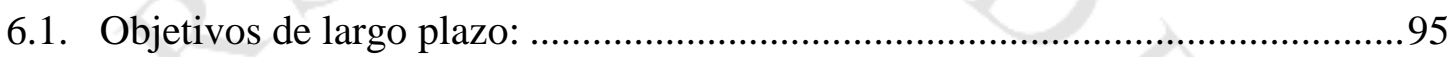

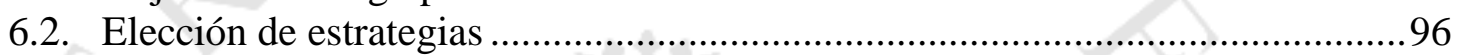

6.2.1. - Matriz de Fortalezas, Oportunidades, Debilidades y Amenazas (FODA)96

6.2.2. - Matriz Interna - Externa (IE) .................................................................97

6.2.3. - Matriz de la Gran Estrategia (GE) ........................................................98

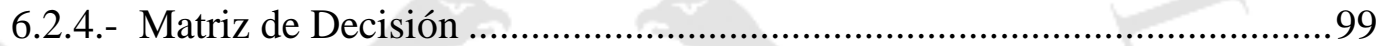

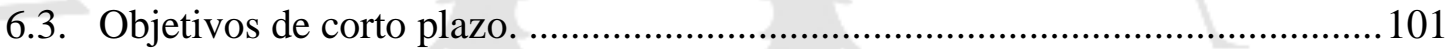

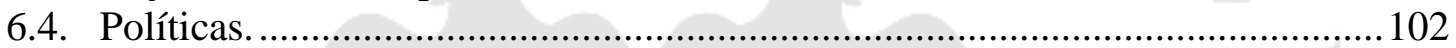

CAPÍTULO VII: PLAN DE MARKETING .......................................................105

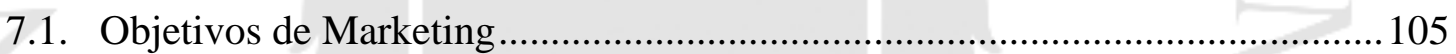

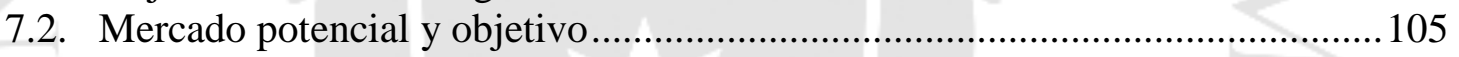

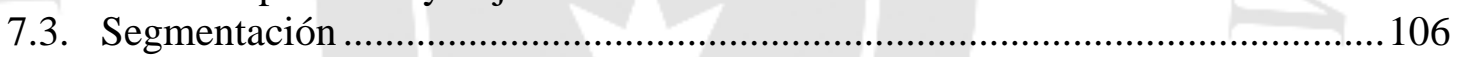

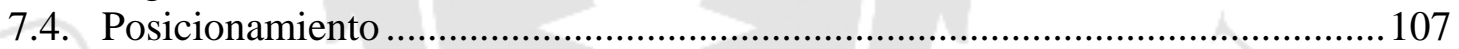

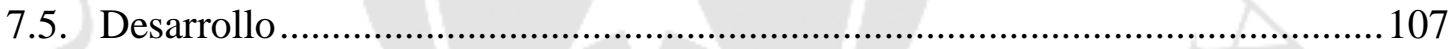

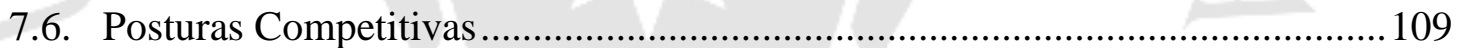

7.7. Producto (ficha técnica, envase, embalaje, etiquetado) ……………………........ 109

7.8. Precio (método para determinar precios, medios de pago) .................................113

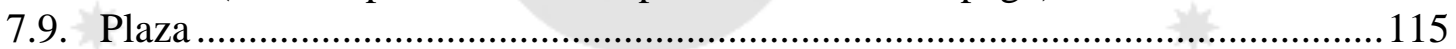

7.10. Promoción (estrategias de ingreso al mercado) ...............................................116

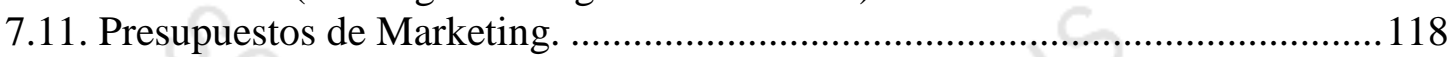

7.12. Principales factores claves de éxito a controlar …………………………........ 120

CAPÍTULO VIII: PLAN DE OPERACIONES Y/O PRODUCCIÓN ...............121

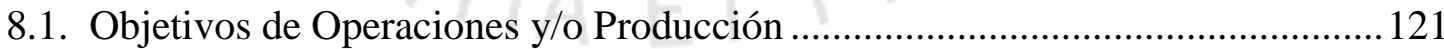

8.2. Tamaño del proyecto y factores determinantes del mismo................................... 121

8.3. Diseño y distribución de planta (flujo de trabajo y flujo de materiales) .............124

8.4. Localización, maquinarias, equipos y mobiliario ……………………………......126

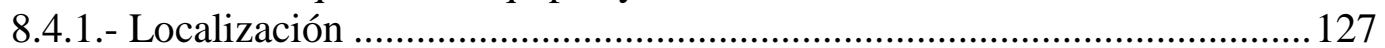

8.4.2.- Maquinarias, equipos y mobiliario: ............................................................. 130

8.5. Diagrama de flujo del proceso de producción y tecnología ..................................133

8.5.1.- Descripción de los principales procesos del proyecto ................................ 135

8.6. Descripción de productos, presentaciones, empaque, patentes, certificaciones, autorizaciones sanitarias, etc. 
8.7. Programa de Producción: utilización de capacidad instalada propia o de terceros, control de producción, asignación de recursos, control de reproceso, tiempos muertos y devoluciones por defecto

8.8. Sistema de control de procesos, calidad y costos operativos ............................. 140

8.9. Logística, gestión de existencias, compras, logística de entrada y salida, distribución de productos.

8.10. Gestión de mantenimiento correctivo y preventivo, seguridad y salud en el trabajo.

8.11. Descripción de las principales herramientas de control .................................. 142

8.12. Principales factores claves de éxito a controlar ............................................... 143

CAPÍTULO IX: PLAN LOGÍSTICO ......................................................................144

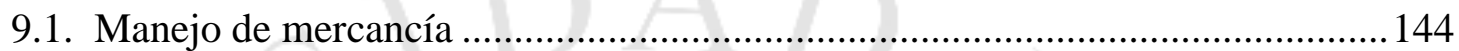

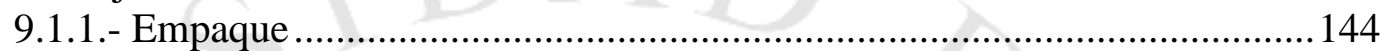

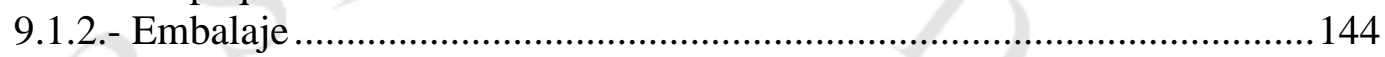

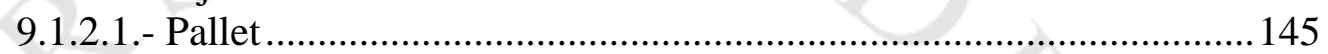

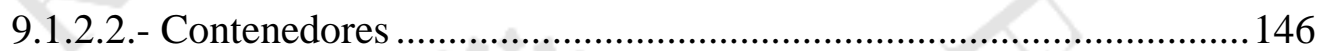

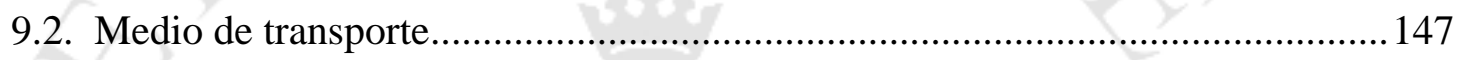

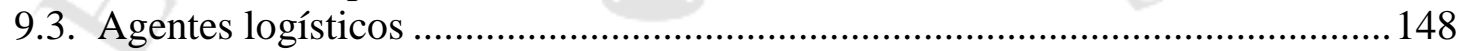

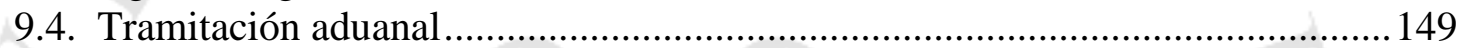

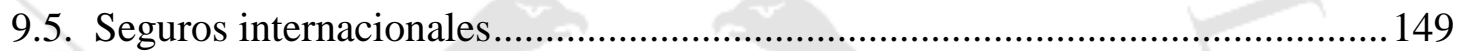

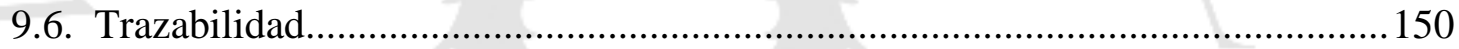

CAPÍTULO X: GESTIÓN DE CALIDAD ...............................................................151

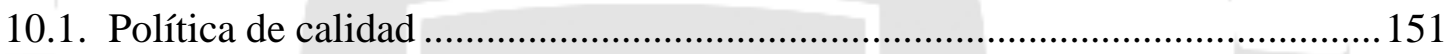

10.2. Análisis de las principales herramientas de control de calidad ......................... 152

10.3. Programa de gestión de calidad para el futuro del negocio ............................ 152

10.4. Principales factores claves de los procesos a controlar................................... 153

\section{CAPÍTULO XI: PLAN DE ADMINISTRACIÓN Y RECURSOS HUMANOS}

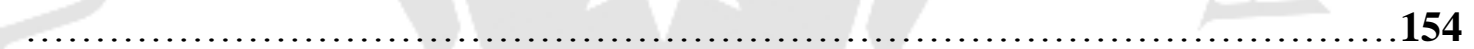

11.1. Objetivos de Administración y Recursos Humanos......................................... 154

11.2. El organigrama, descripción de puestos por área y definición el perfil del

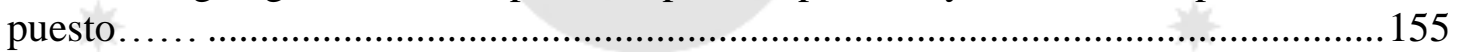

11.3. Política de selección, contratación, capacitación y desarrollo ........................... 158

11.4. Descripción de los principales procesos del negocio - Flujograma.................. 160

11.5 Diseño de las principales herramientas y/o formatos de control........................ 162

11.6. Definición de los principales factores claves de éxito a controlar ..................... 163

CAPÍTULO XII: PLAN DE FINANZAS (PRESUPUESTOS PROYECTADOS Y ANÁLISIS DE RENTABILIDAD) ............................................................164

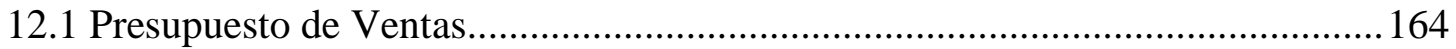

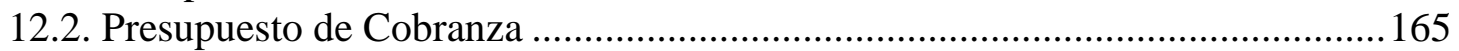

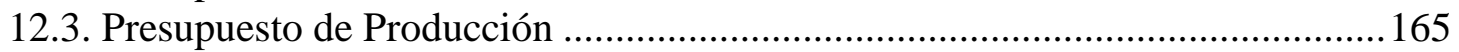

12.4 Presupuesto de Compras de Materiales de Producción............................................ 166

12.5 Presupuesto de Compras de Materiales de Empaque......................................... 166

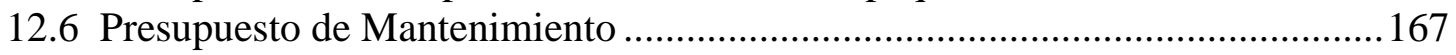

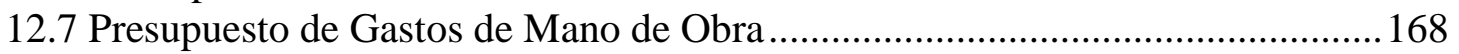

12.8 Presupuesto de Gastos Indirectos de Fabricación ...............................................168

12.9 Presupuesto de Gastos de Administración ........................................................ 169 


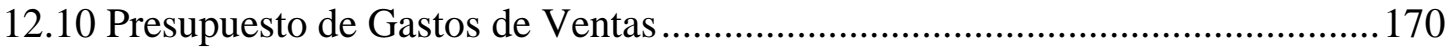

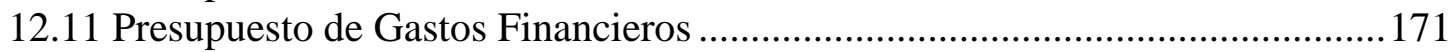

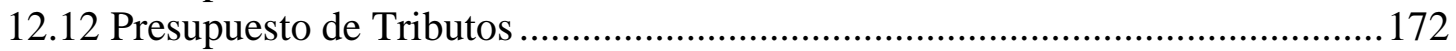

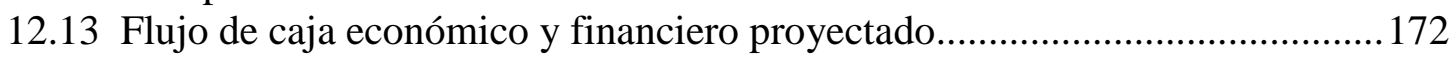

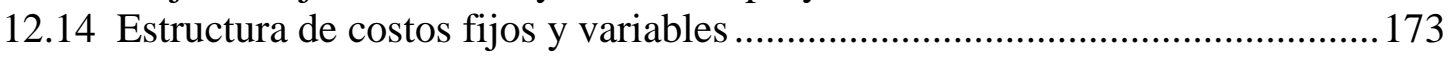

12.15 Margen y determinación de precio de venta FOB ....................................... 175

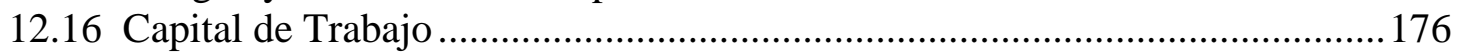

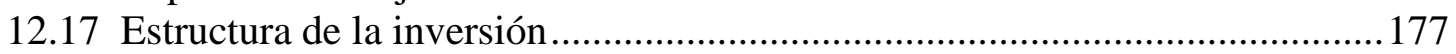

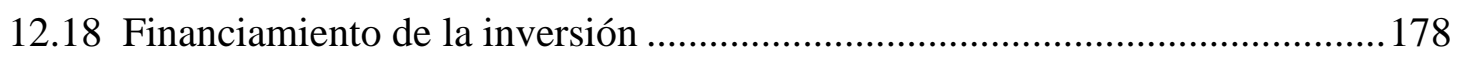

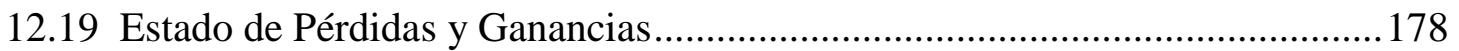

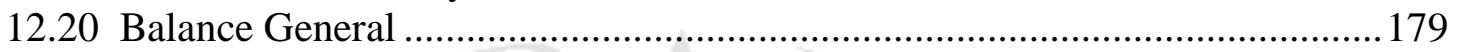

12.21 Evaluación Económica y financiera del negocio (TIR, TIRF, VAN Y VANF)

CAPÍTULO XIII: EVALUACIÓN Y CONTROL ..................................................182

13.1. Balanced Scorecard (Identificación de Indicadores)...................................... 182

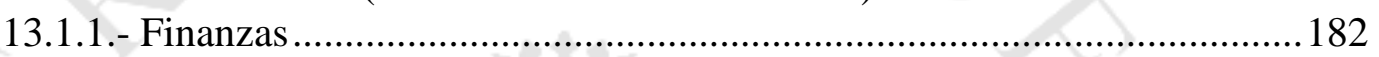

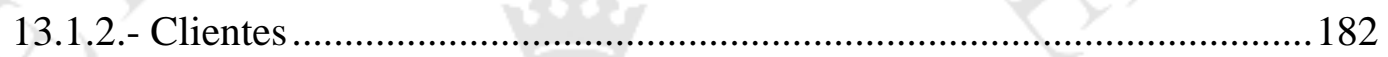

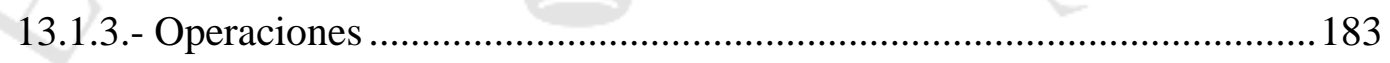

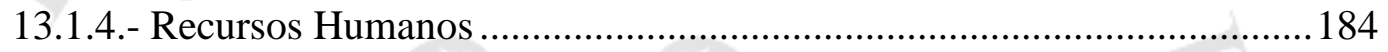

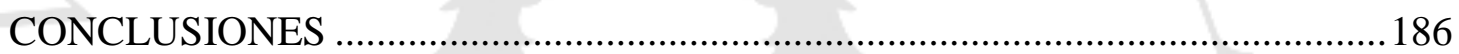

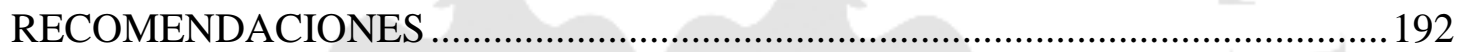

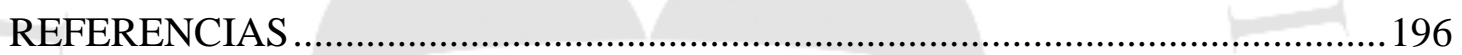

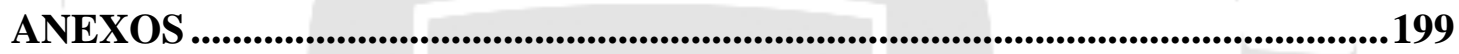

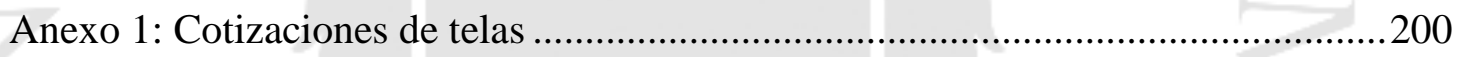

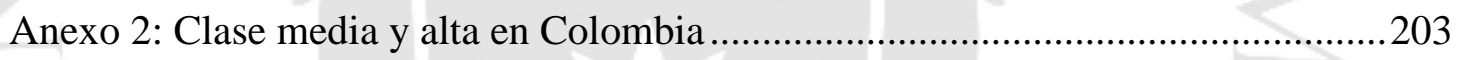

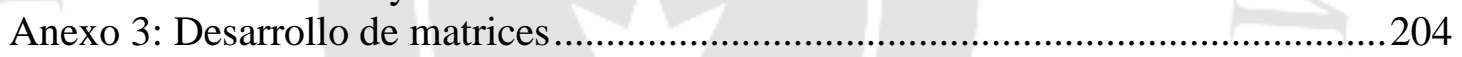

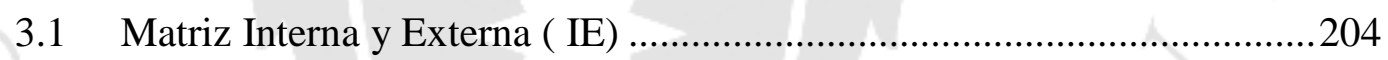

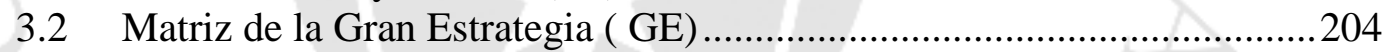

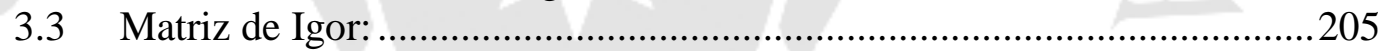

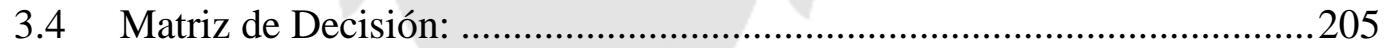

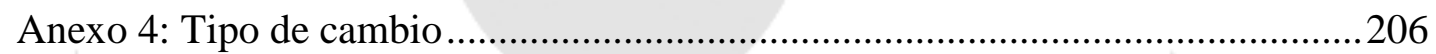

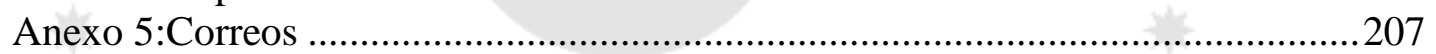

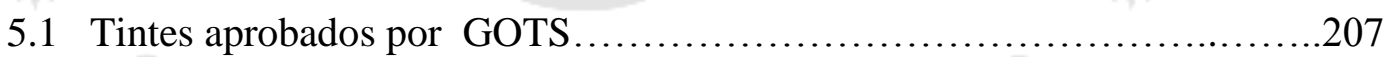

5.2 Cotización de certificación GOTS ....................................210

5.3 Proveedor de Envases.................................................213

5.4 Proveedor de Embalaje................................................215

Anexo 6: Reglamento de confecciones..................................217 


\section{ÍNDICE DE CUADROS}

Cuadro $\mathrm{N}^{\circ}$ 1: Productos Potenciales en Colombia .................................................2 24

Cuadro N²: Ventas de Categoría Ropa para bebés y niños: Volumen 2010-2014

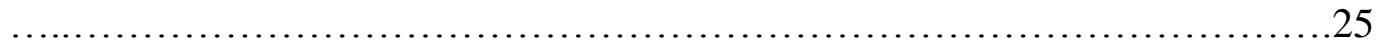

Cuadro N³: Ventas de Categoría Ropa para bebés y niños: Volumen 2015-2019

..................................................................... 25

Cuadro $\mathrm{N}^{\circ} 4$ : Resumen del Modelo Canvas ......................................................2 28

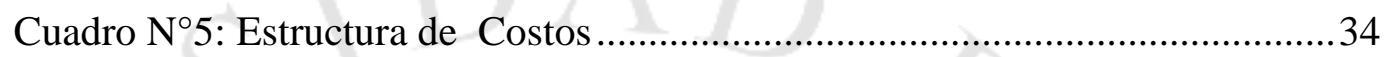

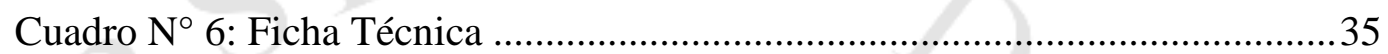

Cuadro N 7: Potencialidad de los países de Latinoamérica. .................................. 37

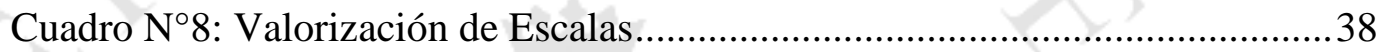

Cuadro $N^{\circ}$ 9: Criterios para la selección del Mercado Internacional. ....................39

Cuadro $N^{\circ} 10$ : Estadísticas de Importaciones Colombianas (2012-2015) .............40

Cuadro $\mathrm{N}^{\circ} 11$ : Millones de habitantes por rangos de Población infantil en

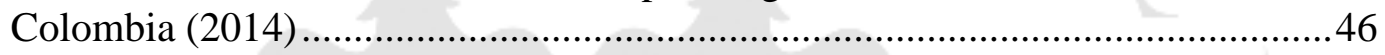

Cuadro N²12: Demanda Potencial (2015) ........................................................ 47

Cuadro $N^{\circ}$ 13: Demanda Objetivo Internacional Mensual (2016-2020)...............48

Cuadro $N^{\circ}$ 14: Demanda Objetivo Internacional Mensual (2016) .......................48

Cuadro $N^{\circ}$ 15: Demanda Objetivo Internacional Anual (2016-2020) ..................49

Cuadro No 16: Empresas Productoras de algodón orgánico Peruano (2015) ....... 49

Cuadro $\mathrm{N}^{\circ} 17$ : Empresas Productoras de ropa para bebes con algodón orgánico en

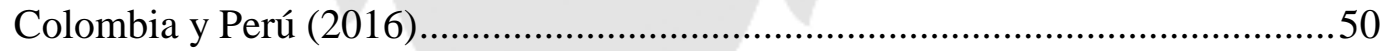

Cuadro $N^{\circ} 18$ : Proyección de oferta en US\$ 2014-2019......................................51

Cuadro $\mathrm{N}^{\circ}$ 19: Cantidad importada por kilogramos de prendas por Colombia

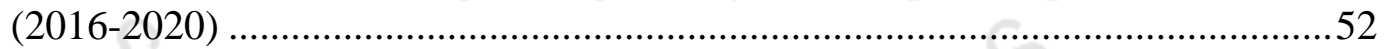

Cuadro N²0: Importaciones de prendas de Perú a Colombia (2010-2015) ........53

Cuadro $N^{\circ} 21$ : Precios FOB referenciales en kilogramos 2015 (US\$/KG)...........54

Cuadro $N^{\circ} 22$ : Precios FOB referenciales 2011-2018 (US\$/KG) .........................55

Cuadro $\mathrm{N}^{\circ}$ 23: Indicadores Económicos (2014) .................................................61

Cuadro N²4: Crecimiento Económico de Socios Comerciales (2015-2015)......64

Cuadro N²5: Tasa de Cambio en Colombia (2010-2015) ..................................65

Cuadro N²6: Crecimiento Poblacional Proyectado (2016-2020) ........................66

Cuadro $N^{\circ} 27$ : Estadísticas Vitales (2005-2020) ..................................................6 68

Cuadro N 28: Valorización de Escalas............................................................... 74

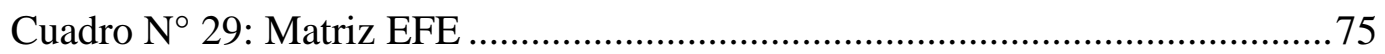


Cuadro $\mathrm{N}^{\circ} 30$ : Principales competidores de produtos sustitutos (2014) ............... 78

Cuadro No 31: Principales empresas que compran Algodón Orgánico (2015) .... 79

Cuadro $N^{\circ}$ 32: Principales proveedores de Algodón Orgánico a nivel Mundial (2015)

Cuadro $N^{\circ}$ 33: Principales tiendas para bebé Colombianas (2016)..................... 82

Cuadro $N^{\circ}$ 34: Exportaciones peruanas al mundo (2015) .................................. 84

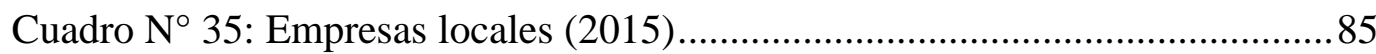

Cuadro $N^{\circ}$ 36: Exportaciones Peruanas a Colombia (2015) ................................86

Cuadro $N^{\circ}$ 37: Países importadores a Colombia (2014).....................................8 88

Cuadro $\mathrm{N}^{\circ}$ 38: Exportaciones de prendas a Colombia (2015)..........................8 89

Cuadro $N^{\circ}$ 39: Medidas Impositivas para la sub-partida Nacional 6111.20.00.0

No 39: Medidas Impositivas para la sub-partida Nacional 6111.20.00.0

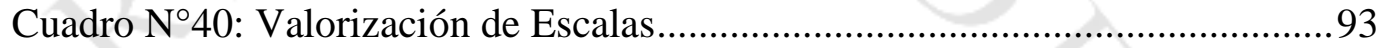

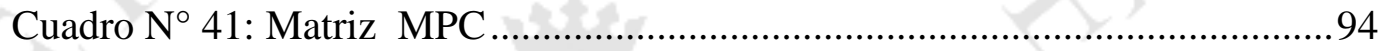

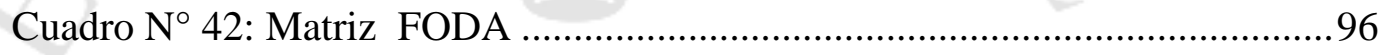

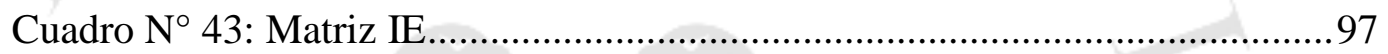

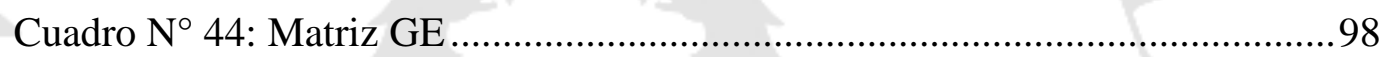

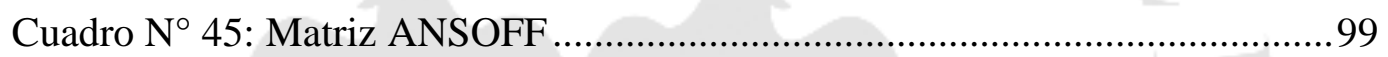

Cuadro $N^{\circ}$ 46: Matriz de Decisión ....................................................................... 100

Cuadro N47: Fases y Actividades Promocionales .............................................. 108

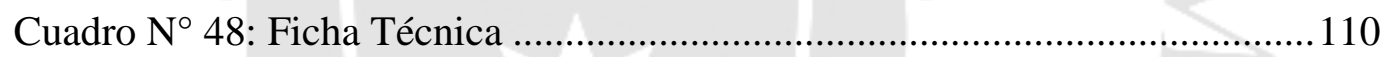

Cuadro $N^{\circ}$ 49: Presupuesto de Marketing (2016-2020) ...................................... 120

Cuadro N50: Demanda Objetivo Proyectada en Kg y US\$ (2016-2020) .......... 122

Cuadro N ${ }^{\circ} 51$ : Demanda potencial proyectada por kg (2016-2020) ................... 123

Cuadro N ${ }^{\circ} 52$ : Demanda Potencial Proyectada expresada en Kg y US\$ (2016-

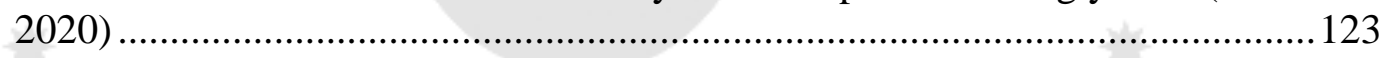

Cuadro N53: Demanda Objetivo Proyectada en Kg y US\$ (2016-2020) .......... 124

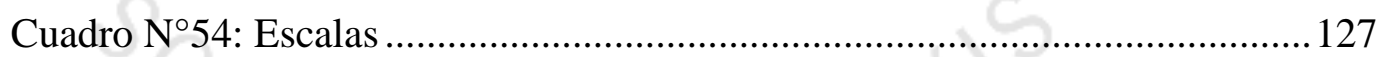

Cuadro N ${ }^{\circ} 55$ : Criterios para la Macro Localización .......................................... 128

Cuadro N56: Criterios para la Micro localización ............................................ 128

Cuadro N 57: Maquinarias y Mobiliario …….................................................. 131

Cuadro N58: Capacidad de Almacenamiento y procesamiento......................... 139

Cuadro N59: Capacidad de Procesamiento por utilizar y utilizada (2016)....... 140

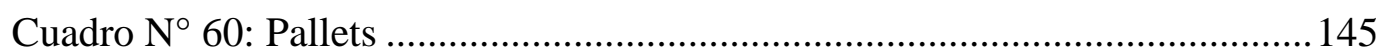

Cuadro $\mathrm{N}^{\circ}$ 61: Herramientas de Control de Calidad ........................................... 152

Cuadro N62: Presupuesto de ventas n US\$ (2016-2020).................................. 164

Cuadro N63: Presupuesto de Cobranzas Anual en US\$-5 años (2016-2020)... 165 
Cuadro N${ }^{\circ} 64$ : Presupuesto de Producción Anual en US\$-5 años (20162020).. 1655

Cuadro $N^{\circ} 65$ : Materiales de Producción en US\$ (2016-2020) ............................ 166

Cuadro N66: Materiales de Empaque en US\$ (2016-2020) ............................. 166

Cuadro $N^{\circ} 67$ : Presupuesto de Material de Empaque en US\$-5 años(2016-2020)

Cuadro N68: Presupuesto de Mantenimiento anual en US\$-5 años (2016-2020)

Cuadro N69: Presupuesto de MOD en US\$-5 años (2016-2020) ...................... 168

Cuadro N70: Presupuesto de Gastos de Fabricación Anual en US\$-5 años (20162020).

Cuadro N ${ }^{\circ} 71$ : Presupuesto de Gastos de Administración Anual en US\$-5 años

(2016-2020).

Cuadro N ${ }^{\circ} 72$ : Presupuesto de Gastos de Ventas Anual en US\$-5 años (20162020)

Cuadro No73: Presupuesto de Gastos Financieros (2016-2020) ........................ 171

Cuadro No74: Presupuesto de Tributos en US\$ (2016-2020) ........................... 172

Cuadro N75: Flujo de Caja económico y financiero en US\$ (2016-2020)....... 173

Cuadro $N^{\circ} 76$ : Costos Fijos anualizados en US\$ (2016-2020) ........................... 174

Cuadro No77: Costos Variables en US\$ (2016-2020) ......................................... 174

Cuadro N78: Gastos de Exportación en US\$ (2016-2020) ............................... 175

Cuadro N79: Costo Total por Prenda a Exportar en US\$ (2016) ...................... 175

Cuadro No80: Determinación del Precio FCA en US\$ (2016-2019) ...................176

Cuadro N ${ }^{\circ} 81$ : Capital de Trabajo en US\$ (2016-2020) .................................... 176

Cuadro N82: Estructura de Inversión en US\$ .................................................. 177

Cuadro No83: Estructura de Inversión (2016-2020) .......................................... 178

Cuadro No84: Estado de Resultados Integrales en US\$ (2016-2020) ................. 179

Cuadro N 85: Balance General en US\$ (2016-2020)....................................... 180

Cuadro N ${ }^{\circ} 86$ : Ratios Económicos y Financieros (2016-2020) .......................... 181

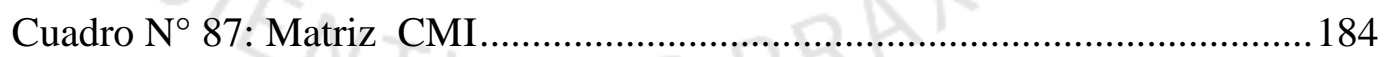

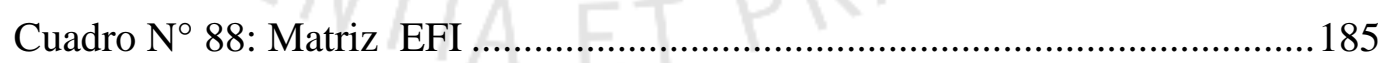




\section{ÍNDICE DE GRÁFICOS}

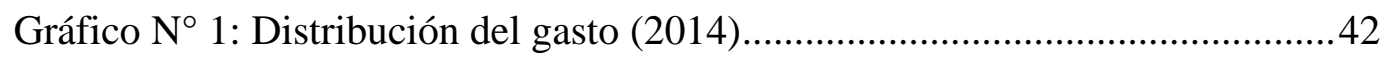

Gráfico $\mathrm{N}^{\circ}$ 2: Factores que influyen en la decisión de compra (2014) ................43

Gráfico $\mathrm{N}^{\circ}$ 3: Factores que influyen en la decisión de compra de textiles(2014) 44

Gráfico N4: Demanda histórica en miles de US\$ de prendas (2010-2014) ........52

Gráfico $N^{\circ}$ 5: Canales de Comercio y Distribución de prendas para bebés(2014)

Gráfico $\mathrm{N}^{\circ}$ 6: Evolución del PBI Colombiano (2005-2015) .....................63

Gráfico No 7: Cifras Colombianas (2014-2016).................................................63

Gráfico No 8: Crecimiento de la Industria (2000-2016) ....................................64

Gráfico $N^{\circ}$ 9: Nacimientos por grupo de edad en Colombia (2014) ....................67 67

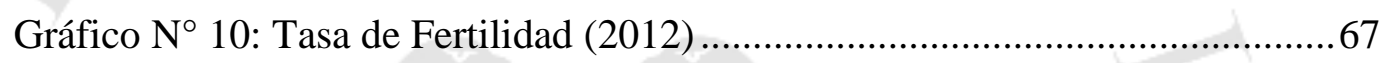

Gráfico $\mathrm{N}^{\circ}$ 11: Colombianos que usan internet (2013) ....................................... 70

Gráfico $\mathrm{N}^{\circ}$ 12: Diamante de Porter ................................................................... 76

Gráfico No 13: Producción y Comercio de algodón orgánico(2014) .....................79

Gráfico $N^{\circ}$ 14: Proceso del Método Costing ..................................................... 114

Gráfico $N^{\circ}$ 15: Pago Contra Documento - D/P ............................................... 115

Gráfico $\mathrm{N}^{\circ} 16$ : Flujo de trabajo y flujo de materiales ........................................ 125

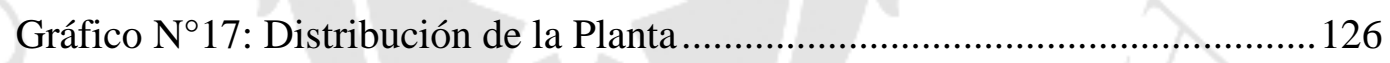

Gráfico $\mathrm{N}^{\circ}$ 18: Diagrama de flujo del proceso de producción y tecnología......... 137

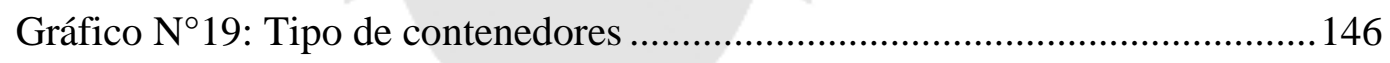

Gráfico N²0: Tipo de transporte en Colombia - Bogotá (2015) ....................... 147

Gráfico N $\mathrm{N}^{\circ}$ 21: Mapa de Procesos ................................................................ 150

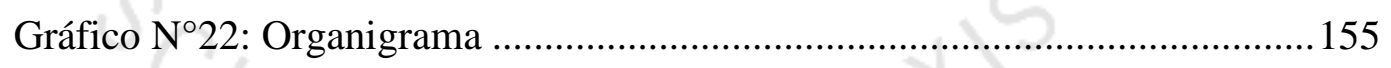

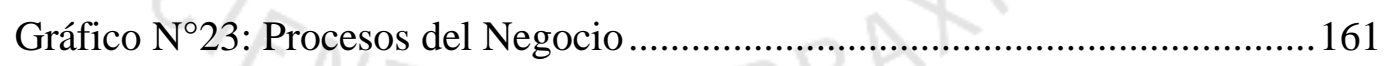




\section{RESUMEN EJECUTIVO}

La empresa denominada Teco Caricias S.A.C se creará específicamente para fines del presente trabajo, el cual consiste en realizar un plan de negocios para exportación. Estará conformada por los accionistas Andrea Ovalle Velazco, José Ángel Velazco y Víctor Alfredo Ovalle Raá, los cuales proponen la venta de prendas de vestir para bebés (Bodies).

El producto estará elaborado con algodón $100 \%$ orgánico peruano, donde los colores que primarán serán: crema, café y verde oliva pues estos son nativos de la planta algodonera. Estos bodies serán distintos a los de la competencia debido a que los empaques son elaborados con materiales ecológicos. Este es el caso de la bolsa de yute que favorece al medio ambiente y los clientes podrán otorgarle otro uso como el almacenamiento de productos agroalimentarios del hogar, como azúcar, cereales, etc.

Por otro lado, las prendas serán diferenciadas por los diseños exclusivos, para los cuales existirán dos diseñadores tanto Peruano como Colombiano. Al iniciar la presente empresa se trabajará con la elaboración de prendas de una sola estación para observar la acogida que se tendrá del público con el propósito de expandirse a largo plazo. El beneficio que traerán las prendas orgánicas será que cuando los bebés usen los bodies su piel no se irritará ni producirá reacciones alérgicas; además, la temperatura corporal de ellos se mantendrá de forma natural.

El mercado objetivo al cual se exportarán las prendas antes mencionadas estará segmentado por las edades de 0-24 meses dado que en este rango el público objetivo ha 
sido favorable. Se realizó un análisis comparativo entre países donde el interés por consumo de compras de prendas orgánicas es alto y el resultado fue favorable para Colombia. En este país, existe una tendencia creciente para la industria textil y la rentabilidad para invertir es una de las más altas en Latinoamérica. Por ende, se eligió la ciudad de Bogotá por contar con una clase media mayoritaria y principalmente porque es la capital del mercado Colombiano.

Las estrategias que se utilizarán para ingresar al mercado Colombiano en el entorno de marketing se darán por las visitas a ferias, empresas y brókeres. Luego de realizar estas actividades, se lanzará el producto, lo que implicará una entrega de muestras, afiches y la creación de la página web. Cuando se realicen las ventas del producto, se deberá brindar un servicio post venta dándole seguimiento a clientes al azar para averiguar si existió satisfacción al momento de la compra de los bodies. Por otro lado, las estrategias a utilizar en el entorno operacional, serán la implementación de principios y políticas de negociación a través del comercio justo. También, se deberá implementar, un proceso logístico para facilitar la exportación del producto con indicadores para un óptimo seguimiento. Por último, en la logística existirá una evaluación de trazabilidad para que los procesos ofrecidos sean los correctos.

La inversión requerida para este proyecto será de US\$39 032.04 dólares americanos, la cual estará financiada en un $75 \%$ por capital propio. Con el análisis financiero, mostrado en el último capítulo del presente proyecto, se apreciará que es viable debido a que tanto el VAN económico como el financiero son positivos con US\$57 532.88 y US\$58 350.88 respectivamente. Además, el COK (20.58\%) es mayor que el WACC (18.97\%) y que la tasa de préstamo por el banco (20.19\%). Estos 
indicadores se deben dar porque es el mínimo de retorno que la empresa espera obtener. El tiempo en la cual la empresa recuperará la inversión se dará a finales del tercer año.

El precio al cual está condicionado el VAN y el TIR antes propuesto y al que se exportarán las prendas será de US\$10.71 los primeros tres años para luego incrementarse a US\$11.01 bajo la modalidad aérea por el Incoterm FCA. Sin embargo, si se requierese utilizar Incoterm CIP, es decir, incluir a ese precio el seguro además del flete, el precio final será de US\$12.77. Este precio comprenderá los costos de producción como: los insumos (tela), la cual será obtenida por el proveedor principal Bergman Rivera S.A.C; las bolsas de yute como envase; las etiquetas orgánicas; la compra de maquinaria, entre otros costos productivos y logísticos. 


\section{CAPITULO I: DESCRIPCIÓN DE LA SITUACIÓN ACTUAL DEL NEGOCIO}

En el presente documento se da una idea del plan de negocio para la exportación de prendas de bebé (bodies), elaboradas en algodón orgánico. El producto debe comprender los requisitos de calidad y preferencias del país de destino para que se incorpore a dicho mercado y satisfaga así las expectativas del consumidor y cliente final.

En las siguientes secciones se observará que se realizó un análisis de la idea, oportunidad y modelo de negocio, englobándose en un estudio de mercado. Todo esto, seguido de un estudio técnico que pretende conocer más sobre el país a dónde se exportará mediante una evaluación interna y externa seguida de un plan de marketing, operacional, logístico, administrativo y de calidad adecuado. Por último, se terminará el presente estudio con la evaluación financiera y las conclusiones.

Se creará una empresa para el plan de negocio propuesto, la cual se dedicará a la producción, comercialización y exportación de prendas del sector de bebés. La imagen a difundir será la destacada calidad y elegancia de las prendas realizadas por manos peruanas con diversas exigencias del mercado internacional. El principal objetivo es tomar una decisión con respecto a la oportunidad y viabilidad del emprendimiento para que este negocio pueda surgir de manera óptima.

La razón social a ser usada será de una Sociedad Anónima Cerrada (S.A.C.) propiedad de Andrea Gabriela Ovalle Velazco, como socia principal, con DNI: 
70669721 con número de RUC: 1279660700, domiciliada en la Calle Esteban Bentarelli 121, San Borja, Lima, Perú.

Para la denominación de la empresa se decidió relacionar las palabras "Teco" como textiles ecológicos y "caricias" que se vincula con la suavidad y delicadeza de los bebés. Además, la marca con la cual se irá será, la misma por su significado, TecoCaricias. Por otro lado, se denominará "S.A.C" pues la empresa es creada por socios mayoritarios, los cuales son el Sr. José Ángel Velazco y Sr. Víctor Alfredo Ovalle Raá, quienes participarán de forma directa y activa en la administración de la empresa, y permitirán tener mayores posibilidades para ampliar la inversión.

La inversión requerida para este proyecto será de US\$38 719.46, la cual estará financiada en un $75 \%$ por capital propio. Esta inversión está dada por los conceptos de: maquinarias y equipos, muebles y enseres, capital de trabajo y los gastos preoperativos. El capital social será fraccionado entre los tres (3) socios por un total de US\$29 039.60, equivalente al 75\% del total de inversión, donde el restante $25 \%$ será financiado por un préstamo bancario; el Sr. Ovalle Raá tendrá un aporte del 30\%, seguido del Sr. Velazco con $30 \%$ y la creadora del presente negocio, Srta. Ovalle, tendrá un aporte del $40 \%$.

Con respecto al régimen tributario laboral, según una entrevista realizada al Sr. Diego Zubiaga Velarde (2016), actual Tributarista de una reconocida empresa de consultoría contable (BDO), antes de acogerse a un régimen tributario laboral se tiene que analizar si se cumple con las especificaciones dadas. Para que esta empresa pueda acogerse a este Régimen se debe verificar que se cumplan diversos requisitos, como: 
1. Los ingresos en el ejercicio no deben superar los $\mathrm{S} / 525,000.00$

2. El valor de los activos fijos, con excepción de los predios y vehículos no deben superar los $\mathrm{S} / 126,000.00$

3. El monto de las adquisiciones propias (sin incluir compras de activos fijos), no supere los S/ 525, 000.

4. No tener más de 10 trabajadores en la empresa.

En este caso, “Teco Caricias S.A.C” se acogerá al Régimen Especial (RER) cuando se inicie, debido a que bajo este régimen sólo se tendría que realizar un pago mensual de $1,5 \%$ de sus ingresos netos mensuales, sin obligación de hacer un pago ni, presentar la Declaración Jurada Anual del Impuesto a la Renta anual, ni de llevar libros y registros contables aparte de los registros de compras y ventas. La empresa en un largo plazo se acogerá al régimen General de acuerdo a las perspectivas de crecimiento.

Los gerentes principales que conformarán la empresa serán: (1) Gerente General, Andrea Ovalle; (2) Lilian Patricia Ponce de León, Jefa del área Comercial (ventas, documentación y marketing); (3) Alfredo Urbina, Jefe de Producción y Logística, el cual tendrá a cargo a tres operarios en la parte de producción de calidad.

\subsection{Visión}

Ser una empresa Peruana reconocida y competente por la alta calidad y exclusividad de los diseños, en el plazo de cinco años, en el mercado de Bogotá dentro del sector orgánico de prendas para bebés. 


\subsection{Misión}

Teco Caricias S.A.C se dedica a la compra de telas orgánicas de origen peruano, dirigida hacia el sector bebés, para luego confeccionar bodies con diversos insumos orgánicos y diseños propios para venderlos a los padres de familia en el mercado de Bogotá con alta calidad y con certificación GOTS (Global Organic Textile Standard).

\subsection{Valores}

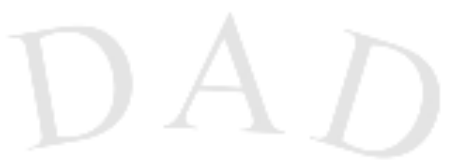

- Puntualidad: La empresa se compromete a ser puntual con respecto a la entrega de pedidos y sobre todo con los plazos acordados para la producción de las prendas pactadas en los contratos. Se realizarán seguimientos a los pedidos, con una persona de contacto en el mercado acordado.

- Respeto: La lealtad hacia la organización, honestidad y respeto mutuo es un pilar importante para la organización. Todo esto englobará un trato transparente hacia los clientes como a los trabajadores de la empresa. Esta integridad se cumplirá fomentando un buen entorno laboral con los trabajadores, tanto operarios como gerentes.

- Excelencia: La excelencia además de ser un valor será un objetivo a lograr para la empresa en su primer año de producción. Este valor se cumplirá teniendo la máxima calidad en las prendas que ofrece al mercado, destacando por sus diseños únicos y la elaboración de los mismos mediante una mejora continua.

- Trabajo en Equipo: El trabajo en equipo motivará a que exista unión en la empresa. Aquí el personal se apoyará entre sí de manera incondicional ante los inconvenientes que se puedan desarrollar u objetivos trazados durante sus labores. 
- Responsabilidad: Teco Caricias S.A.C debe estar comprometida con la responsabilidad social de la empresa, tanto con los colaboradores y trabajadores de la misma. Esto se cumplirá aplicando la política de "dos por uno", es decir, cada dos prendas que se compren una será otorgada a pobladores de bajos recursos para que así mejoren su calidad de vida. Por otro lado, estará comprometida con el buen uso de los insumos (telas) y cuidado con el medio ambiente.

- Comunicación: Existirá una óptima comunicación horizontal. Esta se va a lograr cuando los gerentes y empleados deseen aportar ideas para la empresa o deseen dialogar. La comunicación se dará de forma igualitaria: tendrá la misma influencia y valor tanto por una entidad de alto, mediano o bajo grado.

\subsection{Código de ética}

Se contará con un código de ética el cual tendrá las normas o principios más destacados, tales como:

- Con los proveedores y clientes:

- Se deberá seleccionar a los proveedores que cumplan con los requisitos para la exportación de las prendas, es decir, estos deben utilizar materiales que no perjudiquen al medio ambiente como el uso de pesticidas. Por otro lado, los proveedores deberán presentar las certificaciones internacionales adecuadas, como lo es GOTS.

- Debe existir confidencialidad en cuanto a los diseños elaborados en la empresa. Estos no podrán ser plagiados por otro proveedor o cliente que puedan hacer uso indebido del mismo. 
○ Se deberá ofrecer productos innovadores de la más alta calidad de algodón orgánico, los cuales estén en stock y no ofrecer alguno que no exista o esté en proceso de elaboración.

- Con respecto a la Gerencia:

- No se deberá aceptar, ni entregar presentes a los gerentes fuera de épocas festivas. Sólo se aceptarán en temporada Navideña y en el onomástico del trabajador.

- Deberá llevar las cuentas de la empresa y sus labores asignadas con responsabilidad, con total transparencia y primando la puntualidad.

- Con respecto a los trabajadores de la empresa:

- Debe existir un trato igualitario. La empresa rechazará la violencia y la discriminación por status económico, raza o ante cualquier condición. Si existiese algún caso, será sancionado con el despido inmediato del trabajador.

o Toda la información y material de la empresa no podrá ser copiado y /o tomado en préstamo respectivamente. 


\section{CAPITULO II: ANÁLISIS DE LA IDEA, OPORTUNIDAD Y MODELO DE NEGOCIO}

\section{1.- Identificación y análisis de la problemática actual}

La diferencia entre las prendas tradicionales y las prendas orgánicas es el algodón. Según el Centro de Comercio Internacional, en La Guía del exportador de Algodón (2016), las semillas para la obtención del algodón tradicional tienen alteraciones genéticas tratadas con fertilizantes, insecticidas, químicos y pesticidas mientras que, las semillas del algodón orgánico son naturales y para su producción se emplea, en vez de químicos, humus al igual que para controlar las plagas se hace uso de insectos para no perjudicar el cultivo.

El problema de las prendas tradicionales es que causan irritación en la piel de los bebes (sarpullido) entre otros efectos debido al uso de los químicos ya mencionados. Este problema afecta en mayor proporción a los recién nacidos, ya que tienen una piel delicada, y originarían un gasto extra en los padres de familias con la compra de medicamentos y tratamientos para las reacciones alérgicas en ellos.

Según la Sociedad Peruana de Dermatología (2015), la piel del recién nacido y niños pequeños es un $40 \%$ más delgada y porosa que la de un adulto por lo que origina que estos absorban sustancias (por ejemplo de la ropa) hacia su cuerpo con mucha facilidad provocando daños respiratorios. Por otro lado, el PH de ellos es 8.9 veces menor que las demás personas, lo cual produce irritabilidad y se corre el riesgo de que, ciertas sustancias o por la calidad de la prenda (sintéticos, algodón o lana), dañen su piel. 
Mario Távara (2016), Presidente del Capítulo de Pediatría Social, sostiene que existen ciertas características en las prendas sintéticas o de mala calidad que originan que aumente la posibilidad de toxicidad y lesiones por el uso de estos. Al momento que producen problemas en la piel del bebé se deben aplicar ciertas recomendaciones para su recuperación como es el uso de cremas, visitas al médico y control, lo que origina preocupación por la salud además de gastos extras en la economía familiar.

Según la OMS (Organización mundial de la salud), el cultivo de algodón convencional requiere un elevado uso de pesticidas y fertilizantes (representaría $10 \%$ de los pesticidas utilizadas por solo 2,5 a $3 \%$ de las tierras cultivadas). (Organización

Mundial de la Salud, 2014)

Lo que la OMS declara, es que el uso de prendas comunes no sólo afecta a la piel del bebé sino también al medio ambiente ya que los pesticidas y fertilizantes tienen químicos que causan daño a las tierras de cultivo, agua, aire y hasta a la diversidad del mundo.

\section{2.- Descripción de la idea de negocio como alternativa de solución}

Como se mencionó en el capítulo anterior, las prendas tradicionales causan irritaciones en los bebés, las cuales se pueden prevenir usando prendas de algodón orgánico. Comprando estas prendas ayudarían al medio ambiente, ya que las prendas orgánicas no usan fertilizantes.

Ahora nos preguntaremos, ¿Por qué usar prendas orgánicas en vez de prendas de algodón normal? Según (Paris \& Rovatti, 2016), nos relatan que a la piel del bebé se le 
debe dar un cuidado correcto mediante el uso de prendas de tejidos suaves, como la orgánica, como una preferencia para la salud del bebé y respeto a la naturaleza.

Según la OMS (2016), el algodón orgánico está cultivado sin pesticidas lo cual tiene un beneficio de doble protección tanto a la piel del bebé como para el medio ambiente. Usando prendas de fibras naturales, mantendrá la temperatura natural del bebé y se evitarán las irritaciones y reacciones alérgicas en la piel.

Como lo dice Myriam Gonzáles-Oviedo (2013), la piel del bebé es más delicada por ello menos resistente a las ropas ásperas o gruesas. Ella propone que los pediatras y dermatólogos garanticen que las prendas cumplan con controles de calidad, sean certificados como inocuos (libres de residuos químicos tóxicos, formaldehído y colorantes) para que así los infantes puedan tener mayor salud.

\section{3.- ¿Por qué la idea sería una oportunidad de negocio?}

La idea de negocio surgió por un cruce de información estadística, tendencias de mercado y una observación realizada por la Oficina Comercial del Perú en Colombia, de donde se pudo verificar el interés que existe por prendas para bebés preferentemente producido con materiales orgánicos.

Esta idea será una oportunidad de negocio ya que las prendas para bebé tienen una clasificación de producto estrella en el mercado extranjero, como se puede apreciar en el Cuadro $\mathrm{N}^{\circ} 1$. Además, si a estas se les añade un valor agregado como lo es el proceso de cultivo haría que la demanda de estas crezca. El cultivo es libre de pesticidas, herbicidas y fertilizantes químicos. El algodón orgánico, con el cual se elaborarán las prendas de bebés son esenciales, puesto que protegen la delicada piel del 
bebé y cuida el medio ambiente. Los productos son llamados estrellas porque tienen una visión de crecimiento y participación importante en el mercado en cuanto a las importaciones; al ser catalogados como productos prometedores significan que estos tienen, a largo plazo, una buena perspectiva en las importaciones para el mercado.

Según SIICEX (2016), en un estudio de Servicios al exportador: Guía de Mercado Colombia, para que los productos puedan ser calificados tanto como estrellas y prometedores, deben de regirse mediante la metodología de la Comisión Económica de Naciones Unidas para América Latina y el Caribe (CEPAL), la cual identifica a los productos que cuentan con potencial en el mercado Colombiano.

\begin{tabular}{|c|c|c|}
\hline & $\begin{array}{c}\text { Cuadro } \mathrm{N}^{\circ} 1: \\
\text { Productos Potenciales en Colombia (2015) }\end{array}$ & \\
\hline Partida & Descripción & Clasificación \\
\hline 190531 & Galletas dulces ( con adición de edulcorante) & Estrella \\
\hline 180690 & $\begin{array}{l}\text { Los demás chocolates y demás preparaciones } \\
\text { alimenticias }\end{array}$ & Estrella \\
\hline 180100 & Cacao en grano, entero o partido crudo o tostado & Estrella \\
\hline 200290 & Los demás tomates preparados o conservados & Estrella \\
\hline 230910 & $\begin{array}{l}\text { Alimentos para perros o gatos, acondicionados para } \\
\text { la venta al por menos }\end{array}$ & Estrella \\
\hline 160416 & Anchoas en conserva, entero o en trozos. & Prometedor \\
\hline 600622 & Tejidos de punto, de algodón teñidos & Prometedor \\
\hline 611120 & $\begin{array}{l}\text { Prendas y complementos de vestir, para bebés, } \\
\text { de punto. }\end{array}$ & Estrella \\
\hline 630140 & Mantas de fibras sintéticas & Estrella \\
\hline
\end{tabular}

Según las estadísticas de Euromonitor (2015), presentados en el Cuadro $\mathrm{N}^{\circ} 2$, en la categoría de ropa para bebés en Colombia, cuenta con un registro en el 2014 del 7\% en ventas lo que alcanza un valor de US\$1753 millones. Por otro lado, se observa una tasa de crecimiento del $29.08 \%$ con respecto del 2010 al 2014 en el sector para ropa de bebé y niños hasta los 2 años. Además, en el cuadro $N^{\circ} 3$ se observa la previsión de 
ventas hasta el 2019, donde las ventas tienen una tasa de crecimiento constante de $5.30 \%$ en promedio.

A comparación con el 2014, Euromonitor (2016) estima que el sector de prendas para niños y bebés crecerá para el 2019 en un 5.40\% lo que haría que la empresa tenga estabilidad económica y sea solvente incurrir en el negocio.

\section{Cuadro $\mathbf{N}^{\circ}$ 2:}

Ventas de Categoría Ropa para bebés y niños en Colombia: Volumen 2010-2014

\begin{tabular}{llllll}
\hline '000 unidades & 2010 & 2011 & 2012 & 2013 & 2014 \\
\hline Ropa del bebé & $4,178.30$ & $4,435.80$ & $4,682.10$ & $4,935.90$ & $5,207.00$ \\
Ropa para niños & $13,422.60$ & $14,349.30$ & $15,139.40$ & $15,987.20$ & $16,898.40$ \\
& & & & & \\
Ropa para niñas & $19,657.00$ & $20,950.80$ & $22,060.40$ & $23,315.20$ & $24,651.70$ \\
Total & $37,257.90$ & $39,735.90$ & $41,881.90$ & $44,238.30$ & $46,757.20$
\end{tabular}

Fuente: Euromonitor

Elaboración Propia

Cuadro $\mathbf{N}^{\circ}$ 3:

Ventas de Categoría Ropa para bebés y niños en Colombia: Volumen 2015-2019

\begin{tabular}{llllll}
\hline '000 unidades & 2015 & 2016 & 2017 & 2018 & 2019 \\
\hline Ropa del bebé & $5,491.00$ & $5,787.60$ & $6,097.40$ & $6,421.03$ & $6,759.10$ \\
Tasa de Crecimiento & & $5.40 \%$ & $5.35 \%$ & $5.31 \%$ & $5.26 \%$ \\
& & & & & \\
\hline $\begin{array}{l}\text { Fuente: Euromonitor } \\
\text { Elaboración Propia }\end{array}$ & & & & & \\
\end{tabular}

Según las estadísticas observadas en los cuadros anteriores, se aprecia que existe cierto tipo de ventajas en el negocio como la tasa de crecimiento hacia el 2019, la cual será de $5.25 \%$ y que es un producto estrella para el mercado exterior. Por otro lado, lo que diferenciará a Teco Caricias S.A.C de las otras empresas que están en el mismo sector, es que se contará con un socio estratégico: "Bergman, Rivera S.A.C”, el cual 
brindará las telas necesarias para la empresa las mismas que están certificadas a nivel internacional.

Además, existirá un acuerdo de exclusividad de diseños con los clientes y proveedores que adquieran las prendas. Estos diseños, serán trabajados por diseñadores de modas, Alberto de Las Casas (Peruano) y Lola Kids (Colombiana), que han participado en el Miami Fashion Week y conocen las tendencias del mercado internacional especialmente al que se está dirigido. Las prendas que cuenten con estos prestigiosos diseños no podrán ser plagiados por otras empresas ya que contarán con un registro de propiedad intelectual.

\section{4.- Propuestas de innovación en el negocio}

La propuesta de innovación tendrá tres (3) enfoques, desde el punto de vista del producto, modelo de negocio y tecnología.

Con respecto al producto, el grado de novedad de los bodies es bajo, debido a que ya existen en el mercado. Sin embargo, el valor y la utilidad es alta y diferenciada dado que la calidad y elegancia de las prendas realizadas por manos peruanas cuentan con las exigencias del mercado internacional. El valor agregado se evidenciará dado que, desde la obtención de los insumos hasta la entrega del producto terminado al cliente, se contará con certificación GOTS. Por otro lado, el producto conllevará a generar más puestos de trabajo para los peruanos, y tendrán requisitos de calidad y preferencias para que se incorpore al mercado extranjero y pueda así satisfacer las expectativas del consumidor final. El atributo esencial es que las prendas son orgánicas, no llevan pesticidas, y esto genera que los consumidores (bebés) no tengan reacciones 
alérgicas o exista algún problema con su piel. Además, el empaquetado que será usado (bolsas de yute) podrán ser reciclados a diferencia del uso de bolsas plásticas utilizados por otras empresas.

Se buscará una innovación incremental desde los ropones normales que se venden hacia las madres de familia, los que tendrán una mejora que logrará que contribuya con la satisfacción de las mismas. La mejora que se propondrá será que las prendas no contarán con adornos sobresalientes debido a que los consumidores (bebés) pueden ingerirlos o rasparse con el roce de ellos. Por otro lado, las telas serán más suaves que las normales, ya que son elaboradas con algodón orgánico como ya se mencionó anteriormente.

Con respecto al modelo de negocio, se planificará de manera minuciosa la selección de locales en el mercado extranjero enfocado al tema de Fast Fashion (moda rápida), es decir, se venderán en las tiendas las últimas tendencias del mercado para que cuando estas se adquieran, pueda existir labor social: cuando los clientes compren de dos (2) prendas a más generarán apoyo a las Comunidades Latinoamericanas de bajos recursos económicos, los cuales se darán mediante la entrega de una (1) prenda.

La perspectiva tecnológica estará enfocada en la adquisición de máquinas industriales de último modelo; sin embargo, como la materia prima es de algodón orgánico y por ende delicado, estas tendrán un corte determinado para que el trabajo de los operarios pueda darse de manera rápida y eficiente. Al tener un corte único, los diseños serán innovadores. Las prendas se diferenciarán de las otras ya que estas no serán tradicionales. Los bodies serán cruzados debido a que muchas madres temen que 
la cabeza del bebé pueda lastimarse. Por otro lado, no contarán con broches automáticos puesto que la OMS (2014) ha declarado que están elaboradas de níquel al igual que las presillas y provocan daño. Así serán innovadores y más prácticos para su uso.

\section{5.- Diseño del negocio innovador, creativo y estratégico: (Modelo Canvas)}

A continuación se muestra el Cuadro $\mathrm{N}^{\circ} 4$, el cual será desarrollado en la siguiente sección.

\section{Cuadro $\mathbf{N}^{\circ}$ 4: \\ Resumen del Modelo Canvas}

\begin{tabular}{ll}
\hline Segmento de Mercado & Sector A y B \\
\hline Propuesta de valor & $\begin{array}{l}\text { Prendas elaboradas de algodón orgánico en empaque ecológico } \\
\text { ( bolsa de yute) + contacto clave }\end{array}$ \\
$\begin{array}{l}\text { Canales Relaciones con clientes } \\
\text { Canal Directo }\end{array}$ & Alianza con empresas, pagos puntuales, obsequios \\
Fuentes de ingresos & Tela de algodón + hilos orgánicos+ equipos+ RH \\
Recursos Clave & Confección de prendas de vestir \\
Actividades Clave & Bergman Rivera S.A.C \\
\hline Asociaciones Clave & CF + CV de la producción \\
\hline Estructura de Costos & \\
\hline
\end{tabular}

\subsection{1.- Segmentos de mercado}

El segmento de mercado al cual está dirigido es un nicho enfocado en el mercado de bebés ( 2 primeros años), el cual presenta características homogéneas y la necesidad de ser vestidos con ropa de algodón orgánico. El proyecto está enfocado en el mercado de Colombia - Bogotá hacia el sector socioeconómico A/B.

El consumidor es el bebé desde que nace hasta los 24 meses de edad, los cuales obtendrán beneficios de la prenda. El cliente de este producto es su familia, especialmente se va a centrar en las madres ya que ellas desean lo mejor en calidad para sus hijos. De la misma forma, la persona responsable de la adquisición será la madre, 
dado que el niño no tiene la capacidad de tomar sus propias decisiones ni es conocedor del tipo de vestimenta que usa.

\subsection{2.- Propuestas de valor}

Los padres de familia comprarán los bodies debido a que son diferentes de la competencia porque: en primer lugar, el empaque será dado en bolsa de yute (son ecológicos, ayudan al medio ambiente y pueden darle otros usos); cuentan con una elaboración limpia, es decir libres de pesticidas lo que origina una ayuda y respeto hacia el medio. Por último, los clientes podrán personalizar los bodies con diseños bordados de acuerdos a los gustos y preferencia que presenten por dos prestigiosos diseñadores reconocidos.

Un problema que los consumidores tienen y se puede ayudar a solucionar se dará en cuanto a los materiales de los bodies orgánicos puesto que estos son más suaves a comparación de los comunes por lo que ayudará a que la piel de los bebes no se irrite.

Una propuesta clave, es que se contará con una persona en el mercado de destino de estas exportaciones. Esta persona estará encargada de revisar el stock de los productos y observar cuáles son los que obtienen mayor demanda. Además, tendrá contacto directo con el cliente para requerimientos futuros de productos o para la intervención ante algún problema que pueda existir con ellos. Esto permitirá hacer un seguimiento continuo para la mejora de la empresa. 


\subsection{3.- Relaciones con clientes}

La relación que se tendrá será de forma directa debido a que las ventas crecerán y por ende la cantidad de clientes crecerá. Esta relación estará ligada a la de "Co-creación", ya que permitirá al cliente crear valor cuando participe en algún proceso del presente negocio.

El valor que ellos crearán será la elección de un diseño de los cinco (5) que la empresa les otorgará. Una vez elegido el diseño se procederá a realizar un sondeo al azar vía web entre la población del mercado elegido, los cuales si cuentan con una respuesta favorable se realizará la confección del mismo en diversas cantidades.

\subsection{4.- Fuentes de ingresos}

La fuente de ingreso se dará por transacciones de pagos puntuales por parte de los clientes Colombianos. Se darán "combos” o paquetes con algunas empresas que están posicionadas con la marca Teco Caricias. Si se observa que los clientes compran dos veces o más, significará que les agradó el producto, entonces se les otorgará una promoción de descuento por un periodo de 2 años. Es decir, cada seis meses a lo largo de dos años se les dará un obsequio de los productos (Combos o paquetes).

\subsection{5.- Recursos clave}

El principal recurso es la tela de algodón e hilos orgánicos puesto que sin este insumo no se puede llevar a cabo la elaboración de los bodies. Las telas de algodón según el Anexo 1, se dividirán en Algodón Pima orgánico y Tangüis Orgánico con cierta gama 
de colores según el requerimiento del cliente, las cuales presentan diferentes texturas y grosor según la temporada en la que se encuentre el país de destino (Verano/Invierno).

En segunda instancia, pero no menos importante, está el recurso humano, ya que sin ellos no se podrá hacer uso de los insumos, maquinas, proyectos, entre otros. Los equipos industriales como la máquina cortadora y remalladora son otro factor clave, ya que sin estas herramientas no se podría seguir con el negocio. Por otro lado, sin las ventas no es posible generarse ingresos y por ende el ciclo del negocio no será viable. Para la venta de estas prendas se necesitarán contar con los derechos de propiedad intelectual registrados de los diseños de las prendas, para evitar el plagio y uso por marcas de la competencia.

\subsection{6.- Actividades clave}

La actividad clave es la confección de prendas de vestir. Se comprarán las telas e hilos al proveedor Bergman Rivera S.A.C y luego se procederá a la elaboración de los ropones para bebés, los cuales tendrán una calidad superior al de la competencia. Los requerimientos mínimos que Bergman solicita a las nuevas empresas son que las compras de sus telas sean de mínimo $120 \mathrm{~kg}$ o más y el tiempo de entrega de 60 días después de haber recibido el $50 \%$ de adelanto y aprobado una muestra de prueba o requerimientos brindados por el comprador (Teco Caricias S.A.C). Estas muestras demoran de 10 a 15 días y pueden ser entregadas en los lapsos de tiempo que el cliente desee por un año. Por otro lado, como se aprecia en el Anexo 1 de Telas en Stock, estas pueden ser adquiridas a lo largo del año 2016 a un mejor precio, con un pedido mínimo de $20 \mathrm{~kg}$ y su pago debe ser al contado. Debido a que Teco Caricias S.A.C es una empresa nueva en el mercado se cumplirán dichos requerimientos mediante un contrato 
que establece el pago de las compras a 60-90 días para que pueda brindar un mayor soporte a la empresa.

Otro aspecto importante es el marketing. Debido a que no se cuentan con muchos recursos, se desarrollarán activaciones en las ferias y/o puntos de venta más importantes lo que generará un apoyo esencial a la venta de la marca. Además, existirán ofertas en fechas emblemáticas como la navidad y el día del niño las cuales se darán a conocer tanto en las tiendas como en la página web de la empresa (esta se creará en el transcurso del primer año de que esté posicionada en el mercado de destino).

Con respecto a la resolución de problemas, como ya se mencionó, existirá una persona clave en el mercado de destino para que dé solución ante algún problema o dificultad que presente el cliente. Esto generará un servicio post venta reconocido.

\subsection{7.- Asociaciones clave}

Se creará una relación de cliente-proveedor con Bergman Rivera S.A.C, debido a que es el proveedor más reconocido a nivel nacional de telas e hilado orgánico. Se debe tener en cuenta que será el único proveedor de telas, dado el análisis realizado, al igual que es el único comercializador de telas con colores nativos (verde, café y el tradicional blanco/crema).

Esta alianza se basa en que proporcionará insumos de exclusividad, es decir, cada mes dará una cantidad pactada de tela e hilado a lo largo de los años puestos en el contrato, el cual se renovará (actualizará) cada año para ver si el stock determinado para Teco Caricias S.AC es el correcto o si se debe pedir más para la siguiente temporada. Todo esto se da con el propósito de evitar que la empresa se quede sin insumos de alta 
calidad. Una vez que se cumplan los 2 años de la alianza con esta empresa y los pagos sean puntuales, se bajarán los precios a un $4 \%$.

\subsection{8.- Estructura de costos}

Los costos serán sobre todo variables de acuerdo a la cantidad de producción. A continuación se mostrarán los costos por prenda (variables) y algunos costos fijos como lo son los servicios, contador externo, remuneraciones, mantenimiento de las maquinarias, etc.

Con respecto a los gastos pre-operativos, estos se darán una sola vez a lo largo de la creación de la empresa como lo es: el diseño del plan de negocios, para conocer más el mercado de destino; la garantía del alquiler del local; las licencias y constitución de la empresa; la página web y la remodelación del local administrativo. El total de estos gastos son de US\$5 200 lo que equivale al 12.8\% del total de inversión.

Con respecto a los costos variables, estos serán; la tela, el hilo, empaque, embalaje. Estos tendrán un costo por prenda de US\$5.08 y se vendería a un precio de US\$ 10.71 , por lo que existiría un $53 \%$ de ganancia.

Los costos fijos están divididos en; el alquiler de local (el cual tiene un costo mensual de US\$900 y equivale al $2.23 \%$ de la inversión total), los servicios, el contador externo y el mantenimiento de maquinarias que equivalen al $0.72 \%, 0.17 \%$ y $0.11 \%$ respectivamente. Con respecto a las remuneraciones, se consideran a los tres (3) gerentes y los operarios, los cuales equivalen a un 7\% de la inversión. 


\section{Cuadro $N^{\circ}$ 5:}

Estructura de Costos (2016)

\begin{tabular}{|c|c|c|c|c|}
\hline Costos Variables & $\begin{array}{l}\text { US\$/ } \\
\text { PRENDA }\end{array}$ & Costos Fijos & $\begin{array}{l}\text { US\$ } \\
\text { Mensual }\end{array}$ & $\begin{array}{l}\text { \% sobre la } \\
\text { inversión }\end{array}$ \\
\hline Tela de algodón $O$. & 4.14 & Alquiler del Local & 900 & $2.23 \%$ \\
\hline Hilo Orgánico & 0.35 & Servicios (Agua, Luz, Internet+ Teléfono) & 291 & $0.72 \%$ \\
\hline Bolsa de Yute & 0.03 & Contador Externo & 69 & $0.17 \%$ \\
\hline Caja de cartón & 0.02 & $\begin{array}{l}\text { Mantenimiento de Maquinaria (anual US\$ } \\
508 \text { ) }\end{array}$ & 42.5 & $0.11 \%$ \\
\hline Etiqueta & 0.13 & Remuneración Gerentes + Operarios & 2,618 & $6.48 \%$ \\
\hline total 1 & 5.08 & total 2 & $3,920.5$ & 40,404.64 \\
\hline
\end{tabular}

Elaboración Propia 


\section{CAPITULO III: ESTUDIO DE MERCADO}

\section{1.- Definición del producto o servicio}

En el Cuadro $\mathrm{N}^{\circ} 6$, se muestra la ficha técnica del producto, la cual brinda una definición del producto como "Ropones de cuerpo completo para bebés de 0-24 meses". Estas están elaboradas de algodón $100 \%$ orgánico las cuales contarán con tallas hasta los dos años y su peso será de 200 gr. Las certificaciones con las que estas prendas contarán serán Global Gap, IMO y GOTS.

\section{Cuadro $\mathbf{N}^{\circ}$ 6:}

Ficha Técnica

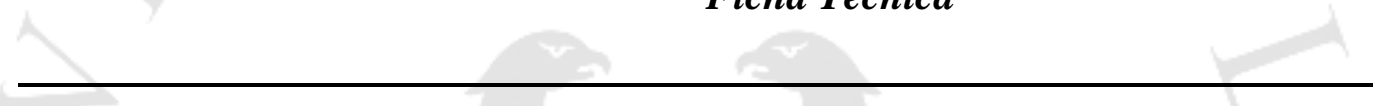

Prendas y complementos de vestir de punto para bebés, de algodón.

\begin{tabular}{|c|c|}
\hline Descripción & Ropones de cuerpo completo para bebés de $0-24$ meses. \\
\hline Composición & Prendas y complementos $100 \%$ de algodón orgánico. \\
\hline $\begin{array}{l}\text { Sub-partida } \\
\text { arancelaria } \\
\text { Sector }\end{array}$ & $\begin{array}{l}611120000 \\
\text { Textil }\end{array}$ \\
\hline Categoría & Tejidos de Punto \\
\hline Zonas de & Lima \\
\hline Producción & \\
\hline $\begin{array}{l}\text { Presentación } \\
\text { Certificados }\end{array}$ & $\begin{array}{l}\text { Tallas: } 0-2 ; 2-4 ; 4-6 ; 6-8 ; 8 \text { a más meses. } \\
\text { Colores: Tonos pasteles ( blanco, café y verde olivo) } \\
\text { Peso: } 200 \mathrm{gr} \\
\text { Certificado GlobalGAP } \\
\text { IMO } \\
\text { Global Organic Textile Standard (GOTS) }\end{array}$ \\
\hline
\end{tabular}

Elaboración Propia

El producto a desarrollar serán las prendas ecológicas para bebés (bodies) hechas con algodón $100 \%$ orgánico en colores nativos. El proceso de cultivo del algodón orgánico, por parte de los proveedores, se dará en suelos tratados, los cuales no hacen uso de fertilizantes, pesticidas ni herbicidas lo cual es un apoyo hacia el medio 
ambiente y por ello cuentan con certificaciones a nivel internacional que aumentan la calidad de la prenda.

Los colores nativos de las telas que se usarán serán en tonos pasteles (crema, café y verde oliva) porque no contarán con productos químicos que puedan contaminar o dañar las prendas. Según el Departamento de Dermatología (2016), las telas orgánicas son ideales para el uso de bebes con piel sensible, eczema infantil y dermatitis atópica. Por ende, estas prendas tendrán una textura suave y delicada al tacto, con bordados de punto sencillos en cuello y mangas; así como un color que contraste con las telas.

Una gran ventaja que se tiene ante los otros productores, es que estas prendas cuentan con cortes únicos; además de diseños innovadores por personas de alto prestigio internacional. Otra característica importante y diferenciada es que los bodies son cruzados y no causarán temor porque la abertura de la parte del cuello del body pueda apretar la cabeza del bebé o causarle algún raspón como lo hacen los bodies tradicionales.

\section{2.- Selección del mercado internacional}

La exportación de prendas de vestir dirigido al sector bebés se dará hacia un país Latinoamericano por diversas facilidades para exportar y por los tratados comerciales existentes. Como se aprecia en el Cuadro $\mathrm{N}^{\circ} 7$, realizado por Proexport Colombia (2014), un inversionista tiene mayores posibilidades para invertir en dicho mercado ya que existen mejores oportunidades debido a que muestra un nivel de potencialidad mayor a otros países a pesar de que no es el más grande en la región. El rango señalado 
es de 38 , esto significa que un $38 \%$ de los pobladores que van a ese país generarían rentabilidad para la inversión. El rango de potencialidad va de 1-50. Donde 50 significa que es $100 \%$ seguro y hay éxito en la inversión extranjera directa. Como se aprecia, Colombia es el mejor país Latinoamericano con esta perspectiva. Por otro lado, la visión para que estos productos crezcan en Colombia y se pueda abrir hacia otros mercados es 30 veces mayor a la que existía en el pasado, esto significa que han mejorado a la vez en recursos naturales, tecnología, su política fiscal es estable y actualmente se mantiene como una economía emergente.

La potencialidad, según el Ministerio de Industria y Turismo de Colombia (2015) abarca diversos aspectos para llegar a esta estimación, como la calidad de riquezas naturales, ubicación geográfica, el intercambio comercial, desarrollo equilibrado de lo social y económico.

Colombia, tiene un $38 \%$ de rentabilidad para invertir porque su aprovechamiento tecnológico está incrementando al igual que la identidad de sus pueblos. La economía Colombiana ha crecido en promedio un $4.8 \%$ originando que esté por encima de todos los países Latinoamericanos. Se invertirá en este país dado que en los próximos 4 años se estima que la mitad de la población representará la clase media y clase media alta, a la cual este proyecto está enfocado.

\section{Cuadro $\mathbf{N}^{\circ}$ 7:}

Potencialidad de los países de Latinoamérica (2014)

\begin{tabular}{llllll}
\hline & Argentina & Brasil & Colombia & México & Perú \\
\hline Potencialidad & 16 & 24 & $\underline{\mathbf{3 8}}$ & 23 & 19 \\
\hline $\begin{array}{llll}\text { Fuente: Proexport Colombia } \\
\text { Elaboración Propia }\end{array}$ & & & & \\
\end{tabular}


En el Cuadro $\mathrm{N}^{\circ}$, se aprecia que se ha tomado a Brasil y México como países para la toma de decisión sobre el mercado final de acuerdo al Cuadro $\mathrm{N}^{\circ} 7$ puesto que ellos compiten por la potencialidad de crecimiento en inversión. El peso que se dará deberá sumar 1 entre todos los factores elegidos. La calificación se dará de 0 a 4, mostrado en el cuadro 7, la cual tendrá una valorización de escalas de la siguiente manera:

\section{Cuadro $\mathbf{N}^{\circ}$ 8:}

Valorización de Escalas

\begin{tabular}{ll}
\hline Escala & \\
\hline No inversión & 1 \\
Inversión con riesgos & 2 \\
Puede Invertir & 3 \\
Inversión exitosa & 4 \\
\hline
\end{tabular}

Elaboración Propia

Los factores a elegir son tres (3) debido a que son los más importantes para la toma de decisión al momento de comprar los bodies. Uno de estos, es la tasa de Fertilidad: cuántos hijos tiene una mujer, porque así se conocerá si se invertirá en un país que cuenta con un alto número de recién nacidos para el uso de las prendas o no. Según el Banco Mundial (2015), Colombia cuenta con 2.32 hijos por mujer mientras que Brasil y México 1.81 y 2.2 respectivamente. Este factor tiene el peso más elevado junto con el factor de la tasa de natalidad para que se pueda decidir si es viable la inversión. La tasa de natalidad es por cada mil nacimientos y cuántos son los que permanecen vivos por un año. Colombia cuenta con un $16.08 \%$, mientras que Brasil y México 15\% y $18 \%$ respectivamente.

Con respecto a la tasa de crecimiento económico, según el Banco Mundial, se estima que Colombia tenga un $4.70 \%$, México un $1.10 \%$ y Brasil un $2.50 \%$. Todos 
estos factores con sus respectivas calificaciones hacen un total en Colombia de 3.60, siendo superior ante los países de México y Brasil para invertir.

\section{Cuadro $\mathbf{N}^{\circ}$ 9:}

Criterios para la selección del Mercado Internacional

\begin{tabular}{|c|c|c|c|c|c|c|c|}
\hline \multirow{2}{*}{ Factor } & \multirow[b]{2}{*}{ Peso } & \multicolumn{2}{|c|}{ Colombia } & \multicolumn{2}{|c|}{ Brasil } & \multicolumn{2}{|c|}{ México } \\
\hline & & Calificación & Total & Calificació & Total & Calificación & Total \\
\hline 1.- Tasa de & 0.40 & 4 & 1.60 & 3 & 1.20 & 2 & \\
\hline Fertilidad & & & & & & & 0.80 \\
\hline 2.- Tasa de & 0.40 & 3 & 1.20 & 2 & 0.80 & 4 & \\
\hline Natalidad & & & & & & & 1.60 \\
\hline 3.- Tasa de & 0.20 & 4 & 0.80 & 3 & 0.60 & 2 & 0.40 \\
\hline Crecimient & & & & & & & \\
\hline Total & & & 3.60 & & 2.60 & & 2.80 \\
\hline & 1.00 & & & & & & \\
\hline
\end{tabular}

Elaboración Propia

\section{3.- Análisis de la demanda}

\subsection{1.- Distribución geográfica del mercado de consumo}

Esta empresa operará en dos unidades geográficas. Debido a la magnitud con la que cuenta este negocio se comenzará a exportar al mercado Colombiano, específicamente a la ciudad de Bogotá, pues es la capital del país y es donde existe una mayor concentración de la población. Una vez centralizado y ganado el mercado de Bogotá, se comercializará en el mercado local, Lima- Perú. A las personas que se les venderá el producto serán a las madres de Colombia, y los consumidores serán niños de 0-24 meses.

Como se muestra en el cuadro $\mathrm{N}^{\circ} 10$, según Pro Colombia (2016), la mayor cantidad de importaciones que recibe Colombia son hacia Bogotá. Para el año 2015, Bogotá registró una compra de US\$692 243.19 superando a Santander, el cual es el segundo departamento con mayor demanda en la compra de prendas y complementos 
de vestir naturales. Por otro lado, según la información regional dada por Pro Colombia (2015), Bogotá es el centro de oportunidades más grandes del país, seguido de Valle del Cauca y Cundinamarca.

\section{Cuadro $\mathbf{N}^{\circ}$ 10:}

Estadísticas de Importaciones Colombianas (2012-2015)

\begin{tabular}{lccccc}
\hline $\begin{array}{l}\text { Departamento de } \\
\text { Colombia }\end{array}$ & $\mathbf{2 0 1 2}$ & $\mathbf{2 0 1 3}$ & $\mathbf{2 0 1 4}$ & $\mathbf{2 0 1 5}$ & TOTAL \\
\hline Bogotá & $\mathbf{5 0 6 , 4 9 6 . 4 8}$ & $\mathbf{5 7 3 , 2 5 6 . 5 6}$ & $\mathbf{4 7 4 , 5 2 8 . 5 3}$ & $\mathbf{6 9 2 , 2 4 3 . 1 9}$ & $\mathbf{2 , 2 4 6 , 5 2 4 . 7 6}$ \\
Cundinamarca & & $15,540.24$ & & & $15,540.24$ \\
Norte de Santander & $45,051.08$ & & 52.32 & & $45,103.40$ \\
Santander & $682,442.04$ & $553,662.92$ & $566,057.83$ & $334,646.93$ & $2,136,809.72$ \\
Valle del Cauca & $73,251.18$ & $31,039.59$ & $20,960.88$ & $9,375.71$ & $134,627.36$ \\
San Andrés y & $3,492.82$ & & & & $3,492.82$ \\
Providencia & & & & & \\
Antioquía y Otros De. & $3,374,426.52$ & $2,874,383.99$ & $1,439,377.79$ & $1,299,073.34$ & $8,987,261.64$ \\
Total & $4,719,910.92$ & $4,047,883.30$ & $2,500,977.35$ & $2,335,339.17$ & $13,604,110.74$ \\
\hline \multicolumn{7}{c}{ Fuente: DANE y Colombia trade } & & & & \\
\multicolumn{2}{c}{ Elaboración Propia } & & & &
\end{tabular}

Según las estadísticas de DANE (2015) Bogotá, es el departamento con mayor población a nivel de la región, este cuenta con 8'743,000 habitantes. Hasta comienzos del 2014 su PIB y PIB per cápita fueron de US\$93 774 millones y US\$12 219.08 respectivamente. El área de Bogotá es de 1,636.59 km2, donde un 52\% de la población son mujeres y un $30 \%$ de estas son madres. Por otro lado, un $99.40 \%$ de la población de Bogotá cuenta con todos los servicios públicos de forma óptima lo que incrementa que su status económico y social sea el más grande de la región, lo cual genera que se posicionen en clase media y media alta.

La dirección Distrital de Relaciones Internacionales, Bogotá Global (2014), informa que Bogotá es la octava ciudad Latinoamericana para poder hacer negocios generando rentabilidad y el número 49 a nivel mundial. Este ranking se basa en la facilidad con la que contará el presente negocio para poder expandirse y obtener 
ganancias. Lo más importante es la ubicación geográfica privilegiada que presenta, la cual genera un acceso directo a diversos mercados.

\subsection{2- Caracterización de la demanda}

\subsubsection{Gustos y preferencias}

Actualmente en Colombia se evidencia un incremento considerable en la demanda de productos ecológicos que encaja con un estilo de vida que se trasmite incluso en el vestir, sobre todo en Bogotá.

Proexport (2014) indicó que los colombianos prefieren que las prendas sean confeccionadas con materiales suaves y diversidad de insumos como el hilado, los cuales tienen que ser producido sin químicos tóxico, Además, la presentación para estas prendas deben estar en un empaque a su talla, por ende se presentarán en bolsas de yute porque son biodegradables y presentan baja conductividad térmica de humedad lo que hará que las prendas permanezcan intactas.

En la calidad de las prendas tiene que primar los diseños vanguardistas como los vestidos tejidos o con bordados a mano. Según el portal colombiano "Elbebe.com" (2014), las madres ponen a sus hijos prendas amplias y ligeras para que puedan tener más movilidad. Además, estas prendas deben ser de fibras naturales para evitar que la piel del bebé se irrite o contraiga alergias. Por ejemplo, se ha comprobado durante la investigación que los colombianos buscan ser elegantes y prácticos en el vestir.

Las madres colombianas necesitan ahorrar tiempo y tener más seguridad al momento de vestir a sus bebés. Por eso, ellas requieren prendas que sean de uso sencillo y abotonado, dado que al momento de vestir al bebé y hacer movimientos bruscos 
colocando prendas comunes pueden dañarlo. Asimismo, prefieren ropa con adornos muy simples porque si los adornos son complejos o presentan pedrería temen que estos puedan caerse y el bebé llevárselo a su boca.

La moda colombiana se da por temporadas (verano-primavera/otoño-invierno), se priorizan los insumos de calidad importados y el diseño. Colombia busca en sus prendas alto nivel de innovación y calidad para lograr satisfacción exigente de las madres de los infantes puesto a que ellos mismos (los bebés) no tienen la capacidad para elegir sus prendas.

Según un estudio realizado por Global Pyme en "El consumidor Colombiano" (2014) indicó que la distribución del gasto de este consumidor se da en el sector de alimentos con un $30 \%$; gastos varios con $24 \%$; y vestuario y calzado con un $22 \%$ dentro del cual las prendas para bebés y niños ocupan más del $50 \%$.

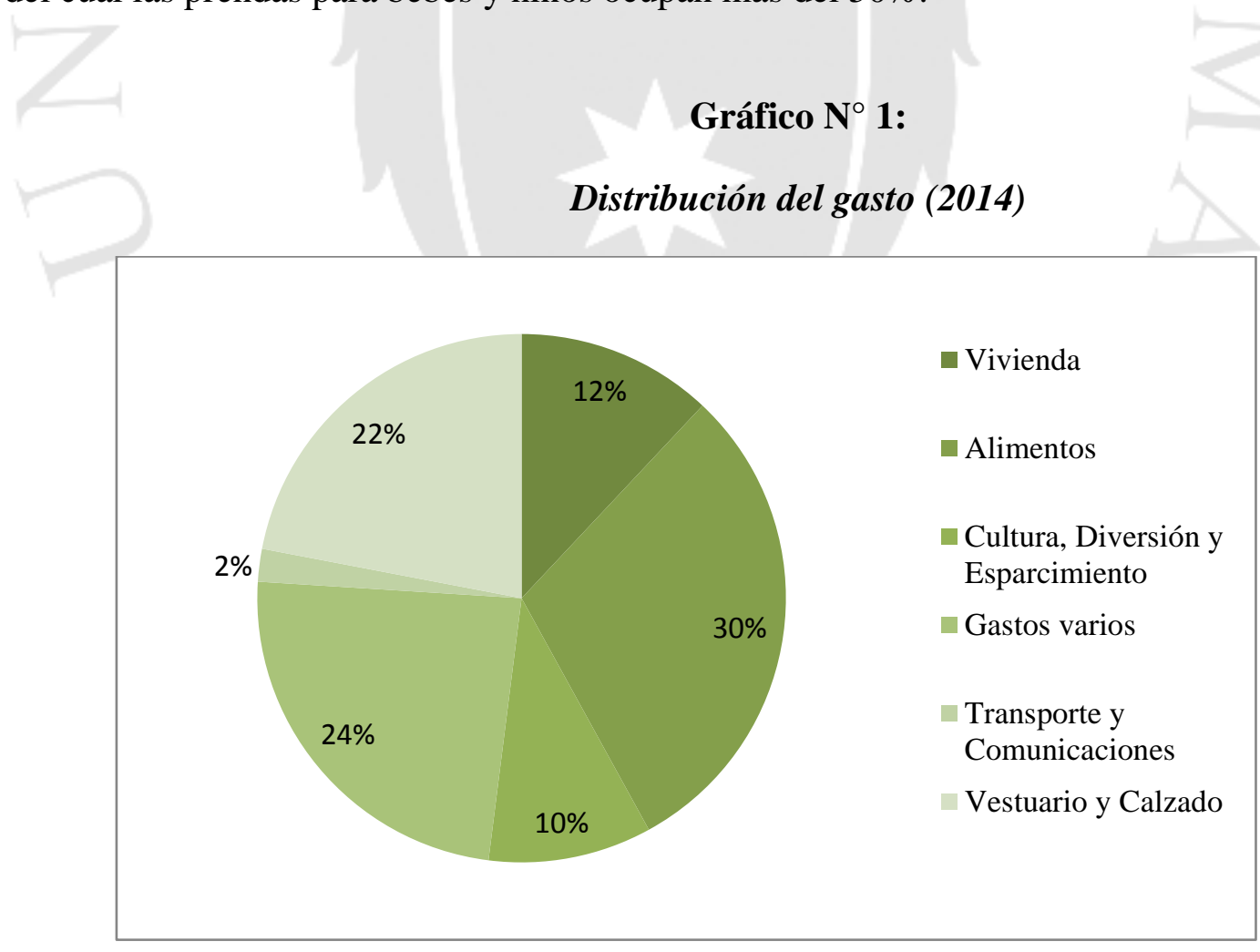

Elaboración Propia

Tomada de "EL consumidor Colombiano", Sandra Ortiz, Colombia, 2014,

http://www,globalpyme,org/memorias/el-consumidor-colombiano,pdf 
Los factores que más influencia tienen en la decisión de compra según el Gráfico $\mathrm{N}^{\circ} 2$, son la compra por gusto $(58.74 \%)$, luego sigue la compra por necesidad (16.55\%), por moda, marca, costumbre, entre otros factores. De otro lado, el Gráfico $\mathrm{N}^{\circ}$ 3 muestra las decisiones de compra en diferentes grupos. El consumidor en general, realiza las compras principalmente por necesidad $(55.23 \%)$ y por gustos $(29.61 \%)$. Un factor secundario en el poder decisional de las compras de prendas de vestir, se da por la marca $(3.11 \%)$ y un $1.51 \%$ por impulso o instinto.

\section{Gráfico $\mathbf{N}^{\circ}$ 2:}

Factores que influyen en la decisión de compra (2014)

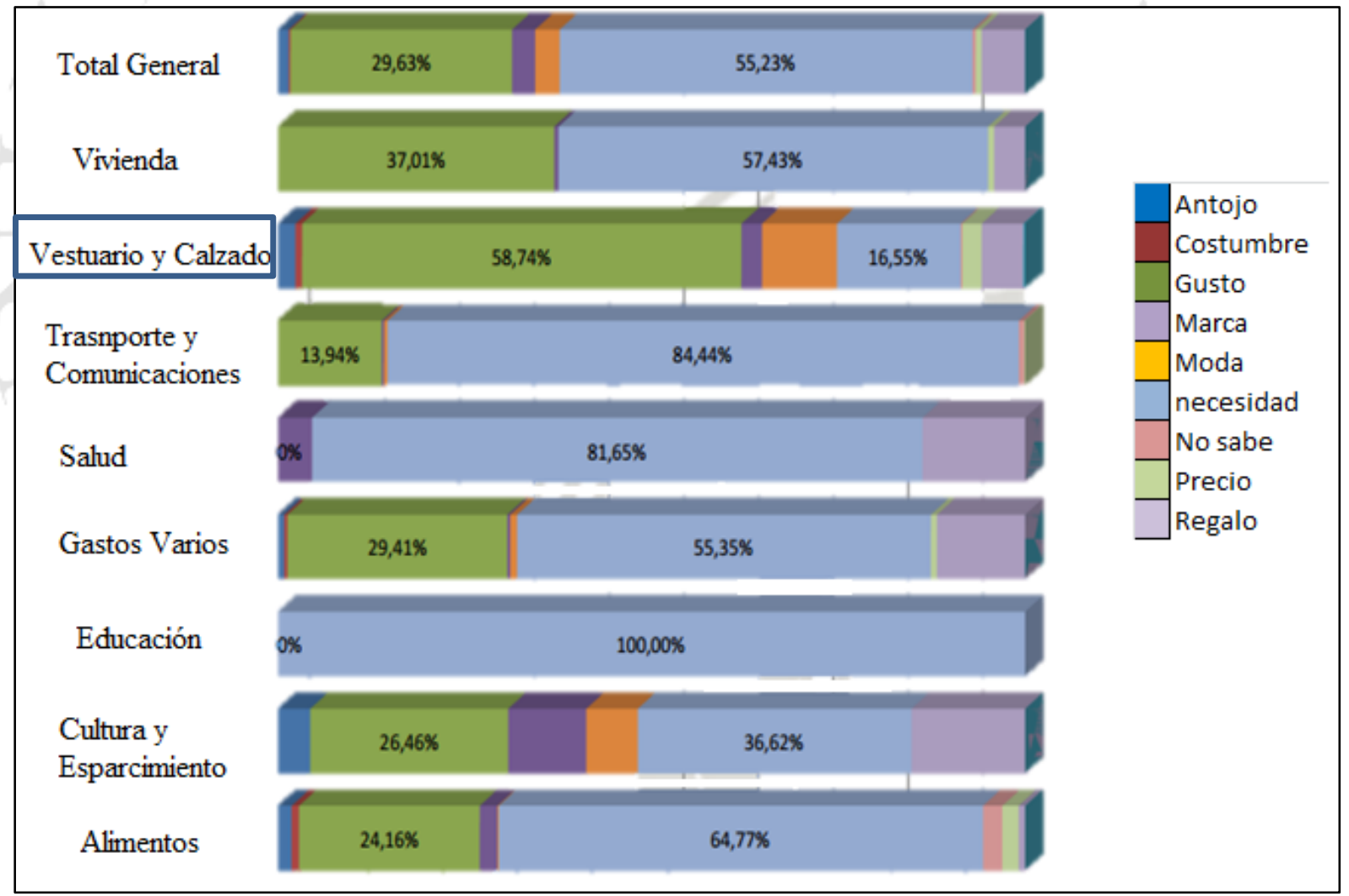

Elaboración Propia

Tomada de "EL consumidor Colombiano", Sandra Ortiz, Colombia, 2014, http://www,globalpyme,org/memorias/el-consumidor-colombiano,pdf 


\section{Gráfico $\mathbf{N}^{\circ}$ 3:}

Factores que influyen en la decisión de compra de textiles (2014)

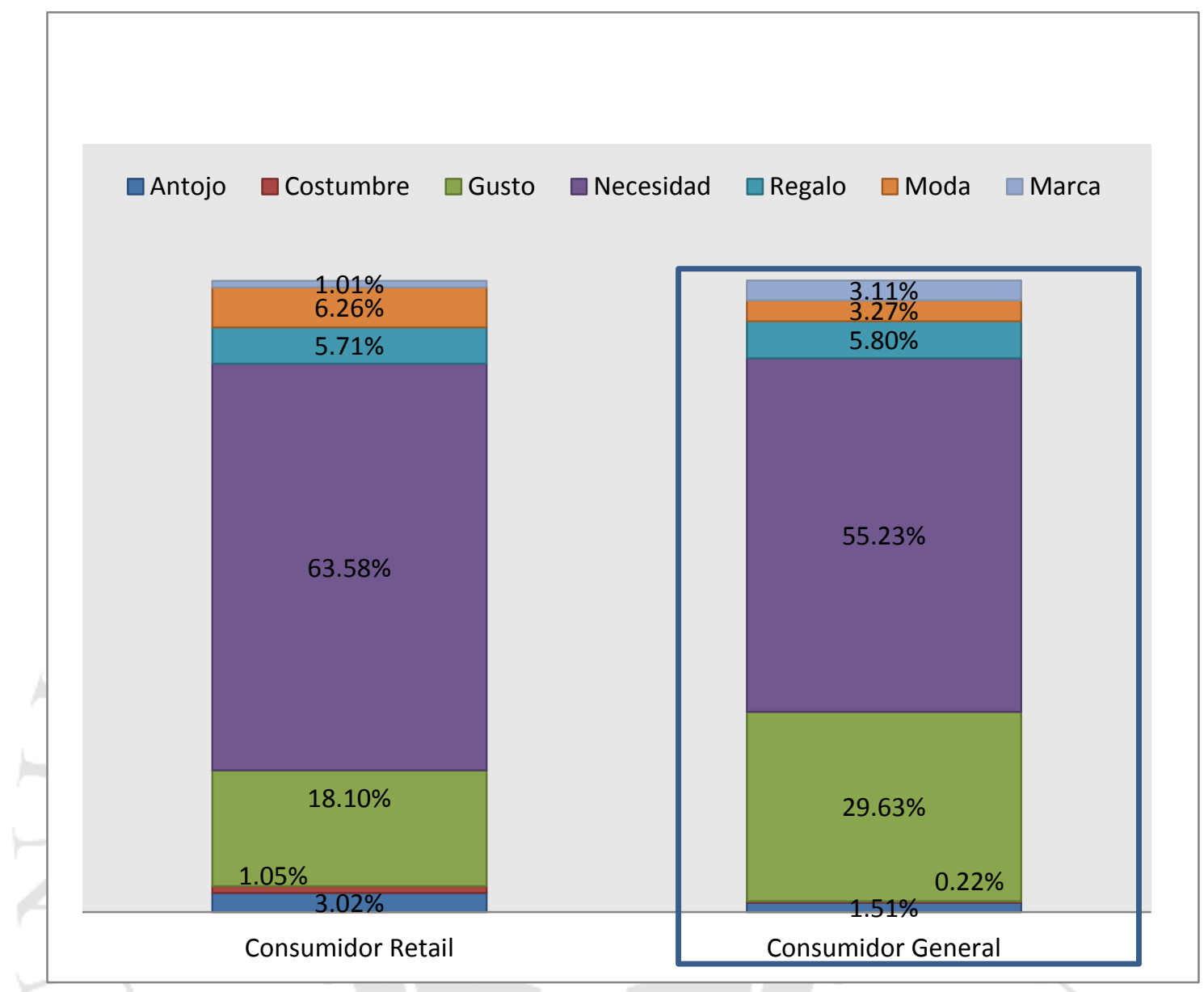

Tomada de "El consumidor Colombiano", Sandra Ortiz, Colombia, 2014, http://www,globalpyme,org/memorias/el-consumidor-colombiano,pdf

\subsubsection{Tendencias en el mercado de destino}

Según Grisar, Alexander (2015), desde el 2008, Colombia tiene una preferencia favorable para el uso de productos naturales, ellos piensan que al comprar materiales orgánicos estarán apoyando favorablemente a la conservación del planeta. Este aporte ecológico que se otorga ha originado un crecimiento hacia el consumo orgánico en 16 $\%$ a nivel mundial.

Desde hace algunos años, se ha lanzado en Colombia un proyecto llamado “Algodón orgánico en Colombia”, el cual originó que se compre algodón orgánico de 
Colombia a un precio no tan diferenciado del convencional con el objetivo de que los productores y exportadores comercialicen más este producto. El gobierno Colombiano, está aportando intereses financieros lo que causa a la vez más empleo nacional y más estabilidad económica.

Friendly es la primera empresa Colombiana que entra al mercado de textiles orgánicos para bebés. Esta empresa tiene una visión puesta en el futuro sobre el algodón orgánico dadas las condiciones climáticas favorables del país, la rentabilidad positiva y la expansión del mercado internacional.

Por todo lo apreciado en la caracterización de la demanda, la fórmula estratégica para entrar al mercado será la de ofrecer bodies con una calidad alta y diseños de moda debido a que según la Guía de Mercado Colombiano (2016), elaborado por Promperú, las prendas de vestir Peruanas, especialmente las de punto, tienen una relación positiva en cuanto a la tendencia de la moda y la calidad de la misma.

\subsection{3.- Proyección de la demanda internacional}

Un estudio realizado para el mercado colombiano recuerda que:

"En este mercado, hay una presencia importante de la oferta colombiana de prendas de vestir, la cual posee una buena relación entre diseño, calidad de la confección y precio. Las empresas peruanas deben estar conscientes que para diferenciarse, ingresar y mantenerse en el mercado colombiano, deberán desarrollar varias colecciones al año, que obedezcan a las tendencias más recientes de la moda." (Siicex, 2014, p. 22)

De esta forma Siicex (2014) indica que muchas de las prendas de vestir colombianas para este sector se abastecen de prendas confeccionadas en Gamarra. Por otro lado, Euromonitor (2015), indicó que el consumo de prendas de vestir y accesorios en el mercado colombiano ha tenido un crecimiento del $4.70 \%$. 
El grupo de ropa infantil y de bebe en Colombia, cuenta con un mercado objetivo de 13'141,100 niños, entre los 0 y 14 años los cuales representa el $29,6 \%$ de la población nacional, y en el que a su vez, se identifican los siguientes rangos de edad más específicos. (En Colombia, 2014, p.1)

El diario En Colombia (2014) indicó que los diversos diseños para el grupo de edad de 0 a 4 años son de 9,6\% del total de la población Colombiana. Se indica también que las mejores regiones donde están las empresas productoras son Antioquía y Bogotá (hacia donde está dirigido el plan de negocios), lo cual indica que Bogotá tiene facilidad para satisfacer la demanda interna y tener tanto importaciones como exportaciones de manera sostenible.

\section{Cuadro $\mathbf{N}^{\circ}$ 11:}

Millones de habitantes por rangos de Población infantil en Colombia (2014)

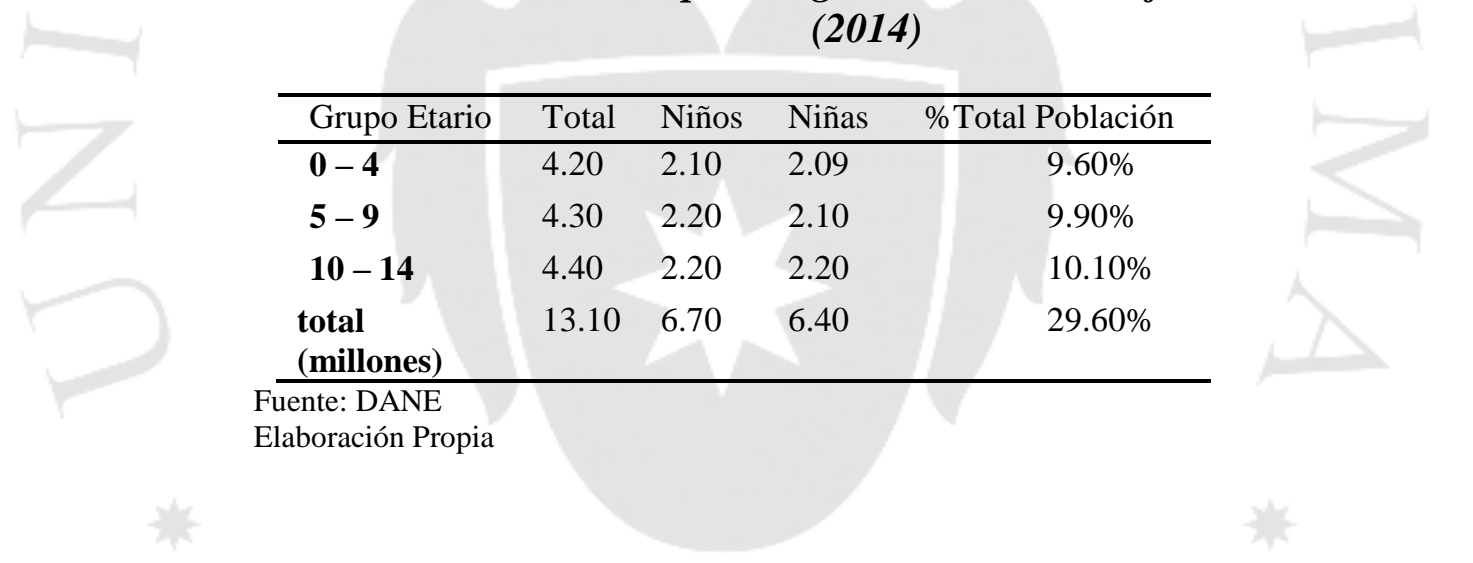

Como se aprecia en el Cuadro $\mathrm{N}^{\circ} 12$ la ciudad elegida es Colombia. El mercado meta es de 46’245,297 habitantes, de los cuales, un $18.90 \%$ pertenecen a la ciudad de Bogotá. Este segmento, se dividirá hacia la plaza de infantes de 0 a 24 meses de edad, que abarca un 6\%, dando como resultado 151,604 de habitantes. El consumo de ropa será dado por los bebés, por ello, no se escogen a las madres para la construcción del nicho. El mercado potencial por habitantes es de US\$454 811.00, considerando el poder de compra del que se hablará más adelante, y el costo de prendas en cada cliente es de 
US\$18.10 per cápita con un valor unitario por prenda de US\$43.52. El mercado objetivo será del $4 \%$ a los largo de los 5 primeros años y el mercado potencial inicial será de un $0.50 \%-1 \%$.

\section{Cuadro $\mathbf{N}^{\circ}$ 12:}

Demanda Potencial (2015)

\begin{tabular}{|c|c|c|c|}
\hline Segmentación & $\begin{array}{l}\text { Población } \\
\text { Objetivo - } \\
\text { Diciembre } 2014\end{array}$ & Observaciones & Fuente de Información \\
\hline Colombia & $46 ’ 245,297$ & Mercado Meta & The world fact book - CIA \\
\hline Bogotá & $8^{\prime} 743,000$ & Segmento & The world fact book - CIA \\
\hline $\begin{array}{l}\text { Personas entre } 0-2 \\
\text { años }(6 \%)\end{array}$ & 524,580 & $\begin{array}{l}\text { Construcción del Nicho - } \\
\text { bebés }\end{array}$ & DANE \\
\hline Sector AB_(28,9\%) & 151,604 & $\begin{array}{l}\text { Construcción del Nicho - } \\
\text { bebés }\end{array}$ & ANDI - DANE \\
\hline $\begin{array}{l}\text { Mercado potencial en } \\
\text { prendas : } 3 \text { prendas } \\
\text { por año }\end{array}$ & 454,811 & $\begin{array}{l}\text { Construcción del nicho por } \\
\text { medio de equivalencias entre } \\
\text { poder de compra y costo de } \\
\text { las prendas en cliente final }\end{array}$ & $\begin{array}{l}\text { Euromonitor - gasto en dólares } \\
\text { por ropa / per cápita ( } 18,1 \text { US\$ } \\
\text { per cápita por prenda con precio } \\
\text { de } 43,52 \text { US } \$ \text { por prenda }=3 \\
\text { prendas por año) }\end{array}$ \\
\hline $\begin{array}{l}\text { Mercado objetivo } 4 \% \\
\text { mercado potencial }\end{array}$ & 18,192 & $\begin{array}{l}\text { Demanda Potencial de la } \\
\text { población -Mercado objetivo } \\
\text { - Prendas Anuales }\end{array}$ & Resultado de Ecuación \\
\hline
\end{tabular}

Elaboración Propia

En base a la demanda potencial hallada, se considera tener un $0.65 \%$ de participación, lo cual da como resultado una demanda objetivo para el año 2015 de 11 520 prendas y US\$123 379.00

Este resultado se ha desarrollado con respecto al cubicaje, el cual se detallará en el plan logístico. Sin embargo, en el presente capítulo se especificará la cantidad de pallets a exportar y porqué se ha decidido exportar 1440 prendas al mes. En el cuadro №13 se detalla la demanda potencial desde el 2016 al 2020 por kilogramo según la estimación de personas proyectadas en Bogotá y su consumo per cápita. Todos estos datos fueron sacados del World Fact Book y Colombiatex (2016). 


\section{Cuadro $N^{\circ}$ 13:}

Demanda Objetivo Internacional Mensual (2016-2020)

\begin{tabular}{llll}
\hline Años & Personas proyectadas & Consumo per cápita & Demanda potencial por kg \\
\hline $\mathbf{2 0 1 6}$ & 151,604 & 18.10 & \\
$\mathbf{2 0 1 7}$ & 154,181 & & $2,744,032.40$ \\
$\mathbf{2 0 1 8}$ & 156,802 & $2,790,676.10$ \\
$\mathbf{2 0 1 9}$ & 159,468 & $2,838,116.20$ \\
$\mathbf{2 0 2 0}$ & 162,179 & $2,886,370.80$ \\
\hline
\end{tabular}

Elaboración Propia

Se exportará el primer año 8 pallets de 20’ en diferentes meses del año, el cual se aprecia en el Cuadro $\mathrm{N}^{\circ} 14$, donde en cada pallet contendrá 1440 prendas. Cada pallet tiene una capacidad de 18 cajas y en cada una de estas 80 prendas. Por otro lado, en el Cuadro $\mathrm{N}^{\circ} 15$ se aprecia la misma demanda de forma anualizada por 5 años, señalando además el número de cajas, kilos y monto en dólares a exportar.

\section{Cuadro $\mathbf{N}^{\circ}$ 14:}

Demanda Objetivo Internacional Mensual (2016)

\begin{tabular}{|c|c|c|c|c|c|c|c|c|}
\hline $\begin{array}{c}\text { AÑN } 1 \\
(2016)\end{array}$ & MES 1 & MES 2 & MES 4 & MES 5 & MES 7 & MES 8 & MES 11 & TOTAL \\
\hline Prendas & 1,440 & 1,440 & 1,440 & 1,440 & 1,440 & 1,440 & 2,880 & 11,520 \\
\hline $\begin{array}{l}\text { LCL (1 } \\
\text { Pallet) }\end{array}$ & & & 1 & 1 & 1 & & 2 & 8 \\
\hline US\$ & $15,422.40$ & $15,422.40$ & $15,422.40$ & $15,422.40$ & $15,422.40$ & $15,422.40$ & $30,844.80$ & 123,379 \\
\hline $\begin{array}{l}\text { US\$ por } \\
\text { prenda }\end{array}$ & 10.71 & 10.71 & 10.71 & 10.71 & 10.71 & 10.71 & 10.71 & 10.71 \\
\hline
\end{tabular}

Elaboración Propia 


\section{Cuadro $\mathbf{N}^{\circ}$ 15:}

Demanda Objetivo Internacional Anual (2016-2020)

\begin{tabular}{lllllll}
\hline & AÑO 2016 & AÑO 2017 & AÑO 2018 & AÑO 2019 & AÑO 2020 & TOTAL \\
\hline Prendas & 11,520 & 12,960 & 14,400 & 15,840 & 17,280 & $\mathbf{7 2 , 0 0 0}$ \\
Cajas & 2,880 & 3,240 & 3,600 & 3,960 & 4,320 & $\mathbf{1 8 , 0 0 0}$ \\
LCL (Pallets) & 8 & 9 & 10 & 11 & 12 & $\mathbf{5 0}$ \\
Kilos & $2,333.00$ & $2,624.00$ & $2,916.00$ & $3,208.00$ & $3,499.00$ & $\mathbf{1 4 , 5 8 0 . 0 0}$ \\
US\$ & $123,379.00$ & $138,802.00$ & $154,224.00$ & $169,646.00$ & $185,069.00$ & $\mathbf{7 7 1 , 1 2 0 . 0 0}$ \\
\hline
\end{tabular}

Elaboración Propia

\section{4. - Análisis de la oferta}

\subsection{1. - Características de los principales productores de prendas de} vestir

En el Cuadro $\mathrm{N}^{\circ} 16$, se aprecia las empresas que producen algodón orgánico en el Perú. En este caso se ha escogido a Bergman Rivera S.A.C para que abastezca las telas a la empresa dado que es la primera empresa Latinoamericana que cuenta con la certificación bajo GOTS desde los sembríos de Cañete hasta el final de la producción. Por otro lado, cuentan con "trato justo" para cada uno de los trabajadores, apoyo al medio ambiente dado que están libres de pesticidas, sostenibilidad de los productos utilizados para la elaboración de la tela y, lo más importante, la trazabilidad del algodón empleado.

\section{Cuadro $\mathbf{N}^{\circ}$ 16:}

Empresas Productoras de algodón orgánico Peruano (2015)

\begin{tabular}{ll}
\hline RUC & EMPRESA \\
\hline $\mathbf{2 0 5 1 6 4 3 8 4 4 5}$ & BERGMAN RIVERA S.A.C \\
$\mathbf{2 0 3 2 8 0 7 5 2 6 2}$ & PERU NATURTEX PARTNERS \\
$\mathbf{2 0 4 1 8 1 0 8 1 5 1}$ & HILANDERIA DE ALGODON PERUANO \\
$\mathbf{2 0 1 3 3 5 3 0 0 0 3}$ & CREDITEX - CIA. IND. TEXTIL CREDISA \\
\hline
\end{tabular}

Elaboración Propia

Fuente: PROMPERU 
Las cinco empresas productoras peruanas más destacadas de prendas de vestir que usan algodón orgánico y las exportan tanto al mercado Colombiano como a otros países son las que aparecen en el Cuadro $\mathrm{N}^{\circ} 17$. Las empresas peruanas más cotizadas según el directorio orgánico del portar Organic S.A. (2016) son Eco Bebé, la cual ofrece comodidad, suavidad y protección para la piel del bebé. Los clientes compran sus prendas porque recalcan las propiedades hipo alergénicas que poseen. De otro lado, está la empresa Nanael Organic, quien es la competencia más fuerte que se tendrá dado que cuentan con línea para bebés de algodón orgánico y otra con algodón orgánico de colores nativos además de usar materiales eco amigables, es decir, 100\% orgánico en los broches y su estampado.

Con respecto al mercado Colombiano, el productor más destacado es The Green baby y Bao Baby Organic, los cuales se enfocan en ofrecer diversos productos como prendas de vestir sólo para bebés basada en la experiencia de ser Madre. La empresa Colombiana Proaltex S.A.S es la única certificada por la GOTS, la mayor competencia hacia Teco Caricias S.A.C.

\section{Cuadro $\mathbf{N}^{\circ}$ 17:}

Empresas Productoras de ropa para bebes con algodón orgánico en Colombia y Perú (2016)

\begin{tabular}{|c|c|c|}
\hline $\mathrm{N}^{\circ}$ & EMPRESAS PERUANAS & EMPRESAS COLOMBIANAS \\
\hline 1. & ECO BEBE & 1. THE GREEN BABY \\
\hline 2. & NANEL ORGANIC & 2. BAOBABY ORGANIC \\
\hline 3. & ECO INFANTY, BEBÈS ECOLÒGICOS & 3. PROALTEX S.A.S \\
\hline 4. & ANPI ORGANIC & 4. FRIENDLY \\
\hline 5. & $\begin{array}{l}\text { CONFECCION DE ROPA ORGANICA PARA } \\
\text { BEBES }\end{array}$ & 5. ORGANIC COTTON \\
\hline
\end{tabular}




\subsection{2.- Proyección de la oferta}

En el cuadro $\mathrm{N}^{\mathrm{o}} 18$, se muestra el valor FOB a exportar por los próximos cinco (5) años al mercado colombiano según Veritrade (2015). El porcentaje de crecimiento brindado por Euromonitor (2016), recalca el crecimiento de las exportaciones colombianas debido a la estabilidad económica del PIB y a la tasa de fertilidad, es decir, se espera que las madres lleguen a tener 2.42 hijos por mujer (DANE, 2016). En el 2015 exportaron unas veinte empresas al mercado colombiano. Sin embargo, se estima que para los próximos años unas 31 empresas lo hagan.

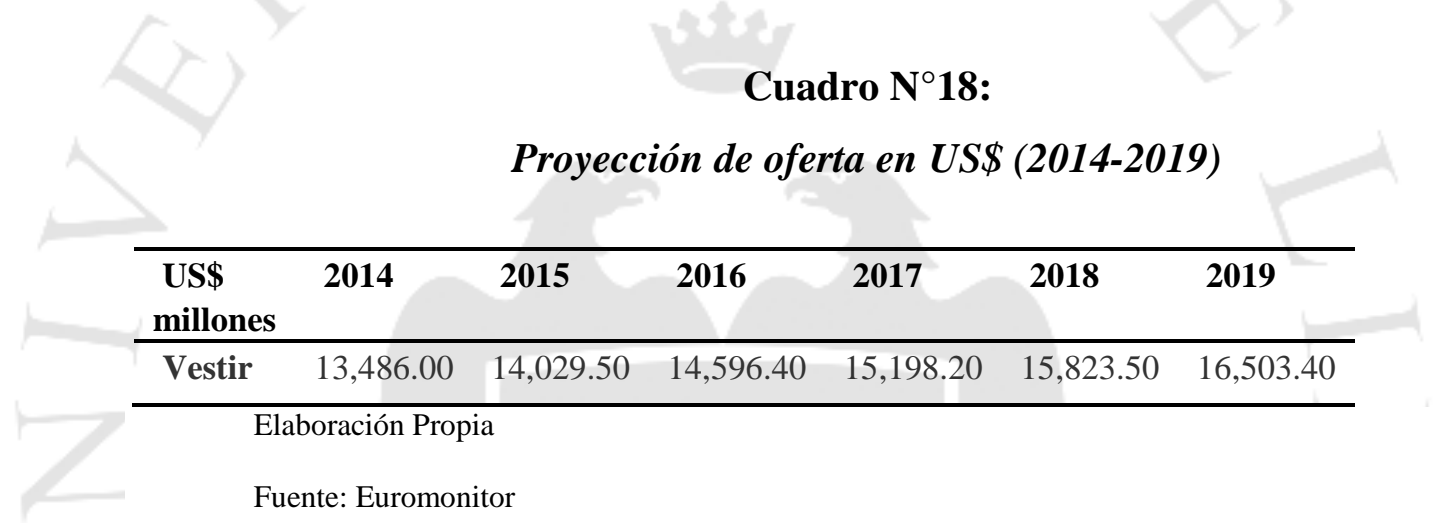

\section{5.- Importaciones del producto o servicio}

El Cuadro $\mathrm{N}^{\circ} 19$, obtenido por Trademap (2015), muestra la cantidad importada de prendas de vestir por Colombia en kilogramos, la cual ha tenido un crecimiento importante del $21 \%$ del 2013 al 2014.

El año que más crecimiento mostró fue el 2012 con un $46.76 \%$ de importaciones. Por otro lado, en el Gráfico $\mathrm{N}^{\circ} 4$, se muestra el crecimiento progresivo de la demanda histórica en US\$ por prendas. El año que más aumentó fue el 2012 con un $80.06 \%$. Sin embargo, el último año ha crecido un $23 \%$. 


\section{Cuadro $\mathbf{N}^{\circ}$ 19:}

Cantidad importada por Kilogramos de prendas por Colombia (20102015)

\begin{tabular}{lllllll}
\hline Código & Descripción del producto & $\mathbf{2 0 1 0}$ & $\mathbf{2 0 1 1}$ & $\mathbf{2 0 1 2}$ & $\mathbf{2 0 1 3}$ & $\mathbf{2 0 1 4}$ \\
\hline '61112000 & $\begin{array}{l}\text { Prendas y complementos } \\
\text { (accesorios) de vestir, de } \\
\text { punto, para bebés: De algodón } \\
\text { Tasa de Crecimiento }\end{array}$ & $298,932.00$ & $355,416.00$ & $521,612.00$ & $482,613.00$ & $583,937.00$ \\
& & & & & \\
\hline
\end{tabular}

Fuente: Trademap

Elaboración Propia

Gráfico $\mathbf{N}^{\circ}$ 4:

Demanda histórica en miles de US\$ de prendas (2010-2014)

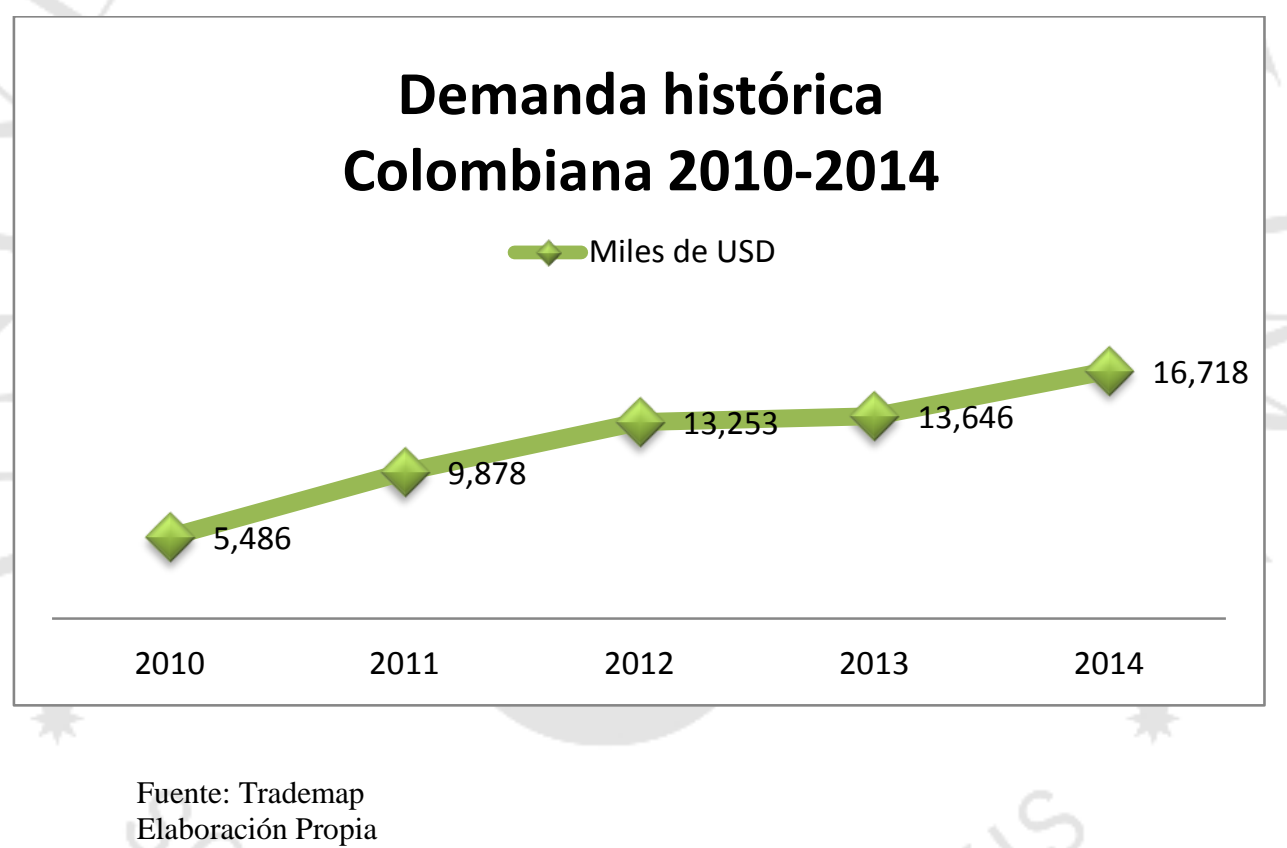

Se aprecia, en el Cuadro $\mathrm{N}^{\circ} 20$ las importaciones de prendas de Perú a Colombia, según fuente de la SUNAT (2015), desde el 2010 al 2014, las cuales han ido en aumento.

Del 2011 al 2012 se generó un aumento de la demanda colombiana por este tipo de productos. En el año 2013 se observa una tendencia creciente al año anterior por más del triple de su valor: En valor FOB cuenta con un total de US\$190 823.10. 
Sin embargo, en el año 2014, se refleja una pérdida en las exportaciones peruanas por un valor FOB de US\$103 121.01. Las tasas de crecimiento más notables fueron del 2011 al 2012 con $33.30 \%$ y la del 2012 al 2013 con un auge del $274.40 \%$. Se espera que en el 2015 este porcentaje sea positivo.

\section{Cuadro $\mathbf{N}^{\circ}$ 20:}

Importaciones de prendas de Perú a Colombia (2010-2015)

\begin{tabular}{llllll}
\hline & $\mathbf{2 0 1 0}$ & $\mathbf{2 0 1 1}$ & $\mathbf{2 0 1 2}$ & $\mathbf{2 0 1 3}$ & $\mathbf{2 0 1 4}$ \\
& FOB US\$ & FOB US\$ & FOB US\$ & FOB US\$ & FOB US\$ \\
\hline Colombia & $169,620.60$ & $38,251.20$ & $50,970.00$ & $190,823.10$ & $103,121.01$ \\
Tasa de Crecimiento & $-77.40 \%$ & $33.30 \%$ & $274.40 \%$ & $-46.00 \%$ & \\
\hline
\end{tabular}

Fuente: SUNAT

Elaboración Propia

\section{6.- Análisis de precios}

\subsubsection{Determinación del costo promedio}

La elasticidad precio-demanda, expresa los cambios porcentuales de la cantidad demandada en función a los del precio. Por ende, a través de la información recabada en Infotrade, se hizo un cálculo más exacto del precio FOB referencial para las prendas de vestir ecológica para bebés. De esa forma, se utilizó los precios FOB unitarios de cada una de las empresas peruanas exportadoras; y se hizo el cálculo con la participación de cada una. Con ello, se obtuvo un precio FOB promedio de US\$65.81/kg, lo que equivale a un precio por prenda de US\$10.71.

El Cuadro N²1 muestra la información recolectada de Infotrade (2015), sobre precios FOB en el mercado de destino: 


\section{Cuadro $\mathbf{N}^{\circ}$ 21:}

Precios FOB referenciales en kilogramos 2015 (US\$/KG)

\begin{tabular}{clc}
\hline & EMPRESA & $\begin{array}{c}\text { PRECIO FOB } \\
\text { EN KG }\end{array}$ \\
\hline $\mathbf{1}$ & MANUFACTURAS AMERICA E I R L & 60.41 \\
$\mathbf{2}$ & INDUSTRIAS NETTALCO S,A, & 60.71 \\
$\mathbf{3}$ & LENNY KIDS S,A,C, & 84.45 \\
$\mathbf{4}$ & PERU FASHIONS S,A,C, & 47.36 \\
$\mathbf{5}$ & MANUFACTURAS CHRISTCI S,R,LTDA, & 66.49 \\
$\mathbf{6}$ & SAN VICENTE TEXTIL COTTON S,A,C & 27.62 \\
$\mathbf{7}$ & INNOVA BABY M,A, E,I,R,L & 89.50 \\
$\mathbf{8}$ & SERVICIOS FLEXIBLES SOCIEDAD & 97.58 \\
& ANONIMA CERRADA & \\
\hline & Fuente: Infotrade & \\
& Elaboración propia
\end{tabular}

\subsubsection{Análisis histórico y proyección de precios}

En la siguiente cita de Notriago, se hablará acerca de los precios de algodón por hectárea para poder llegar a entender mejor el Cuadro $\mathrm{N}^{\circ} 22$.

Se ve un panorama favorable según los precios para el 2015 hacia los productores de algodón, lo cual genera mayor expectativa de aumentar el área sembrada de 5,000 a 7,500 ha para la siembra en el 2015. Esto afecta hacia los indicadores de un mercado favorable como el precio, el cual es de 210 dólares por quintal fibra del algodón americano, y además la escasez según de oferta a nivel mundial del producto de fibra larga. (Notiagro, 2014)

En el cuadro $\mathrm{N}^{\circ} 22$, se muestran los precios promedios anuales, que han tenido las prendas de bebé elaboradas de algodón, a lo largo de los últimos años. Estos han variado debido a que no existe mucha cosecha del algodón y la oferta aumentó. Sin embargo, para este año existe una mayor proyección sobre el precio. Se aprecia que en el 2013 el precio promedio por prenda bajó; en el 2015 a pesar que no se exportó gran cantidad de prendas, el precio subió a US\$10.54. De otro lado, se dio una estimación de valor FOB, precio neto total y unitario para los próximos años. 


\section{Cuadro $\mathbf{N}^{\circ}$ 22:}

Precios FOB referenciales 2011-2018 (US\$/KG)

\begin{tabular}{lllll}
\hline Total período & Peso Neto Kg. & Valor FOB US\$. & (US\$/KG) & US\$ x Prenda \\
\hline 2018 & $22,712.55$ & $1,250,325.61$ & 55.05 & 11.01 \\
2017 & $20,647.77$ & $1,110,849.94$ & 53.80 & 10.76 \\
2016 & $20,443.34$ & $1,094,740.59$ & 53.55 & 10.71 \\
2015 & $18,584.85$ & $851,707.75$ & 45.83 & 10.54 \\
2014 & $26,777.05$ & $1,199,284.19$ & 44.79 & 10.30 \\
2013 & $34,694.46$ & $1,447,232.00$ & 41.71 & 9.59 \\
2012 & $29,825.37$ & $1,432,617.24$ & 48.03 & 11.05 \\
2011 & $15,887.91$ & $760,476.59$ & 47.87 & 11.01 \\
\hline Fuente: PROMPERU STAT & & & \\
Elaboración Propia & & &
\end{tabular}

\section{7.- Canales de comercialización y distribución del producto}

El CIC (Comercio Internacional de Colombia, 2016), relata que existen dos canales de distribución. El primero, se da para "Productos de consumo", los cuales se dividen en cuatro sub canales y son: (1) el Canal Directo, para ventas por teléfonos, correo TV, etc.; (2) el Canal Detallista, que son las tiendas especializadas, boutiques, hipermercados, etc.; (3) el Canal Mayorista, para productos de gran demanda; y por último está (4) el Sub Canal Agente que se basa sólo en el marketing del producto. El segundo canal está dado para productos industriales o de "Negocio a Negocio" donde se encuentran los canales para las ventas de productos agrícolas, materias primas hacia clientes industriales y fabricantes a través de tratos comerciales.

Según PROCOLOMBIA (2015), en Colombia existen canales muy diversos de distribución como ya se mencionaron, pero para el sector de prendas orgánicas para bebés se dan en almacenes por departamento (22\%), cadenas nacionales e internacionales (10\%), Almacenes especializados (16\%), Almacenes de descuentos (26\%), Importadores Directos (20\%), Agentes de ventas y distribuidores (6\%); pero donde se ha concentrado la mayor facturación es el canal de Minoristas en Almacenes 
de Descuento ya que cuentan con más potencial para vender estas prendas y promociones; por tanto, obtienen más ingresos.

Según un estudio de la Embajada Española en Colombia (2014), el comercio minorista en Bogotá es altamente competitivo puesto que representa más del 50\% de las ventas del sector. Este canal se caracteriza porque cuenta con la presencia de diversos puntos de venta. Pro Colombia, identifica a este como uno de los países de América Latina con mayor descentralización. Las zonas más importantes de comercialización son Bogotá, Medellín, Cali, Bucaramanga y Cartagena. Es en Bogotá donde el método de venta directa a través de catálogo y almacenes especializados ha incrementado su participación orientados a población con ingresos medios y altos.

\section{Gráfico $\mathbf{N}^{\circ}$ 5:}

Canales de Comercio y Distribución de prendas para bebés (2014)

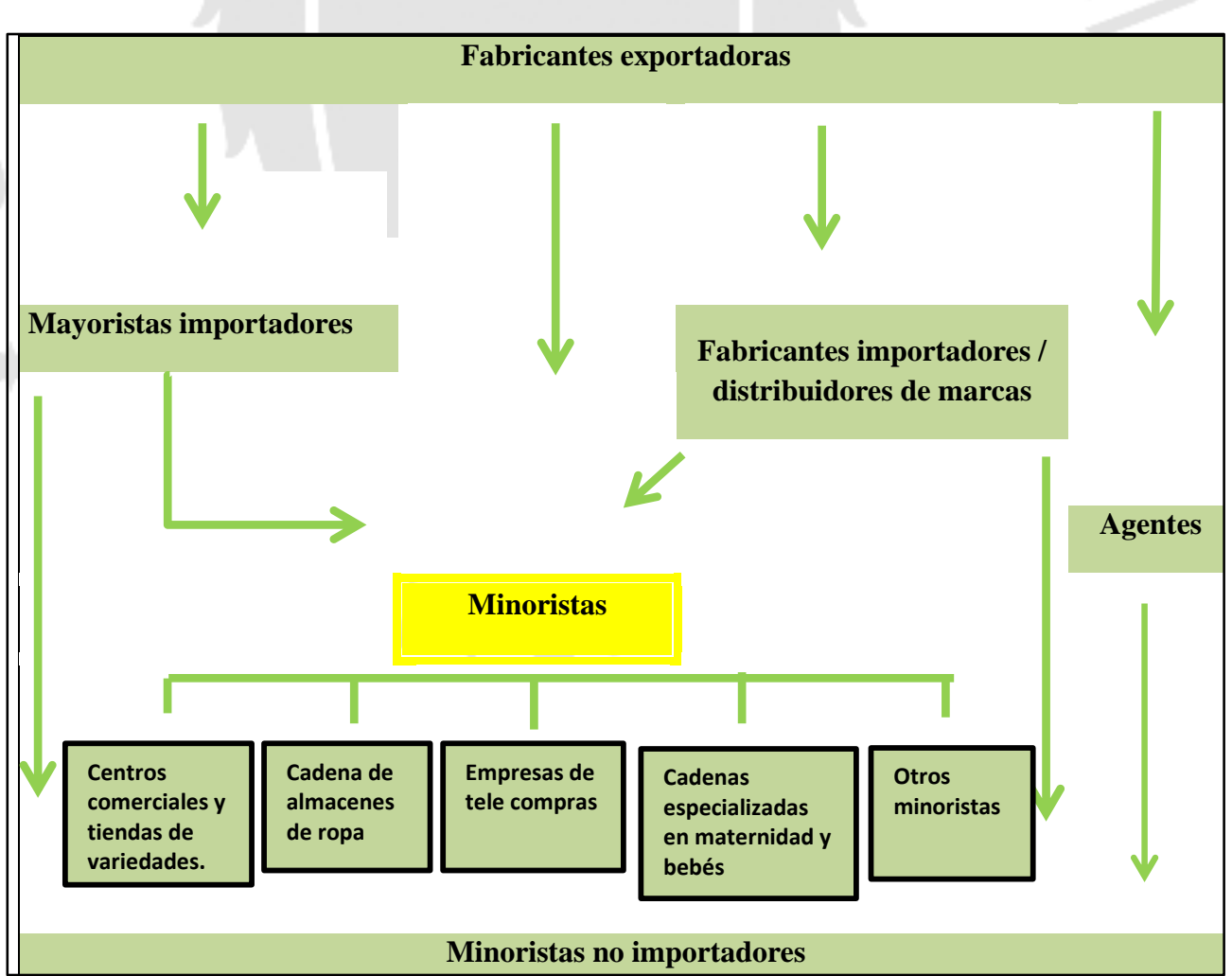

Elaboración Propia

Recuperado de "Estructura y Canales de comercio para la ropa de bebés", el 17 de setiembre del 2014. En: http://www,cbi,eu/system/files/marketintel/Estructura_y_canales_de_comercio_para_la_ropa_de_bebes,pdf 
En el Gráfico N`5 se aprecian los canales de comercio que utiliza el mercado Colombiano para la distribución de prendas de bebés. El canal óptimo a seleccionar para la exportación de prendas será el "Canal de Minoristas" porque opera a través de tiendas, cadenas especializadas y otros minoristas con lo cual se obtendrá mayor control sobre los resultados y márgenes de ganancia con la reducción de costos. Esta empresa se enfocará en dirigirse hacia las cadenas especializadas en maternidad y bebés. La ventaja competitiva de este canal minoristas será el de ofrecer exclusividad en el servicio y en las prendas (diseños propios, calidad, marca y servicio post venta).

Por otro lado, los precios de venta tomados estarán relacionados a la forma de ingreso en el mercado de destino, la cual se dará mediante las ventas a los importadores (fabricantes - minoristas - consumidores). Esto genera beneficios en cuanto a la entrega de productos a los clientes finales dado que usando este medio se agilizarían las operaciones en destino. Por último, al tener contacto directo con el importador se le dará un seguimiento post venta más canalizado. 


\section{CAPITULO IV: EVALUACIÓN EXTERNA}

\section{1. - Análisis PESTE}

Según DANE (2015), el territorio Colombiano es muy extenso, con una población de 47846160 habitantes, lo que origina que sea el tercer país más poblado y el quinto poder económico en América Latina. El entorno colombiano al cual Teco Caricias S.A.C se enfrentará no es muy positivo, por ende se evaluará la evolución que Colombia ha tenido a lo largo de los últimos años.

En resumen, Colombia tiene un Gobierno de derecha a pesar que la delincuencia y corrupción priman. Un aspecto positivo es el crecimiento sólido de la economía colombiana en comparación con América Latina. El nivel socioeconómico es positivo ya que hacia el 2019 la clase media alta abarcará más de la mitad de la población local. Por último, la tendencia hacia utilizar lo ecológico se está volviendo fuente primaria de vida debido a las enfermedades que producen ciertos químicos y la contaminación ambiental que estos generan.

\subsection{1. - Fuerzas políticas, gubernamentales y legales (P)}

Según el Diario Pensamiento en Colombia (2015), afirma que la estabilidad política colombiana no es buena por diversos factores. En primer lugar, la inteligencia política está encabezada por ex presidentes y ex miembros de la República lo que origina que sus derechos sean más estables. En segundo lugar, existe por parte del gobierno colombiano apoyo hacia los militares, esto se debe que a que Colombia es la 
democracia más antigua de América del Sur y existen desigualdades que originan diversos conflictos. Finalmente, en el último año se realizó un Censo y se evidenció que existió un progreso en cuanto a los derechos laborales de las personas, donde el salario mínimo para el presente año por una jornada laboral de ocho horas en Colombia es de US\$616 lo que significa que por esa remuneración pueden darse gustos, como la compra de prendas.

Colombia cuenta con 4 legislaciones. La primera, es el Acuerdo 042, donde las empresas públicas y privadas deben regular el inventario único documental con el fin de "Fijar políticas y establecer reglamentos necesarios para garantizar la conservación y el uso adecuado del patrimonio documental de la Nación de conformidad con los planes y programas que sobre la materia adopte la Junta Directiva”. (Archivo General de la Nación, 2015, p.1)

El segundo, es el decreto número 2516, el cual explica la modalidad de selección de la mínima cuantía colombiana que incluyen diversas leyes de corrupción y de contratación de recursos públicos. En tercer lugar, está el Estatuto Anticorrupción, el cual abarca mecanismos a utilizar para la prevención e investigación de los actos de corrupción y su control de forma pública. Por último, se encuentra la ley Anti trámites del decreto 0019 dado en el 2012, para suprimir y reformar regulaciones en la administración pública.

Para enfatizar sobre el Gobierno y la Política Colombiana, comenzaremos preguntando: ¿El Gobierno Colombiano es de izquierda o derecha? según Colombia aprende (2014), es un país de derecha puesto que se le conoce como un país unitario, democrático y social. Es un país presidencialista, ya que los mismos pobladores hacen valer sus derechos mediante la elección de un Gobernante el cual va a representarlos para que su nación pueda desarrollarse frente a las demás y sea la mejor. Colombia es 
uno de los pocos países que no tiene la obligación de ejercer su voto en los procesos electorales, esto origina que los pobladores no estén presionados para hacer algo que no desean. El derecho de libertad prima de manera óptima ante este factor.

Según el Ministerio de Relaciones Exteriores (2014), lo que llevó a que Colombia tenga buena relación con el exterior inició desde el siglo XX, cuando el Presidente Marco Fidel Suarez realizó una alianza con EE.UU. para diversificar relaciones con el resto del mundo y sean potentes aliados frente a los demás países. Esto fue positivo pues Colombia comenzó a crecer de forma económica, social, cultural, etc. originando la eliminación de restricciones entre los países vecinos y sus socios comerciales.

La Junta Directiva del Banco de la República Colombiana (2015), recalcó que los socios comerciales de la nación más importantes son EE.UU., Zona Europea, China, Brasil, Ecuador, Venezuela, Perú y Chile. Lo que origina un escenario positivo para que Teco Caricias S.A.C, que es una empresa peruana, pueda entrar sin restricciones y con beneficios de crecimiento.

Lo más resaltante en la actualidad es la presencia de las FARC (Fuerzas Armadas Revolucionarias de Colombia). El diario el País (2015), cuyo origen es colombiano, sacó un reportaje del riesgo político y las FARC. Ellos señalan que existió un acuerdo de paz entre el Gobierno Colombiano y las FARC que está originando tranquilidad y confianza para la libre circulación de la población local como para los extranjeros promoviendo el turismo y la inversión en el país generando así beneficios económicos. Un factor clave es que el riesgo país de Colombia se redujo en 103 puntos y para el 2016 existirá mayor estabilidad en cuanto a lo operacional como financiero. 
Según los puntos propuestos en tanto las fuerzas políticas, gubernamentales y legales es favorable invertir en Colombia debido a que es un país donde prima la democracia, es unitario y social. Todo esto, brinda un beneficio a la empresa dado que no existirían obstáculos en cuanto al ingreso de mercancías.

\subsection{2. - Fuerzas económicas y financieras (E)}

Una de las economías más sólidas y en crecimiento de América Latina es Colombia, con un PBI creciente, según DANE, registrando variaciones positivas en el año 2013 con un $4.30 \%$.y en el 2014 con 4.90\%. De otro lado, la inflación con respecto al 2013 se ha mantenido en un $1.94 \%$.

El desempleo colombiano ha disminuido progresivamente (en el 2013 fue de $9.60 \%$ y actualmente es de $9.30 \%)$.

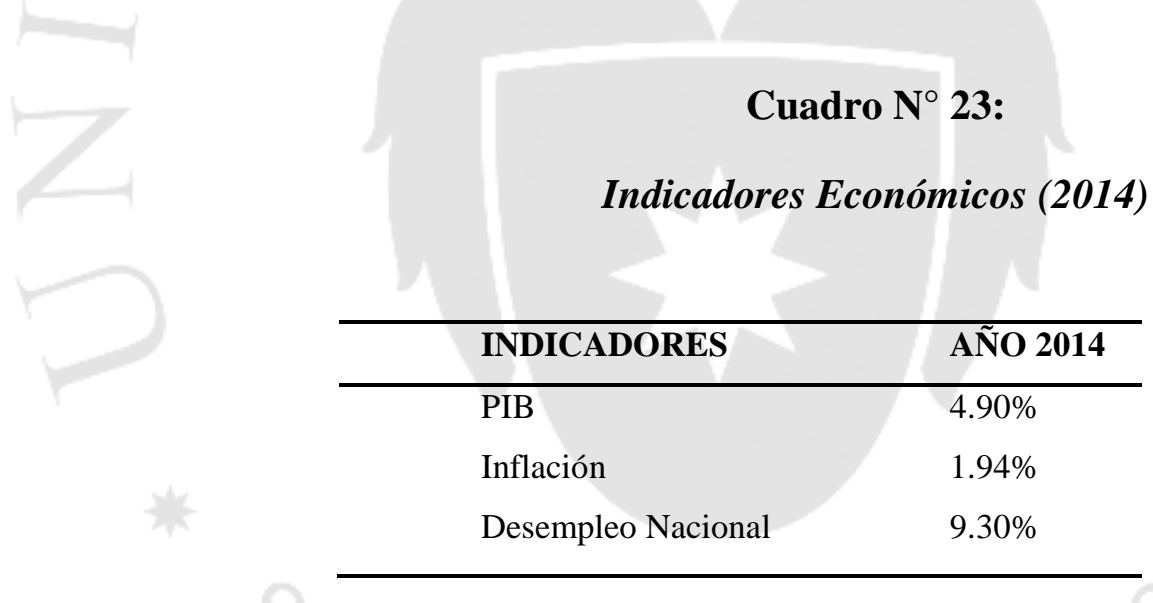

Fuente: DANE

Elaboración Propia

En cuanto al poder adquisitivo, el último año fue de US\$13 000, donde se muestra un crecimiento del $7.14 \%$. Con respecto a los aranceles, Perú cuenta con un porcentaje liberado de ad valoren CIF del $100 \%$ por la Comunidad Andina. Es decir, no se impone tasas o impuestos para estas mercancías cuando entran a Colombia siempre y cuando se presente el certificado de Origen. 
Según SUNAT (1993), existe un acuerdo comercial entre Perú y Colombia que genera y promueve un óptimo desarrollo comercial de forma equitativa. Esta norma, rechaza la práctica desleal, es decir, debe existir un comercio justo. Por otro lado, no se pueden entregar subsidios a las exportaciones.

Colombia tiene diversos acuerdos comerciales. Un Acuerdo Multilateral es el de la OMC (Organización Mundial del Comercio); los acuerdos de Ámbito Regional con los que cuentan son de la Comunidad Andina y ALADI (Asociación Latinoamericana de Integración). Por último, se encuentran en negociaciones para la Relación Comercial Comunidad Andina- Unión Europea.

Según el Fondo Monetario Internacional (FIM), la evolución del PBI colombiano será favorable para los próximos años y esto permitirá que la empresa genere mayor rentabilidad y a la vez contribuirá con el PBI del país. En el gráfico $\mathrm{N}^{\circ} 6$ se mostrará el auge que Colombia tiene y en el gráfico $\mathrm{N}^{\circ} 7$ el pronóstico hacia el presente año 2016, el cual parece crecer con respecto al 2015, puesto que bajó a 3.10\%.Por otro lado, las importaciones crecerán para el presente año a un 8.20\%, lo que favorece a Teco Caricias S.A.C para seguir con el negocio. 


\section{Gráfico $\mathbf{N}^{\circ}$ 6:}

Evolución del PBI Colombiano (2005-2015)

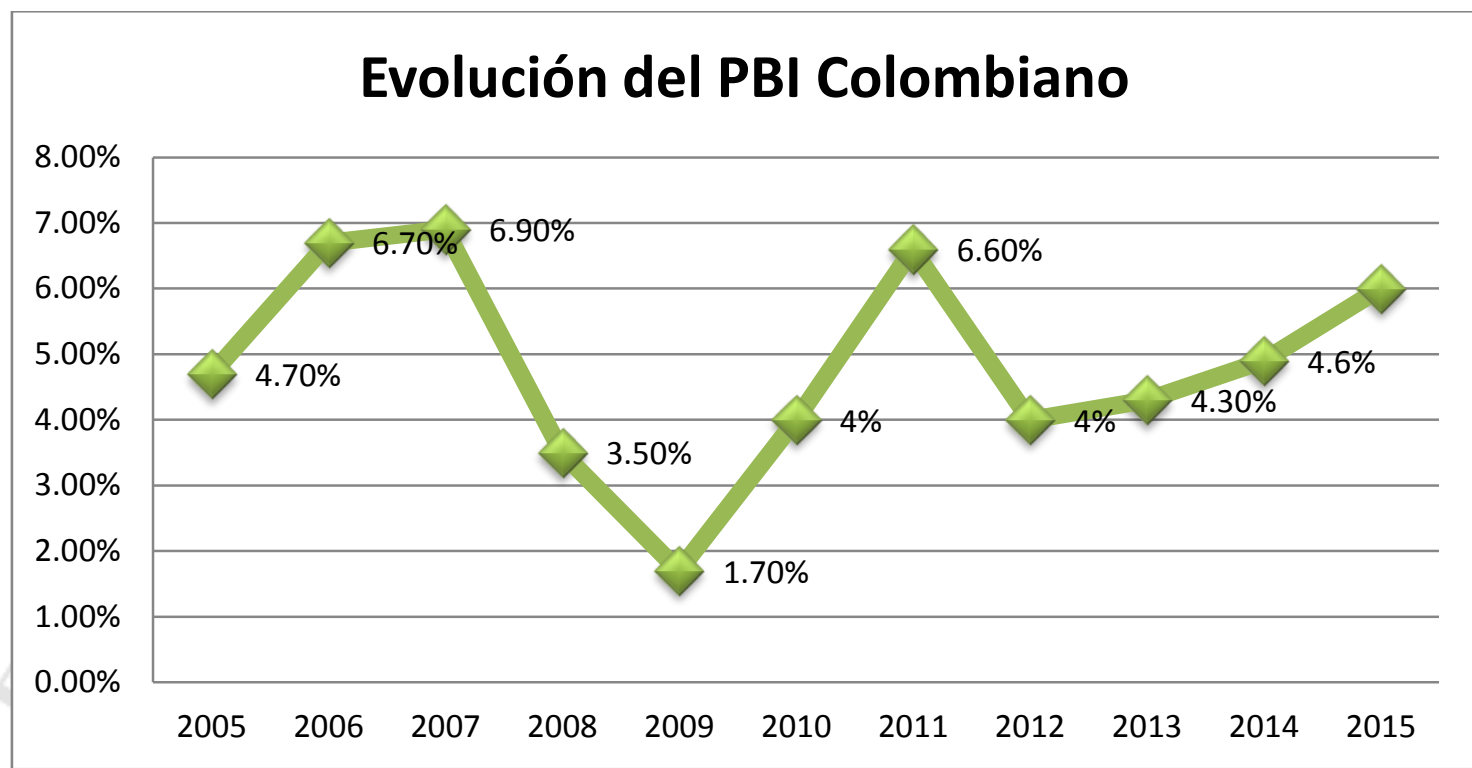

Elaboración Propia

\section{Gráfico $\mathbf{N}^{\circ}$ 7:}

Cifras Colombianas (2014-2016)

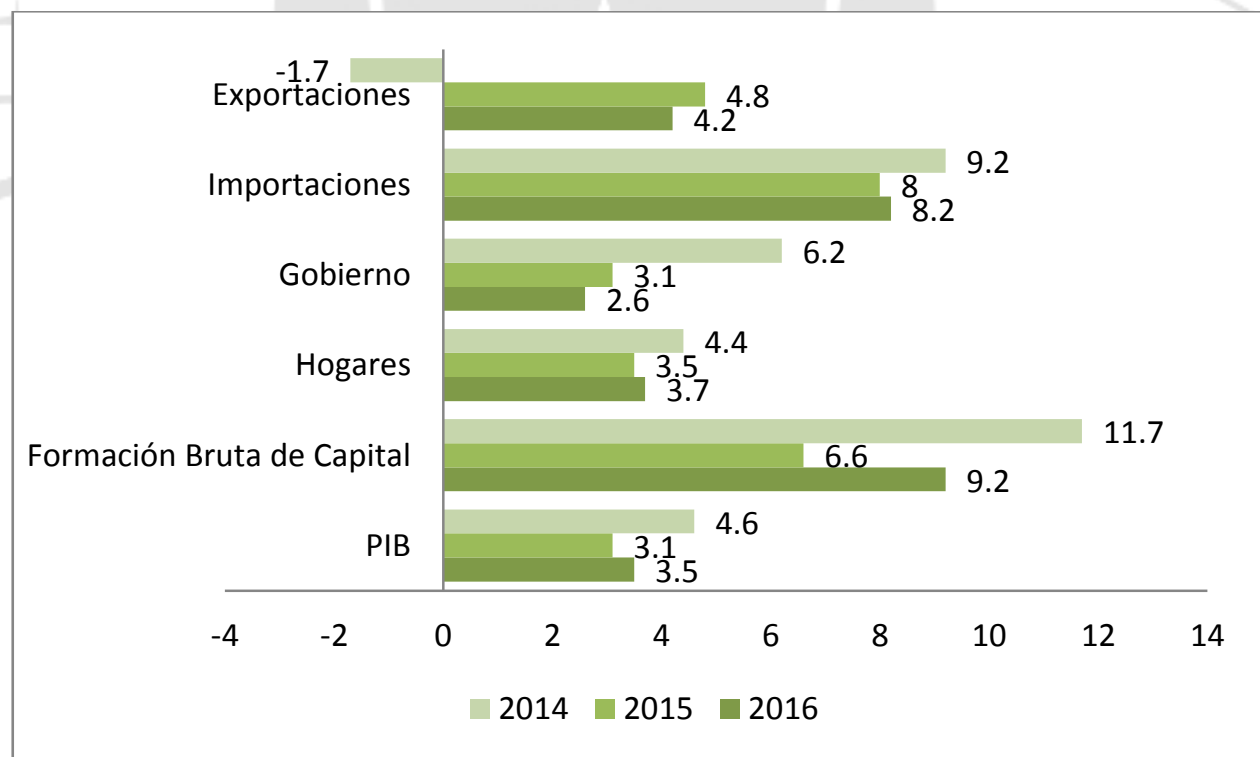

Elaboración Propia

Sacado del DANE

Con respecto a la industria textil, como se aprecia en el Gráfico $\mathrm{N}^{\circ} 8$, el panorama futuro para el 2016 crecerá en un 4\%. Todo esto hará que las inversiones de la empresa tengan una rentabilidad mayor. Por otro lado, en el Cuadro $\mathrm{N}^{\circ} 24$, se muestra 
el crecimiento económico de los socios comerciales de la región. Se aprecia que Perú creció un $5.50 \%$ por encima de Europa, USA, entre otros.

\section{Gráfico $\mathbf{N}^{\circ}$ 8:}

Crecimiento de la Industria (2000-2016)

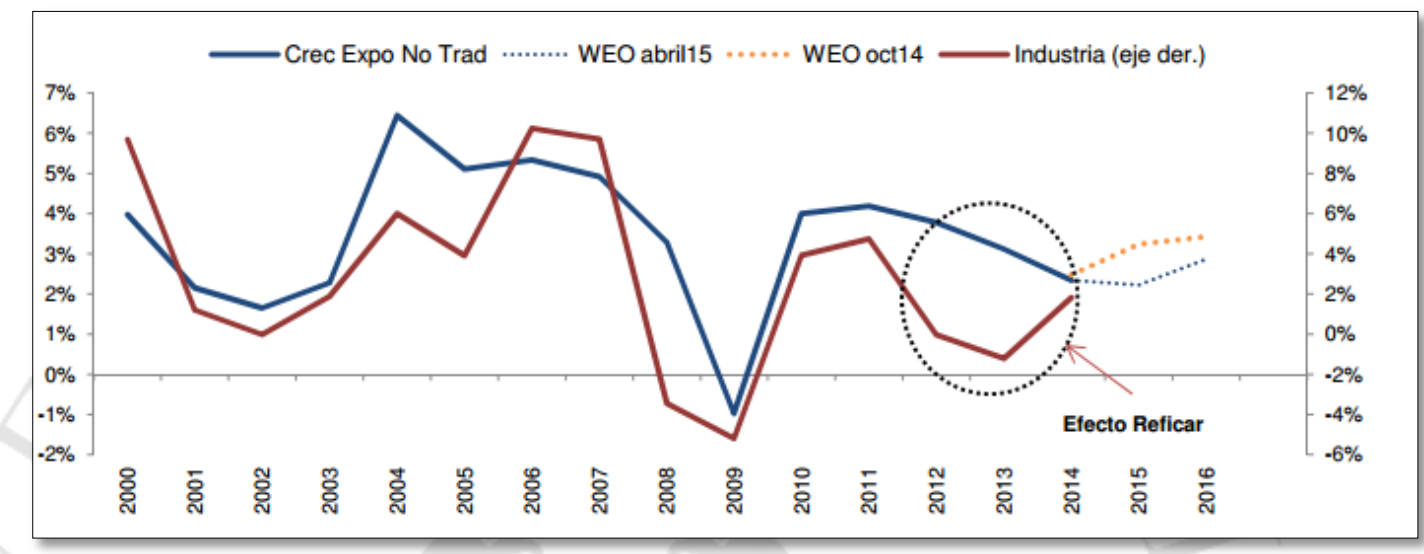

Elaborado por DANE, IMF, Banco de la República

\section{Cuadro $\mathbf{N}^{\circ}$ 24:}

Crecimiento Económico de Socios Comerciales (2014-2015)

\begin{tabular}{lllllll}
\hline \multicolumn{1}{c}{ Año } & \multicolumn{3}{c}{2014} & & 2015 & \\
\hline País o Región & Bajo & Central & Alto & Bajo & Central & Alto \\
USA & 2.30 & 2.40 & 2.50 & 2.40 & 3.00 & 3.60 \\
Europa & 0.70 & 0.80 & 0.90 & 0.20 & 0.90 & 1.60 \\
China & 7.20 & 7.30 & 7.40 & 6.40 & 7.00 & 7.50 \\
Ecuador & 3.40 & 3.80 & 4.20 & 2.00 & 3.00 & 4.00 \\
México & 20 & 2.20 & 2.40 & 2.30 & 3.30 & 4.00 \\
Venezuela & -5.00 & -4.00 & -3.00 & -6.00 & -4.00 & -2.00 \\
Perú & 2.60 & 2.80 & 3.00 & 3.00 & 4.70 & 5.50 \\
Brasil & -0.10 & 0.10 & 0.20 & 0.00 & 0.70 & 1.20 \\
Chile & 1.50 & 1.70 & 1.90 & 2.50 & 3.00 & 3.50 \\
\hline \multicolumn{7}{c}{} \\
& Elaboración Propia & & &
\end{tabular}

Por último, el Peso Colombiano es la moneda de la región, la cual es controlada por la el Banco de la República y señala en el 2015, que la tasa de cambio del peso colombiano se calcula de acuerdo al mercado cambiario por las compras y ventas de divisas. Esto se da por la cantidad de pesos por un dólar estadounidense. Por ejemplo, 
en el Cuadro $\mathrm{N}^{\circ} 25$, se puede observar que por cada 2746 pesos colombianos equivalen a un dólar americano, siendo este entorno no muy favorable para los colombianos. Sin embargo, si se aprecia desde la perspectiva de otro país como lo es de Perú hacia Colombia, el entorno es positivo puesto que se puede tener más dólares para invertir.

\section{Cuadro $\mathbf{N}^{\circ}$ 25:}

Tasa de Cambio en Colombia (2010-2015)

\begin{tabular}{cl}
\hline Año & $\begin{array}{l}\text { Promedio anual } \\
\text { en US\$ }\end{array}$ \\
\hline $\mathbf{2 0 1 0}$ & $1.897,89$ \\
$\mathbf{2 0 1 1}$ & $1.848,17$ \\
$\mathbf{2 0 1 2}$ & $1.798,23$ \\
$\mathbf{2 0 1 3}$ & $1.868,90$ \\
$\mathbf{2 0 1 4}$ & $2.000,68$ \\
$\mathbf{2 0 1 5}$ & $2.746,47$ \\
Elaboración Propia \\
Sacado de Banco de la República Colombia
\end{tabular}

De acuerdo a los datos propuestos en este sub capítulo, se generaría un beneficio hacia la empresa, debido a que la economía en la cual se invertirá es sólida, no existirían riesgos financieros y lo más importante es que el poder adquisitivo de los colombianos está auge y podrán comprar más prendas orgánicas.

\subsection{3. - Fuerzas sociales, culturales y demográficas (S)}

La población Colombiana ha experimentado un rápido crecimiento poblacional, sobre todo en el 2015. Según la DANE (2016), la cifra de crecimiento con relación a la de los últimos años ha sido de un $1.60 \%$. En el Cuadro $\mathrm{N}^{\circ} 26$, se aprecia las proyecciones poblacionales hacia el 2016 por rangos de edad. El grupo al cual se está enfocado es de 0 a 4 años, donde existe un crecimiento de casi $1 \%$. El grupo de edad que más porcentaje de crecimiento representa es el de la tercera edad (70 a 74 años) con un 19\% 
de crecimiento hacia el 2020. En general la población colombiana crecerá en promedio un $4.50 \%$, lo que permitirá la inversión hacia las exportaciones de prendas de vestir.

\section{Cuadro $\mathbf{N}^{\circ}$ 26:}

Crecimiento Poblacional Proyectado (2016-2020)

\begin{tabular}{llllll}
\hline Grupos de edad & Total_2016 & Total_2017 & Total_2018 & Total_2019 & Total_2020 \\
\hline Total & $48,747,708$ & $49,291,609$ & $49,834,240$ & $50,374,478$ & $50,911,747$ \\
$\mathbf{0 - 4}$ & $4,335,151$ & $4,348,076$ & $4,359,358$ & $4,367,826$ & $4,373,565$ \\
$\mathbf{5 - 9}$ & $4,263,048$ & $4,270,908$ & $4,280,527$ & $4,290,373$ & $4,298,770$ \\
$\mathbf{1 0 - 1 4}$ & $4,265,999$ & $4,256,204$ & $4,252,711$ & $4,252,922$ & $4,255,643$ \\
$\mathbf{1 5 - 1 9}$ & $4,321,654$ & $4,299,236$ & $4,279,637$ & $4,264,866$ & $4,254,234$ \\
$\mathbf{2 0 - 2 4}$ & $4,306,036$ & $4,307,133$ & $4,299,104$ & $4,287,040$ & $4,274,906$ \\
$\mathbf{2 5 - 2 9}$ & $4,022,291$ & $4,083,624$ & $4,138,652$ & $4,183,803$ & $4,216,692$ \\
$\mathbf{3 0 - 3 4}$ & $3,605,504$ & $3,676,508$ & $3,750,017$ & $3,822,631$ & $3,891,467$ \\
$\mathbf{3 5 - 3 9}$ & $3,264,933$ & $3,318,380$ & $3,369,633$ & $3,424,448$ & $3,485,871$ \\
$\mathbf{4 0 - 4 4}$ & $2,909,621$ & $2,961,657$ & $3,027,900$ & $3,096,815$ & $3,160,456$ \\
$\mathbf{4 5 - 4 9}$ & $2,875,587$ & $2,856,190$ & $2,834,721$ & $2,824,243$ & $2,833,416$ \\
$\mathbf{5 0 - 5 9}$ & $5,608,105$ & $5,630,116$ & $5,638,765$ & $5,645,491$ & $5,658,490$ \\
$\mathbf{6 0 - 6 9}$ & $3,164,665$ & $3,296,675$ & $3,432,179$ & $3,572,088$ & $3,716,337$ \\
$\mathbf{7 0 - 7 4}$ & 967,539 & $1,013,539$ & $1,061,933$ & $1,110,984$ & $1,160,128$ \\
\hline
\end{tabular}

Elaboración Propia

Fuente: DANE

Otro indicador esencial para el análisis, es la tasa de natalidad, debido a que este refleja la cantidad de mujeres que tienen hijos a una determinada edad las cuales estarán dispuestas a adquirir productos para sus bebés.

Según el DANE (2014), las mujeres de 20 a 24 años de edad son madres, las cuales equivalen a un 29\% de la población (Ver Gráfico Nº 9). Seguidamente, están las mujeres de 15 a 19 años y de 25 a 29 años con un $22 \%$ respectivamente. Como se aprecia en el Gráfico $\mathrm{N}^{\circ} 10$, según la tasa de fertilidad, las mujeres tienen 2.32 hijos cada una. 


\section{Gráfico $\mathbf{N}^{\circ}$ 9:}

Nacimientos por grupo de edad en Colombia (2014)

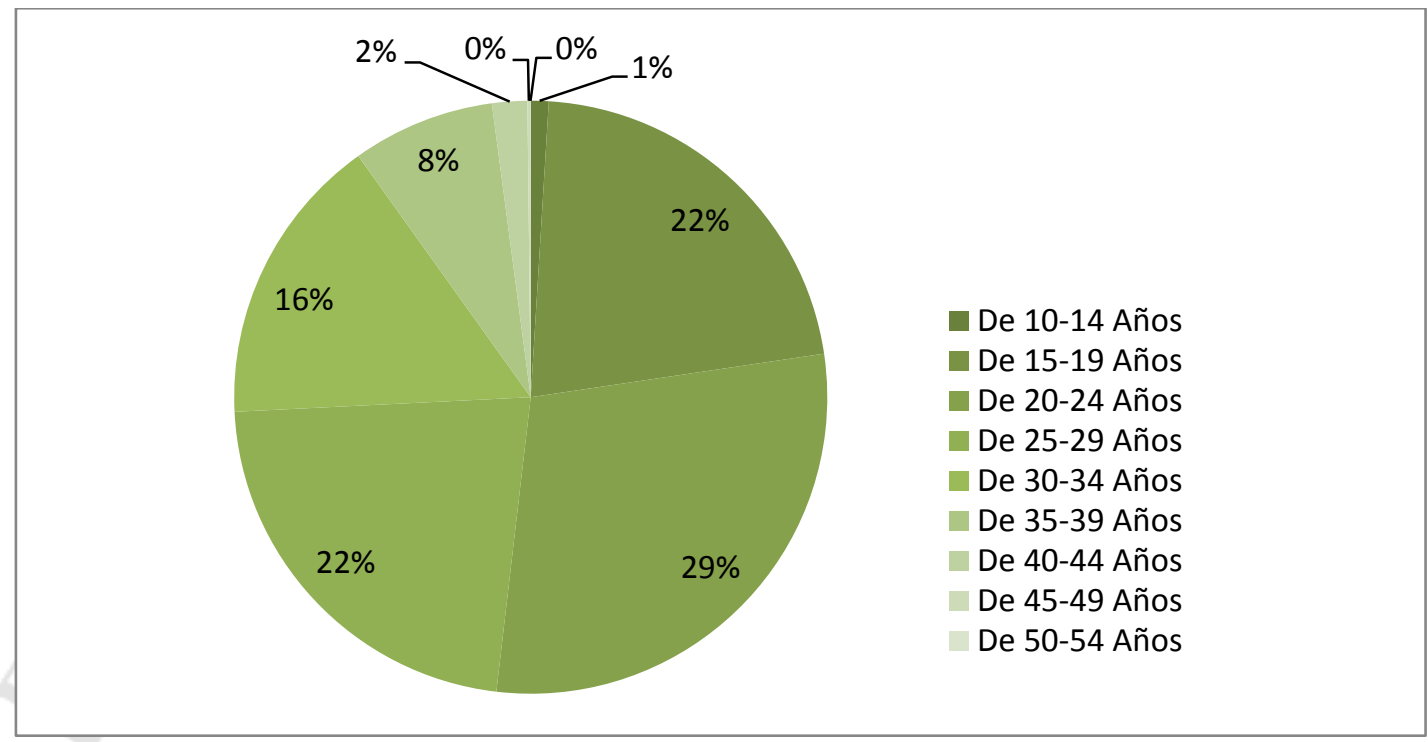

Fuente: DANE

Elaboración Propia

\section{Gráfico $\mathbf{N}^{\circ}$ 10:}

Tasa de Fertilidad (2012)

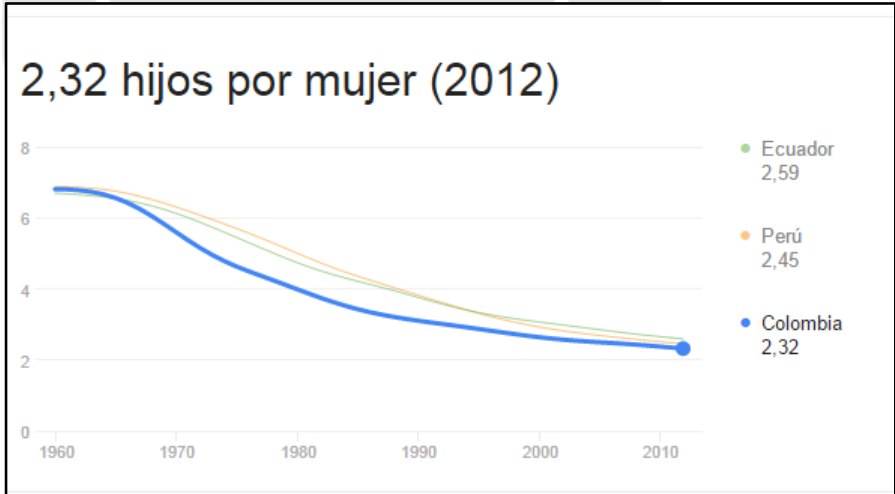

Recuperado de "Banco Mundial”, el 04 de octubre del 2015.En:

http://data.worldbank.org/country/colombia

Las estadísticas vitales según la ONU (2015), son los nacimientos vivos hasta el primer año, muertes por año, tasa de natalidad, mortalidad, crecimiento natural, tasa de fertilidad y el índice de mortalidad infantil. Observando el Cuadro $\mathrm{N}^{\circ} 27$, apreciamos que estos datos están dados en los periodos del 2005-2010, 2011 -2015 y las 
proyecciones hacia el 2020. Las presentes estadísticas también son las más vitales para el proyecto debido a que el mercado al cual se dirige son los recién nacidos. Los nacimientos por año están disminuyendo al igual que la tasa de natalidad y las muertes por año. Este no es un panorama muy favorable. Sin embargo, está existiendo mayor crecimiento poblacional y la tasa de mortalidad infantil está disminuyendo.

\begin{tabular}{|c|c|c|c|c|c|c|c|c|}
\hline Periodo & $\begin{array}{l}\text { Nacimientos } \\
\text { Por Año }\end{array}$ & $\begin{array}{l}\text { Muertes por } \\
\text { Año }\end{array}$ & $\begin{array}{l}\text { Cambio } \\
\text { Natural por } \\
\text { Año } \\
\end{array}$ & $\begin{array}{l}\text { Tasa de } \\
\text { Natalidad }\end{array}$ & $\begin{array}{l}\text { Tasa de } \\
\text { Mortalidad }\end{array}$ & $\begin{array}{l}\text { Crecimiento } \\
\text { Natural }\end{array}$ & $\begin{array}{l}\text { Tasa de } \\
\text { Fertilidad }\end{array}$ & $\begin{array}{l}\text { Mortalidad } \\
\text { Infantil }\end{array}$ \\
\hline $2005-20010$ & $804,000.0$ & $249,000.0$ & $555,000.0$ & 18.0 & 5.6 & 12.4 & 2.1 & 19.1 \\
\hline $2011-2015$ & $764,000.0$ & $273,000.0$ & $491,000.0$ & 16.2 & 5.8 & 10.4 & 1.9 & 16.7 \\
\hline 2016-2020 & $729,000.0$ & $300,000.0$ & $429,000.0$ & 14.8 & 6.1 & 8.7 & 1.8 & 14.0 \\
\hline
\end{tabular}

Elaboración propia Fuente: ONU

Las tendencias de consumo, como se pudo apreciar en el Capítulo $\mathrm{N}^{\circ} 3$, en gustos y preferencias para la elección de prendas de vestir, se da propiamente por los gustos $(58.74 \%)$, seguido por la necesidad de tenerlas (16.55\%). Otro factor que destaca es la marca, la cual tiene un porcentaje bajo de $3.11 \%$ y por impulso de $1.51 \%$. Es por eso que Teco Caricias S.A.C se ha enfocado más en los diseños de las prendas para que resulte rentable la inversión.

"La clase media colombiana es una de las que han crecido en la región los últimos 15 años. El 54\% de colombianos mejoró sus estatus económicos entre 1992 y 2008” (BANCO MUNDIAL, 2014)

Lo que influyó al crecimiento de las clases sociales, es el aumento en la fuerza laboral de la mujer, la cual ocupa en el ranking el primer lugar en Latinoamérica. El diario El Tiempo (2015), relata que la clase media colombiana superó por primera vez la pobreza, esto se da por el crecimiento económico y su estabilidad en los próximos 
años La aparición de trabajos informales no es un escenario muy favorable, lo que genera un ajuste positivo en la economía y contribuye a que este porcentaje siga en auge. En el 2014 la pobreza ocupaba un $28 \%$ y la clase media obtuvo un $30.50 \%$. (Ver anexo 2)

Según lo mencionado en las fuerzas sociales, demográficas y culturales, se aprecia que para la empresa existe un escenario favorable debido al crecimiento poblacional del país, especialmente en el grupo de edad que va de $0-4$ años con un 1 $\%$. Sin embargo, se tiene un obstáculo importante porque la tasa de natalidad y fertilidad del país no es favorable.

\subsection{4. - Fuerzas tecnológicas y científicas $(T)$}

Como se muestra en el Gráfico N¹1, según el Banco Mundial (2013), el 51.70\% de los pobladores colombianos en el 2014 usan Internet (en auge desde el 2000, donde el uso era de tan sólo 2.20\%). Este es un factor favorable para la empresa debido a que al largo plazo, se usará esta herramienta para las ventas al crearse una tienda Espejo. Así, una vez que el producto sea reconocido a nivel de todo Colombia, se procederá a vender la marca vía web. Las plataformas de venta por internet ayudarán a que las ventas propiamente dichas sean accesibles de manera personalizada y sin cargos extras.

Por otro lado, se dará la creación de aplicativos para celulares los cuales no tendrán costo para su descarga. Según el Diario El Tiempo (2016), los pagos en las tiendas o centros, podrán ser pagados desde la "muñeca", es decir, se ha creado y admitido en Colombia una pulsera especial que permitirá realizar pagos mediante su uso con tan sólo acercarse a los módulos de referencia para este dispositivo. 


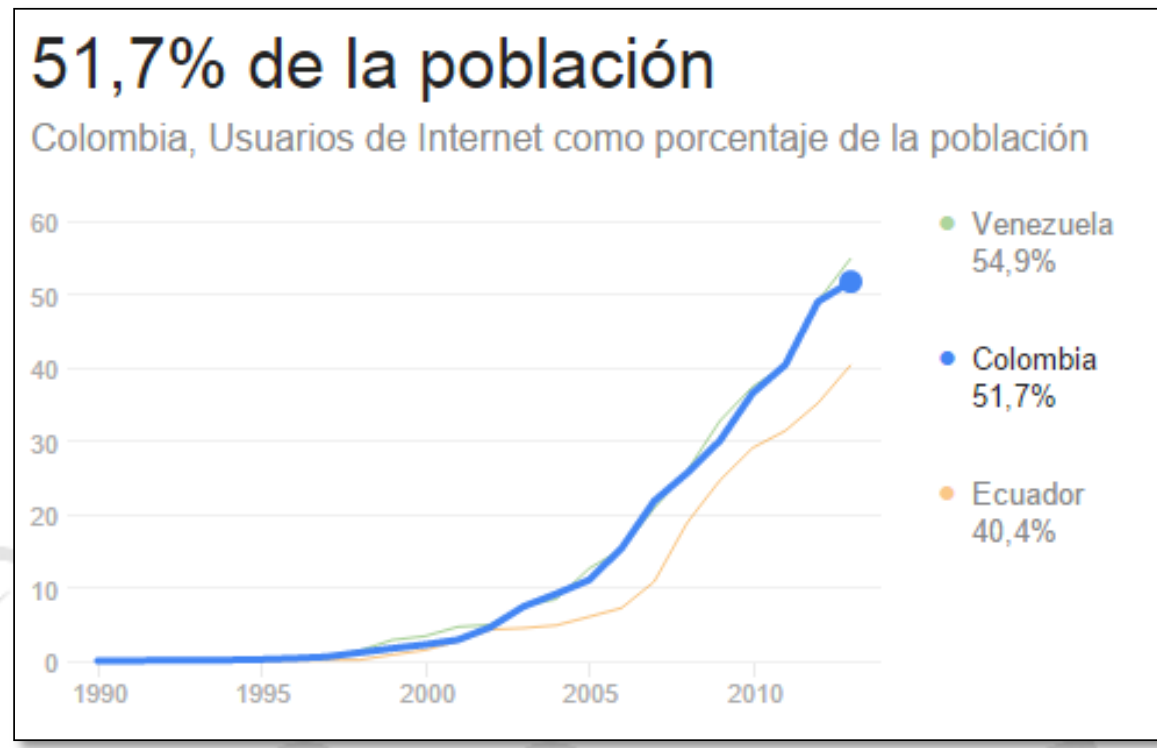

Recuperado de "Banco Mundial”, el 04 de octubre del 2015.En:

http://data.worldbank.org/country/colombia

El uso de diversos medios de comunicación como los medios electrónicos, radio, televisión, cine, videos e internet es indispensable y está en auge sobre todo para la educación, tal como el Ministerio de Educación Colombiano (2015) afirma que gracias a estos existe una mejora en el aprendizaje tanto de los niños y adolescentes de escuelas como de los docentes logrando que se pueda potenciar una mejor estructura de lógica en el pensamiento de los niños.

Las principales entes reguladoras de las comunicaciones según el Ministerio de Comunicación Colombiana (2015) son: CRS (Comisión de Regulación de las Comunicaciones) la cual se encarga de regular y poner reglas en cuanto a servicios de comunicaciones, y la FEDESOFT (Federación Colombiana de la Industria del Software) cuyo objetivo es promover y desarrollar todo relacionado al software de Colombia de forma nacional e internacional. 
Por tanto, y según los datos mencionados, es favorable para la empresa en un largo plazo porque los beneficios propuestos del internet van a ser utilizados en la tienda espejo cuando la empresa esté mejor posicionada en el mercado.

\subsection{5.- Fuerzas ecológicas y ambientales (E)}

Según La Revista Portafolio.co (2015, p.1), Colombia ocupa el segundo lugar a nivel mundial con respecto a la biodiversidad. Por ende, para poder proteger al medio ambiente, una empresa llamada Gaira Vitare ha decidido reciclar los desechos electrónicos del país; ellos se encargan de triturar los productos recibidos y crear nuevos productos electrónicos.

Los animales en peligro de extinción colombianos son diversos, tal como: el Armadillo que se considera en peligro de extinción debido a que los pobladores colombianos comían su carne; la Guacamaya bandera, las que se cazan para ser traficadas de manera ilegal al extranjero; los Manatíes del Caribe quienes son cazados para el tráfico de su carne, piel y grasa. Por otro lado, está el Oso Perezoso, el cual tiene una tasa de supervivencia del $30 \%$ y la Rana Dorada, la cual está en peligro de extinción por la tala ilícita de árboles y la minería informal que se presenta en el país. Con las pieles de estos animales se elaboran trajes para la clase más alta (se hacen abrigos y zapatos para los recién nacidos que tiene una tendencia alta hacia este sector).

Según la Organización de Naciones Unidas para la alimentación y la Agricultura, (2015), en Colombia ha crecido el consumo de productos orgánicos sobre todo en Bogotá. La revista América Económica (2016) relata que las plantaciones agrícolas y las granjas donde se cultivan el algodón han optado por alejar las prácticas que produce la contaminación medio ambiente, como lo hacen otros mercados. Todas 
estas prácticas "Bio" se dan para mejorar el bienestar teniendo una visión a futuro de la población.

Heryk Farfán (2016) relata que a pesar de que Colombia cuenta con las condiciones mínimas para realizar cultivos de algodón, se han realizado proyectos los últimos 10 años para mejorar las condiciones de cultivo y los productos finales que se darán a base de ellos. Es por ello, que en el 2014 se llevó a cabo la primera cosecha de algodón orgánico, la cual está generando rentabilidad económica. En Agosto del 2015 se comenzó a recoger dicha cosecha y su objetivo fue fomentar el consumo y el uso de productos orgánicos ya que la población al usar los productos convencionales están matándose lentamente debido al contacto directo con los químicos.

La revista Semana (2014), de Colombia, hace referencia a que Colombia desea entrar al mercado de productos orgánicos, dado que es poco explorado por su país, con el objetivo de conquistar a diferentes países especialmente a Europa llevando "algodón verde", donde el 99\% de producción textil representan prendas elaboradas con químicos en las plantas, o plaguicidas en sus cultivos. Gracias a los proyectos dados, la empresa Friendly, en el 2015 presentó su primera colección de ropa orgánica exclusivas para bebés.

Las fuerzas ecológicas y ambientales citadas anteriormente son adecuadas para la compañía debido a que ha bajado el uso de prendas de pieles (por la caza de animales) y se centran más en el uso de prendas naturales o llamadas eco amigables para favorecer al medio ambiente. 


\section{2. - Matriz de Evaluación de Factores Externos (EFE)}

En la matriz EFE se muestran las oportunidades y amenazas las cuales tendrán escalas del 1 al 4, donde 1 es pobre (no mucha importancia) y 4 es superior (mayor importancia), apreciándose en el Cuadro $\mathrm{N}^{\circ} 28$.

La matriz, que se muestra en el Cuadro $\mathrm{N}^{\circ} 29$, alcanzó un puntaje de 2.65 debido a que cuenta con mayor cantidad de consumidores por la tasa creciente de natalidad (puntaje de 0.60) y por la amenaza de entrada de productos con menos precio como lo son los chinos (puntaje de 0.80). Este resultado según la valorización de escalas hace hincapié que la empresa puede invertir sin riesgo alguno.

Para esta empresa, tener una cantidad de consumidores notables, será un factor importante en cuanto a las oportunidades porque las ventas de los bodies comenzarían a incrementarse. Por ello, se le da un peso de 0.20 (el mayor sobre todas las oportunidades) y un valor de 3 (poder invertir), lo que otorga un puntaje ponderado de 0.6. Estos pesos están divididos de acuerdo a la cantidad de oportunidades que existan, en este caso de 7. Se aprecia también que los factores que menos peso tienen son las ventajas con los TLC, tasas de desempleo y la inflación de los precios de estos productos. A cada uno de ellos se le dio un peso de 0.50 , ya que son los más bajos y un valor de 2, debido a que la inversión con estas oportunidades se darían con riesgos porque las ventas de las prendas no dependen del TLC sino de la calidad que presentan; el empleo también se daría a consecuencia de las ventas que existan.

Las amenazas que sobresalen sobre el producto serán tres las cuales son: (1) la creación de los impuestos para entrar a Colombia; (2) los impuestos que pueda poner el Gobierno y la repercusión con el producto; (3) y que los productos chinos entren a Colombia con precios menores al de la empresa. El factor más importante es el que las 
prendas Chinas puedan entrar al mercado Colombiano y desplazar a Teco Caricias S.A.C. Por ende, se le otorga un puntaje de 4 y un peso de 0.20 .

Lo que pudiera negar la entrada a la empresa a este tipo de negocio, es la creación de impuestos o cláusulas de restricción. Este factor no tiene una clara perspectiva hacia futuro. Sin embargo, tiene peso de 0.30 y un valor de 3 debido a que si ocurre es importante notarlo para futuras inversiones. Por último, la amenaza de creación de impuestos que se establezcan hacia el producto es de importancia media, por eso que el puntaje es de 2 y se le imputa un peso de 0.05 , el cual es bajo. La solución será entrar con productos sustitutos o similares que tengan las mismas funciones.

\section{Cuadro $\mathbf{N}^{\circ}$ 28:}

\section{Valorización de Escalas}

\begin{tabular}{lc}
\hline \multicolumn{1}{c}{ Escala } & \\
\hline Menor importancia & 1 \\
Importancia media & 2 \\
Importancia de invertir & 3 \\
Mayor importancia & 4 \\
\hline
\end{tabular}

Elaboración Propia 
Cuadro $\mathbf{N}^{\circ}$ 29:

Matriz EFE

\begin{tabular}{|c|c|c|c|}
\hline Oportunidades & Peso & Valor & $\begin{array}{c}\text { Puntaje } \\
\text { Ponderado }\end{array}$ \\
\hline $\begin{array}{l}\text { Ventaja porque existe un TLC con diversos países y } \\
\text { una buena relación con ellos. }\end{array}$ & 0.05 & 2 & 0.10 \\
\hline $\begin{array}{l}\text { Mayor tecnología de información origina que } \\
\text { seamos más exitosos e innovadores en cuanto a } \\
\text { productos y marketing. }\end{array}$ & 0.10 & 3 & 0.30 \\
\hline $\begin{array}{l}\text { Mayor cantidad de consumidores por la tasa } \\
\text { creciente de natalidad. }\end{array}$ & 0.20 & 3 & $\mathbf{0 . 6 0}$ \\
\hline $\begin{array}{l}\text { PBI está en aumento origina mayores adquisiciones } \\
\text { por parte del cliente }\end{array}$ & 0.10 & 1 & 0.10 \\
\hline Tasa de desempleo disminuye & 0.05 & 1 & 0.05 \\
\hline $\begin{array}{l}\text { Inflación con tendencia a la baja mantiene precios de } \\
\text { los productos }\end{array}$ & 0.05 & 2 & 0.10 \\
\hline $\begin{array}{l}\text { Existe apoyo por parte del gobierno hacia nuevas } \\
\text { empresas }\end{array}$ & 0.10 & 2 & 0.20 \\
\hline$\underline{\text { Amenazas }}$ & & & \\
\hline $\begin{array}{l}\text { Creación de los impuestos ad-valorem para entrar al } \\
\text { mercado Colombiano }\end{array}$ & 0.10 & 3 & 0.30 \\
\hline $\begin{array}{l}\text { La creación de impuestos por parte del Gobierno } \\
\text { afectan de forma directa al producto }\end{array}$ & 0.05 & 2 & 0.10 \\
\hline $\begin{array}{l}\text { Ingreso al mercado de productos de menor precio } \\
\text { ( como los productos Chinos) }\end{array}$ & 0.20 & 4 & $\mathbf{0 . 8 0}$ \\
\hline TOTAL & 1.00 & & 2.65 \\
\hline
\end{tabular}

Elaboración Propia 


\section{CAPITULO V: ANÁLISIS COMPETITIVO}

\section{1.- Análisis de las 5 fuerzas competitivas de Michael Porter.}

El gráfico $\mathrm{N}^{\circ} 12$ mostrará un resumen de las fuerzas competitivas a tratar en el presente capítulo.

\section{Gráfico $N^{\circ}$ 12:}

Diamante de Porter

\section{Amenaza de nuevos competidores: ALTA}

- No existen barreras de entrada para otros competidores.

- Tienen acceso a la distribución.

- Mejor tecnología que la de la empresa

- El valor de la marca más posicionada.

- India y Turquía: principales productores de algodón orgánico.

Poder Negociador de los proveedores: ALTA

- Alta disponibilidad de materias primas y de buena calidad.

- Se cuenta con un sólo proveedor: BERGNAM RIVERA S.A.C

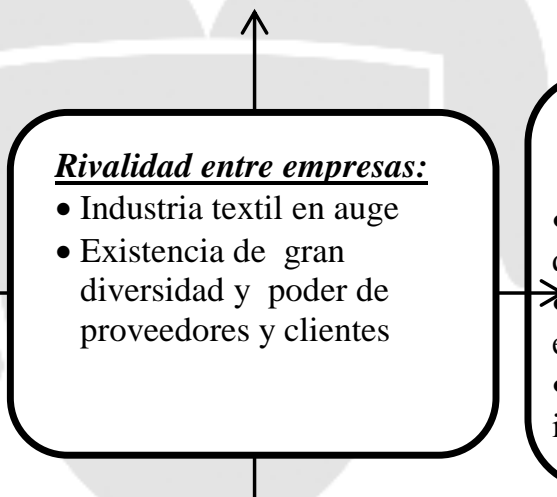

Poder Negociador de los clientes:

- Negociaciones con empresas que tienen costos fijos.

Clientes informados y exigentes

- Dependen del precio de los insumos

Amenaza de productos sustitutos: ALTA

- Prendas Chinas a menor costo.

- Prendas de algodón sintético u otra fibra no natural.

- Presencia de competidores nacionales fuertes.

Elaboración propia 
- Amenaza de Productos Sustitutos:

Los productos sustitutos son las prendas de bebés sintéticas o artificiales (no orgánico). Esta es una amenaza alta puesto que dichas prendas tienen menores costos, más diseños y otros colores, lo que las hace más llamativas para los clientes. Por otro lado, los clientes podrían adquirir otras prendas porque están en zonas más cercanas a su hogar o lugar de labores, las cuales difícilmente son de fibras naturales. Por último, un factor muy importante es el precio que tienen las prendas Chinas, ya que la mano de obra en ese país es barata al igual que los insumos, lo que origina que las prendas estén por debajo de un precio normal. En conclusión, la amenaza de los productos sustitutos es alta ya que ahora el mercado colombiano no tiene una tendencia de consumir lo orgánico aunque se están realizando estudios para que esta mentalidad del consumidor colombiano cambie (Colombiatex, 2016).

En el Cuadro $\mathrm{N}^{\circ} 30$ se aprecian los principales competidores de estos productos y su variación porcentual que registró en el 2014 al igual que la participación en el mercado. Así, las confecciones Textimax SA tuvo participación del 17\% seguido de Textile Sourcing Company, todas estas empresas se dedican a la ventas de prendas de vestir para usos deportivos. Su precio promedio oscila según la SUNAT (2014) entre US\$8.40 a US\$13.67 FOB por prenda, a comparación de las orgánicas que pueden llegar a costar hasta US\$43.12 según Veritrade (2014). La empresa ENKA (2015) de Colombia, es una de mayores fabricantes de fibras sintéticas en su mercado tanto para la elaboración de prendas como para resinas de plástico. Esta, tiene gran demanda entre la población Colombiana debido a que a comparación de los productos naturales tienen 
gran ventaja de precio, lo que causa que la población vea a este tipo de oferta muy llamativa y de fácil acceso para venderlas a un precio aún por debajo de la competencia.

\section{Cuadro $\mathbf{N}^{\circ} 30$ :}

Principales competidores de productos sustitutos (2014)

\begin{tabular}{lcc}
\hline Empresa & \% Var 14 & \%part \\
\hline CONFECCIONES TEXTIMAX S A & $22 \%$ & $17 \%$ \\
TEXTILE SOURCING COMPANY & $3895 \%$ & $10 \%$ \\
S.A.C. & & \\
LIVES S.A.C & $31 \%$ & $5 \%$ \\
ROMERO MUÑOZ JUAN DAVID & $212 \%$ & $2 \%$ \\
REPRIND S.A.C. & $-23 \%$ & $2 \%$ \\
TEXTILES CAMONES S.A. & $102 \%$ & $2 \%$ \\
Otras Empresas (317) & -- & $33 \%$ \\
\hline
\end{tabular}

Elaboración Propia

Fuente: SUNAT

- Amenaza de nuevos competidores:

Según Pro Export Colombia (2014), para la importación de prendas de algodón orgánico al mercado Colombiano no existen barreras de entrada, por ello los competidores acceden al mercado con oportunidades altas para generar beneficios económicos. Además, afirma que la fibra de algodón orgánica es escasa en Colombia, en consecuencia no existirá mucha competencia y se tendrá la oportunidad de sobresalir sobre las otras empresas a base de los diseños que se realizarán. Los países como China, EE.UU., entre otros, tienen mejor tecnología y mayor cantidad de canales de distribución que las empresas peruanas. Los competidores más importantes son las empresas que se dedican a la producción y al comercio de algodón orgánico, el cual es esencial para la elaboración de las prendas. Según Veritrade (2014), estos son Turquía e India; como se aprecia en el Gráfico $\mathrm{N}^{\circ} 13$ (producción basadas en toneladas) estos 
países lideran el mercado con un 39\% y $23 \%$ respectivamente; mientras que Perú con un $11 \%$ por encima del mercado Estadounidense.

\section{Gráfico $\mathbf{N}^{\circ}$ 13:}

Producción y Comercio de algodón orgánico (2014)

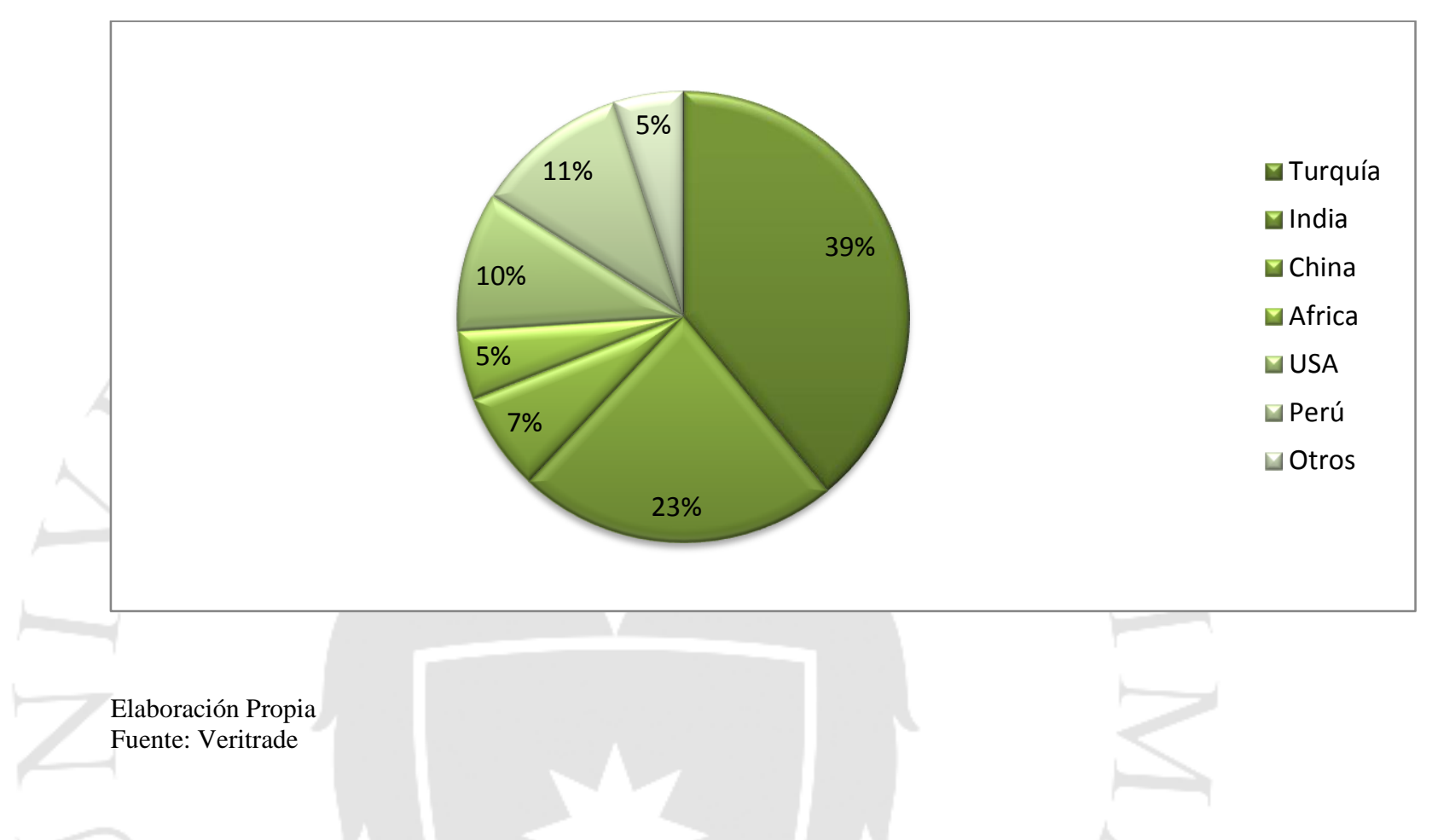

Por otro lado, las mejores empresas a nivel mundial de confección de algodón orgánico que podrían comprar prendas de Teco Caricias S.A.C y entrar al mercado Colombiano u a otro serán las que se aprecian en el Cuadro $\mathrm{N}^{\circ} 31$, como lo son Nike, Wall Mart y América Aparel de USA.

\section{Cuadro $\mathbf{N}^{\circ}$ 31:}

Principales empresas que compran Algodón Orgánico (2015)

\begin{tabular}{ll}
\hline Empresa & País \\
\hline American apparel & Estados Unidos \\
Avanti Inc. & Japón \\
C\&A & Países Bajos \\
Coop-Schweiz & Suiza \\
Hess Natur & Alemania \\
Wall-Mart & Estados Unidos \\
Nike & Estados Unidos \\
\hline
\end{tabular}


- Poder Negociador de los Proveedores:

En esta área existirá una alta disponibilidad de materias primas como lo son el hilo orgánico y las telas. Un factor importante, el cual se debe mejorar es que las telas e hilos son muy difíciles de encontrar en Lima, por eso el mejor proveedor y más cercano con el que se podrá realizar una alianza es con BERGMAN RIVERA S.A.C. Dado que Teco Caricias S.A.C sólo tendrá un proveedor, el poder de negociación de este será muy alto y se dependería de su stock o la disponibilidad que ellos tendrían para la empresa.

Como ya se mencionó, en el Cuadro $\mathrm{N}^{\circ} 16$ del capítulo 3.4.1 se muestran a los cuatro proveedores de algodón orgánico Peruano, los cuales son Bergman Rivera S.A.C, Perú Naturex Partners, Hilandería de algodón Peruano y Creditex. Todas estas están ubicadas en el distrito de Lima. Sin embargo, se eligió a Bergman Rivera S.A.C por los precios accesibles a comparación de las otras empresas. Además, porque ellos conocen muy bien el mercado colombiano. En el mes de enero del presente año asistieron al Colombiatex (feria de moda en Colombia), para buscar nuevas tendencias en los gustos de la población Colombiana y así mejorar la calidad de las prendas y los colores que ofrecen. Según Colombiatex (2016), Bergman Rivera S.A.C, es una de las pocas empresas que cuentan con certificación GOTS, la cual es una certificación que valida las fibras como naturales, libres de pesticidas y químicos. Por otro lado, el proceso de elaboración del algodón también es certificado por SKAL Internacional. Todas estas virtudes generaron que se escoja por encima de los otros proveedores originando que su nivel de decisión sobre Teco Caricias S.A.C sea muy alto. 
En el Cuadro $\mathrm{N}^{\circ} 32$, según Quiminet (portal web orgánico), se muestra los principales proveedores de algodón orgánico en el resto del mundo, de los cuales el más conocido es Buhler Quality Yarns Corp, el cual cuenta con certificaciones de alto nivel para la exportación de estas prendas al resto del mundo. Por otro lado Proaltex de Colombia, es el único en todo su país que cuenta con GOTS.

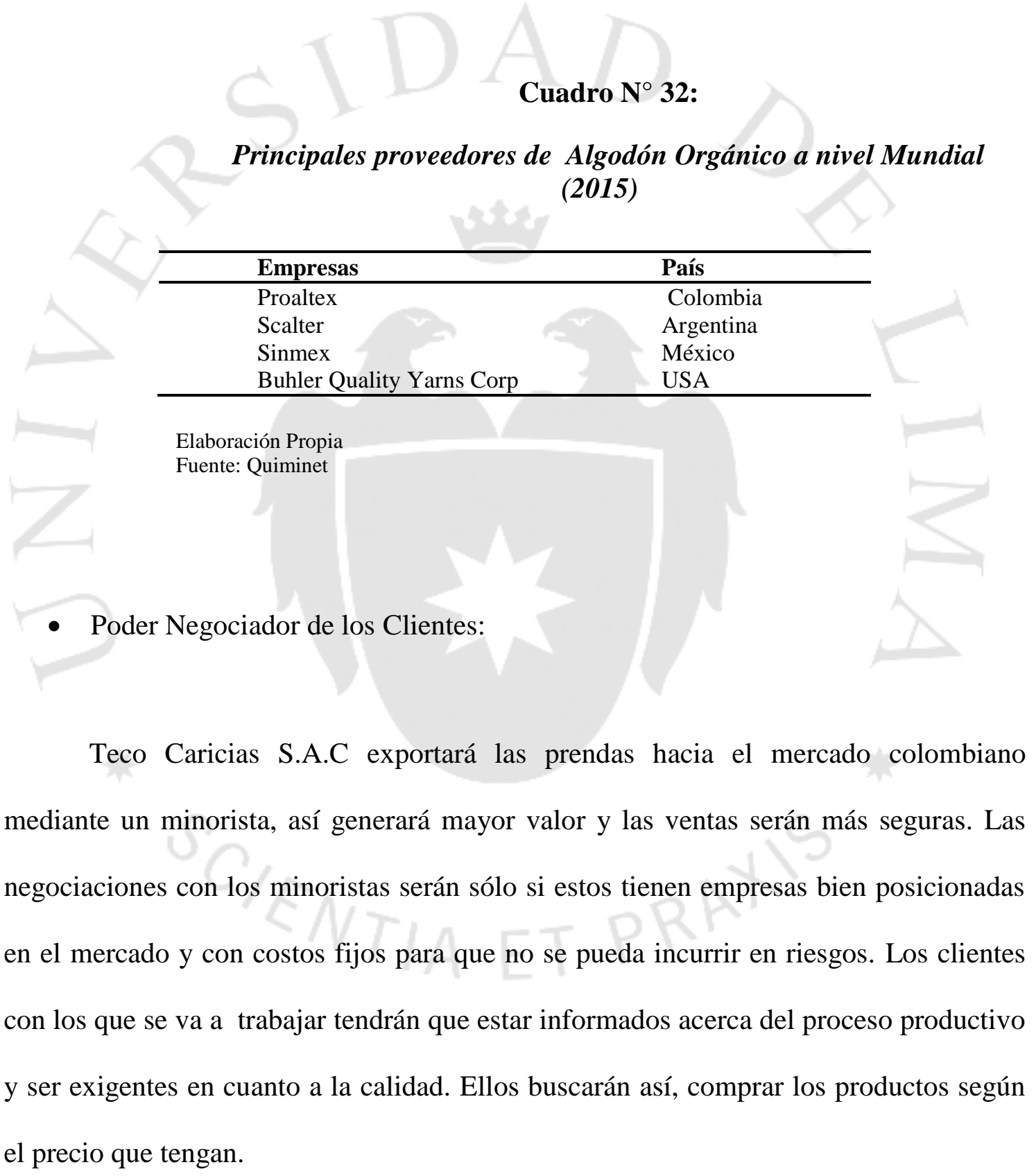

Las principales tiendas de Colombia, según un contacto que se tiene en el mercado de destino (Pala Cuellar), que venden prendas para bebés, ya sean orgánicas o 
no, son las que se muestran en el Cuadro $\mathrm{N}^{\circ} 33$. Estas tiendas, no sólo ofrecen productos orgánicos, sino también de otras fibras ya que genera mayor rentabilidad. La marca Friendly, la cual es una de las más reconocidas y únicas proveedoras de algodón orgánico vende sus prendas en diferentes tiendas de los centros comerciales de Bogotá, tales como el Centro Comercial Santafé, Titán plaza y Centro mayor.

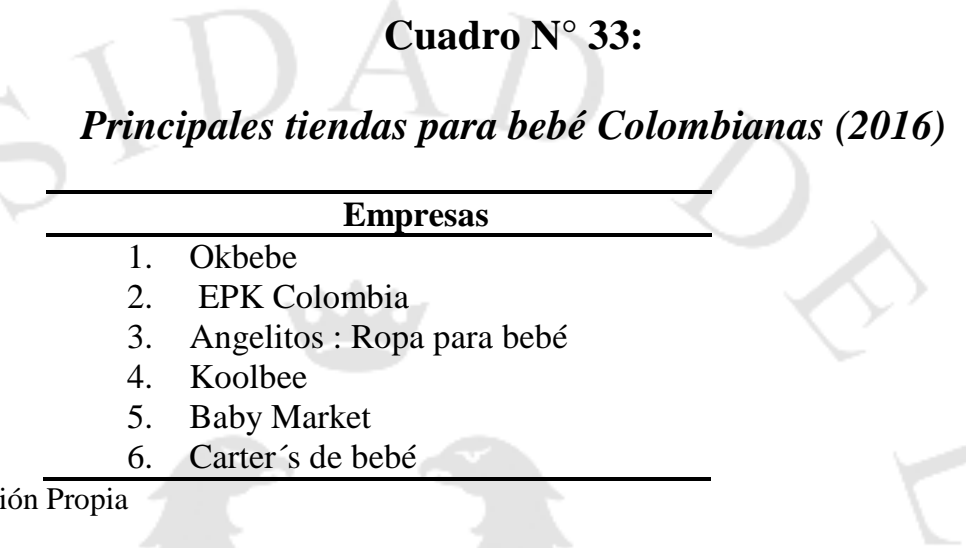

Si a la tienda le fuese mal y existiese éxito con la venta de sus productos, entonces el poder de negociación de Teco Caricias S.A.C no podría ser alto, debido a que para acceder a las tiendas colombianas existirían barreras como la demanda de los clientes. Se posicionaría en la empresa EPK ya que ellos tienen diferentes sectores de prendas en la tienda. Uno de ellos es del algodón orgánico. Por otro lado, se escogió a dicho proveedor porque está certificado con buenas prácticas de proceso y material.

- Rivalidad entre empresas:

Un factor importante y que favorece a la presente empresa es que la industria textil está en auge en todo el mundo, debido a que son insumos de primera necesidad; además, los textiles tienen una gama diversa de proveedores y clientes. La industria textil orgánica no es un mercado competitivo porque las empresas que elaboran y 
confeccionan algodón orgánico son escasas, aproximadamente cuatro por país. Estas son pocas debido a que, como se mencionó en el primer capítulo, el proceso de elaboración de estas demanda más tiempo y cuidado. Por otro lado, para vender textiles orgánicos se necesita certificaciones GOTS o SKAL International, las cuales son difíciles de obtener.

Por todo ello, las empresas competidoras que existen en Colombia son aproximadamente seis, entre ellas EPK de Colombia, la cual tiene certificaciones calificadas y gran demanda entre sus clientes. Según (Colombiatex, 2016), estas empresas se posicionan de acuerdo a la cantidad de las prendas, su calidad y el precio. EPK, tiene una gran ventaja sobre las otras empresas debido a que es reconocida internacionalmente y cuenta con el apoyo de Pro Inversión Colombia.

\section{2.- Análisis de la competencia local}

Las empresas locales que se dedican a la producción y comercialización de prendas a nivel internacional se presentan en el Cuadro $\mathrm{N}^{\circ} 34$. Aquí se pude apreciar que a lo largo del 2015, la mejor empresa es Manufacturas América EIRL, la cual obtuvo una participación del 20\%, seguido de Perú Fashion S.A.C. e Industrias Nettalco S.A con una participación del 3\% y $12 \%$ respectivamente. Manufacturas América EIRL refleja el primer puesto en exportaciones porque se dirigen a diferentes nichos, su calidad de algodón orgánico es alta y sus diseños son estandarizados para cualquier sector que lo requiera. Este es un factor que afectaría negativamente a Teco Caricias S.A.C si es que se quiere competir con ella. Según su historia, son líderes nacionales desde 1988 en la confección de ropa infantil, esto a la vez podría favorecer a la empresa si se llegara a tercerizar las confecciones puesto que podría ser reconocida internacionalmente. Lo 
único que se puede proponer es realizar una alianza con los diseñadores para que el valor agregado de las prendas sea alto.

Por otro lado, existen PYMES que no exportan pero son muy buenas a nivel local, las cuales se aprecian en el Cuadro $\mathrm{N}^{\circ} 35$, donde las más reconocidas son Anpi Organic y UMA Organic Cotton. Estas empresas se dedican a comercializar prendas orgánicas tanto para bebés como para niños y mujeres en el periodo de gestación.

La empresa UMA Organic vendría a ser la competencia directa sobre Teco Caricias S.A.C, ya que ellos a la vez fabrican algodón pero con la marca de Bergman Rivera S.A.C, la cual es proveedora de las telas de la empresa en la cual el presente proyecto está enfocado. Esto favorecería en el reconocimiento de las marcas de la Tela, ya que en la etiqueta de las prendas de competencia sale que la empresa Bergman es la proveedora de sus telas. Sin embargo, un factor negativo vendría a ser que la calidad de estas, es la misma que las de Teco Caricias S.A.C. Por ende, lo que se debe hacer para que sea superior será la confección personalizada de los diseños de las prendas.

\section{Cuadro $\mathbf{N}^{\circ}$ 34:}

Exportaciones peruanas al mundo (2015)

\begin{tabular}{lll}
\hline Empresa & Peso Neto Kg. & Valor FOB US\$ \\
\hline MANUFACTURAS AMERICA E I R L & $111,399.07$ & $6,817,772.51$ \\
PERU FASHIONS S.A.C. & $77,347.03$ & $2,864,809.90$ \\
& & \\
INDUSTRIAS NETTALCO S.A. & $45,498.31$ & $2,848,384.78$ \\
FIGI S INTERNATIONAL CO EIRL & $22,336.26$ & $2,011,991.89$ \\
LENNY KIDS S.A.C. & $20,478.01$ & $1,705,790.12$ \\
MANUFACTURAS CHRISTCI & $20,194.67$ & $1,102,072.85$ \\
S.R.LTDA. & & \\
\end{tabular}

Fuente: DATASUR

Elaboración Propia 


\section{Cuadro $N^{\circ}$ 35:}

\section{Empresas locales 2015}

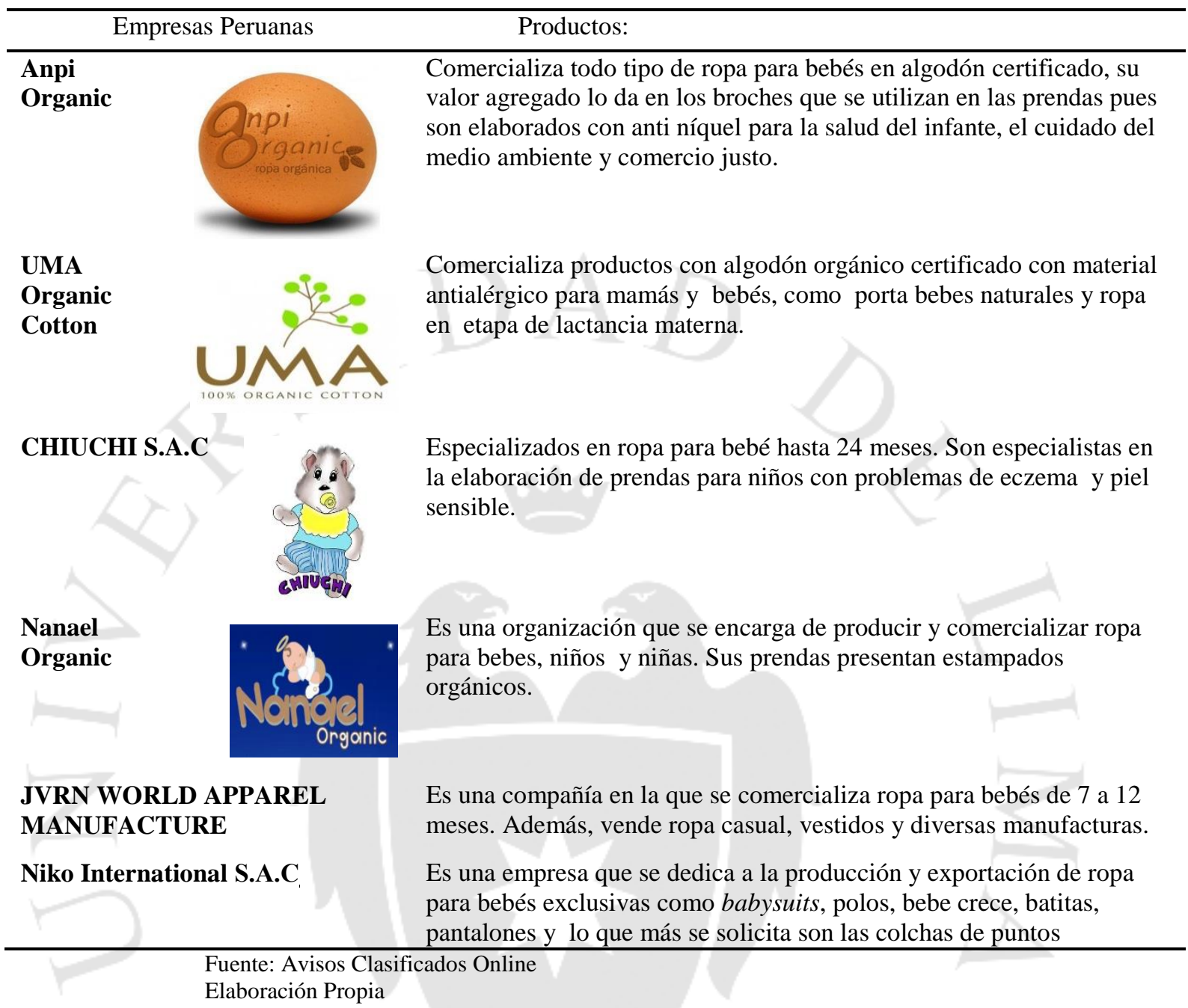

\section{3.- Principales empresas exportadoras o importadoras peruanas}

En cuanto a las principales empresas exportadoras peruanas al mercado de Colombia desde el 1 de enero del 2014 hasta el presente mes, como se muestra en el Cuadro $\mathrm{N}^{\circ}$ 36, se encuentra en primer lugar Manufacturas América EIRL con un peso neto de $16,127.17 \mathrm{~kg}$ y un valor FOB de US\$736 923.08, representando el $46.5 \%$ de las exportaciones totales peruanas a Colombia de este producto. 
En segundo lugar, se encuentra Confecciones Mariana S.R. LTDA (valor FOB de US\$202 351.52) y Manufacturas Christci S.R.LTDA (valor FOB de US\$152 645.90) con un $18 \%$ y $9 \%$ de participación respectivamente.

Como ya se mencionó en el punto anterior, lo que afectaría negativamente a la empresa, si se llegara a competir con Manufacturas América en el mercado local, es la calidad de sus prendas. Sin embargo, Teco Caricias S.A.C tendría una ventaja sobre Manufacturas América ya que ellos se basan en diseños peruanos para la elaboración de sus prendas. En cambio Teco Caricias S.A.C al ser la competencia directa de estos sobre la elaboración de las prendas ganaría reconocimiento y prestigio puesto que estarían enfocadas al 100\% en los diseños de acuerdo a los requerimientos del mercado Colombiano y elaborados por diseñadores reconocidos, tanto peruano como colombiano, llegando a tener una visión más global sobre la población.

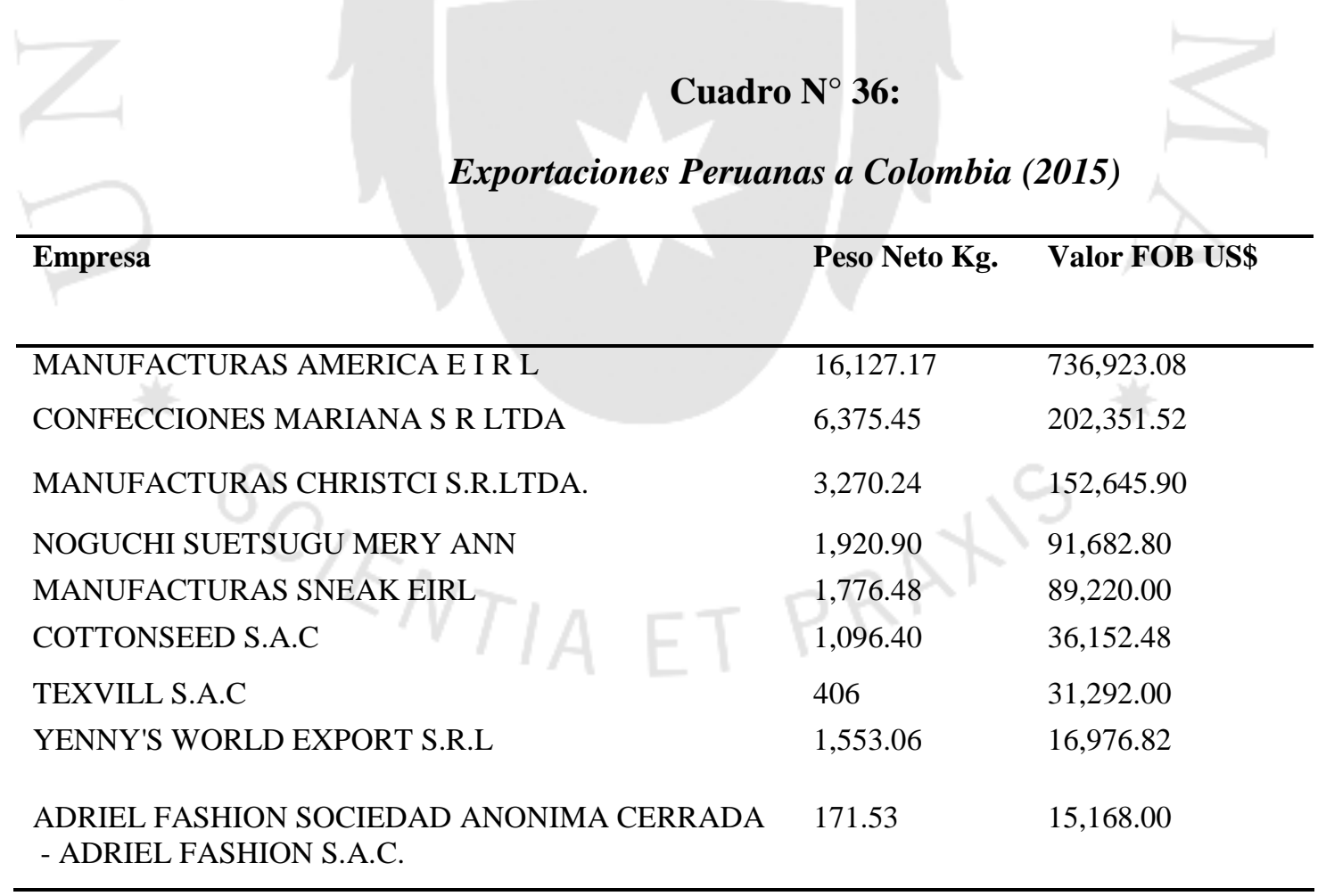

Fuente: Infotrade

Elaboración Propia 


\section{4. - Análisis de la competencia internacional}

Según Trademap (2015), las importaciones de Colombia hacia el mundo representan un $0.24 \%$, mientras que las Peruanas consolidan un $7.6 \%$ (ver cuadro $\mathrm{N}^{\circ} 37$ ). El mercado Chino lidera la lista con una participación de $72.1 \%$ y un valor aproximado de US\$12 millones con una cantidad importada de 548 toneladas, posicionándose así como el principal socio comercial, seguido de Perú obteniendo en el año 2014 un valor de US\$1.3millones donde importó 27 toneladas.

La competencia internacional afecta negativamente a Teco Caricias S.A.C, ya que China abarca un $72 \%$ de toda la población Colombiana. Es decir, prefieren las prendas elaboradas por ellos en vez que las peruanas, esto se debe a que el precio de las prendas son más baratos y las ventas que presentan se dan al por mayor. Sin embargo, la calidad de las prendas Chinas no es buena a comparación de las peruanas, por ende, lo que se debe hacer para sobresalir y afrontar mejor sobre este país deberá ser, el brindar un valor agregado, en este caso serán los diseños reconocidos.

Por otro lado, esta competencia favorece al mercado porque a pesar de las grandes participaciones que presenta China, Perú ocupa el segundo lugar y está por encima de India que es uno de los mayores productores a nivel mundial de algodón orgánico. 


\section{Cuadro $\mathbf{N}^{\circ}$ 37:}

Países importadores a Colombia (2014)

\begin{tabular}{|lccc}
\hline Exportadores & \multicolumn{2}{c}{ Indicadores comerciales } \\
\cline { 2 - 4 } & $\begin{array}{l}\text { Valor importada } \\
\text { en 2014 (miles de } \\
\text { US\$) }\end{array}$ & $\begin{array}{l}\text { Participación de las } \\
\text { importaciones para } \\
\text { Colombia }(\%)\end{array}$ & $\begin{array}{c}\text { Cantidad importada } \\
\text { en 2014 en toneladas }\end{array}$ \\
\hline Mundo & 16,718 & 100 & 548 \\
China & 12,053 & 72.1 & 414 \\
\hline Perú & 1,265 & 7.6 & 27 \\
\hline India & 753 & 4,5 & 21 \\
Camboya & 658 & 3,9 & 15 \\
Bangladesh & 482 & 2,9 & 32 \\
Indonesia & 352 & 2,1 & 10 \\
Tailandia & 313 & 1,9 & 8 \\
\hline
\end{tabular}

Fuente: Trademap

Elaboración Propia

\section{5. - Principales empresas exportadoras internacionales}

Según DATASUR de Colombia, son aproximadamente 140 empresas internacionales las que exportan prendas de algodón orgánico para el sector de bebés hacia Colombia. Entre las principales empresas que exportan esta partida se encuentra la empresa Skykids USA Inc., la cual representa un $28 \%$ del total de las exportaciones a Colombia. Se aprecia, según el Cuadro $N^{\circ} 38$, que la empresa Peruana se posiciona en el puesto 6 con un valor FOB US\$234 212.78 y una participación en ese mercado del 5\%.

Esto impacta la situación de la empresa positivamente porque si existiese un posicionamiento de Teco Caricias S.A.C en este ranking, estaría por encima de Manufacturas América (empresa peruana) debido a la calidad y al prestigio que tendría en Colombia por los diseñadores. Así, el reconocimiento llevaría consigo un incremento en las ventas y llegase a ser una de las Top 5 en importaciones hacia Colombia. 
Cuadro $\mathbf{N}^{\circ}$ 38:

Exportaciones de prendas a Colombia (2015)

\begin{tabular}{llc}
\hline Empresa Internacional & Suma de & Suma de \\
& US\$ FOB & 33085.16 \\
\hline SKYKIDS USA INC & $1,354,145.12$ & 9532.68 \\
OHANASIA LTD & $439,841.72$ & 14154.67 \\
ASIA WEST LTD & $370,690.40$ & 14258.45 \\
WELLY E-TRADE LIMITED & $292,522.80$ & 8957.63 \\
QINGDAO S\&G APPAREL LIMITED & $251,770.80$ & 4397.80 \\
MANUFACTURAS AMERICA E.I.R.L. & $234,212.78$ & 6778.67 \\
MOTHERCARE U.K. LTD & $206,825.32$ & 1846.30 \\
INDUSTRIA DE DISENO TEXTIL S.A. & $131,397.71$ & 2837.70 \\
INDITEX & & 4776.31 \\
LITTLE ME A DIVISION OF MAMIYE & $107,618.63$ & \\
BROTHERS INC & & \\
SHEARVAN CORPORATE S.A. & $102,024.55$ &
\end{tabular}

Fuente: DATASUR

Elaboración Propia

\section{6. - Barreras arancelarias y no arancelarias}

\section{Barreras arancelarias:}

La sub-partida arancelaria de prendas de vestir para bebés, como se aprecia en el Cuadro $\mathrm{N}^{\circ} 39$, tiene un porcentaje liberado de ad valoren CIF del $100 \%$ por la Comunidad Andina. Es decir, no se imponen tasas o impuestos para estas mercancías cuando entran a Colombia siempre y cuando se presente el certificado de Origen.

Según SUNAT (1993), existe un acuerdo comercial entre Perú y Colombia el cual genera y promueve un óptimo desarrollo comercial de forma equitativa. Esta norma, rechaza la práctica desleal, es decir debe existir un comercio justo. Por otro lado, no se pueden entregar subsidios a las exportaciones.

Esta imposición de barreras favorece a la empresa ya que por existir acuerdos comerciales, como la Comunidad Andina, hace que no se pague nada de Ad-Valoren y facilita así a las importaciones de estas prendas. Con respecto al comercio justo, 
promovida por organizaciones no gubernamentales, también favorece a Teco Caricias S.A.C ya que esta, tendría una relación comercial con los productos y los consumidores dándole un seguimiento en el proceso de cultivo y la elaboración de la materia prima (algodón) como en el servicio post venta de los clientes.

\section{Barreras no arancelarias:}

Existen ciertas certificaciones como:

- IMO: Es una empresa líder en servicios de inspección y certificación orgánica sostenible de responsabilidad social y comercio justo. Esta empresa genera confianza de calidad en el mundo

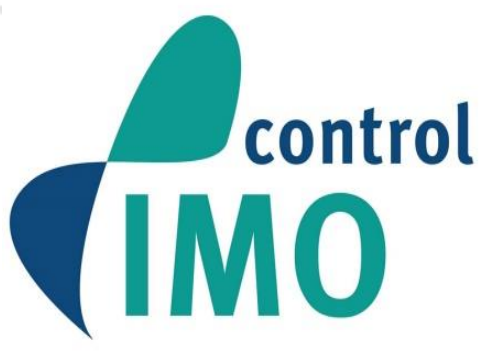
entero.

Esta certificación serviría de forma óptima para que controle la producción, proceso y comercialización de fibras ecológicas y productos textiles como lo son las prendas orgánicas.

Dentro de IMO control se ofrecen las siguientes certificaciones:

- Global Organic Textile Standard-Gots: Cubre la producción, procesamiento, fabricación, empaque, etiquetado, exportación, importación y distribución de todas las fibras naturales. El etiquetado se subdivide en dos niveles y esta diferencia es sólo

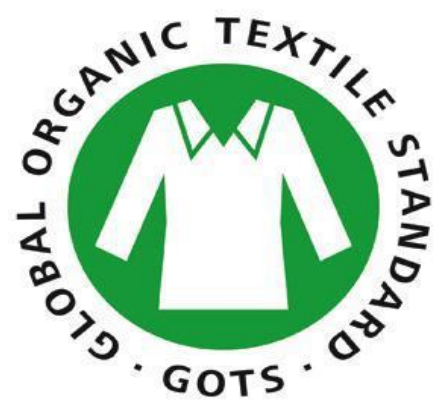
por la cantidad de material orgánico en conversión con el producto final. 
- Teco Caricias S.A.C otorgaría la certificación de responsabilidad social y comercio justo con la capacidad de adaptación a las condiciones locales (laborales). Todo esto reflejada en el certificado de Fair for Life.

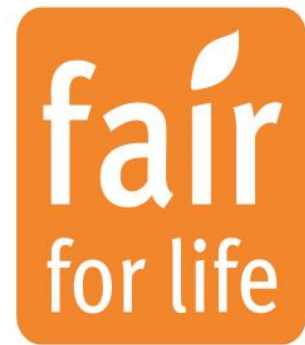
esto reflejada en el certificado de Fair for Life.

Estas certificaciones se darían para favorecer a la producción de las prendas orgánicas. Las barreras no arancelarias estarían favoreciendo hacia un impacto positivo sobre la empresa debido a que el proveedor de los insumos, Bergman Rivera S.A.C, cuenta con la certificación de IMO y GOTS. Esto haría que el producto sea más competitivo por su prestigio a nivel internacional. Lo que se implementará, a partir del quinto año, será la Certificación Fair For Life para que sea completa en cuestión de calidad reconocida a nivel mundial.

\section{Cuadro $\mathbf{N}^{\circ}$ 39:}

Medidas Impositivas para la sub-partida Nacional 6111.20.00.00

\begin{tabular}{ll}
\hline \multicolumn{1}{c}{ Gravámenes Vigentes } & Valor \\
\hline Porcentaje Liberado ADV & $100 \%$ \\
Impuesto Selectivo al Consumo & $0 \%$ \\
Impuesto General a las Ventas & $16 \%$ \\
Impuesto de Promoción Municipal & $2 \%$ \\
Derecho Específicos & N.A. \\
Derecho Antidumping & N.A. \\
Sobretasa & $0 \%$ \\
Unidad de Medida: & $\mathrm{U}$ \\
\hline
\end{tabular}

Fuente: SUNAT

Elaboración Propia 


\section{7. - Matriz del Perfil Competitivo (MPC) - Industria Textil}

Las escalas para del MPC se medirán al igual que las matrices mostradas en los capítulos anteriores. Esta está reflejada en el Cuadro $\mathrm{N}^{\circ} 40$ donde se le brindará un puntaje de 1 al factor que se no sea de importancia a comparación con otras. La escala de 2, al factor que sea importante pero no afecte al momento de invertir; 3 al factor que sí sea importante para invertir y de 4 al que tenga mayor importancia y al que el invertir conlleve a ganancias. Por otro lado, se le dará un puntaje que va del 0-1, este es divido entre la cantidad de factores para que al sumar sea igual a 1 que equivale al $100 \%$ y muestre racionalidad en relación a la asignación del puntaje. Si es 0 , no influye mucho en la empresa y si es 1 , significa que influye al $100 \%$.

Como se aprecia en la matriz de perfil competitivo en el Cuadro $\mathrm{N}^{\circ} 41$, la empresa Teco Caricias S.A.C tiene un puntaje de 3, el cual es mayor a la competencia porque resalta la calidad de productos y servicio que se ofrecerá. Se realizó la comparación con Manufacturas América y Confecciones Mariana pues estas son las empresas más competitivas que existen en el Perú y las que cuentan con mayor porcentaje en sus exportaciones a nivel internacional. La competencia directa para Teco Caricias S.A.C será Manufacturas América ya que esta también exporta al mercado Colombiano.

Los factores para determinar el éxito fueron siete. La calidad de productos y servicios con la lealtad de los clientes, la cual se le otorga el mayor valor por la importancia que presentan en la empresa. El mayor puntaje tanto para Manufacturas América (puntaje de 2.45) y Confecciones Mariana (menor puntaje con 2.35) como para Teco Caricias S.A.C se da con respecto a la calidad del algodón y a la variedad de diseños con las que se contará, debido a que el valor agregado la demanda de los 
productos será elevado junto con la lealtad que los clientes tendrán a través de su compra.

El personal de la empresa debe ser capacitado para la realización de las confecciones utilizando tecnología de primera en sus procesos. Si las maquinarias no fueran de alta calidad, las prendas lo reflejarían. Lo que se desea es que al momento de la compra el cliente perciba por sí sólo la calidad de esta y el trabajo minucioso brindado. De esta manera se daría un marketing directo, lo que se complementaría con publicidad en los centros y ferias más importantes. Es por eso que el factor de publicidad tiene gran importancia al momento de realizar la inversión del proyecto. El menor peso para las tres empresas, se da en la competitividad de precios a pesar que el valor es el más alto, debido a la influencia baja que se tiene sobre las empresas a consecuencia de las ventas reflejadas por la calidad del producto.

\section{Cuadro $\mathbf{N}^{\circ}$ 40:}

Valorización de Escalas

\begin{tabular}{ll}
\hline \multicolumn{1}{c}{ Escala } & \\
\hline Menor importancia & 1 \\
Importancia media & 2 \\
Importancia de invertir & 3 \\
Mayor importancia & 4 \\
\hline
\end{tabular}

Elaboración Propia 


\section{Cuadro $N^{\circ}$ 41:}

Matriz MPC

\begin{tabular}{|c|c|c|c|c|c|c|c|}
\hline \multirow[b]{2}{*}{ Factor determinante de éxito } & \multicolumn{3}{|c|}{$\begin{array}{l}\text { TECO CARICIAS } \\
\text { S.A.C }\end{array}$} & \multicolumn{2}{|c|}{$\begin{array}{l}\text { MANUFACTURAS } \\
\text { AMERICA E.I.R.L. }\end{array}$} & \multicolumn{2}{|c|}{$\begin{array}{l}\text { CONFECCIONES } \\
\text { MARIANA S R } \\
\text { LTDA }\end{array}$} \\
\hline & Peso & Valor & Puntaje & Valor & Puntaje & Valor & Puntaje \\
\hline Tecnología utilizada en los procesos & 0.10 & 3 & 0.30 & 2 & 0.20 & 2 & 0.40 \\
\hline Personal Capacitado & 0.15 & 3 & 0.45 & 3 & 0.45 & 2 & 0.30 \\
\hline Calidad de productos y Servicios & 0.20 & 4 & 0.80 & 3 & 0.60 & 2 & 0.40 \\
\hline Publicidad & 0.15 & 1 & 0.15 & 2 & 0.30 & 1 & 0.15 \\
\hline Competencia de precios & 0.10 & 4 & 0.40 & 3 & 0.30 & 4 & 0.40 \\
\hline Lealtad al cliente & 0.20 & 3 & 0.60 & 2 & 0.40 & 2 & 0.40 \\
\hline Posicionamiento en el mercado & 0.10 & 3 & 0.30 & 2 & 0.20 & 3 & 0.30 \\
\hline TOTAL & 1.00 & & 3.00 & & 2.45 & & 2.35 \\
\hline
\end{tabular}

Elaboración Propia 


\section{CAPITULO VI: ELECCIÓN DE OBJETIVOS, ESTRATEGIAS Y POLÍTICAS}

\section{1. - Objetivos de largo plazo:}

Formar y consolidar una empresa productora y comercializadora con la cual se espera vender al final de los próximos siete años un total de 60000 prendas al mercado Colombiano.

El objetivo específico es llegar a crecer hasta un 5\% entre los cinco primeros años con la exportación de prendas hacia el mercado Colombiano y que estas puedan ser comercializadas en otros puntos de venta, como distintas ciudades, tanto de Colombia como de América Latina.

Por otro lado, la empresa deberá encontrar, después de cinco años que esté establecida en Colombia, un nuevo proveedor de telas para tenerlo como segunda opción. Todo esto se daría en caso que la empresa se desligue de Bergman Rivera S.A.C.

Otro objetivo será la implementación de una planta propia en el plazo de cinco años. Esto permitirá alcanzar a la vez otro objetivo, el cual es contar con un total de 100 trabajadores para los primeros 10 años; lo cual origina que se cuente con planta y personal propio y diseñadores que sólo trabajen con Teco Caricias S.AC.

El último objetivo y el más importante es la instauración de un Gobierno Corporativo basado en temas de Responsabilidad Social en un plazo de seis años. Este objetivo se dará para brindar apoyo hacia los infantes de bajos recursos económicos, tanto de Colombia como de Perú, para que después de 10 o 15 años se puedan beneficiar más países de América Latina. 


\section{2. - Elección de estrategias}

\subsection{1. - Matriz de Fortalezas, Oportunidades, Debilidades y Amenazas (FODA)}

En Cuadro $N^{\circ}$ 42, se apreciará la Matriz de Análisis FODA ampliada. Además de las

Fortalezas, Oportunidades, Debilidades y Amenazas, se mostrará un match entre estas

lo que originará la aplicación de estrategias específicas para la empresa.

\section{Cuadro $N^{\circ}$ 42:}

\section{Matriz FODA}

\begin{tabular}{|c|c|c|}
\hline rons & $\begin{array}{l}\text { Fortalezas- F } \\
\text { F1: Contactos con otras empresas y } \\
\text { distribuidoras internacionales. } \\
\text { F2: Se trabajará con White Cotton, la } \\
\text { cual es una certificación que garantiza } \\
\text { calidad, trato justo al trabajador y el } \\
\text { respeto por la tierra. } \\
\text { F3: Conocimiento y experiencia en el } \\
\text { mercado. } \\
\text { F4: Equipo de trabajo altamente } \\
\text { capacitado. }\end{array}$ & $\begin{array}{l}\text { Debilidades }-\mathrm{D} \\
\text { D1: Existe dispersión } \\
\text { geográfica con respecto a los } \\
\text { proveedores Locales. } \\
\text { D2: La marca no es conocida. } \\
\text { D3: Gran número de } \\
\text { competencia en Colombia. } \\
\text { D4: Precios altos }\end{array}$ \\
\hline $\begin{array}{l}\text { Oportunidades- } \mathrm{O} \\
\text { O1: Creación de oportunidades } \\
\text { de trabajo y satisfacción del } \\
\text { cliente. } \\
\text { O2: Convenios } \\
\text { O3: Asistencia a eventos y } \\
\text { ferias para que su producto sea } \\
\text { más conocido. } \\
\text { O4: Desarrollo en todo el } \\
\text { mundo sobre clústeres textiles. }\end{array}$ & $\begin{array}{l}\text { Estrategias } \boldsymbol{F O} \\
\text { F1,2-O1 : } \\
\text { La empresa buscará la fidelización } \\
\text { hacia los clientes mediante un CRM. } \\
\text { F3-O3,4 : } \\
\text { Brindar información completa a los } \\
\text { clientes sobre productos que ofrezca la } \\
\text { compañía } \\
\text { F3-O2,3,4: } \\
\text { Teco Caricias S.A.C buscará } \\
\text { posicionarse en el sector textil } \\
\text { mediante el esquema de penetración y } \\
\text { desarrollo de mercado. }\end{array}$ & $\begin{array}{l}\text { Estrategias } \boldsymbol{D O} \\
\text { D4-O2: } \\
\text { Creación de acuerdos } \\
\text { internacionales con otras } \\
\text { empresas. } \\
\text { D2,4-O3: } \\
\text { Buscar estrategias de } \\
\text { diferenciación para impulsar la } \\
\text { marca de la empresa. } \\
\text { D3-O4: } \\
\text { Dar seguimiento a la } \\
\text { competencia mediante sistemas } \\
\text { tecnológicos }\end{array}$ \\
\hline $\begin{array}{l}\text { Amenazas - A } \\
\text { A1: Falta de personal en la } \\
\text { empresa por motivo de la } \\
\text { estabilidad económica( } \\
\text { remuneraciones bajas) } \\
\text { A2: Mayor competencia en } \\
\text { tecnología de otras empresas } \\
\text { exportadoras- China. } \\
\text { A3: Costos de la competencia } \\
\text { son más bajos } \\
\text { A4: Escases del cultivo de } \\
\text { algodón en otros países, lo cual } \\
\text { afecta a su empresa }\end{array}$ & $\begin{array}{l}\text { Estrategias } \boldsymbol{F A} \\
\frac{\text { F2-A1: }}{\text { Buscar el desarrollo de actividades }} \\
\text { diferenciadas como el trato justo. } \\
\text { F1,3,4-A4: } \\
\text { Contactar a nuevas empresas } \\
\text { proveedoras del mismo insumo. }\end{array}$ & $\begin{array}{l}\text { Estrategias DA } \\
\text { D4-A2: } \\
\begin{array}{l}\text { Ofrecer descuentos atractivos } \\
\text { para los clientes. }\end{array} \\
\text { D3.A2: } \\
\text { Adquisición e Implementación } \\
\text { de Tecnología de punta para el } \\
\text { proceso de producción }\end{array}$ \\
\hline
\end{tabular}

Elaboración Propia 
Como resultado de esta matriz, la estrategia a utilizar será la de penetración en el mercado debido a que la empresa deberá posicionarse en la mente del cliente de una manera óptima y quedar como una marca de prestigio.

Se puede apreciar en el Anexo 3 cómo funcionan las matrices que se darán en los siguientes sub capítulos, las cuales son: Matriz Interna y Externa; la de Gran Estrategia; Igor; y por último la Matriz de decisión.

\subsection{2. - Matriz Interna - Externa (IE)}

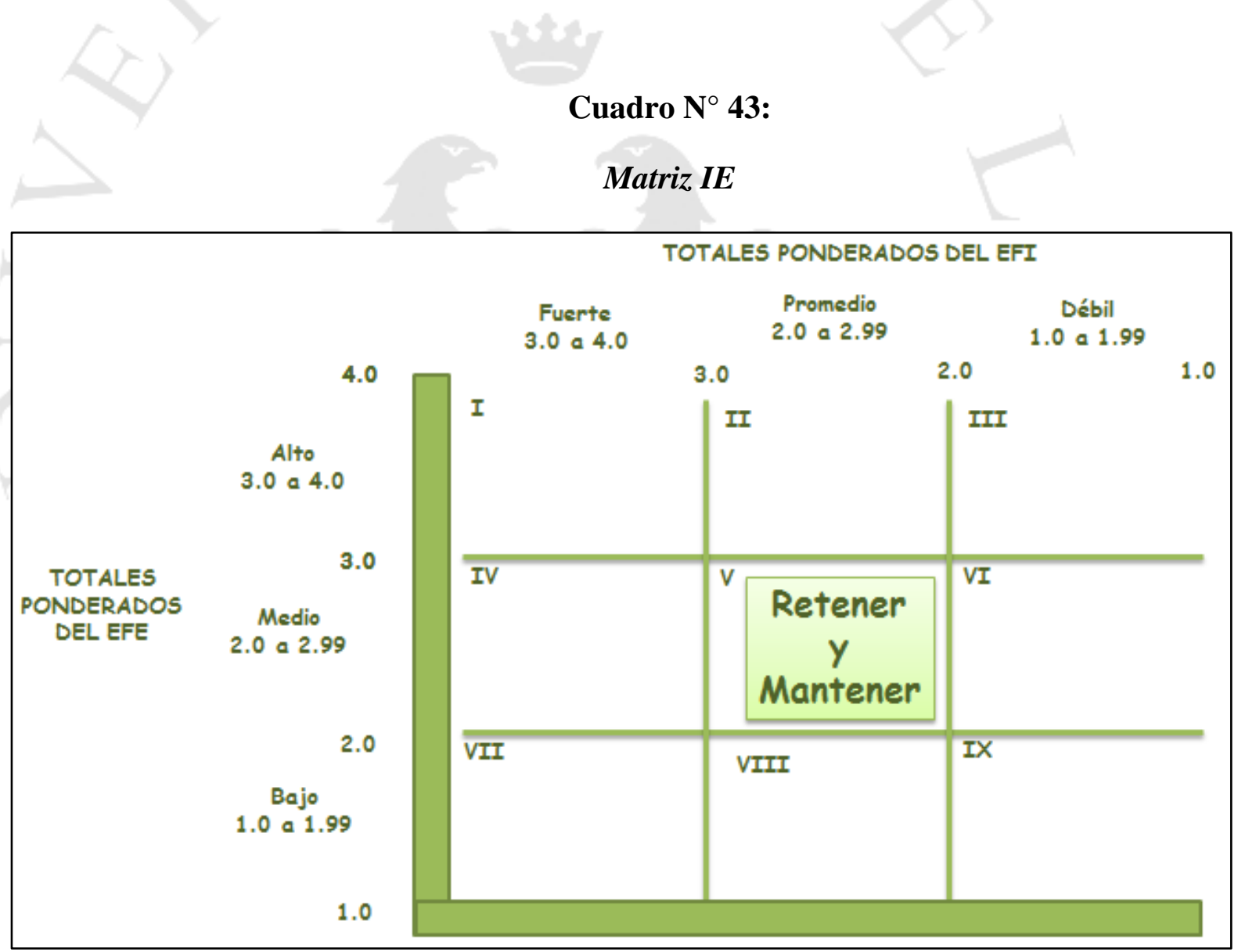

Elaboración Propia

El total ponderado de la Matriz EFE mostrado en el Cuadro $\mathrm{N}^{\circ} 29$ de capítulos anteriores, es de 2.65 , se ubica en el cuadrante del medio. Por otro lado, el resultado de la matriz EFI, mostrado en el último capítulo, es de 2.90 y se encuentra en el cuadrante 
promedio (medio). Por tal motivo, si se unen los dos resultados, se centralizan en el cuadrante número V. por lo que se tendrá que aplicar la sub estrategia llamada "retener y mantener". Para esto, se debe utilizar una estrategia de penetración de mercado y desarrollo de productos para que Teco Caricias S.AC sea reconocida como una empresa de alta calidad y prestigio.

\subsection{3. - Matriz de la Gran Estrategia (GE)}

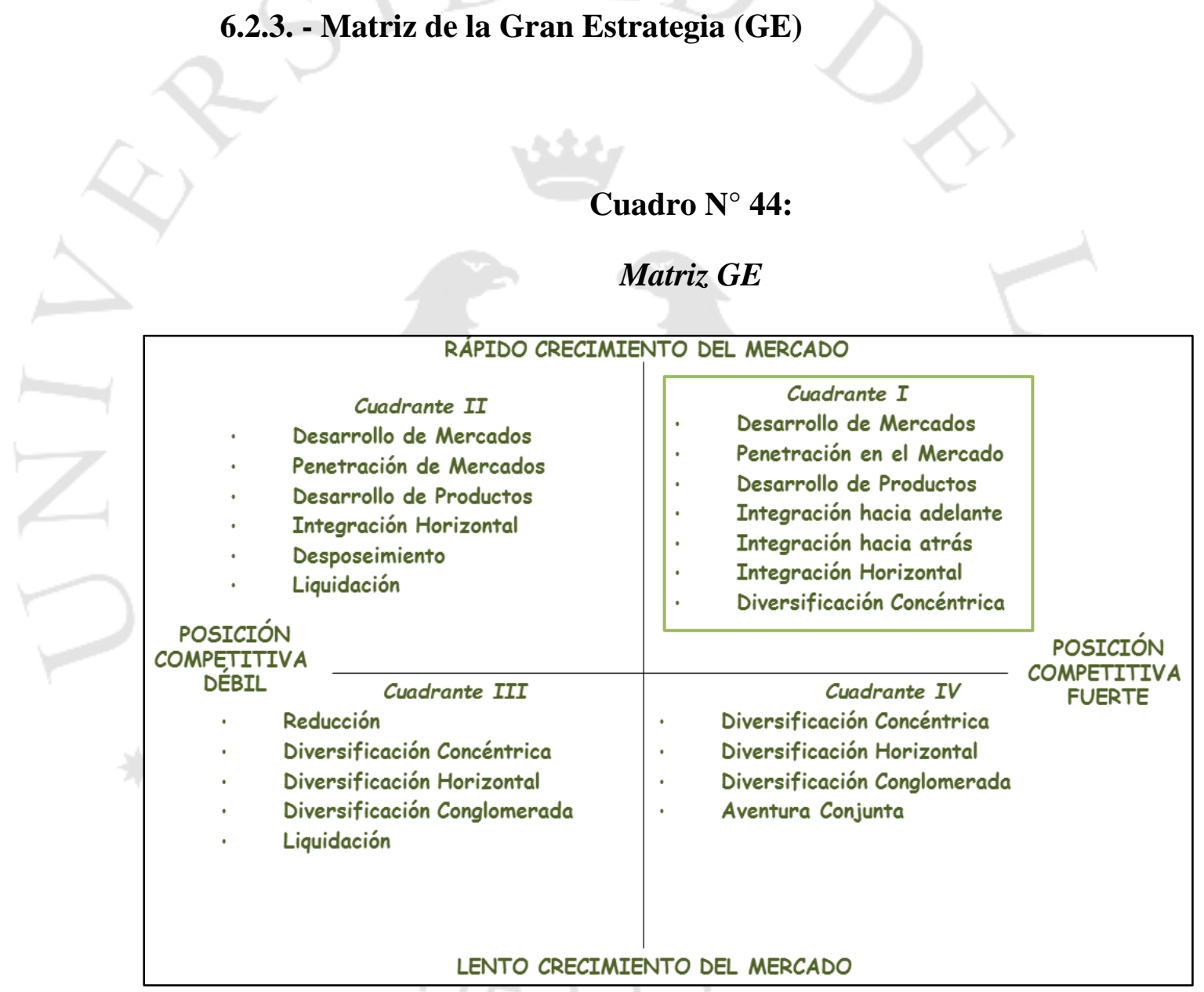

Elaboración Propia

Con la matriz de la Gran Estrategia, mostrada en el cuadro $\mathrm{N}^{\circ} 44$, se formularán estrategias alternativas desde una posición competitiva la cual es fuerte dado que existe mucha competencia en Colombia (estará en el cuadrante derecho). Además, el crecimiento del mercado de bebés es rápido por lo que estará en el cuadrante superior. 
Como resultado, las prendas de vestir para bebés estarán ubicadas en el cuadrante I, donde se utilizan estrategias como: penetración de mercado, desarrollo de productos, integración hacia adelante, atrás y horizontal, y diversificación concéntrica. Sin embargo, se utilizarán: la estrategia de penetración de mercado porque el mercado al cual nos dirigimos no está saturado y su consumo se puede incrementar de forma notable; desarrollo de producto para que las ventas de los bodies crezcan y así poder tener un mayor control sobre distribuidores. Todo esto se dará para una correcta consolidación con el cliente como la mejor empresa para los consumidores (bebés).

\subsection{4.- Matriz de Decisión}

Antes de llegar a una conclusión sobre la matriz de decisión, se analizará la matriz de ANSOFF para tener una mayor proyección de la estrategia a utilizar.

\section{Cuadro $\mathbf{N}^{\circ}$ 45:}

Matriz ANSOFF

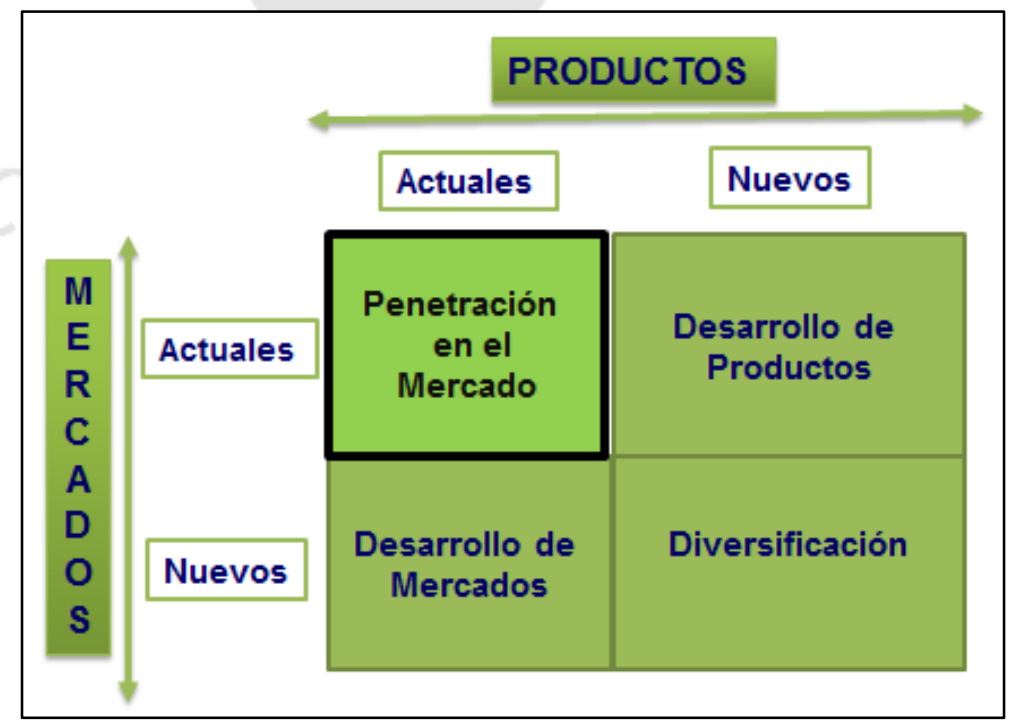

Elaboración Propia 
La estrategia específica a utilizar con la matriz de Igor, mostrada en el cuadro $\mathrm{N}^{\circ} 45$, será la de penetración de mercado ya que el producto de los bodies existe y es para el mercado actual de los bebés. Esto se dará para acrecentar la participación de los bodies para bebes en el mercado colombiano.

\section{Cuadro $\mathbf{N}^{\circ}$ 46:}

Matriz de Decisión

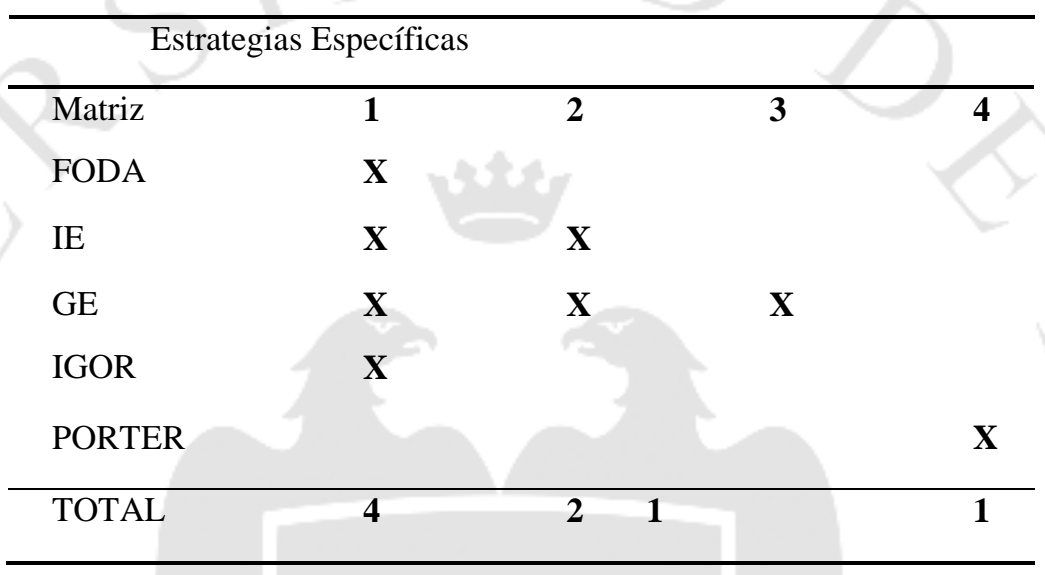

Elaboración Propia

Las estrategias específicas mostradas en la matriz están representadas en números, las cuales se detallan a continuación:

1. Penetración de mercados

2. Desarrollo de productos

3. Desarrollo de mercado

4. Nicho de diferenciación

La diferencia de las estrategias y otras son amplias. Todos estos conceptos fueron extraídos del material del curso del Profesor de la Universidad de Lima, Juan Manuel Ravelo (2015). Con respecto al objetivo de la Estrategia de Penetración de mercado se da para que la empresa pueda aumentar su nivel de participación a través de campañas de marketing u otras que permitan a la vez abrir nuevos puntos de venta. La 
estrategia de Desarrollo de Productos se daría para que las ventas puedan crecer (en este caso por los bodies). Una diferencia clave de esta estrategia con otras es que aquí pueden implementarse nuevos productos como por ejemplo mantas y otras prendas de vestir para infantes, de esta manera la empresa pueda ser más conocida y competitiva a través del valor agregado que ofrece.

De otro lado, se encuentra la Estrategia de Desarrollo de Mercados la cual se da para que los bodies no sólo puedan estar en Bogotá-Colombia sino expandirse a las demás ciudades y países del mundo. El objetivo de esta estrategia es que la empresa pueda tener más éxito que la competencia aprovechando diversos mercados con mejores situaciones económicas a las del mercado actual, mejor tecnología, entre otras cualidades. Las tres estrategias mencionadas anteriormente son calificadas como estrategias externas intensivas. Por último, la estrategia de nicho de diferenciación es una estrategia genérica competitiva que tiene como característica las ventajas en la calidad del producto y un alcance amplio en el mercado.

La estrategia a escoger es la de "Penetración de mercado", ya que tiene la mayor puntuación con respecto a las otras, la cual es 4 . Por tal motivo, la empresa buscará aumentar la participación de mercado para los productos de prendas de vestir para bebés a través de campañas publicitarias en el mercado colombiano con el motivo de generar una mejor conciencia de la marca en la mente del cliente. Otra estrategia de penetración de mercado será el cambio de los diseños de la prenda cada cuatro meses para darle un toque fresco o moderno y atraer mayor clientela.

\section{3.-Objetivos de corto plazo.}

- Tener una venta anual mínima de 12000 prendas al mercado de Bogotá Colombia en el primer año de iniciado el proyecto. 
- Lograr que las ventas se dupliquen en el segundo año.

- Lograr un posicionamiento marcado en la mente del consumidor mediante marketing directo en las calles de Bogotá para que pueda reconocer la marca en los primeros tres años.

- Participar en no menos de cinco ferias internacionales en los primeros cuatro años.

- Lograr implementar la estrategia de fidelización hacia los empleados mediante la utilización de bonos, premios y capacitaciones a lo largo de los tres primeros años.

\section{4. - Políticas.}

- Área Organizacional ( General):

- La empresa basará sus principios y políticas de negociación a través del esquema de comercio justo.

- Teco Caricias S.A.C aplicará los conceptos de responsabilidad social en relación con los diversos actores en el tercer año de haber consolidado la empresa.

- La igualdad primará tanto para el personal de la empresa como para los proveedores y clientes.

- Área de RH:

- Se tendrán métodos de incentivo hacia el personal (ganancias de ventas) y capacitaciones cada dos meses sobre las nuevas técnicas de diseños o de producción, dado sea el caso. 
- Además, todos los trabajadores deben contar con un seguro de salud por seguridad ante algún inconveniente, tanto en la empresa como en lugares públicos, el cual será proporcionado por la empresa. Será opcional contar con un seguro familiar (EPS), el cual se descontará de su sueldo.

- Se llevarán a cabo talleres de liderazgo para el personal y campañas de salud tres veces año.

- El personal que se reclutará por medio de entrevistas para ser parte de la empresa no deberá tener influencias o contactos directos con la empresa para que así exista igualdad entre los trabajadores

- Área de Finanzas:

○ El gerente financiero sólo podrá pagar a los proveedores los días viernes y cada dos semanas, mediante un documento oficial (facturas).

- El uso y manejo del capital de la empresa debe usarse de una forma adecuada.

- Basarse sobre los principios de las de Normas Internacionales de Información Financiera de Contabilidad de la empresa.

- Área Comercial y Logística :

- Se aceptará la compra de telas sólo cuando se tenga el certificado de que estas cuenten con una Política Medioambiental Amigable y de forma responsable, la cual deberá ser orgánica mediante la GOTS.

- Se deberá evaluar los productos a comprar tanto de telas como del envase y embalaje para las prendas. Se tendrá mucho cuidado debido a que todo será orgánico. 
○ El proveedor que no entregue un certificado original quedará automáticamente desligado de la empresa.

- Calificar a los principales proveedores y brókeres a nivel nacional de forma anual.

- Las ventas deberán ser pactadas con un mes de anticipación para preparar a las líneas aéreas y contenedores especiales con el objetivo que el envío de la mercadería sea óptima.

- El personal de esta área (específicamente los que están realizando confecciones) deberán laborar de 8:00 a 16:00 horas, mientras que las otras áreas desde las 10:00 a 18:00 horas. Esto se organiza para que las otras áreas puedan revisar al final del día las prendas y dejar un informe para el despacho con un lead time óptimo. 


\section{CAPITULO VII: PLAN DE MARKETING}

\section{1.-Objetivos de Marketing}

- Obtener una participación de mercado del $1 \%$ para los tres primeros años de exportación.

- A lo largo del sexto año se deberá tener una participación del 1.5\% de mercado con respecto a las ventas.

- Mantener el posicionamiento sobre calidad e innovación en la mente del consumidor a partir del segundo año que la empresa esté en el mercado.

- Contar con una rentabilidad financiera estable a los largo de los cinco primeros años de apertura del proyecto a través de auditorías realizadas por el contador externo.

\section{2.-Mercado potencial y objetivo}

El mercado potencial de Teco Caricias S.AC se dirigirá en dos grupos. En primera instancia al consumidor, el cual son los bebés y a los clientes que son los padres de familia. Según Euromonitor (2015), ellos comprarán aproximadamente tres prendas por año para los bebés, lo que equivale a 454811 de personas en la capital Colombiana. Esta construcción del nicho se da por medio de equivalencias entre el poder de compra y el costo de las prendas en cliente final. Es decir, el gasto en dólares por ropa/per cápita es de US\$18.1 por prenda con precio de US\$43.52.

Con respecto al target primario, el cual es el público que está más cercano a la compra de estas prendas, son las madres. Según Euromonitor (2016), las madres de aproximadamente 35 años que cuentan con un posicionamiento económico elevado 
buscan que las prendas sean de alta calidad y no consideran al precio de estos como un factor importante para su adquisición.

\section{3.-Segmentación}

El mercado será Colombia - Bogotá. Las personas a las que la empresa se dirigirá tendrán de 0 a 24 meses de edad, los cuales tienen un alcance del $6 \%$ de toda la población. Además, se dirigirán al $28.9 \%$ de estas personas las cuales son del sector socioeconómico $\mathrm{AB}$.

Dentro del mercado elegido aparece el segmento de Padres de familia los cuales tienen un estilo de vida moderno (por la tecnología de hoy). Estos buscan todo lo referido a lo natural. El tema orgánico en Colombia (Colombiatex, 2014) está en auge y es catalogado como el principal factor de compra.

Las madres compran aproximadamente tres prendas al año sólo en los primeros meses del bebé debido al rápido crecimiento. Sin embargo, según Euromonitor (2016), se espera que para los próximos cinco años lleguen a la compra de cinco prendas anuales.

Por otro lado, las prendas que se compran a los niños y niñas de más edad (de 24 meses en adelante) llegan a 6 prendas anuales. Sin embargo, la proyección de compra de estas para el 2020 sigue siendo la misma. Todo esto se da en la clase socioeconómica B. Con respecto a la A, se tiene un aumento en la previsión de ventas colombianas con un $5.4 \%$ de crecimiento sobre la clase B. Es decir, ellos comprarán en promedio 3.2 prendas anuales, la cual no tiene mucha diferencia. 


\section{4.-Posicionamiento}

El producto se va a posicionar en el mercado por su calidad, ya que este ofrece un mejor valor que la competencia. Es diferente en cuanto a la seguridad que brinda su uso debido a que el algodón que se utiliza en la confección de las prendas no tiene pesticidas ni es sintético. Esto hace que la piel del consumidor esté protegida y no sufra irritaciones o alguna reacción alérgica.

Como ya se mencionó, se contratarán a dos diseñadores, un diseñador Peruano y a otro Colombiano, para que ellos realicen sus trabajos en base a lo que requieran los clientes y cuenten con un poco de las dos culturas (Peruana y Colombiana).

Este posicionamiento será exclusivo dado que la empresa se basará principalmente en diseños que lo convierte en un factor clave. Las marcas más importantes y que se destacan por la calidad (la competencia) son Mothercare y EPK.

\section{5.-Desarrollo}

Las fases de implementación serán tres, las cuales tendrán herramientas y serán reflejadas en el Cuadro $\mathrm{N}^{\circ} 47$ (cronograma de fases y actividades promocionales). 
Cuadro $\mathbf{N}^{\circ}$ 47:

Fases y Actividades Promocionales

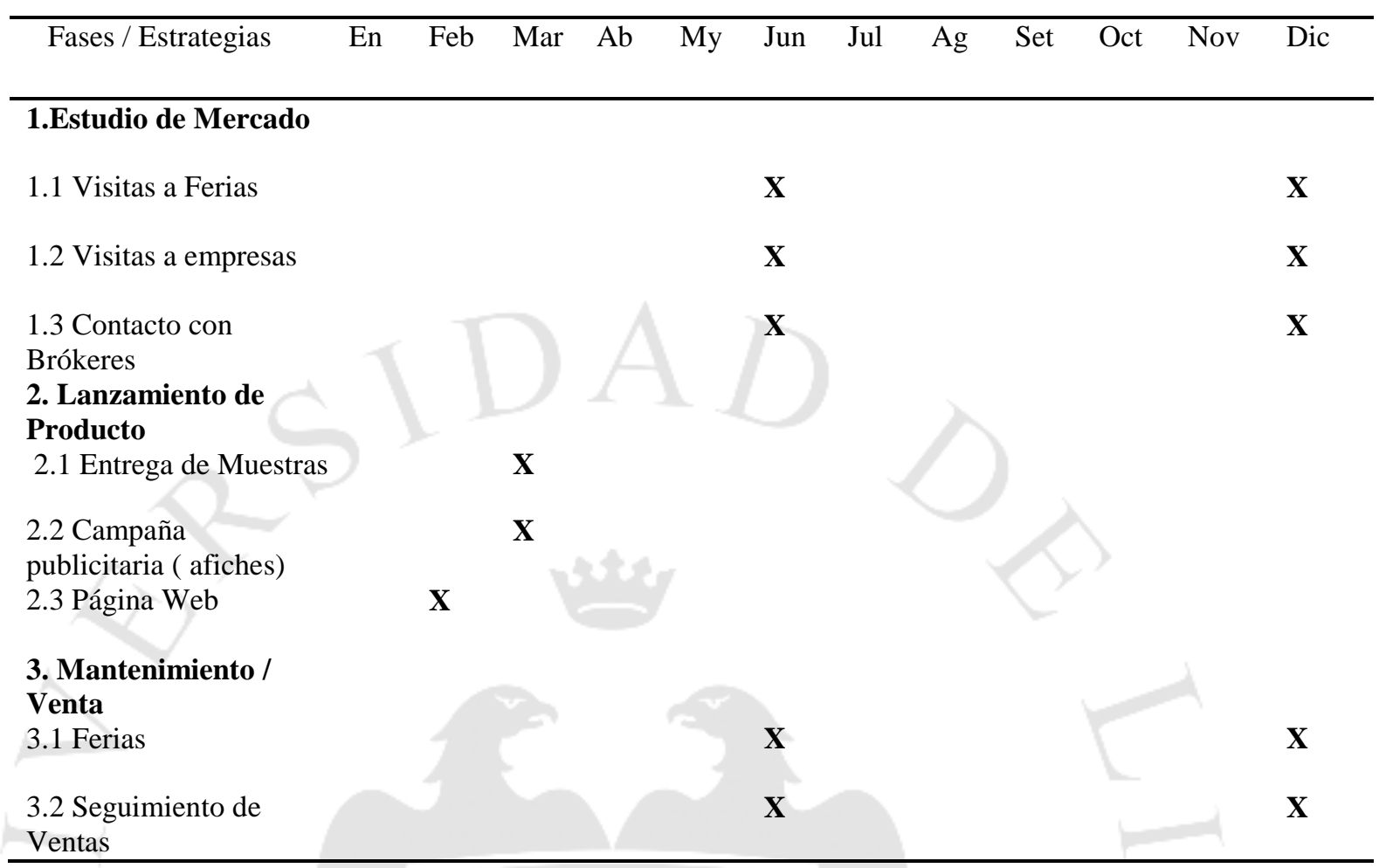

Elaboración Propia

La primera fase será “El estudio de Mercado", el cual se realizará el año 0 y es la fase previa para comenzar el proyecto; aquí es donde se asistirá a Ferias como Colombiatex y Babys and Kids en el mes de junio y diciembre. Además, de realizar visitas en estos mismos meses a empresas reconocidas por el sector para conocer quiénes serán los competidores directos y a la vez a los brókeres que brindarán apoyo a la empresa.

De otro lado, en el año 1 se dará la fase dos, la cual es el lanzamiento del producto. Se darán muestras a la persona de contacto, la cual realizará una campaña publicitaria directa por medio de entrega de afiches en los centros comerciales en Colombia, con lo que se obtendrá información acerca de la situación del producto. 
Por último, se da la estrategia del desarrollo de una página web, la cual se actualizará de manera permanente. La última fase, la cual se realizarán todos los años será Asistencia a Ferias para captar nuevo clientes y visitas a Colombia para estar con la persona de contacto y realizar análisis para ver cómo van incrementando las ventas.

\section{6.-Posturas Competitivas}

La postura competitiva va a ser el "Diseño y Calidad". Sin embargo, la principal postura será la de "Diseños Exclusivos" debido a que la mayoría de empresas en especial las más grandes como Mothercare y EPK se basan en la calidad. No obstante, la empresa Crystal SAS con marcas como Punto Blanco y Gef son las únicas que se basan en diseño y se podrá competir ante ellas de una forma igualitaria (Euromonitor, 2016).

Por otro lado, para esta postura se establecerá una estrategia de ocupante de Nicho de Mercado, donde se especializará en clientes específicos dado que las ventas se limitarán a los padres de familia. Además, se dará la especialización para el usuario final, debido a que las prendas serán elaboradas para satisfacer las necesidades de los bebés.

\section{7.-Producto (ficha técnica, envase, embalaje, etiquetado)}

La ficha técnica está reflejada en el Punto 3.3.1. Sin embargo, en el Cuadro $\mathrm{N}^{\circ} 48$, se muestra un resumen de esta. 


\section{Cuadro $N^{\circ}$ 48:}

\section{Ficha Técnica}

\section{Prendas y complementos de vestir de punto para bebés, de algodón.}

Descripción Ropones de cuerpo completo para bebés de 0-2 años.

Composición Prendas y complementos $100 \%$ de algodón orgánico.

Sub-partida arancelaria

611120000

Sector

Textil

Categoría

Tejidos de Punto

Zonas de Producción

Lima

Presentación

Tallas: 0-2; 2-4; 4-6; 6-8; 8 a más meses.

Colores: Tonos pasteles ( blanco, café y verde olivo)

Peso: 200gr

Certificados

Certificado GlobalGAP

IMO

Global Organic Textile Standard (GOTS)

Elaboración Propia

Con respecto al envase, la empresa exportará las prendas en

bolsas de yute. Estos envases fueron elegidos porque no daña el medio ambiente, son realizados con material orgánico. La duración de estas bolsas son mayores a las del papel o cartón. Además, son resistentes a sufrir alguna rotura o diversos tipos de desgarros que alguna bolsa de papel o plástico presenta. Con este aspecto, la calidad primará y con respecto al diseño, estas bolsas tendrán un lazo especial de algodón para darle un toque natural. El precio actual a cotizar por la empresa proveedora será de US\$0.03 por bolsa. 
Todos los productos del proveedor de envases son reciclados y ecofriendly, tal como se muestra en el Anexo 5.3 en su página web. Esto es importante para que Control Unión Perú pueda darle a la empresa la certificación GOTS. Las bolsas de yute serán dadas por el siguiente proveedor:

\section{- GUANGZHOU COVER RECYCLING BAGS PRODUCTS CO., LTD:}

Tipo de negocio: Fabricante, Empresa de comercio.

Dirección: No. 5, Liulian Road, Jianggao Town, Baiyun District, Guangzhou, Guangdong, China (Mainland)

Teléfono: 0086-020-86163033

Correo Electrónico: cover@gzcover.com ; bag@gzcover.com Web: http://www.gzcover.com/plastic.php?cid=21

Para el embalaje se usarán cajas de cartón de 50 x 40 x 40 cm. Estas cajas tienen una capacidad aproximada de ochenta (80) prendas para la exportación. El peso de la caja será de $0.2 \mathrm{~kg}$ y el peso neto será de $16.2 \mathrm{~kg}$ cada caja. Con respecto al precio, se cotizó a US\$1.5 por caja.

La empresa que proporcionará el servicio sólo

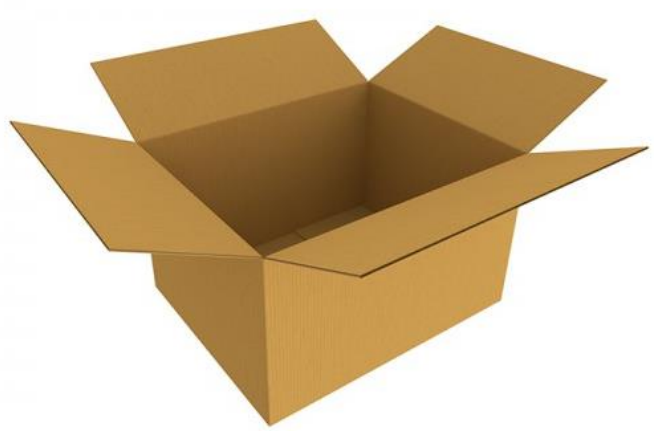
ofrece servicio de embalaje e imprenta con materiales eco amigables con el medio ambiente y $100 \%$ reciclados tal como se puede apreciar en el Anexo 5.4. Los datos del proveedor de embalaje es el siguiente: 
- Shenzhen Zhongtaija Trading Co., Ltd.

Dirección: Jing South Road, la calle Buji, distrito de Longgang, Shenzhen, Guangdong, China.

Tel: 886075528579600

Correo Electrónico: allen@ ztj-cn.com Web: http://ztj-cn.com/en/about.asp?id=4

El etiquetado será de algodón orgánico y deberá cumplir ciertos lineamientos según la Superintendencia de Industria y Comercio de Colombia (2016), los cuales consisten en que deben estar bordadas o estampadas en la prenda, tener la talla de la prenda y demás información en español según se relata en el Anexo $\mathrm{N}^{\circ} 6$.

Using $95-100 \%$ organic fibres:

La empresa a la cual se requerirá es una de las más reconocidas en el

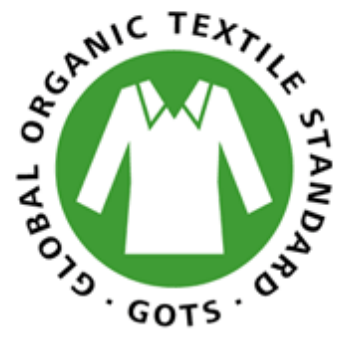

Organic

certified by [certifier's ref.] Licence no [1234] rubro por fabricar etiquetas anti robo de prendas de vestir y de cuidado (orgánicas). El precio unitario de estas etiquetas será de US\$0.13.

El proveedor de etiquetas orgánicas será:

- Shanghai Yilong Industrial Co., Ltd.:

Dirección: East, 2th floor, Lane473, Dunhuang Rd, Putuo Dist, Shanghai, China

Tel: $86-021-62847217$

Correo electrónico: no especificado - Web: http://www.shyilonglabel.com 


\section{8.-Precio (método para determinar precios, medios de pago)}

El precio está fijado por el costo $(\mathrm{CF}+\mathrm{CV})$ adicionándole las ganancias, tal como se muestra en el Capítulo 12. Para determinar dicho precio se utilizó el método de costing (Ver Gráfico $\mathrm{N}^{\circ} 14$ ), que consiste en preparar cotizaciones de los costos (textiles, envases, embalajes, préstamos, obtención de certificados, contrato de un contador, etc.) para determinar no sólo el precio sino también su margen. Con este método, se conocerá la ganancia neta y diversos costos incurridos en el transcurso de la exportación.

Con el fin de comprobar el precio óptimo final, se tendrá que revisar la determinación del precio por el método del pricing, comparándolo con el de la competencia local. Utilizando este método, se tiene que partir del precio de mercado y en base a eso determinar el margen. El precio base elegido con este método a comparación de la competencia es de US\$10.71. De acuerdo a esta variable, se tomarán medidas para que pueda ser rentable la utilización de este método. En primera instancia, se implementará un cuadro de seguimiento, al igual que se hará para todo el plan estratégico, BALANCE SCORECARD de precios de todas las marcas competidoras en Colombia, el cual se actualizará cada 25 días para mantener la información al día de los costos con los cuales se competirán y así decidir si podría subir o igualarse al de Teco Caricias S.A.C. 


\section{Gráfico $\mathbf{N}^{\circ}$ 14:}

Proceso del Método Costing

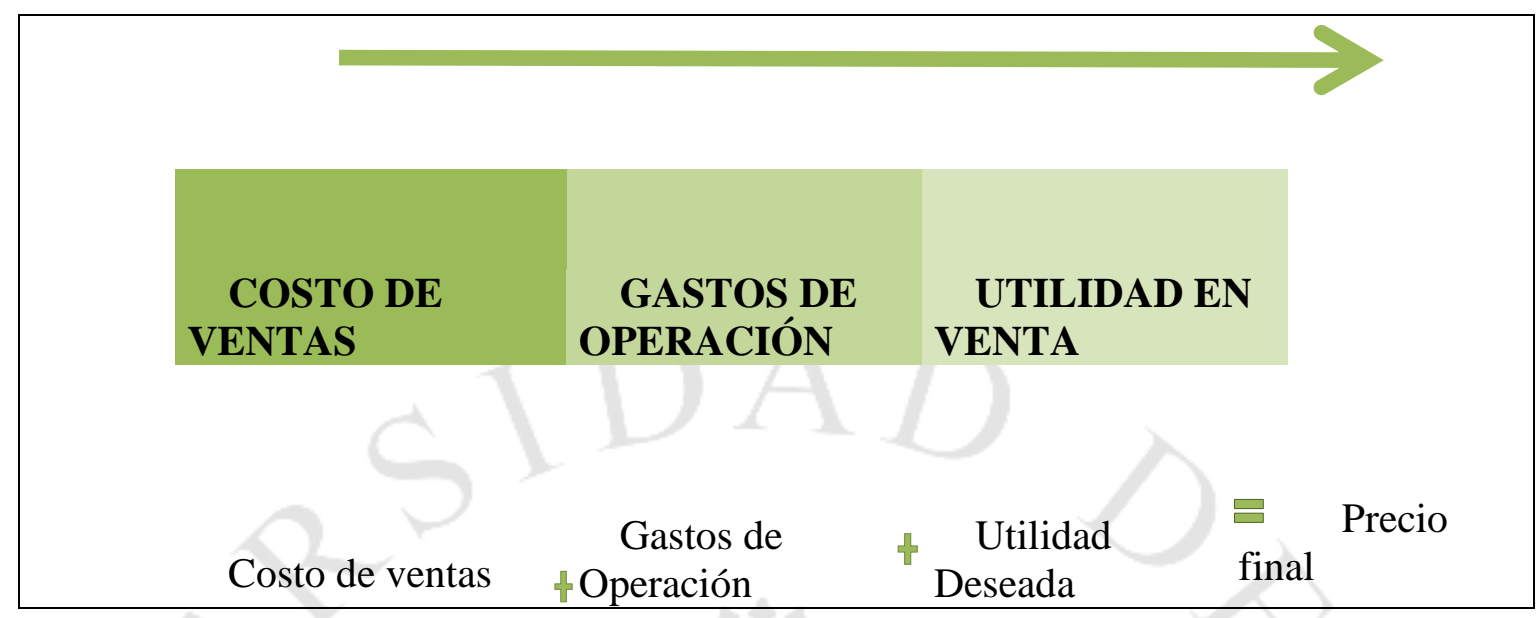

Elaboración Propia

Con respecto al medio de pago, según los supuestos financieros del Capítulo XII, se basan en la inexistencia de incobrables o malas cuentas. Por ende, lo recomendable, por ser la primera exportación, es que se dé un pago contra documentos más conocido como Documentary Collection (D/P) con aval para para que el banco esté a cargo de la transacción y sea más seguro.

Como se aprecia en el Gráfico $\mathrm{N}^{\circ} 15$, este medio de pago consiste en el envío de documentos de la presente exportación, los cuáles sólo se entregarán al comprador si paga el importe que se pactó. Para poder cobrar dicho pago se tendrá que presentar obligatoriamente cuatro documentos, los cuales son: B/L, factura comercial, certificado de origen y el Packing List.

El Banco Popular (2014) indicó que una de las mayores ventajas de utilizar este medio de pago es que es el más barato. Además, el exportador tiene la seguridad de 
tener la mercancía hasta el instante que el importador realice el pago del monto de la transacción o cuando se comprometa al pago aceptando el efecto.

\section{Gráfico $\mathbf{N}^{\circ}$ 15:}

Pago Contra Documento - D/P

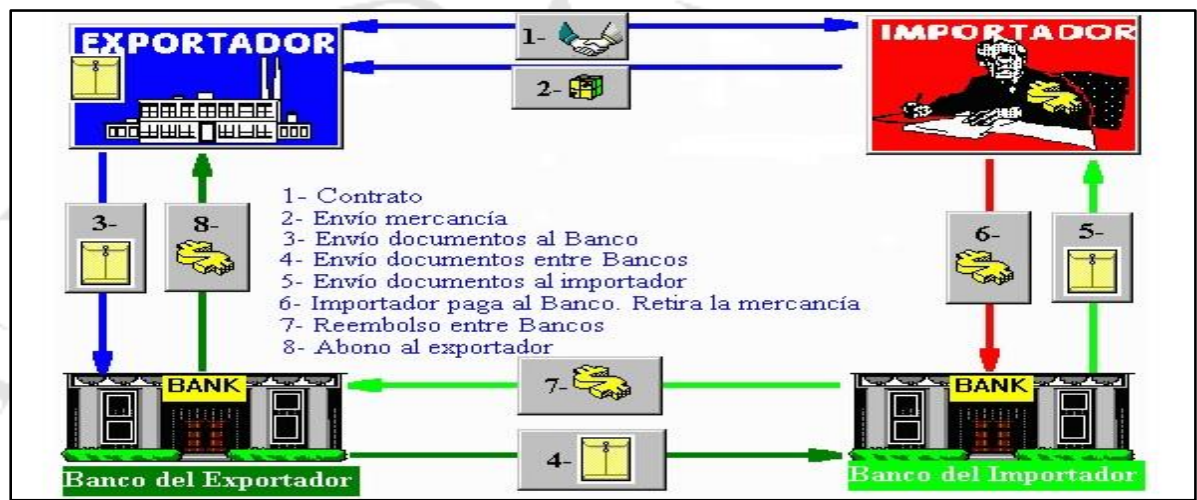

Recuperado de "Medios de Pago", el 16 de setiembre del 2014, En:

http://mediosdepago.wikispaces.com/Remesa+documentaria+(David)

\section{9.-Plaza}

Teco Caricias S.A.C hará uso del Incoterm FCA, es decir se entregará la mercancía dentro de un país de origen antes de la Aduana correspondiente. Por ello, la empresa sólo se encargará de la logística interna hasta el puerto de embarque. El modo de envío de la carga será de forma aérea debido a que es una mercancía delicada y exclusiva y se irá al canal de minoristas.

Por otro lado, se tendrá una relación entre la fuerza de venta y los canales de distribución. En este caso, la fuerza de venta será la persona de contacto en Colombia. Esta tendrá que ofrecer los productos a las tiendas de sector económico alto (A y B). La estrategia que se usará será de fidelización de clientes; la actividad sobre esta será que 
el Gerente General de Teco Caricias S.A.C irá cada dos meses a supervisar o evaluar cómo están creciendo las ventas y la fidelización sobre la marca.

\subsection{0.-Promoción (estrategias de ingreso al mercado)}

Los medios de promoción serán medios on line como páginas web y redes sociales en la etapa de lanzamiento. Estos medios contarán con información general del producto como los diseños de las prendas, el material que se utiliza, los principales certificados con los que se cuenta y la forma mediante la que se les puede contactar.

Por otro lado, el objetivo de tener promoción de ventas será incrementar la demanda del producto. Cuando estas prendas entren al mercado colombiano y se establezcan en cadenas especializadas como en las tiendas, se implementará la promoción de "Lleve uno y la siguiente prenda adquiérala con un 30\% de descuento". Esta promoción durará los quince primeros días y se buscará medir la respuesta del cliente.

Además, se recurrirán a diversas ferias nacionales e internacionales para contactar a clientes potenciales, proveedores y para que el producto sea reconocido. Estas ferias serán:

- COLOMBIATEX DE LAS AMÉRICAS:

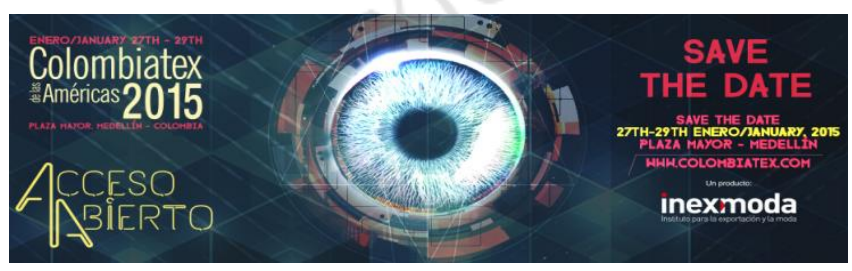


Está ubicada en el mejor escenario de negocios colombiano. Aquí se reúne tanto la oferta como la demanda de los textiles, insumos para la confección de estos y diversos procesos productivos del sistema de la moda.

Colombiatex es una de las ferias más reconocidas del sector debido a que los diseñadores colombianos asisten para acceder a las novedades y tendencias de las confecciones y textiles mundiales.

\section{Ficha técnica de la Feria:}

$\checkmark$ Sectores: Moda, Diseñadores de moda, Industria calzado, Industria de confección, Marroquinería, Textiles

$\checkmark$ Periodicidad: Anual

$\checkmark$ Público: General

Lugar: Palacio de Exposiciones y Convenciones de Medellín

Ciudad: Medellín

País: Colombia

$\checkmark$ Página web: http://colombiatex.inexmoda.org.co/es/

\section{- BABIES \& KIDS}

Esta feria se da especialmente para que los padres o futuros padres puedan encontrar y comprar lo necesario para los bebés. En el sector de moda y textiles, esta

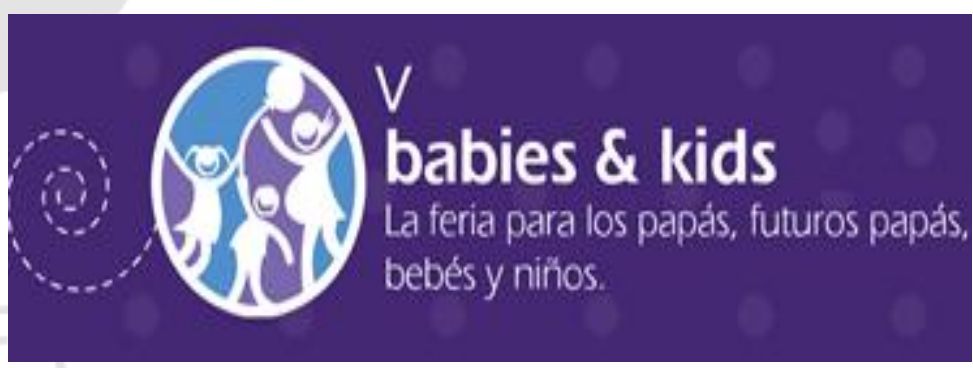
feria congrega a los principales productores, comercializadores y sobre todo importadores de este rubro para que puedan adquirir mayor reconocimiento de su marca. 


\section{Ficha técnica de la feria}

Sectores: Juegos, mobiliario, moda, bebé, higiene, juguetes, muebles, padres

Periodicidad: Anual

Público: General.

Recinto: Corferias - Centro de Convenciones

Ciudad: Bogotá

$\checkmark$ País: Colombia

$\checkmark$ Página web: http://www.feriababiesandkids.com

Por otro lado, una estrategia de promoción que se implementará será la de mantener los descuento más altos del negocio hacia el canal. Otra será, ofrecer muestras gratis a cierto público seleccionado para que cuando lo usen puedan verificar la calidad de las prendas y sean impulsados a una nueva compra; sin embargo, estas muestras se entregarán a las tiendas en donde la empresa venderá las prendas y no en las ferias debido a que Teco Caricias S.A.C en una primera instancia no será expositor. Por último, después de que esté bien posicionado el producto en Colombia, aproximadamente luego de tres años, se realizará un nuevo lanzamiento en la línea de productos como mantas, gorritos, polos, entre otros.

\subsection{1.-Presupuestos de Marketing.}

Con respecto a los medios on line, como la página web y su posicionamiento, son esenciales para la promoción dado que tienen un gran impacto en los clientes. Estos tendrán un valor de US\$500 por implementación y actualizaciones por un año. El encargado será un alumno de INICTEL (UNI). Durante los próximos cuatro años las actualizaciones tendrán costos anuales de US\$150. 
La publicidad se dará mediante paneles publicitarios en las principales calles de Colombia, especialmente en las carreteras 45, y 62 en verano, pues son los lugares donde las personas más transitan en esa época. El encargado de este proyecto será el proveedor PETTY PUBLICIDADES y costará US\$600 por campaña.

El ir a las ferias genera diversos costos previstos como los hoteles y comida en el lapso de la duración de estas. Colombiatex: Tiene una duración de tres días, lo cual genera un gasto en dólares de:

$\checkmark$ Hotel: Medellín Royal, el cual cuenta con traslado hacia la feria, Dirección: Carrera 42 No. 5 Sur US\$140

$\checkmark$ Traslados: Diversos gastos por la ciudad US\$50

$\checkmark$ Comida US\$120

$\checkmark$ Costo de entrada de feria / 200.000 Pesos US\$98

$\checkmark$ Aerolínea Copa Airlines US $\$ 360$

TOTAL: US\$ 768

Babies \& Kids: Tiene una duración aproximada de 5 días en la cual se tendrán diversos gastos como:

$\begin{array}{lll}\checkmark & \text { Hotel: Hotel B3 Virrey, Dirección: Carrera } 15 \text { No 88-36, Chico, } 110010 \\ & \text { Bogotá_ } & \text { US } \$ 350 \\ \checkmark & \text { Traslados_ } & \text { US } \$ 100 \\ \checkmark & \text { Comida } & \text { US } \$ 180 \\ \checkmark & \text { Entrada a la feria_ } & \text { US } \$ 20 \\ \checkmark & \text { Aerolínea Copa Airlines _ } & \text { US } \$ 478\end{array}$

TOTAL: US\$1128

El cuadro $\mathrm{N}^{\circ} 49$ muestra un resumen del presupuesto de marketing dado en todo el capítulo. Todos estos costos estarán reflejados en US\$ durante el lapso de los cinco 
primeros años. Con respecto a los viajes a Colombia, están incluidos los pasajes, visitas a Ferias, contacto con los brókeres, entre otras actividades.

\section{Cuadro $\mathbf{N}^{\circ}$ 49:}

Presupuesto de Marketing (2016-2020)

\begin{tabular}{|c|c|c|c|c|c|}
\hline Descripción / Año & 2016 & 2017 & 2018 & 2019 & 2020 \\
\hline Página Web & 500 & 150 & 150 & 150 & 150 \\
\hline Paneles Publicitarios & 600 & 600 & 600 & 600 & 600 \\
\hline Viajes a Colombia & 1,896 & 1,896 & 1,896 & 1,896 & 1,896 \\
\hline Total & 2,996 & 2,646 & 2,646 & 2,646 & 2,646 \\
\hline
\end{tabular}

Elaboración Propia

\subsection{2.-Principales factores claves de éxito a controlar}

Lo que empuja a que Teco Caricias S.AC tenga rentabilidad es que la calidad del algodón es diferente a la competencia. Además, existirá el reconocimiento de la marca ya que se participará en campañas de promoción, en ferias distintivas para dirigirnos hacia el mercado $\mathrm{AB}$ y quedarnos en la mente del cliente.

Un factor que se utilizará y generará más clientela será el de incorporar la atención de obligaciones sociales de la empresa para con la comunidad como mayor empleos, trato justo y cuidado con el medio ambiente. Es decir, incorporar un proyecto de responsabilidad social.

Por último, las madres de familia comprarán los bodies mediante una campaña constante de marketing lo que hará que la marca permanezca en la mente de ellas. La primera exportación se dará mediante un pago contra documentos para que sea más seguro. 


\section{CAPITULO VIII: PLAN DE OPERACIONES Y/O PRODUCCIÓN}

\section{1.- Objetivos de Operaciones y/o Producción}

- Establecer el volumen de operaciones de forma mensual.

- Tener contacto con los proveedores de producción y servicio logístico a partir del sexto mes de operaciones para realizar una alianza con ellos.

- Implementar un proceso logístico conveniente el cual facilite la exportación del producto en el primer año de producción.

- Establecer un formato de indicadores actualizados sobre las certificaciones en los primeros meses de producción.

- Dar seguimiento al tiempo promedio de almacenamiento, el cual debe de darse de forma diaria con respecto a la cantidad de productos elaborados (80\%), a lo largo de los cinco primeros años.

\section{2.- Tamaño del proyecto $y$ factores determinantes del mismo}

Con respecto al tamaño del proyecto se hablará primero que existirá una tercerización para la obtención de prendas. Existirán tres tipos de máquinas y tres operarios, donde estos trabajarán de forma lineal. Cada uno de estos operarios tendrán asignado una máquina y será el responsable de hacer una parte de la prenda. Las tres personas confeccionarán una prenda en 10 minutos. En una hora se harán seis y en un turno de ocho horas se elaboran 48 prendas. La producción diaria será de 144 prendas. Dependiendo de cómo esté yendo la producción en los próximos tres años, se llevará a cabo la implementación de una planta en Colombia con más trabajadores. 
Con respecto al estudio de mercado mostrado en el punto 3 , se obtuvo una demanda objetivo para los próximos cinco años. Esta se encuentra representada en el Cuadro $\mathrm{N}^{\circ} 50$ con una cantidad en kilos y volumen de prendas totales de $14580 \mathrm{~kg}$ y US\$771 120 respectivamente. La demanda objetivo es de 2333 kilos y en el primer año (2016) se dio porque se exportarán ocho (8) pallets y cada pallet tiene un peso de 292 kilos. Estos pesos se hallan porque se exportarán dieciocho (18) cajas por pallet y cada caja pesará $16.2 \mathrm{~kg}$. Se llegó a la conclusión de exportar dieciocho (18) cajas por pallet debido a que en la conversión de cubicaje (el cual se mostrará más a fondo en el plan logístico) el total de cajas en la base de pallet serán de seis (6) y las filas por pallet ajustado serán de tres (3). Todo esto se dará por el tamaño de contenedores en el cual la empresa exportará los bodies.

\section{Cuadro $\mathbf{N}^{\circ}$ 50:}

Demanda Objetivo Proyectada en Kg y US\$ (2016-2020)

\begin{tabular}{|c|c|c|c|c|c|c|}
\hline & 2016 & 2017 & 2018 & 2019 & 2020 & TOTAL \\
\hline $\begin{array}{l}\text { Demanda } \\
\text { Objetivo (KG) }\end{array}$ & 2,333 & 2,624 & 2,916 & 3,208 & 3,499 & 14,580 \\
\hline $\begin{array}{l}\text { Demanda } \\
\text { Objetivo (US\$) }\end{array}$ & $123,379.20$ & $138,801.60$ & $154,224.00$ & $169,646.4$ & $185,068.8$ & 771,120 \\
\hline $\begin{array}{l}\text { Participación } \\
\text { DO/DP }\end{array}$ & $0.65 \%$ & $0.72 \%$ & $0.79 \%$ & $0.85 \%$ & $0.91 \%$ & - \\
\hline
\end{tabular}

Elaboración Propia

Para hallar la proyección de la demanda objetivo vista en el cuadro anterior, del año 1 al 5 en kilogramos se tomó el consumo per cápita de prendas por personas (Euromonitor, 2015), para luego hallar la demanda potencial de 14580 kilos y demanda objetivo detalla anualmente en el Cuadro $\mathrm{N}^{\circ} 53$; esta demanda por los cinco (5) años da un total de US\$771 120. 
Con respecto al Cuadro $\mathrm{N}^{\circ} 51$, para hallar la demanda potencial proyectada en kilos, gracias a The World Fact Book, se espera que el crecimiento de las personas en Bogotá será de $1.70 \%$ a lo largo de los años del 2016 al 2020. Por otro lado, según Euromitor (2015), el consumo per cápita de ellos es de 18.10, por ende, la demanda potencial por kilogramo crecerá según lo mostrado en el siguiente cuadro.

\section{Cuadro N51:}

Demanda potencial proyectada por $\mathrm{kg}(2016-2020)$

\begin{tabular}{llll}
\hline Años & $\begin{array}{l}\text { Personas proyectadas } \\
\text { (A y B) }\end{array}$ & Consumo per cápita & Demanda potencial por kg \\
\hline $\mathbf{2 0 1 6}$ & 151,604 & 18.10 & $2,744,032.40$ \\
$\mathbf{2 0 1 7}$ & 154,181 & $2,790,676.10$ \\
$\mathbf{2 0 1 8}$ & 156,802 & $2,838,116.20$ \\
$\mathbf{2 0 1 9}$ & 159,468 & $2,886,370.80$ \\
$\mathbf{2 0 2 0}$ & 162,179 & $2,935,439.90$ \\
\hline
\end{tabular}

Elaboración Propia

Para hallar la demanda potencial proyectada, debe tomarse parte de la información del Cuadro anterior ( $\left.\mathrm{N}^{\circ} 51\right)$. Aquí adquiere la demanda potencial por kilos y la convierte en ganancias. Es decir, lo multiplica por el precio al cual se venderá para obtener la demanda potencial en US\$. Por ejemplo en el 2016 se tendrá 2744032.40 kilos en Colombia y el costo sería de 6.90 US\$/ kg. Lo que da un total de US\$18 933824.00

\section{Cuadro $N^{\circ}$ 52:}

Demanda Potencial Proyectada expresada en Kg y US\$ (2016-2020)

\begin{tabular}{llllll}
\hline & 2016 & 2017 & 2018 & 2019 & 2020 \\
\hline $\begin{array}{l}\text { Demanda Potencial } \\
\text { (KG) }\end{array}$ & $2,744,032$ & $2,790,676$ & $2,838,116$ & $2,886,371$ & $2,935,440$ \\
$\begin{array}{l}\text { Demanda Potencial } \\
\text { (US\$) }\end{array}$ & $18,933,824$ & $19,255,665$ & $19,583,002$ & $19,915,959$ & $20,254,535$ \\
\hline
\end{tabular}

Elaboración Propia 
El cuadro mostrado a continuación tiene toda la información del Cuadro $\mathrm{N}^{\circ} 50$.

Sin embargo, se le aumenta el envío de pallets ya explicados y la participación DO/DP. Esta participación se halla mediante la división entre la demanda objetivo y la demanda potencial de los años 2016 al 2020.

\section{Cuadro $\mathbf{N}^{\circ}$ 53:}

Demanda Objetivo Proyectada en Kg y US\$ (2016-2020)

\begin{tabular}{lllllll}
\hline & 2016 & 2017 & 2018 & 2019 & 2020 & TOTAL \\
\hline $\begin{array}{c}\text { Demanda Objetivo } \\
\text { (KG) }\end{array}$ & 2,333 & 2,624 & 2,916 & 3,208 & 3,499 & 14,580 \\
$\quad$ Demanda Objetivo & $123,379.20$ & $138,801.60$ & $154,224.00$ & $169,646.40$ & $185,068.80$ & 771,120 \\
$\begin{array}{c}\text { (US\$) } \\
\quad \text { Participación }\end{array}$ & $0.65 \%$ & $0.72 \%$ & $0.79 \%$ & $0.85 \%$ & $0.91 \%$ & - \\
$\begin{array}{c}\text { DO/DP } \\
\text { Envíos LCL }\end{array}$ & 8 & 9 & 10 & 11 & 12 & 50 \\
\begin{tabular}{c} 
Pallets) \\
\hline
\end{tabular} & & & & & & \\
\hline
\end{tabular}

Elaboración Propia

\section{3.- Diseño y distribución de planta (flujo de trabajo y flujo de materiales)}

En el Gráfico $\mathrm{N}^{\circ} 16$ se apreciará el flujo para la obtención de materiales y el proceso que esta empresa debe seguir con los proveedores de telas, hilos, etiquetas, embalaje y las bolsas de yute, para que los bodies puedan abastecerse de manera óptima y llegar al consumidor final. 


\section{Gráfico $\mathbf{N}^{\circ}$ 16:}

Flujo de trabajo y flujo de materiales

\begin{tabular}{|c|}
\hline Empresa envía listado de \\
materiales a Bergnam S.A.C \\
(Insumos) y Envase, \\
embalaje y etiquetas a \\
empresa China
\end{tabular}

Análisis y evaluación de los mismos

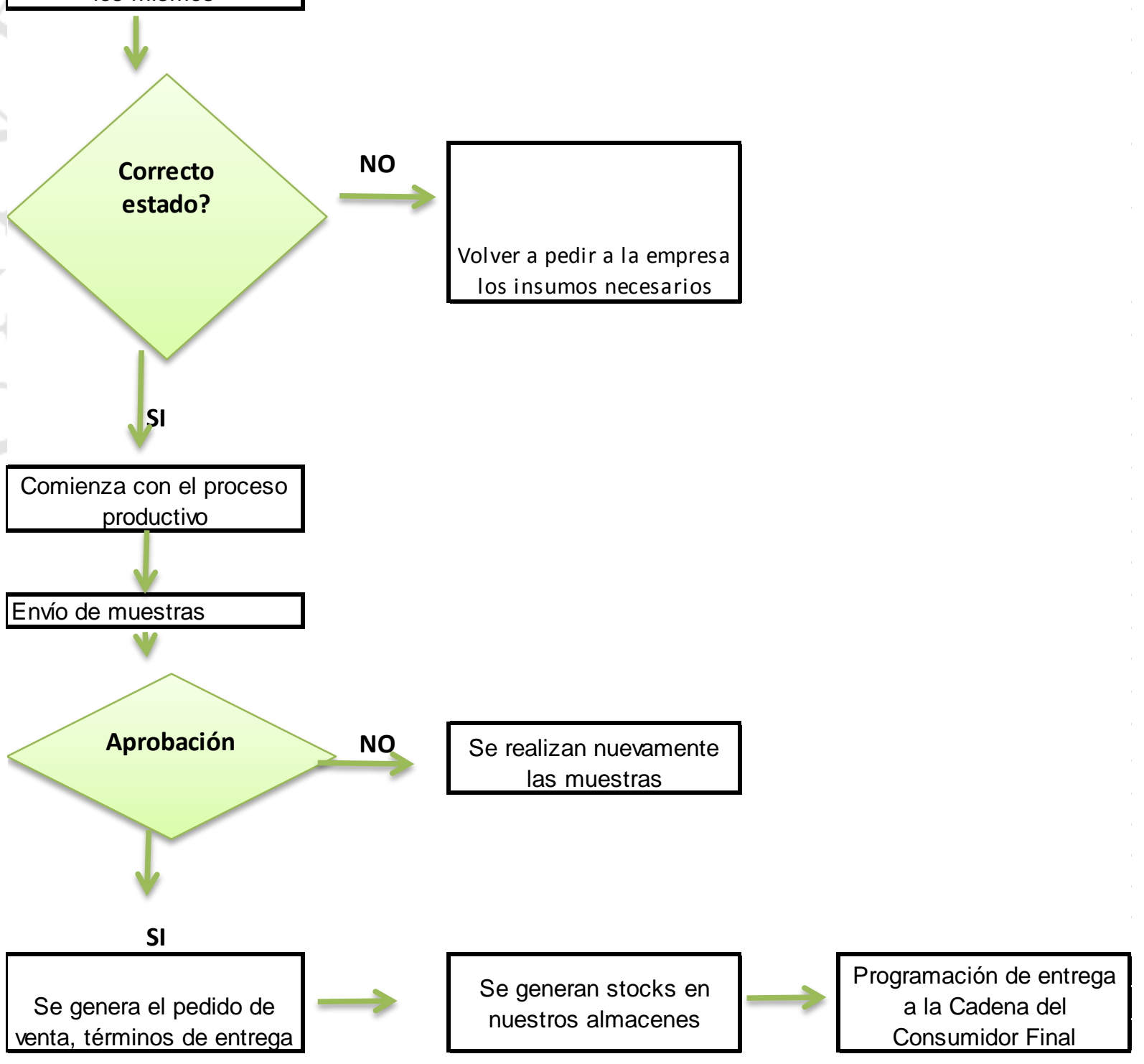

Elaboración Propia 
La distribución de la planta está dividida de forma uniforme para todas las áreas correspondientes. La empresa estará ubicada en el distrito de Los Olivos, en un primer piso con un área de $120 \mathrm{mt}$. El gráfico $\mathrm{N}^{\circ} 17$ muestra que existe un área de servicios, almacén de productos terminados e insumos. Por el sector derecho estarán las oficinas del Departamento de Logística, finanzas (contador), Gerente General, etc. Por último, existirá un área de recepción de clientes y/o proveedores. Además, contará con una sala de reuniones donde se llevarán a cabo las entrevistas y capacitaciones al personal.

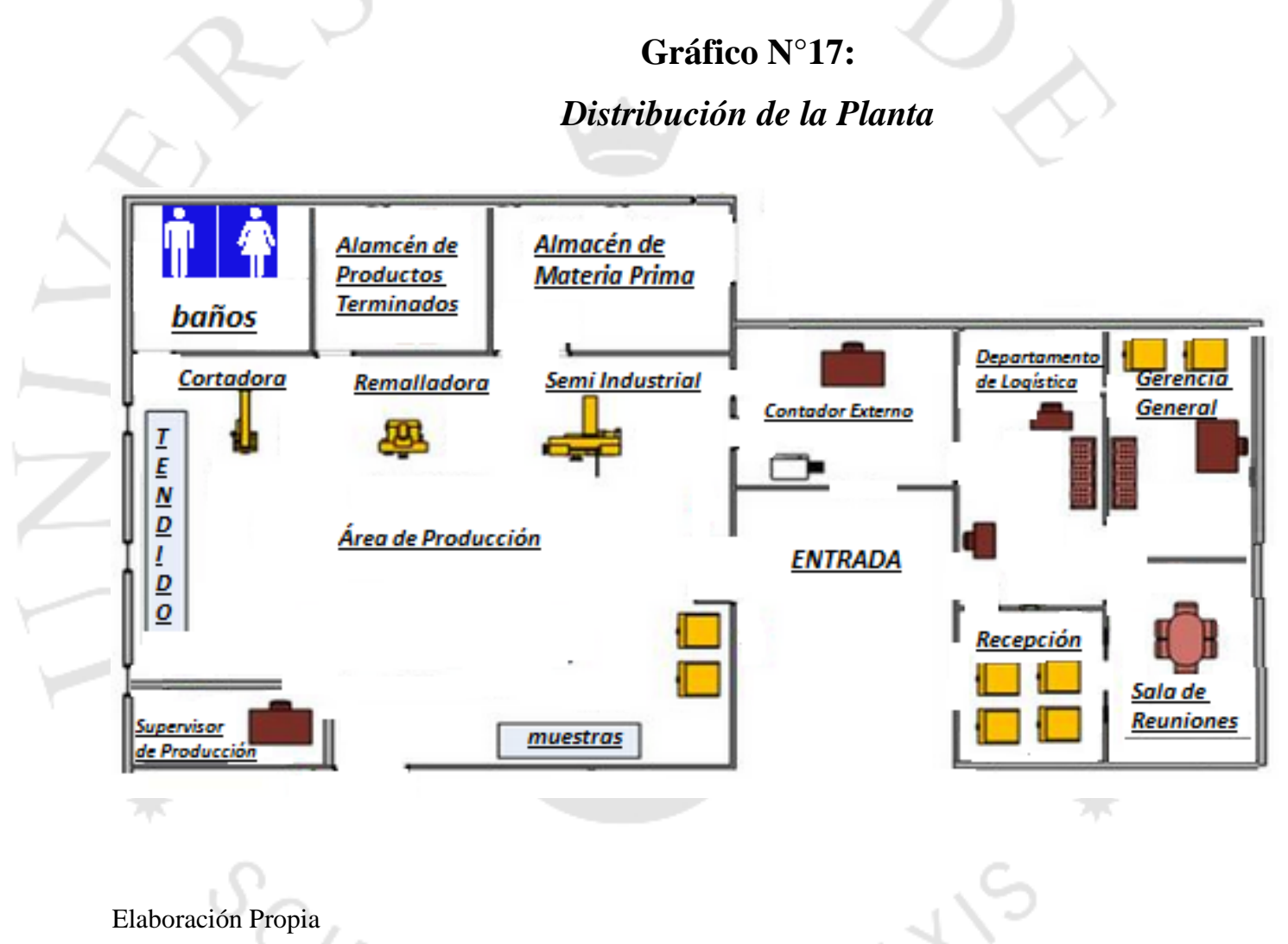

\section{4.- Localización, maquinarias, equipos y mobiliario}

Con respecto a la macro localización se tiene que definir de qué provincia o parte del Perú se traerán los insumos. En este caso, se tendrá un proveedor fijo el cual es la empresa Bergman Rivera S.A.C. Con respeto a la micro localización existirán diversos factores por los cuales se escogerá el distrito en el que tendrá lugar la empresa. 


\subsubsection{Localización}

\section{a) Macro localización:}

El proveedor que extraerá la materia prima lo hará desde la ciudad de Cañete; sin embargo, hay otras ciudades en las cuales existe esta planta, por lo que se analizará por qué se eligió esta ciudad. Para determinar la macro localización se utilizará el método "cualitativo de puntos", para el cual se valorizan los factores de acuerdo a las escalas mostradas en el Cuadro $\mathrm{N}^{\circ} 54$, las cuales van del 1 (siendo la peor) hasta la 4 (la mejor).

El proveedor Bergman tiene sus plantaciones en Cañete y la competencia en Chincha. Según "La Guía del exportador de Algodón Orgánico", dado por el Centro de Comercio Internacional (CCI, 2015), los factores más importantes para realizar un buen negocio de cultivo del algodón orgánico son la disponibilidad de materia prima que traerá consigo las plantaciones y el rendimiento que dará el terreno. El peso entre los dos debe llegar a 1 , por ende se le ha ofrecido un $60 \%$ de preferencia a la disponibilidad de materia prima ya que es la principal fuente económica que llevará para el proyecto. No se le debe dar mayor puntaje a este factor puesto que en la guía de la CCI, indican que el rendimiento del terreno no puede superar el $50 \%$. El puntaje dado para la ciudad de Cañete es la mejor en los dos aspectos. Sin embargo, la diferencia se da en el rendimiento del terreno en Chincha, puesto que en ocasiones los ríos que colindan con los terreros tienen químicos y las tierras son afectadas por estos.

Cuadro N'54:

Escalas

\begin{tabular}{|c|c|}
\hline Escala & \\
\hline Muy Malo & 1 \\
\hline Malo & 2 \\
\hline Bueno & 3 \\
\hline Muy Bueno & 4 \\
\hline
\end{tabular}


Cuadro $\mathbf{N}^{\circ} 55$ :

Criterios para la Macro Localización

\begin{tabular}{llllll}
\hline Factor & Peso & $\begin{array}{l}\text { Cañete } \\
\text { Calificación }\end{array}$ & Total & $\begin{array}{l}\text { Chincha } \\
\text { Calificación }\end{array}$ & Total \\
\hline $\begin{array}{l}\text { 1.- Disponibilidad de } \\
\begin{array}{l}\text { Materia Prima } \\
\text { 2.- Rendimiento } \\
\text { terreno }\end{array}\end{array}$ & 0.60 & 4 & 2.4 & 4 & 2.4 \\
Total & 0.40 & 4 & 1.6 & 2 & 0.8 \\
\hline
\end{tabular}

Elaboración Propia

De acuerdo a la puntuación obtenida en el Cuadro $\mathrm{N}^{\circ} 55$, se tiene los siguientes resultados:

- Disponibilidad de materia prima: El algodón orgánico se extrae de la ciudad de Cañete, considerada la principal zona productiva por su ambiente caluroso y su terreno llano. Por ende, sus cultivos se dan todo el año.

- Rendimiento del terreno: Se obtienen aproximadamente diez (10) plantas por metro lineal, lo que significa aproximadamente unas 100000 plantaciones. Por otro lado, el terreno de Cañete no presentan ríos en sus alrededores, lo que hace que el agua no pueda ser absorbida, pues esta cuenta con diversos químicos que afectan las plantaciones.

b) Micro localización

\section{Cuadro $\mathbf{N}^{\circ} 56$ :}

Criterios para la Micro localización

\begin{tabular}{|c|c|c|c|c|c|c|c|}
\hline \multirow[b]{2}{*}{ Factor } & & \multicolumn{2}{|c|}{ Los Olivos } & \multicolumn{2}{|c|}{ Callao } & \multicolumn{2}{|c|}{ San Martín } \\
\hline & Peso & $\begin{array}{l}\text { Calificaci } \\
\text { ón }\end{array}$ & Total & Calificación & Total & Calificación & Total \\
\hline $\begin{array}{l}\text { 1.- Infraestructura y } \\
\text { Seguridad }\end{array}$ & 0.30 & 4 & 1.2 & 1 & 0.30 & 3 & 0.9 \\
\hline 2.- Tamaño & 0.25 & 3 & 0.75 & 3 & 0.75 & 3 & 0.75 \\
\hline 3.- Costo & 0.45 & 4 & 1.8 & 4 & 1.8 & 2 & 0.9 \\
\hline Total & 1 & & .75 & & 2.85 & & 2.55 \\
\hline
\end{tabular}

Elaboración Propia 
Según Carlos Romero (2015), escritor del libro Técnicas de Gestión de Empresas, relata la existencia de diversos factores y estrategias de mercado para tener una óptima micro localización. En este caso, existirán tres factores y el más importante para la empresa en sus primeros años será la optimización de costos y la rentabilidad que deberá tener la empresa por lo que el costo del local de la empresa deberá ser el menor posible. A este se le ha otorgado una puntuación del $40 \%$ sobre los otros criterios y la calificación mayor (4) para Los Olivos al igual que para el Callao y de 2 para San Martín debido a que sus costos están más elevados. Por otro lado, la infraestructura y la seguridad cuentan con un puntaje más bajo; no obstante, este factor es muy importante para posicionar el local de la empresa. Si se tiene una buena infraestructura no será necesario invertir más. De otro lado, la seguridad es muy importante para que el personal de la empresa pueda trabajar con tranquilidad. A este factor, se le ha dado una puntuación de 30\% con la mejor calificación (4) para Los Olivos, (3) para San Martín y (1) para el Callao por estar declarado en estado de emergencia. Por último, está el factor de tamaño del local, el cual influye en la estructura que tendrá la distribución de la planta. A este factor se le dio un puntaje de $25 \%$ y un peso igualitario a los tres locales ya que cuando se buscaban los tamaños ofrecidos de todos eran iguales.

La oficina a elegir estará ubicada en el distrito de Los Olivos (mayor puntaje con 3.75), puesto que está dentro de Lima Metropolitana y paga menos impuestos. Además, el costo es más económico y presenta una mayor seguridad. El local escogido se encuentra entre la Av. Huandoy y la Av. 2 de octubre (altura del ovalo de infantas, de la panamericana norte). Este local es céntrico, por lo que existe mayor seguridad con la presencia de efectivos policiales. El área correspondiente es de 120 metros, el cual cuenta con dos cuartos de servicios higiénicos y un amplio lugar para poner la 
maquinaria que se adquirirá. El precio del alquiler pactado con la Señora Carmen, propietaria del inmueble, se ha establecido en US\$D 900 mensuales a tratar.

\section{Local a Alquilar}
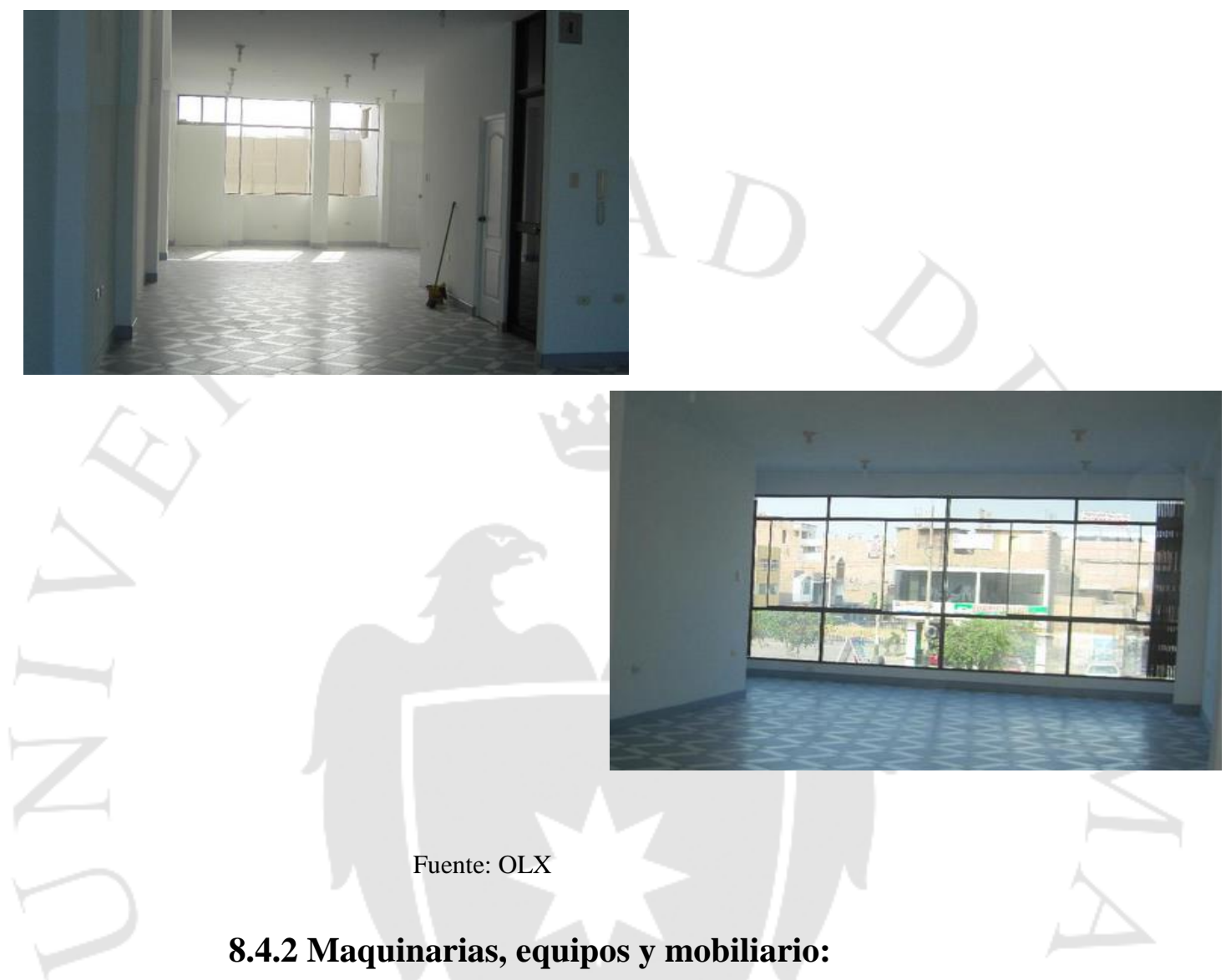

8.4.2 Maquinarias, equipos y mobiliario:

En el cuadro $\mathrm{N}^{\circ} 57$, mostrado a continuación, han sido identificadas maquinarias usadas, en buen estado y tecnológicamente eficientes, que es lo que la empresa requiere.

Además de los equipos mobiliarios que necesita para su funcionamiento. 


\section{Cuadro №57:}

\section{Maquinarias y Mobiliario}

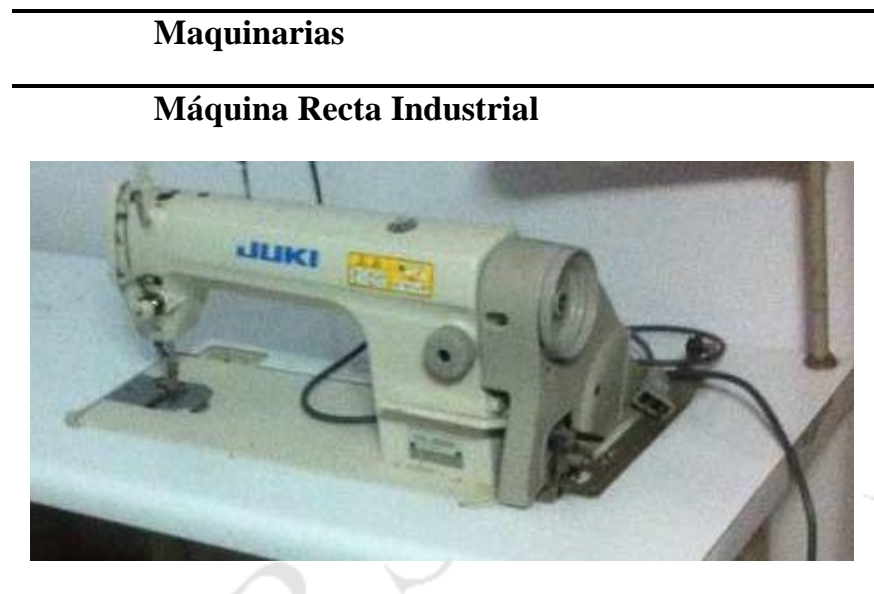

Máquina de coser Semi Industrial

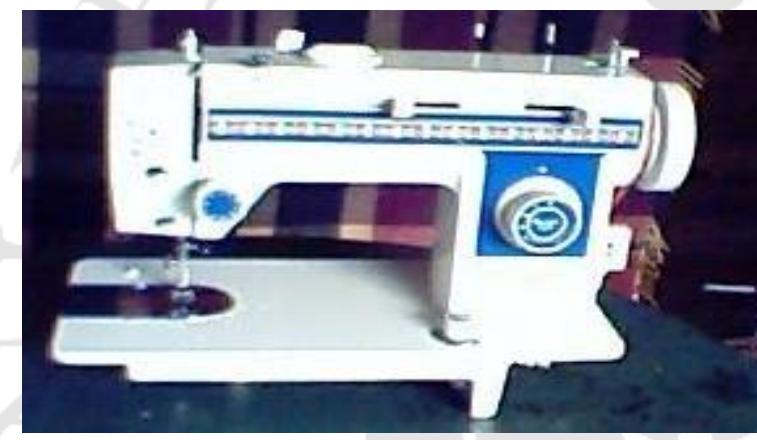

Máquina Cortadora

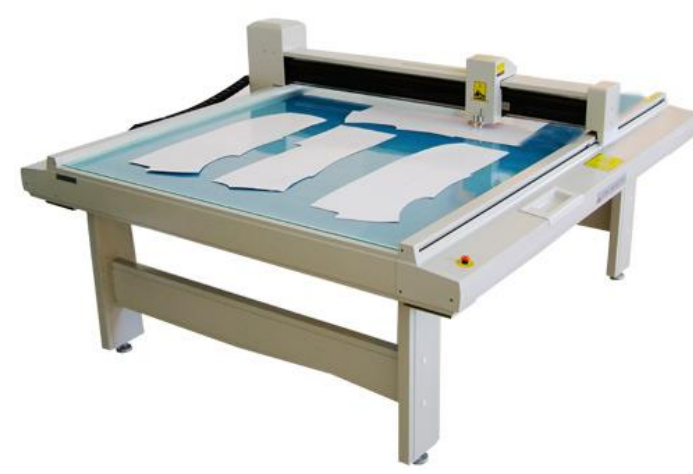

Descripción

- Marca: JUKI

- Industrial

- Precio: S/.750

- Compra: Vía mercado Libre

- Cantidad: 1 unidad

- Maquinaria usada

- Total a invertir: US\$259.52

- Marca: Cruzmaq.

- Semi industrial

- Precio unitario: S/.630

- Compra vía mercado libre

- Cantidad: 3 unidades

- Maquinaria usada

- Total a invertir: US\$653

- Marca: JUKON

- Precio unitario: S/.900

- Compra vía mercado libre

- Cantidad: 1 unidad

- Maquinaria usada

- $\quad$ Total a invertir: US\$311.42 

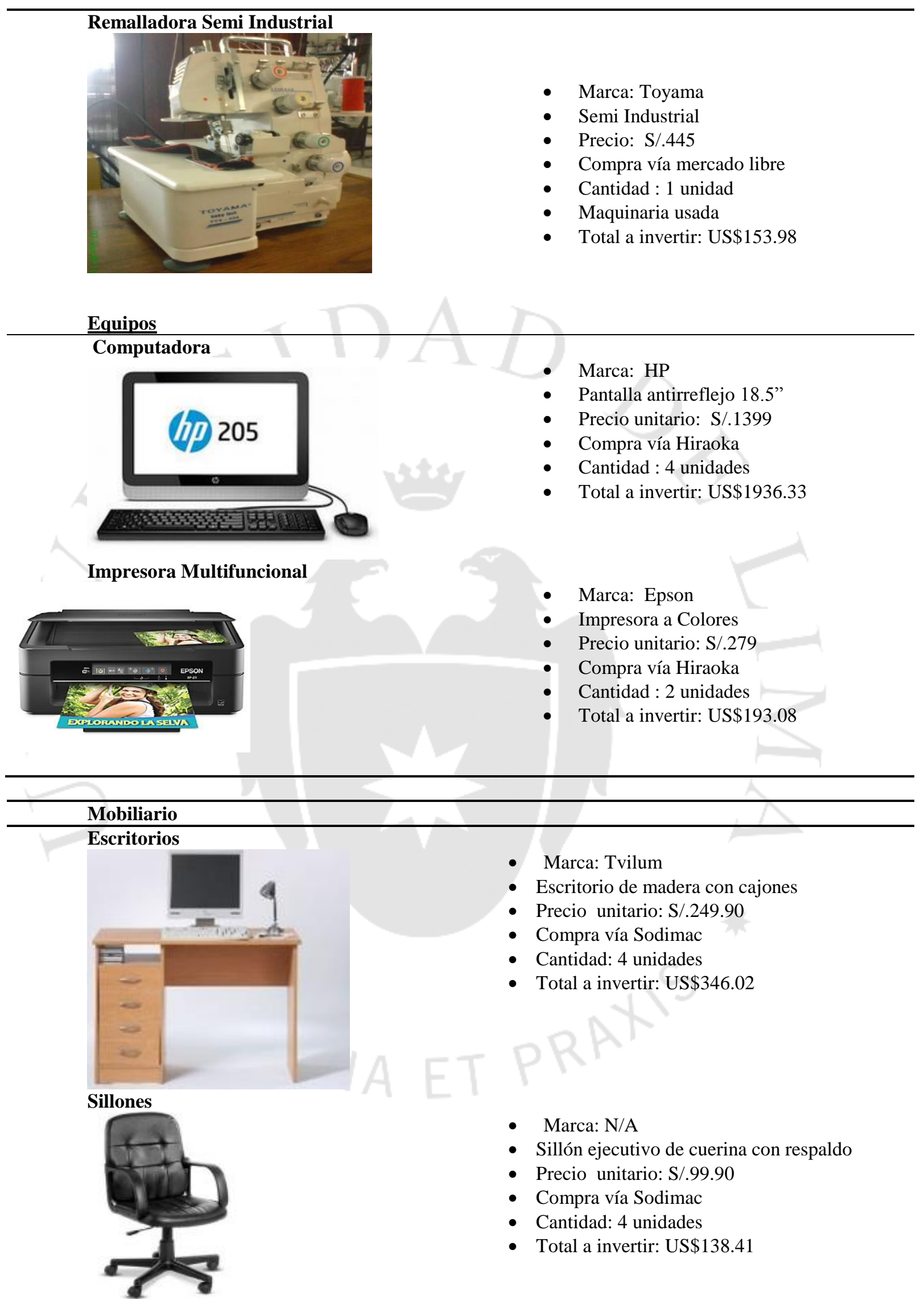

- Marca: Tvilum

- Escritorio de madera con cajones

- Precio unitario: S/.249.90

- Compra vía Sodimac

- Cantidad: 4 unidades

- Total a invertir: US\$346.02

- Marca: N/A

- Sillón ejecutivo de cuerina con respaldo

- Precio unitario: S/.99.90

- Compra vía Sodimac

- Cantidad: 4 unidades

- Total a invertir: US\$138.41 


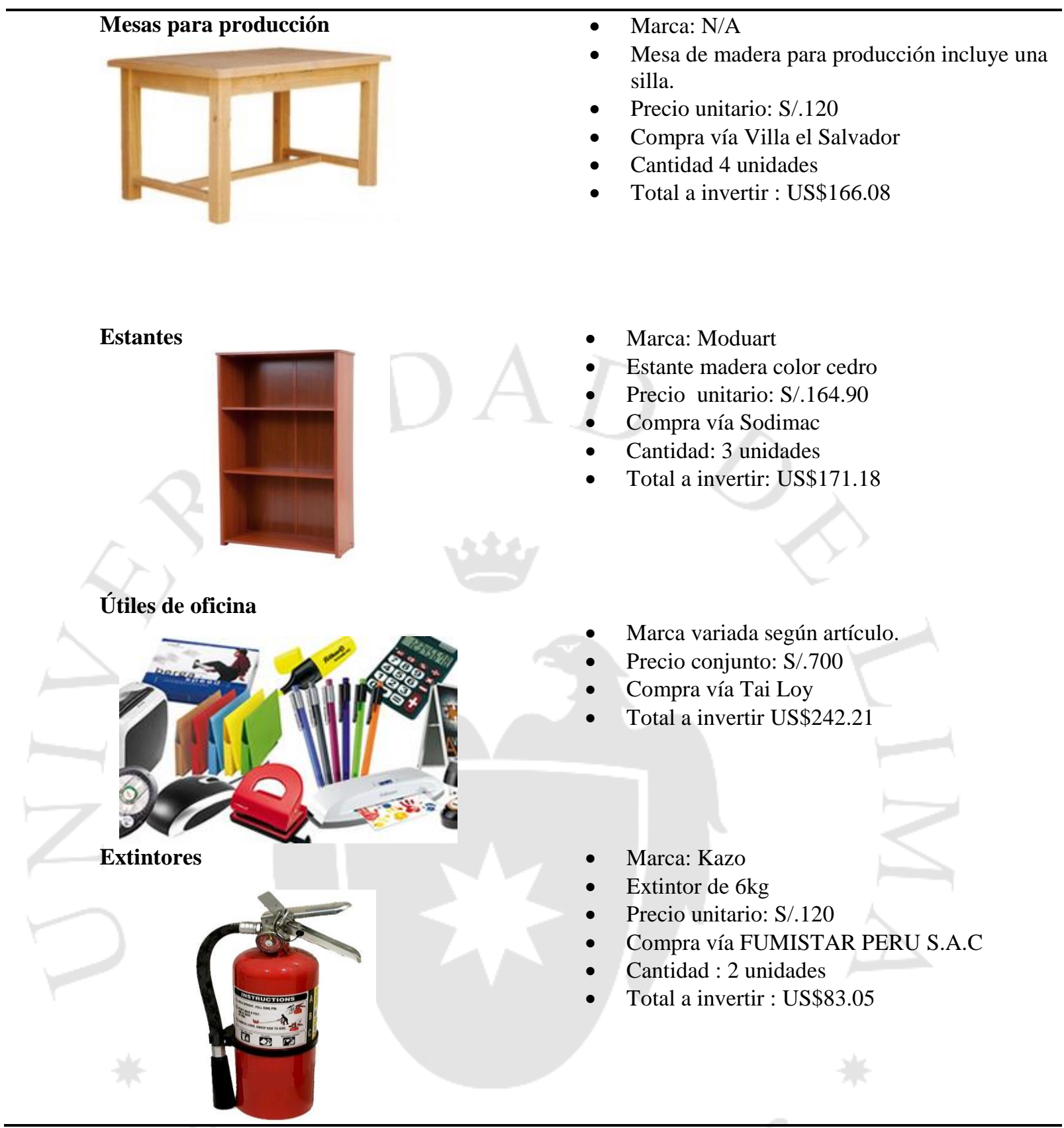

Elaboración Propia

\section{5.- Diagrama de flujo del proceso de producción y tecnología}

La obtención del algodón orgánico la realizará una empresa peruana llamada Bergman

Rivera S.A.C la cual se encargará de todo el proceso productivo. Sin embargo, la empresa se tiene que abastecer de telas orgánicas, hilos orgánicos, etiquetas, bolsas de yute, y el embalaje por otros proveedores. 
Según un estudio especializado sobre la Producción Orgánica de Algodón, realizado por Naturland (2000), la flor del algodón es de autofecundación, por lo que el proceso de producción es un poco más simple. Para que la planta de algodón tenga un proceso de cultivo óptimo es esencial cultivarlas en un lugar con temperaturas altas, entre $26^{\circ}$ y $28^{\circ} \mathrm{C}$, ya que estas no soportan el frío ni la sombra. El PH del suelo también influye y debe estar entre $6^{\circ}$ y $8^{\circ}$ para que así se pueda tener una mayor resistencia a la sequedad. Por otro lado, este debe ser plano y estar cubierto de maleza.

Cuando todas las condiciones mencionadas anteriormente estén dadas, se comenzará con el proceso de cultivo, el cual la siembra de estas semillas debe darse aproximadamente en temperaturas de unos $35^{\circ} \mathrm{C}$, a una profundidad no mayor a los 5 $\mathrm{cm}$ y con una distancia promedio de 50 a $70 \mathrm{~cm}$. A la tierra de cultivo se le deben de poner nutrientes como leguminosas para que exista más nitrógeno en las plantas.

Según nos relata el estudio mencionado, cuando el cultivo se da de forma orgánica se debe promover una protección de las plantas y se deben tener ciertas medidas preventivas como:

1) Configuración de la rotación de cultivos: Debe tener una participación máxima de un tercio en la rotación de esta. Es decir, no debe existir otra plantación en el mismo terreno.

2) Cultivo mezclado con plantas que tienen un efecto repulsivo: no deben de cultivarse junto con cebollas, ajo u ají debido a que esos cultivos atraen gusanos para el algodón, moscas, etc. 
3) Cultivo de plantas atrapadoras: Una medida de prevención óptima es tener a las plantas atrapadoras puesto que estas hacen que las plagas y los gusanos del algodón se mantengan alejados.

4) Elección de variedades: no se deben poner variedades de plantas libres de Gossypol, los cuales se forman en las plantas algodoneras, dado que hacen que los insectos no tengan ganas de comerlas.

5) Plantaciones periféricas: Se deben tener de dos a tres hileras de árboles.

\subsubsection{Descripción de los principales procesos del proyecto}

a) Cotización y aprobación del pedido (prendas): La empresa y el cliente deben especificar los términos de venta, precio, modo de envío, las fechas y requerimientos detallados del producto. Cuando las dos partes estén de acuerdo sobre estos términos se envía una proforma de venta la cual origina que la orden de compra se aprobada.

b) Compra y selección de tela, según especificaciones: Según las especificaciones recibidas por el cliente (color y diseño), se hace el pedido y la compra de las telas e hilos desde la compañía Bergman Rivera S.A.C.

c) Realización de las confecciones: La empresa confeccionará las prendas con un nivel de alta calidad, con las telas e hilos obtenidos.

d) Confección según los requerimientos de la Orden de Compra: Las confecciones comienzan con el corte especializado, según medidas y moldes para cada 
prenda. Luego, los operadores comienzan a unir estas piezas y coser las etiquetas en el cuello de la prenda de forma cuidadosa.

e) Inspección y Auditoria de prendas terminadas: Un supervisor especialista en esta materia revisará de forma general el proceso que siguió la elaboración de las prendas para luego analizar de forma detallada cada una y así se puedan exportar. Las prendas que tengan fallas serán enviadas a un área para que se vuelvan a hacer o sean vendidas en el mercado local detallando que son falladas.

f) Ejecución de acabados. (doblado y puesto en bolsas de yute): Cuando el supervisor haya dado su aprobación, las prendas son dobladas y puestas de forma unitaria en su respectiva bolsa de yute.

g) Empaquetado en cajas: Cada ochenta (80) prendas embolsadas serán empaquetadas en las cajas de cartón corrugadas.

h) Elaboración de documentos para exportación hacia Bogotá: El primer documento a realizar es el packing list en el cual se pone la información del comprador, vendedor y del producto, seguido de la factura comercial. Por otro lado, necesitamos de un Agente de Aduanas para que la exportación sea óptima.

i) Distribución a Almacén de despacho aduanero: Las cajas donde se encuentran las prendas ya confeccionadas de algodón orgánicas para bebés serán trasladadas hacia el almacén de despacho mediante un camión especializado; es 
decir, de acuerdo a la cantidad de cajas a exportar para que se pueda establecer un cubicaje correcto.

En el Gráfico $\mathrm{N}^{\circ} 18$, según el diagrama de operaciones de proceso, se podrá observar el resumen del Flujo de proceso de producción y tecnología. La terminología para este diagrama son que los círculos representan a las operaciones que se darán (ej. Cambios todo lo que influya en los bodies) y los cuadrados se refieren a las inspecciones (verificaciones de cómo va el producto.)

\section{Gráfico $\mathbf{N}^{\circ}$ 18:}

\section{Diagrama de flujo del proceso de producción y tecnología}

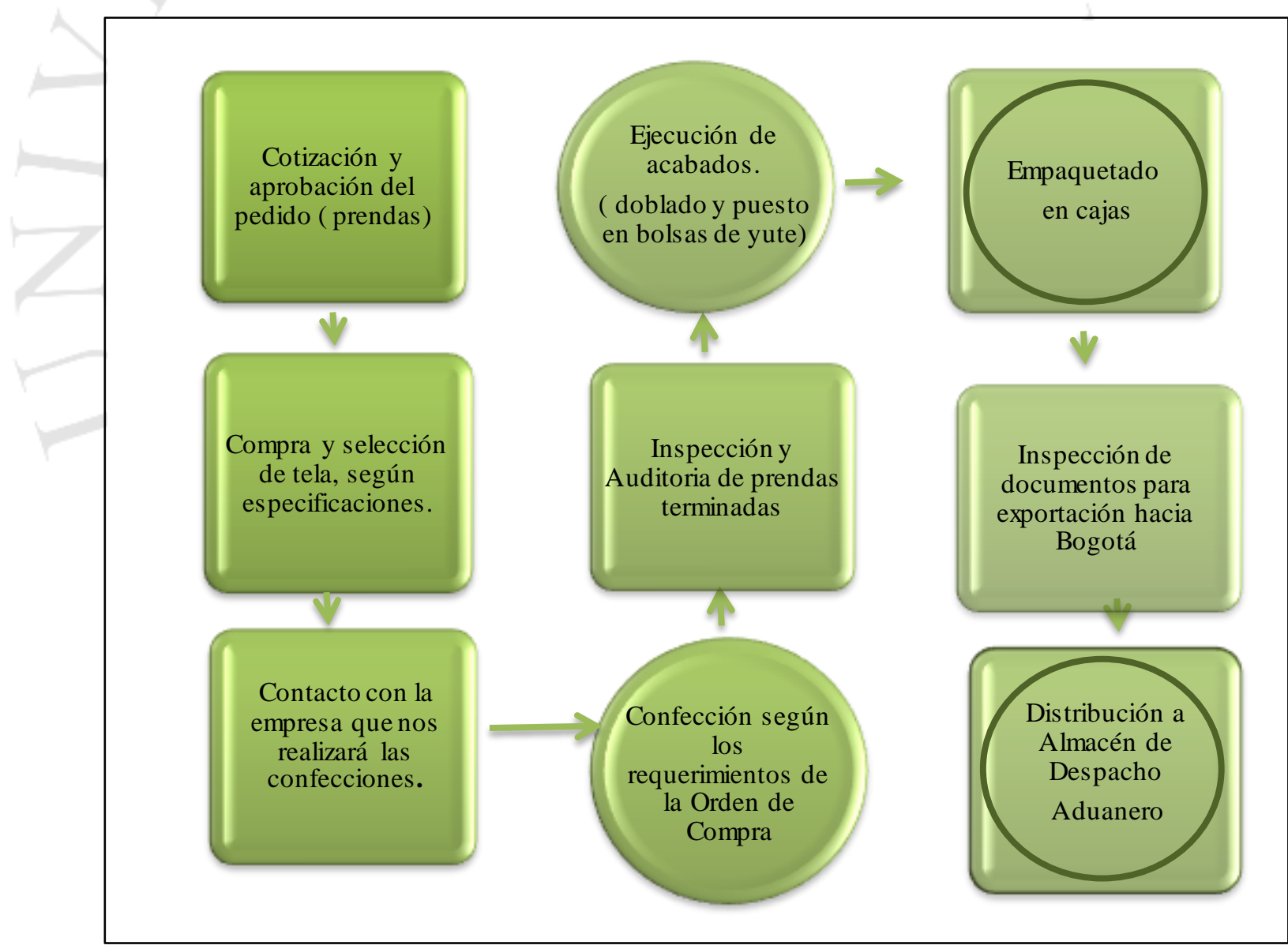

Elaboración Propia 


\section{6.- Descripción de productos, presentaciones, empaque, patentes,}

certificaciones, autorizaciones sanitarias, etc.

Para la presentación de estas prendas, cada una debe estar en un empaque a su talla. Se presentarán en bolsas de yute (empaque) porque son biodegradables y presentan baja conductividad térmica de humedad lo que hará que las prendas permanezcan intactas. Las tallas con las cuales se trabajará serán de $0-2 ; 2-4 ; 4-6 ; 6-8 ; 8$ a más meses. Los colores se darán en tonos pasteles (blanco, café y verde olivo) y el peso de estos será de $200 \mathrm{gr}$.

Como ya se describió en el punto 5.6 las certificaciones que se utilizarán para llevar a cabo esta empresa será la IMO para que controle la producción, proceso y comercialización de fibras ecológicas y productos textiles como lo son las prendas orgánicas. Además la certificación WHITE COTTON, la cual es una certificación que garantiza calidad, trato justo al trabajador y el respeto por la tierra. Estas dos certificaciones están incluidas en la venta del proveedor de la empresa, es decir, al momento de comprar las telas, estas tienen consigo dichas certificaciones, WHITE COTTON, IMO y comercio justo.

Los diseños de las prendas no serán patentados, es decir, no se usarán diseños de otras personas. Los dos diseñadores de la empresa serán los encargados de llevar un estudio de seguimiento con respecto a sus creaciones para que no existan problemas sobre las prendas y no se incurran en gastos extras ( ej. Por pago de multas). 


\section{7. - Programa de Producción: utilización de capacidad instalada propia o}

de terceros, control de producción, asignación de recursos, control de reproceso, tiempos muertos y devoluciones por defecto.

En el siguiente cuadro $\mathrm{N}^{\circ} 58$, se detallará la capacidad instalada y utilizada por parte de la empresa. Se realizarán seis prendas por hora, según los conocimientos de una empresa textil. Las horas que los tres trabajadores tendrán que laborar serán de ocho horas por día.

En la empresa existirán tres máquinas y los trabajadores que estarán haciendo uso de ellas serán capacitados para laborar de forma óptima. En cada máquina se hace una parte de la prenda, por lo que las tres personas confeccionarán una prenda en 10 minutos. En una hora se harán seis prendas y en un turno de ocho horas se elaboran 48 por persona. La producción diaria será de 144 prendas al día y al mes de 3600 prendas en total.

\section{Cuadro $\mathbf{N}^{\circ} 58$ :}

Capacidad de Almacenamiento y procesamiento

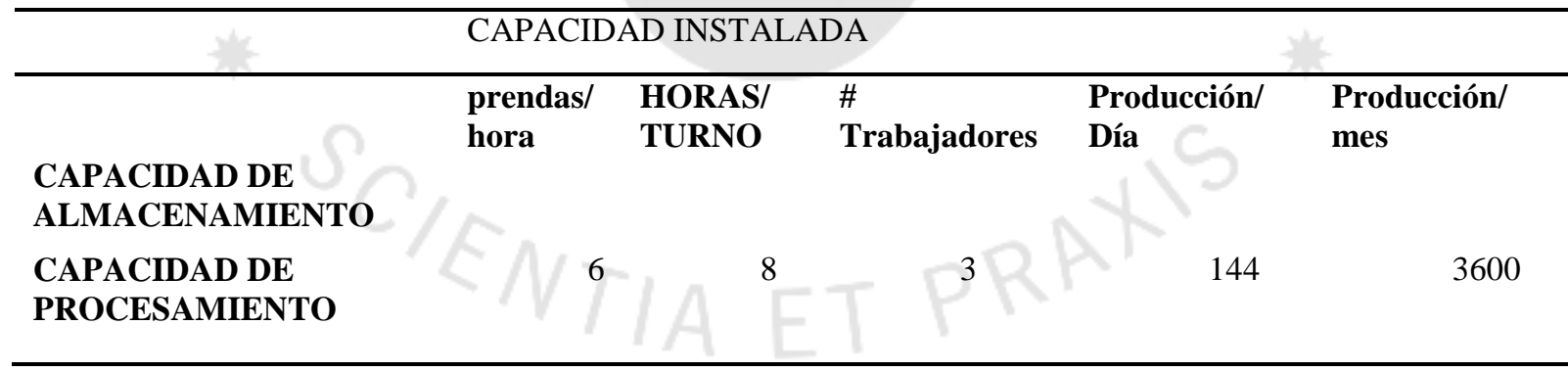

Elaboración Propia

Con respecto a la capacidad de procesamiento, según el cuadro $\mathrm{N}^{\circ} 59$, para el primer año (2016) la capacidad utilizada hace referencia a la producción de prendas que se darán en los meses correspondientes (utilización de los recursos) y la capacidad 
instalada a la producción por mes que los trabajadores harán. En consecuencia, la capacidad por utilizar en noviembre es del $20 \%$, mientras que en otros meses varía según la producción dada.

Cuadro $\mathbf{N}^{\circ}$ 59:

Capacidad de Procesamiento por utilizar y utilizada (2016)

\begin{tabular}{|c|c|c|c|c|c|c|c|c|c|c|c|c|c|}
\hline $\begin{array}{l}\text { Capacidad de } \\
\text { Procesamiento } \\
\text { en unidades } \\
\end{array}$ & 1 & 2 & 3 & 4 & 5 & 6 & 7 & 8 & 9 & 10 & 11 & 12 & TOTAL \\
\hline $\begin{array}{l}\text { Capacidad } \\
\text { Utilizada }\end{array}$ & 1,440 & 1,440 & 0 & 1,440 & 1,440 & 0 & 1,440 & 1,440 & 0 & 0 & 2,880 & 0 & 11,520 \\
\hline $\begin{array}{l}\text { Capacidad } \\
\text { Instalada ( } 8 \\
\text { horas x } 25 \text { días } \\
\text { x 48prendas) }\end{array}$ & 3,600 & 3,600 & 3,600 & 3,600 & 3,600 & 3,600 & 3,600 & 3,600 & 3,600 & 3,600 & 3,600 & 3,600 & 43,200 \\
\hline $\begin{array}{l}\text { Capacidad por } \\
\text { utilizar }\end{array}$ & 2,160 & 2,160 & 3,600 & 2,160 & 2,160 & 3,600 & 2,160 & 2,160 & 3,600 & 3,600 & 720 & 3,600 & 31,680 \\
\hline $\begin{array}{l}\text { Capacidad } \\
\text { por utilizar \% }\end{array}$ & $60 \%$ & $60 \%$ & $100 \%$ & $60 \%$ & $60 \%$ & $100 \%$ & $60 \%$ & $60 \%$ & $100 \%$ & $100 \%$ & $20 \%$ & $100 \%$ & $73 \%$ \\
\hline
\end{tabular}

\section{8.- Sistema de control de procesos, calidad y costos operativos}

Existirá una Supervisora de Producción, la cual estará encargada de llevar a cabo el control de procesos, calidad y costos operativos para los bodies de algodón orgánico. Estos comenzarán con la formulación del presupuesto a utilizar en la realización de las prendas utilizando sus propios criterios, técnicas y experiencia. Por último, se evaluarán los resultados para comenzar con la elaboración del producto a ser entregado al consumidor final. 
El control que se establecerá para que no ocurran pérdidas, tanto de materiales como del producto terminado, será la asignación de una persona encargada en verificar los procesos brindados, pues si un operario se cofunde en la elaboración de la prenda los demás operarios son perjudicados. La tarea de este encargado será de llevar una plantilla especial (guía) y hacer un Chek list acerca de las funciones que están trazando los operarios. Esto se dará cada tres horas.

\section{9.- Logística, gestión de existencias, compras, logística de entrada y salida,}

\section{distribución de productos.}

Teco Caricias S.A.C realizará la compra de insumos como lo son los hilos orgánicos y la tela para los bodies desde que el cliente emita una orden de compra. Las ventas se realizarán los primeros meses de producción para luego cada dos meses seguir con esta cadena. Con respecto a los envases y embalajes, se comprarán en el mes enero y julio. Así, cada seis meses en el almacén irán estos productos ya que son importados y es difícil adquirirlos de forma apresurada.

El mismo responsable de producción se encargará de verificar las tareas que realicen los operarios tanto como las compras que se den. Dicho encargado irá con el Jefe de la empresa a seleccionar las compras, tanto insumos como envases y embalaje y su función será de verificar, mediante un check list, los cumplimientos tanto de certificaciones de las telas como el stock que se tendrá para la elaboración de los bodies y el envase para estos. 


\subsection{0.- Gestión de mantenimiento correctivo y preventivo, seguridad y salud}

en el trabajo.

Se dará un mantenimiento preventivo antes que correctivo en la empresa, el cual servirá para corregir el estado en el que se encuentren los equipos o maquinarias. Por ende, cada seis meses, según la máquina, se dará un mantenimiento para que la vida útil de esta sea más duradera y no generen costos adicionales si se llega a malograr. La máquina bordadora tendrá un mantenimiento cada dos meses; la máquina de recta industrial, la cortadora y la máquina de coser semi industrial contarán con un mantenimiento cada cinco meses.

\subsection{1.- Descripción de las principales herramientas de control}

Una de las principales herramientas de control será la del programa de pedidos. Estos deben tener un tiempo de entrega óptimo. Desde que se genera el pedido deberá pasar como máximo sesenta (60) días para que puedan ser entregadas al consumidor final (desde que se compran los insumos hasta que se entrega al consumidor final).

Por otro lado, se tendrá un indicador de evaluación de eficacia hacia los clientes con los pedidos para tener conocimiento sobre la satisfacción del consumidor final o de los clientes con los productos. Con este indicador se apreciará si la empresa está yendo bien o necesita refuerzos en los trabajos realizados en ella. Por último, posteriormente a que la empresa realice sus ventas, se tendrán índices de rentabilidad y gestión para saber si se están generando utilidades y tener un óptimo rendimiento sobre los recursos invertidos, además de evaluar las consecuencias de las decisiones tomadas en ellas sobre los activos, inventarios y pagos. 


\subsection{2.- Principales factores claves de éxito a controlar}

La empresa necesitará tres tipos de máquinas para realizar el presente proyecto. Estos son la recta industrial, remalladora y cortadora. Los insumos para estas prendas se van a adquirir mediante una política de compras donde el supervisor de producción tendrá que ir a la fábrica de Bergman y asegurarse de que todos los materiales son de calidad. Una vez que se tienen los materiales, los colaboradores comienzan a laborar. En cada máquina estará un colaborador y realizarán su trabajo en cadena. Es decir, los tres juntos harán una prenda en diez minutos. En una hora se hacen seis y en un turno de ocho horas se elaboran 48 prendas. La producción diaria será de 144 prendas al día y al mes de 3600 prendas. 


\section{CAPITULO IX: PLAN LOGÍSTICO}

\section{1.- Manejo de mercancía}

\subsection{1.- Empaque}

El envase primario serán las bolsas de yute: Esto se dará para que al momento del envío no existan espacios vacíos lo que sí ocurriría al utilizarse cajas para cada una de las prendas. Así, el espacio será utilizado al 100\%. Dentro de la caja (embalaje) habrá ochenta (80) prendas con un peso de 200 gramos cada una.

Las dimensiones de estas bolsas son de 20 x $20 \mathrm{~cm}$ aproximadamente y sus propiedades que destacan son: envase flexible, no daña las prendas y son fabricados con fibras naturales.
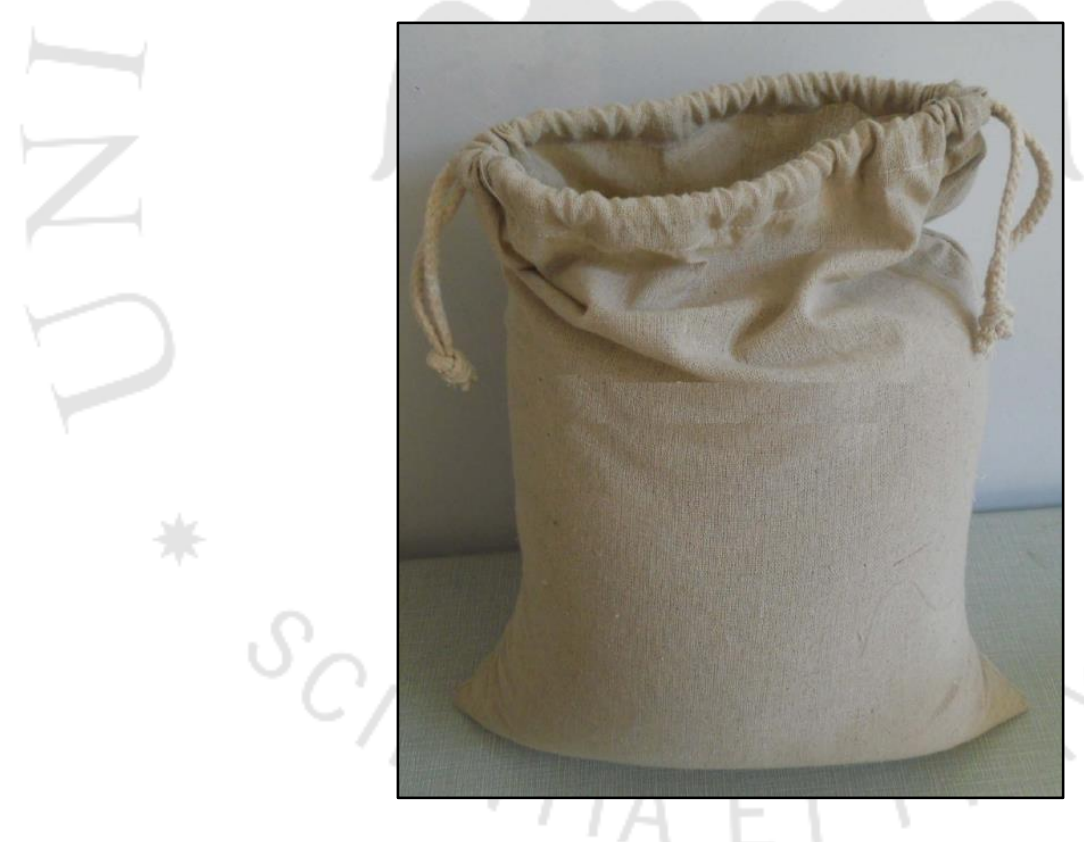

\subsection{2.- Embalaje}

Como ya se mencionó, se usarán cajas de cartón de 50 x 40 x $40 \mathrm{~cm}$. Estas cajas tienen una capacidad aproximada de ochenta (80) prendas para la exportación. El peso de la caja será de $0.2 \mathrm{~kg}$ y el peso neto de $16.2 \mathrm{~kg}$ cada caja. Con respecto al precio, se cotizó a US\$1.5 por caja. El proveedor principal será de Shenzhen Zhongtaija Trading Co., 
Ltd., proveniente de China. Se eligió a este proveedor por sus bajos costos, por su ligereza y por la facilidad con la que cuenta para las importaciones de este producto.

Estas mismas características se escogieron debido a que el transporte será vía aérea y su manipulación será más fácil. Por el contrario, si se escogiera el transporte marítimo, estas cajas sufrirían por la humedad que absorberían y repercutirían directamente al envase primario (bolsas) y dañaría las prendas.

\subsubsection{1.- Pallet}

Las prendas serán colocadas en pallets, las cuales están reflejadas en el Cuadro $\mathrm{N}^{\circ} 60$, donde se especifica que en un pallet de $20^{\prime}$ pueden entrar seis cajas en el piso y tres filas; es decir, un total de cajas de dieciocho.

La ventaja de usar pallets en un envío aéreo es que se ahorra en el costo, en el tiempo tanto de embarque como de tránsito. Existen distintos tipos de pallets aéreos, sin embargo, Teco Caricias S.AC, usará los pallets estándar, los cuales pueden tener un peso máximo de $6804 \mathrm{~kg}$.

Cuadro $\mathbf{N}^{\circ}$ 60:

\section{Pallets}

\begin{tabular}{ll}
\hline \multicolumn{1}{c}{ 1 PALLET } \\
\hline Cajas en el piso & 6 \\
Filas & 3 \\
Total cajas & 18 \\
Total de prendas & 1,440 \\
Kilos & 292 \\
\hline
\end{tabular}

Elaboración Propia 


\subsubsection{2.- Contenedores}

Existen tres tipos de contenedores para el transporte aéreo, los cuales son para carga en general, para animales vivos e isotérmicos. Como se aprecia en el Gráfico $\mathrm{N}^{\circ} 19$ se tomará uno de los contenedores para carga en general, de dimensiones 88 x 125 x 63" al ser uno de los más pequeños y encajaría con la carga a utilizar (prendas) las cuales tienen un peso liviano y no ocupan mucho espacio.

En el caso de la presente empresa, en un inicio (los primeros años a exportar), no se utilizarán contenedores debido a que el volumen no lo requiere, pero una vez que el volumen incremente, en el mediano y largo plazo, se procederá a utilizar como ya se mencionó el de carga general.

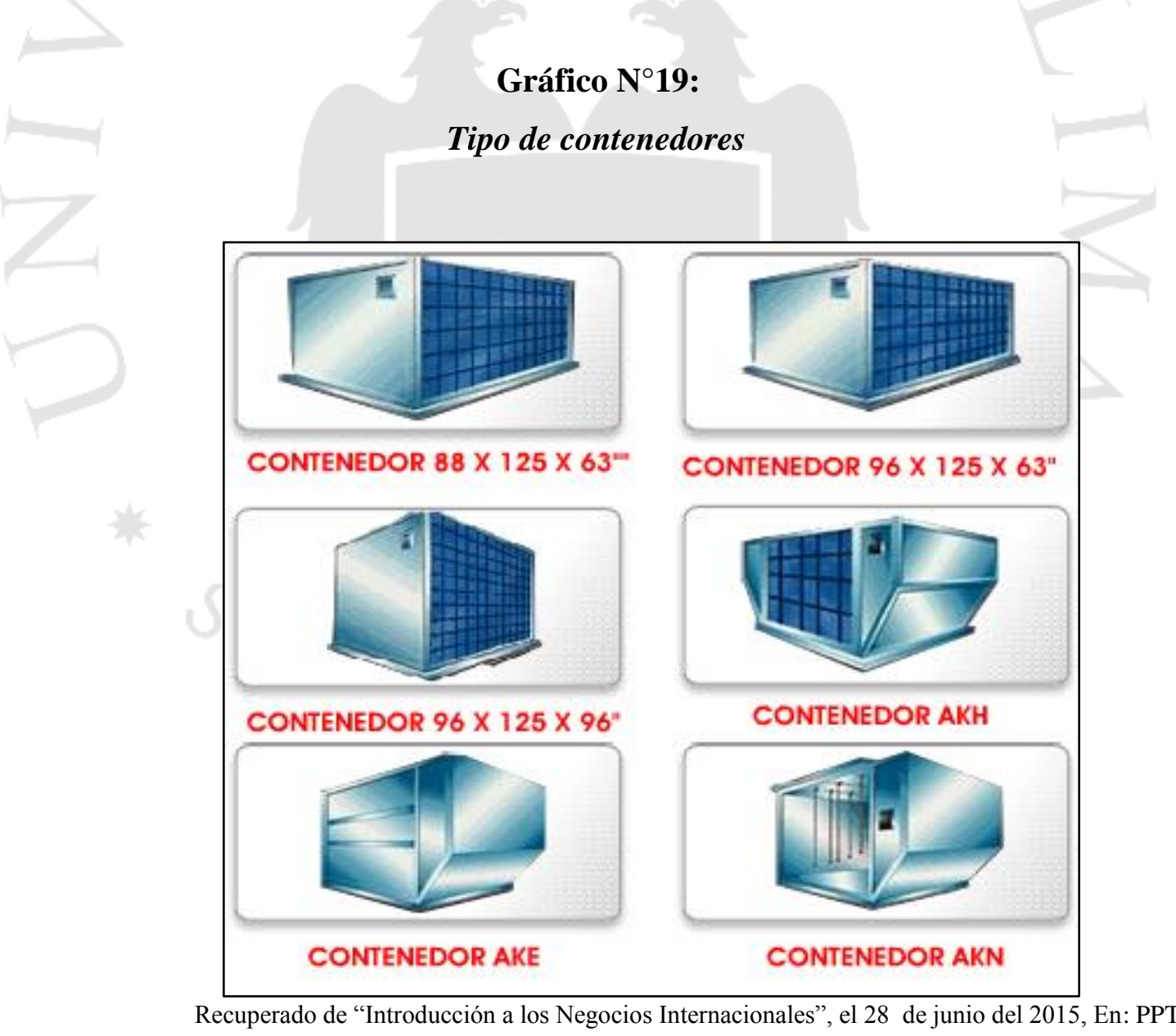

- Universidad de Lima, Profesora Anderson. 


\section{2.- Medio de transporte}

Los envíos por vía aérea hacia Bogotá, como se presenta en el gráfico $\mathrm{N}^{\circ} 20$, según Veritrade (2015), representan un 61\% debido a que es el medio de transporte más usual para la exportación de estas prendas, más seguro y existe mayor facilidad con respecto al tiempo y al manipuleo; por otro lado, se encuentra el transporte terrestre con un $38 \%$ seguido del marítimo, el cual representa un $1 \%$.

Se utilizarán diversas aerolíneas reconocidas para enviar este producto al mercado colombiano, las cuales son: AVIANCA, AEROVIAS DEL CONTINENTE AMERICANO S.A., y ABX AIR INC- SUCURSAL COLOMBIA

\section{Gráfico $\mathbf{N}^{\circ}$ 20:}

Tipo de transporte en Colombia - Bogotá (2015)

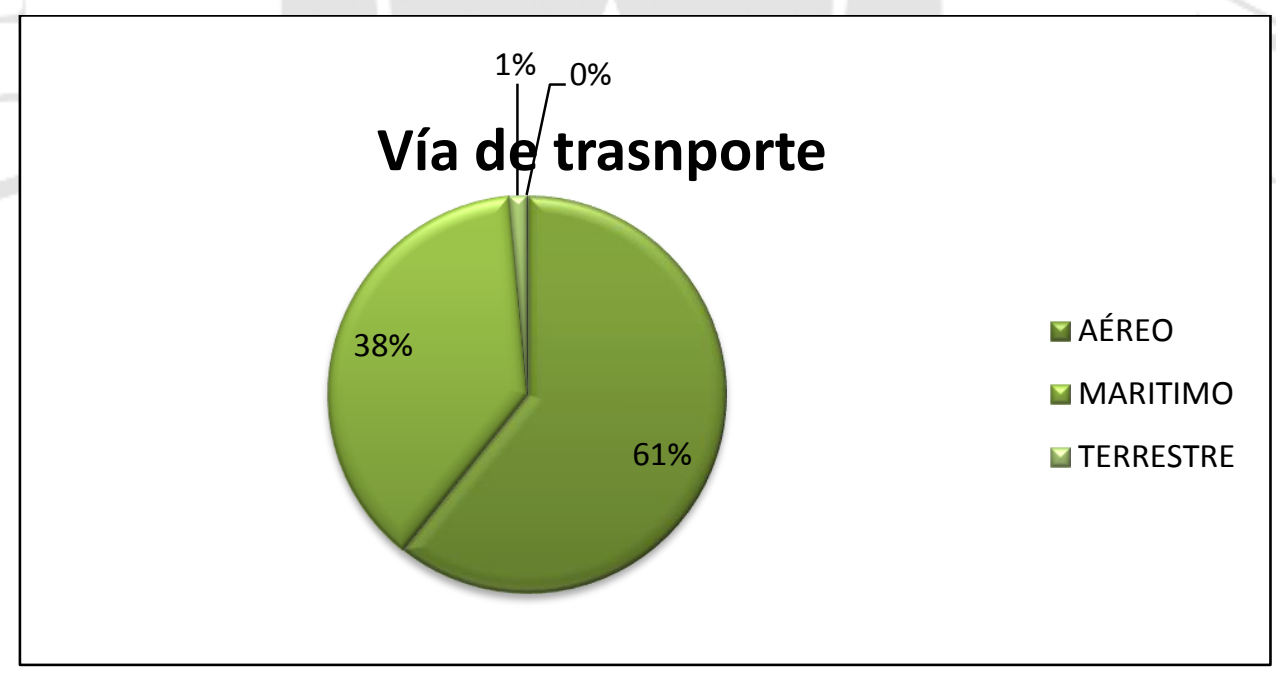

Fuente: VERITRADE

Elaboración Propia

Se escogió el medio de transporte aéreo frente a los otros porque es rápido, puede llegar a cualquier destino, es seguro y se le puede dar un seguimiento directo con respecto a la mercancía que lleva. Sin embargo, el costo es mayor (en este caso es más 
óptimo porque se traslada volúmenes bajos), y existen cierto tipo de restricciones en cuanto al transporte aéreo, por ejemplo, no aceptan un volumen alto de harina de pescado, animales, entre otros hacia diversos puertos y si la carga es muy pesada a veces es denegada.

Ahora, compararemos con los otros medios de transporte. El transporte Marítimo es el más usado, mucho más barato cuando se trata de volúmenes grandes, hay flexibilidad con respecto a las mercancías y es más directo; sin embargo, existe mucho peligro con respecto a robos, daños o pueden infiltrar sustancias peligrosas al producto. Con respecto al transporte terrestre, es igual de cotizado que el marítimo por su costo, no existen muchas restricciones, no obstante los productos agrícolas pueden ser dañados por la contaminación ambiental de hoy en día, no son tan seguros como el aéreo y el tiempo de llegada es mayor.

\section{3.- Agentes logísticos}

El Agente de carga internacional a escoger es Palacios y Asociados (Consorcio Logístico) el cual brinda servicios de Carga Internacional Aéreo, Marítimo, Terrestre y Multimodal. El seleccionado por esta empresa es el Aéreo ya que tiene costos más bajos y menos riesgo de que ocurra un accidente.

Se escogió a este agente porque se diferencia en cuanto el valor agregado que ellos generan en la cadena de suministros con estándares internacionales. Por otro lado, se hizo comparaciones con diversos operadores logísticos como Port Logistics, y AUSA, vía web y los precios eran muy elevados a comparación del escogido. Además, se escogió a Palacios y Asociados ya que este operador cuenta con un programa de 
responsabilidad social de ayuda a la comunidad cercana y apoyan a los trabajadores con escasos recursos económicos. Ellos cuentan con una política de Sistema integrado de Gestión y apoyarán a Teco Caricias S.A.C con la cotización de aerolíneas que estén al alcance de la empresa, dependiendo del volumen a exportar.

\section{4.- Tramitación aduanal}

Los documentos para la exportación definitiva serán los siguientes:

- Guía Aérea o Airway Bill.

- Factura de venta

- Declaración Aduanera de Mercancías

- Documento de Transporte

- Documento de seguro de la mercancía

Por otro lado, las marcas que necesitan este tipo de transporte son el nombre de la compañía aérea, el número de Airway Bill, el destino marcado con su código de tres letras y el número de unidades y embalaje a transportar.

\section{5.- Seguros internacionales}

Teco Caricias S.A.C contará con un seguro internacional de carga aérea por si surgen inconvenientes en el traslado, y será brindado por el operador logístico Palacios y Asociados, las cuales se incluirán en las tarifas del agente. Aunque la carga aérea no tiene muchos riesgos por lo mismo que tiene mayor frecuencia, cobertura y más celeridad en la entrega, esta mercancía contará con un seguro por si existiese 
específicamente daño en la manipulación, robo de las mismas o atraso en la entrega. Por tal motivo, el seguro elegido será de menor costo.

\section{6.- Trazabilidad}

Se utilizará la logística inversa para que se pueda evaluar mejor la trazabilidad con el fin de que el proceso sea óptimo. Se evaluará la cadena de producción de prendas de vestir minuciosamente desde que se emite la orden de compra hasta la entrega del producto final para verificar en el proceso los indicios que estos dejan, como se aprecia en el Cuadro $\mathrm{N}^{\circ} 61$.

\section{Gráfico $\mathbf{N}^{\circ}$ 21:}

Mapa de Procesos

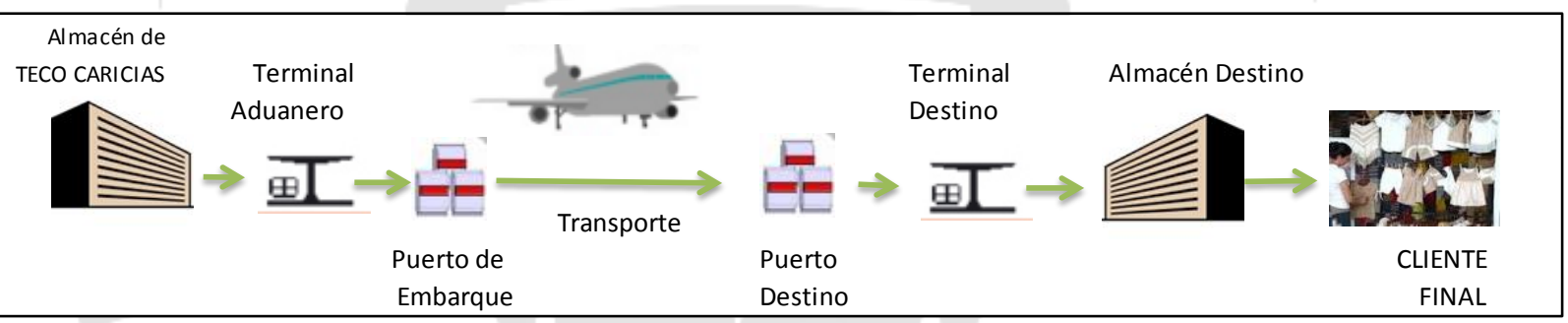

Elaboración Propia 


\section{CAPITULO X: GESTIÓN DE CALIDAD}

\section{1.- Política de calidad}

Los cinco ejes para la confección de una política de calidad son los siguientes:

- Cliente: Los ejecutivos de cuentas o dedicados a los temas del comercio deberán realizar una encuesta a final de calidad de cada servicio.

- Mercado: Se realizarán seguimientos continuos, cada dos meses, a las variables principales de las empresas competidores locales e internacionales como en sus precios y ofertas.

- Empresa: Toda contratación seguirán normas de calidad registradas para las certificaciones, las cuales se darán cada fin de mes.

- Dirección: Los gerentes, cada fin de mes, deberán reunirse con los integrantes de la empresa para ver si existe el compromiso tanto en la elaboración óptima de las prendas como en la gestión de la organización.

- Procesos: En las órdenes de compra los requisitos que solicitan los clientes y el proceso de pedidos que los conforman deben ser cumplidos al $100 \%$ para que así la empresa pueda ser reconocida. 


\section{2.- Análisis de las principales herramientas de control de calidad}

Las herramientas para asegurar la calidad de la empresa serán las siguientes:

\section{Cuadro $\mathbf{N}^{\circ}$ 61:}

Herramientas de Control de Calidad

\begin{tabular}{|c|c|c|c|c|}
\hline Procesos & Herramientas & ¿Qué mide? & Metodología & Responsable \\
\hline $\begin{array}{l}\text { Inspección de } \\
\text { Maquinaria }\end{array}$ & $\begin{array}{l}\text { Agenda con } \\
\text { proveedor } \\
\text { seleccionado para } \\
\text { su mantenimiento }\end{array}$ & $\begin{array}{l}\text {-Los calibres de la } \\
\text { aguja y la tensión del } \\
\text { hilado sean óptimos }\end{array}$ & $\begin{array}{l}\text { Se dará un } \\
\text { mantenimiento dos } \\
\text { veces al año hacia } \\
\text { las máquinas }\end{array}$ & $\begin{array}{l}\text { El seguimiento lo } \\
\text { dará el Gerente } \\
\text { Comercial }\end{array}$ \\
\hline $\begin{array}{l}\text { Revisión de } \\
\text { calidad de } \\
\text { prendas }\end{array}$ & $\begin{array}{l}\text { Check List con } \\
\text { selección aleatoria }\end{array}$ & $\begin{array}{l}\text {-Color y textura dentro } \\
\text { de rangos. } \\
\text {-Hilado sin pulir } \\
\text {-Imperfectos }\end{array}$ & $\begin{array}{l}\text { Se seleccionará } \\
\text { aleatoriamente una } \\
\text { prenda de cada } 50 \\
\text { producidas. }\end{array}$ & $\begin{array}{l}\text { Gerencia de } \\
\text { Producción }\end{array}$ \\
\hline $\begin{array}{l}\text { Etiquetado y } \\
\text { empaquetado }\end{array}$ & & & $\begin{array}{l}\text { Se seleccionará } \\
\text { aleatoriamente una }\end{array}$ & $\begin{array}{l}\text { Operario de } \\
\text { Producción }\end{array}$ \\
\hline renger & & $\begin{array}{l}\text {-Etiquetas con } \\
\text { estándares óptimos ( } \\
\text { mostrar las } \\
\text { certificaciones y la } \\
\text { marca del mismo) }\end{array}$ & $\begin{array}{l}\text { prenda de cada } 50 \\
\text { producidas con } \\
\text { respecto a las } \\
\text { etiquetas y las cajas } \\
\text { cada } 80 \text { prendas. }\end{array}$ & 2 \\
\hline $\begin{array}{l}\text { Transporte } \\
\text { hacia almacén } \\
\text { de la empresa }\end{array}$ & & $\begin{array}{l}\text {-Que el almacén tenga } \\
\text { espacio adecuado para } \\
\text { todas las cajas con } \\
\text { prendas y orden. } \\
\text { - Contabilización de } \\
\text { producción diaria }\end{array}$ & $\begin{array}{l}\text { Se dará una } \\
\text { contabilización al } \\
\text { finalizar el día de } \\
\text { las cajas } \\
\text { transportadas desde } \\
\text { el lugar de } \\
\text { producción hacia el } \\
\text { almacén de la } \\
\text { empresa. }\end{array}$ & $\begin{array}{l}\text { Operario de } \\
\text { Producción }\end{array}$ \\
\hline
\end{tabular}

Elaboración Propia

\section{3.- Programa de gestión de calidad para el futuro del negocio}

Los ISOS de calidad del sector textil que se aplicarán serán los Programas Nacionales

de Capacitación en el cual están puestos los principios generales de higiene y estándares de calidad que se deben cumplir. Por otro lado, se dará el ISO 9001-2008 para que exista una mejora en el sistema de gestión, la eficacia, toma de decisiones y un vínculo 
con el proveedor. Todo esto se dará en el período del quinto año, dado el costo que representa.

A medida que las operaciones existentes de la empresa sean más complejas, es decir, cuando los procesos para la confección de prendas sean mayores, se requerirá nuevo personal capacitado que apoye con estas labores, los cuales tendrán diversas funciones como el de ser operarios y jefes de supervisión en los procesos.

\section{4.- Principales factores claves de los procesos a controlar}

- Los principales factores para la confección de una política de calidad son la calidad de elaboración de la prenda y que la prenda llegue en estado óptimo al cliente final.

- La satisfacción del cliente ayudaría a que los bodies tengan más aceptación en el mercado de competencia local e internacional.

- Con respecto a la elaboración de la prenda, se deberá contar con un stock disponible para ofrecerle al cliente los productos deseados.

- La trazabilidad para asegurar que todo el proceso garantice que las prendas cuenten con lineamientos de control será el de contar con la certificación GOTS, la cual es otorgada por la empresa CONTROL UNION PERU S.A.C, donde se garantiza que desde la obtención de las telas hasta la entrega de los insumos hacia el cliente final se tienen procesos orgánicos.

La calidad de entrega del producto deberá tener una buena presentación teniendo en cuenta la satisfacción del cliente final, además se realizará un seguimiento post venta. 


\section{CAPITULO XI: PLAN DE ADMINISTRACIÓN Y RECURSOS HUMANOS}

\subsection{Objetivos de Administración y Recursos Humanos}

Se darán objetivos puntuales hacia el área de Administración y de Recursos Humanos. Con respecto a los de $\mathrm{RH}$ se tiene:

- El personal de la empresa deberá contribuir de forma productiva en cuanto a las metas propuestas por la empresa: Ser reconocida internacionalmente en cuanto a la calidad de los bodies a partir del segundo año.

- Tener como objetivo primordial para la empresa las necesidades de los trabajadores. Si los miembros de la organización tienen dificultades se les otorgarán opciones para que puedan sentirse bien y afrontar lo que está aconteciendo desde el primer día de sus labores.

- El proceso de selección del personal deberá ser óptimo para así proporcionar una fuerza de trabajo adecuada y pueda mantenerse estable.

- Se deberá contar con un proyecto de responsabilidad social empresarial y ofrecerle un seguimiento continuo de forma mensual.

Con respecto a los objetivos de Administración se darán los siguientes:

- Implementar sistemas de Gestión Autorizada para dar un seguimiento óptimo a los usos que le da la empresa de los materiales, recursos económicos, financieros, etc.

- Se debe rendir un esquema del presupuesto mensual real proyectado y presupuesto de la empresa para que de tal forma se sepa si se cumplió con el objetivo trazado. 
- A lo largo de los 3 primeros años se deben disminuir los costos, realizando un seguimiento de la competencia en cuanto al mismo tema.

\subsection{El organigrama, descripción de puestos por área y definición el perfil}

\section{del puesto}

La empresa estará conformada por dos departamentos de Producción y un departamento de Logística, el cual está reflejado en el Gráfico $\mathrm{N}^{\circ} 22$. Luego se detallarán las descripciones por área y el perfil para cada puesto.

Gráfico $\mathbf{N}^{\circ}$ 22:

Organigrama

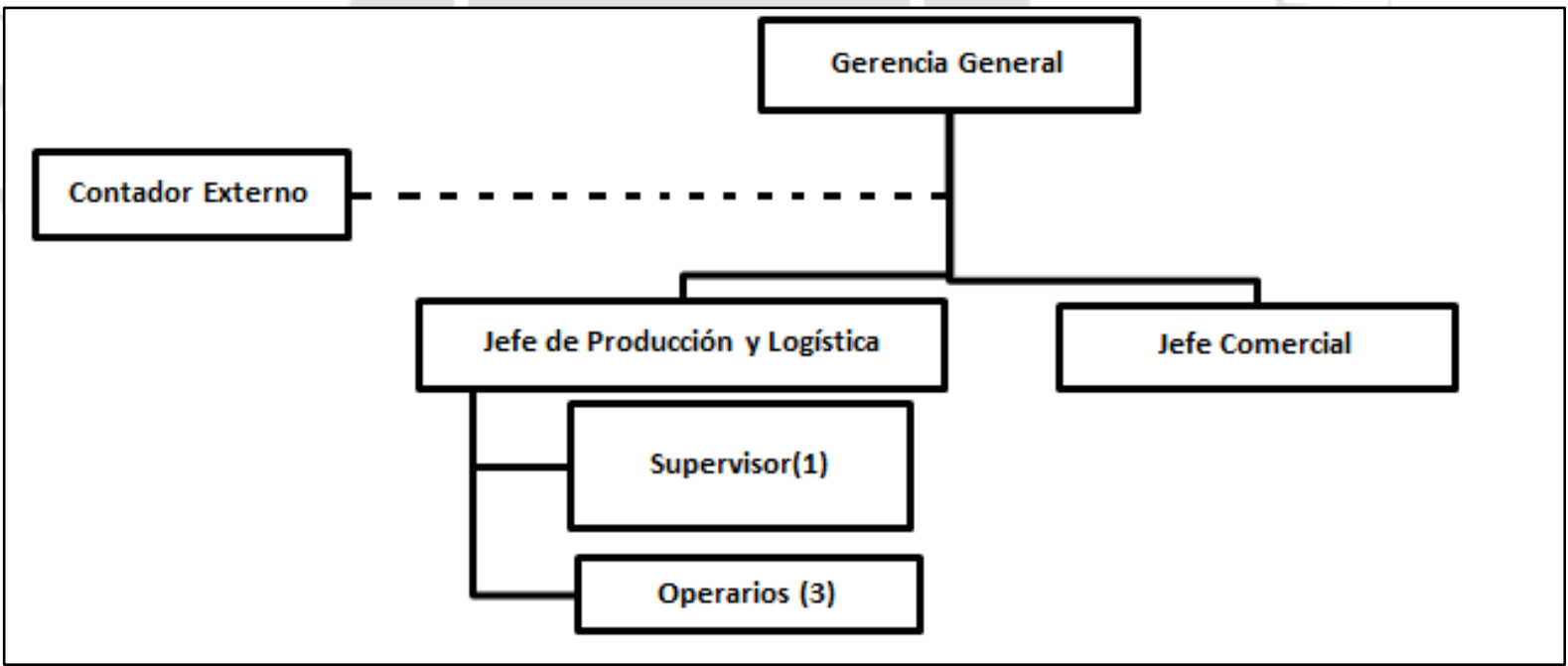

Elaboración Propia

- Gerencia General:

- La gerencia general estará a cargo de la Señorita Andrea Ovalle, la cual será representante legal y se encargará de contactar a los principales 
proveedores para la empresa y clientes. Llevará a cabo un seguimiento y control exhaustivo de todas las áreas de la empresa.

- Debe ejercer la representación legal de la empresa. El gerente debe tener conocimiento de inglés para hablar con clientes en el extranjero y hacer negocios. Además, ser graduado en Ingeniería, Administración o Negocios internacionales con experiencia previa de tres a cinco años. Es esencial que cuente con conocimientos en finanzas para ver la rentabilidad de la empresa y gestionar los niveles de inventarios para luego dárselas al contador externo. Las competencias que este debe tener son: negociación, trabajo bajo presión y comunicación efectiva.

- Contabilidad:

- El Señor Víctor Ovalle, contador y auditor, se encargará de esta área para llevar la contabilidad, de forma segura y transparente, y los estados financieros de la empresa.

- El contador de la empresa debe ser graduado de la carrera de Contabilidad o Auditoría, tener mínimo cinco años de experiencia previa en este ámbito ya que debe elaborar estados financieros en fechas requeridas con información real. Además, debe saber trabajar bajo presión en el caso de elaborar presupuestos para los años futuros de la empresa. La gestión operativa del contador será revisar facturas, hacer negociaciones bancarias y revisar si las inversiones son las correctas. 
- Gerencia de Producción y Logística:

- En esta área se evalúa el insumo y se realizan las confecciones de las prendas para su exportación o comercialización local por los colaboradores. Estos le mostrarán los productos terminados al supervisor de este departamento para que pueda aprobarlos o mandarlos a rehacer. Por otro lado, se encargará de las cotizaciones para la exportación de las prendas con los clientes, informando a la gerencia general sobre las decisiones tomadas.

- Deberá ser titulado en Administración o Negocios Internacionales, contar con experiencia mínima de tres años. Conocimientos avanzados de logística peruana. La competencia esencial que debe presentar es la comunicación efectiva a todo nivel. Deberá realizar un presupuesto trimestral de adquisición de bienes y servicios y tener contacto con agentes logísticos, documentación aduanal, seguros internacionales, etc.

- Área de supervisión: Debe tener visión de negocios y liderazgo sobre los colaboradores. Debe ser titulado en carrera de Ingeniería o técnica afines, tener experiencia mínima de tres años en el sector textil, nivel de conocimientos intermedio de normas de calidad, ISOS, etc.

○ Colaboradores: El perfil de los tres colaboradores para esta área es: tener una carrera técnica de confección o diseño de modas, debe interpretar prototipos o diseños para poder trazar y confeccionar los moldes en prendas, tener mínimo un año de experiencia en este puesto y una dedicación de mínima de ocho horas diarias . 
- Gerencia Comercial:

- Esta área se encargarán de los contratos, ventas, documentación necesaria para las exportaciones que se darán y el marketing que se aplicará. Por otro lado, ellos tendrán la obligación de ver las licencias de exportación, envío de muestras y dar seguimiento presupuestal para luego enviarlo al contador externo.

- El encargado deberá ser titulado en Administración, Negocios Internacionales o Ingeniería y con una experiencia mínima de cinco años en este sector y puesto. El perfil a considerar es que debe contar con inglés avanzado (tratará directamente con clientes y competencia internacional), su comunicación debe ser horizontal y trabajar bajo presión.

\subsection{Política de selección, contratación, capacitación y desarrollo}

- Selección:

○ El Gerente General deberá entrar a la página web de la empresa y ver si los candidatos cumplen con el perfil del puesto a ocupar y llamarlos en un plazo máximo de dos semanas.

- Los candidatos deben pasar por una entrevista psicológica, donde deberán completar con las pruebas.

- Los seleccionados, deberán asistir a un centro médico para realizarse un chequeo general y conocer si existe algún inconveniente con su salud 
para que posteriormente, al estar dentro de la empresa, ellos puedan tener todos los beneficios.

- Contratación:

- No se podrá contratar a ningún personal sin antes pasar por la fase de selección, ya sea personal recomendado o no.

- Antes de contratar al personal se debe fijar un horario y la remuneración para proceder con la firma del contrato. Este se debe dar en un plazo no mayor a la primera semana luego de pasar por el área de selección.

- Los contratados deberán ser mayores de edad sin exclusión alguna.

- Al contratar al personal, se establecerá un contrato inicial por tres meses como periodo de prueba; luego se procederá a realizar contratos por seis meses o un año dependiendo de la capacidad demostrada.

- Capacitación:

- Todo el personal deberá pasar por una capacitación en el área correspondiente durante la primera semana de ser contratado.

- Luego de la primera semana de capacitación se debe observar la evolución que tuvo esta persona para saber si se necesita ofrecerle tres días más de apoyo en cuanto a los conocimientos brindados y aplicados o que pase a su área respectiva. 


\subsection{Descripción de los principales procesos del negocio -Flujo grama.}

El Gráfico $\mathrm{N}^{\circ} 23$ tiene como objetivo brindar soporte sobre el trabajo que debe desarrollar un miembro de la empresa para que el negocio de los bodies funcione y pueda tener mayor rentabilidad y ser reconocidos en el extranjero. Es decir, su cadena de producción debe ser óptima. En esta cadena, se hablará sobre la producción del producto desde que se recibe la orden de compra hasta que este es entregado al cliente final. 
Gráfico $\mathbf{N}^{\circ}$ 23:

\section{Procesos del Negocio}

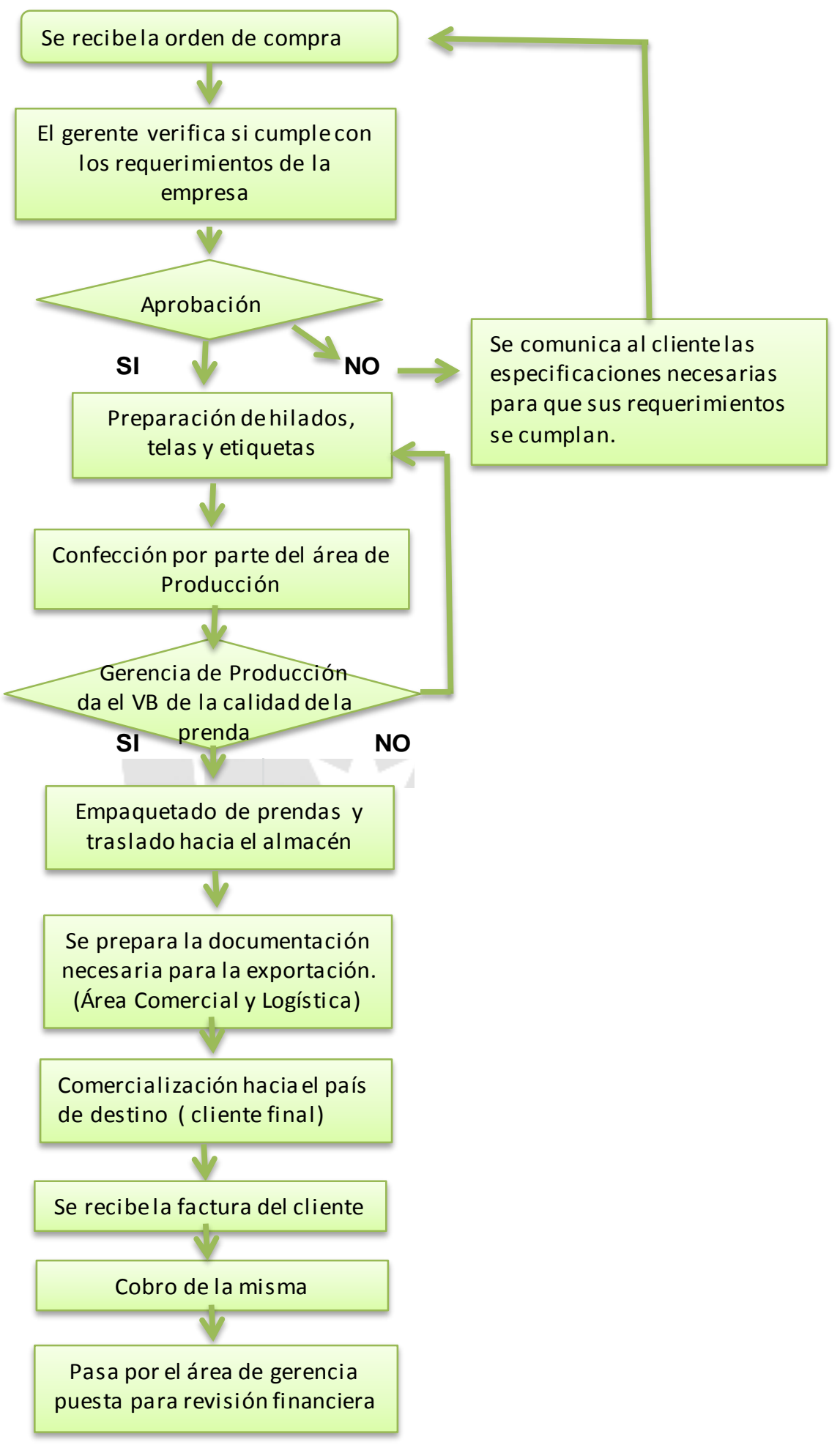

Elaboración Propia 


\subsection{Diseño de las principales herramientas y/o formatos de control}

Los documentos administrativos serán dados por formatos para tener un control sobre la administración. En el plazo del quinto año o cuando las ventas se incrementen y exista estabilidad financiera, se implementarán herramientas en el área de gestión del talento humano. Todos estos estarán detallados a continuación:

- Compras: El formato a utilizar será mediante la obtención de una guía (Excel) para la evaluación continua de los insumos que el proveedor brindará a la empresa de forma mensual dependiendo del volumen que el cliente desee. Este formato controlará que la entrega de materiales se de en el tiempo establecido, que estén en buen estado y que los costos sean razonables con respecto a la competencia. Por otro lado, se debe analizar la obtención de la maquinaria de la empresa y los servicios (agua, internet, publicidad, etc.)

- Finanzas: El formato en Excel y las guías de remisión que se darán en esta área serán para controlar los cobros, donde se indicarán la fecha de inversión y la cantidad a invertir. Por otro lado, al final de estas guías deberá existir la firma y nombre completo del solicitante, tanto como la autorización de la empresa y por quién es recibido.

- Gestión de talento humano: Existirá, los primeros años, un formato de control de asistencia en la empresa. Cuando los empleados ingresen a las 8.30am deberán colocar su nombre, hora y firma en una hoja de control que estará al costado de la puerta de ingreso. Esto se dará con el fin de verificar la hora de ingreso. A largo plazo, se tendrá un dispositivo digital, donde el personal tendrá que colocar su huella para registrarse automáticamente en el sistema. 


\subsection{Definición de los principales factores claves de éxito a controlar}

- Contratar a personal idóneo en cuanto a la Gerencia de la empresa.

- Capacitar al personal adecuadamente para la elaboración de prendas sin falla.

- Dar seguimiento completo a la comercialización de prendas (desde recibir la orden de compra hasta el cobro de las prendas).

- Verificar los costos de la competencia con respecto a los de Teco Caricias S.A.C para hacer un ajuste adecuado al mismo. 


\section{CAPITULO XII: PLAN DE FINANZAS (PRESUPUESTOS PROYECTADOS Y ANÁLISIS DE RENTABILIDAD)}

$\underline{\text { Supuestos Financieros: }}$

- El precio en los dos primeros años será de US\$10.71 mientras que los siguientes tres años se aplicará un precio de US\$11.01.

- El tipo de cambio (TC) durante los cinco primeros años varía (TC proyectado). Por ende, para este presupuesto financiero se tomará un TC promedio de estos años del valor de 3.43 .

- La inexistencia de malas cuentas o incobrables, lo que afecta a los gastos de cobranzas.

- Se venderá todo lo que se produce.

- Se considera la merma (10\%) como inventario final. Todo esto se asume para el tema de donaciones por obsolescencia de moda (Responsabilidad Social).

\subsection{Presupuesto de Ventas}

Según el Cuadro $\mathrm{N}^{\circ} 62$, en el primer año a exportar, se enviarán 11520 prendas, en ocho pallets. Los envíos serán de ocho y se irá aumentando un pallet por año. El valor de exportación del primer año es de US\$123 379.00 y en el 2020 es de US\$190 253.00

\section{Cuadro $\mathrm{N}^{\circ}$ 62:}

Presupuesto de ventas en US\$ (2016-2020)

\begin{tabular}{lrrrrrr}
\hline & \multicolumn{1}{c}{2016} & \multicolumn{1}{c}{2017} & \multicolumn{1}{c}{2018} & 2019 & 2020 & TOTAL \\
\hline Pendas & 11,520 & 12,960 & 14,400 & 15,840 & 17,280 & $\mathbf{7 2 , 0 0 0}$ \\
Pallets & 8 & 9 & 10 & 11 & 12 & $\mathbf{5 0}$ \\
$\begin{array}{l}\text { US\$ por } \\
\text { prenda }\end{array}$ & 10.71 & 10.71 & 11.01 & 11.01 & 11.01 & \\
US\$ total & 123,379 & 138,802 & 158,544 & 174,398 & 190,253 & $\mathbf{7 7 1 , 1 2 0}$ \\
\hline Elaboración Propia & & & & & &
\end{tabular}




\subsection{Presupuesto de Cobranza}

El Cuadro $\mathrm{N}^{\circ} 63$ muestra el presupuesto de cobranzas donde las ventas del producto de exportación (bodies) cobra un $60 \%$ al contado a sus minoristas y un $40 \%$ de crédito a treinta días.

\section{Cuadro $\mathbf{N}^{\circ}$ 63:}

Presupuesto de Cobranzas Anual en US\$ - 5 años (2016-2020)

\begin{tabular}{lrrrrr}
\hline CONCEPTO & \multicolumn{1}{c}{2016} & \multicolumn{1}{l}{2017} & \multicolumn{1}{l}{2019} & \multicolumn{1}{l}{2020} \\
\hline Venta de Productos Exportación: & & & & & \\
Al Contado & $\mathbf{7 4 , 0 2 8}$ & $\mathbf{8 3 , 2 8 1}$ & $\mathbf{9 5 , 1 2 6}$ & $\mathbf{1 0 4 , 6 3 9}$ & $\mathbf{1 1 4 , 1 5 2}$ \\
Al Crédito & $\mathbf{4 9 , 3 5 2}$ & $\mathbf{5 5 , 5 2 1}$ & $\mathbf{6 3 , 4 1 8}$ & $\mathbf{6 9 , 7 5 9}$ & $\mathbf{7 6 , 1 0 1}$ \\
Sub Total & $\mathbf{1 2 3 , 3 7 9}$ & $\mathbf{1 3 8 , 8 0 2}$ & $\mathbf{1 5 8 , 5 4 4}$ & $\mathbf{1 7 4 , 3 9 8}$ & $\mathbf{1 9 0 , 2 5 3}$ \\
Total Ventas & $\mathbf{1 2 3 , 3 7 9}$ & $\mathbf{1 3 8 , 8 0 2}$ & $\mathbf{1 5 8 , 5 4 4}$ & $\mathbf{1 7 4 , 3 9 8}$ & $\mathbf{1 9 0 , 2 5 3}$ \\
\hline
\end{tabular}

Elaboración Propia

\subsection{Presupuesto de Producción}

El cuadro $\mathrm{N}^{\circ} 64$ muestra que el primer año se venderán 11520 prendas haciendo una proyección a los próximos cinco años, los cuales dan un total de 72000 prendas. El año 2016 (1er año) se venderá un pallet en el mes de enero, febrero, abril, mayo, julio, agosto (1440 prendas por cada mes). Sin embargo, en el mes de noviembre se venderán dos pallets (2880 prendas) con el motivo de que el envío llegue a finales de mes y así tener una campaña navideña estable y los clientes puedan aprovechar de una forma óptima sus compras tempranas.

\section{Cuadro $\mathrm{N}^{\circ}$ 64:}

Presupuesto de Producción Anual en US\$- 5 años (2016-2020)

\begin{tabular}{|c|c|c|c|c|c|c|c|}
\hline CONCEPTO & & 2016 & 2017 & 2018 & 2019 & 2020 & TOTALES \\
\hline $\begin{array}{l}\text { Venta de Productos de } \\
\text { exportación: }\end{array}$ & & & & & & & \\
\hline Prendas de vestir & - & 11,520 & 12,960 & 14,400 & 15,840 & 17,280 & 72,000 \\
\hline $\begin{array}{l}\text { Total Venta Productos de } \\
\text { Exportación: }\end{array}$ & - & 11,520 & 12,960 & 14,400 & 15,840 & 17,280 & 72,000 \\
\hline
\end{tabular}

Elaboración Propia 


\subsection{Presupuesto de Compras de Materiales de Producción}

En el siguiente cuadro $\mathrm{N}^{\circ} 65$ se mostrará el costo en dólares por prenda a producir, los materiales de producción son: la tela de algodón, hilo y la etiqueta que irá adentro de la prenda. El costo de los materiales de producción es de US\$5.03

\section{Cuadro $\mathbf{N}^{\circ}$ 65:}

Materiales de Producción en US\$ (2016-2020)

\begin{tabular}{|c|c|c|}
\hline INSUMOS & $\begin{array}{c}\text { COSTO } \\
\text { US\$ / kilo }\end{array}$ & $\begin{array}{l}\text { US\$ } \\
\text { por } \\
\text { PRENDA }\end{array}$ \\
\hline Tela de algodón & 20.70 & 4.14 \\
\hline Orgánico & & \\
\hline Merma de la tela (10\%) & 2.07 & 0.41 \\
\hline Hilo Orgánico & 3.46 & 0.35 \\
\hline Etiqueta & 0.13 & 0.13 \\
\hline Sub total 1 & 26.36 & 5.03 \\
\hline
\end{tabular}

Elaboración Propia

\subsection{Presupuesto de Compras de Materiales de Empaque}

Los materiales que se utilizarán para el empaquetado serán las bolsas de yute y para el embalaje será la caja de cartón. En el cuadro $\mathrm{N}^{\circ} 67$ se aprecia que el precio total por año es de US\$216.00 por bolsas de yute y por el cartón de US\$1498.00

Cuadro N66:

Materiales de Empaque en US\$ (2016-2020)

\begin{tabular}{llrr}
\hline Compra de Material de Empaque & \multicolumn{1}{l}{$\begin{array}{l}\text { Costo } \\
\text { por unidad }\end{array}$} & $\begin{array}{l}\text { Cantidad } \\
\text { de bolsas }\end{array}$ & \multicolumn{1}{l}{$\begin{array}{l}\text { precio } \\
\text { total }\end{array}$} \\
\hline Para Venta Local: & & & \\
Bolsa de Yute & 0.02 & 1440 & 28.80 \\
Caja de cartón corrugado & 0.13 & 1440 & 187.20 \\
\hline
\end{tabular}

Elaboración Propia 


\section{Cuadro $\mathbf{N}^{\circ}$ 67:}

2020)

Presupuesto de Material de Empaque en US\$- 5 años (2016-

\begin{tabular}{llrrrrrr}
\hline Compra Material de Empaque & Presentación & 2016 & 2017 & 2018 & 2019 & 2020 & \multicolumn{1}{c}{ TOT. } \\
\hline Para Venta Exportación: & & & & & & & \\
Bolsas de Yute & Bolsas 200gr & $\mathbf{2 1 6}$ & $\mathbf{2 4 3}$ & $\mathbf{2 7 0}$ & $\mathbf{2 9 7}$ & $\mathbf{3 2 4}$ & $\mathbf{1 , 3 5 0}$ \\
Cajas de cartón & Cajas 16.2kl & $\mathbf{1 , 4 9 8}$ & $\mathbf{1 , 6 8 5}$ & $\mathbf{1 , 8 7 2}$ & $\mathbf{2 , 0 5 9}$ & $\mathbf{2 , 2 4 6}$ & $\mathbf{9 , 3 6 0}$ \\
Total Compra Mat. Emp. & & $\mathbf{1 , 7 1 4}$ & $\mathbf{1 , 9 2 8}$ & $\mathbf{2 , 1 4 2}$ & $\mathbf{2 , 3 5 6}$ & $\mathbf{2 , 5 7 0}$ & $\mathbf{1 0 , 7 1 0}$ \\
\hline
\end{tabular}

Elaboración Propia

\subsection{Presupuesto de Mantenimiento}

En el Cuadro $\mathrm{N}^{\circ} 68$ se aprecia que el mantenimiento del local anual es de US\$262. Esto se da porque trimestralmente se paga la suma de US\$87.3. Por otro lado, el mantenimiento de maquinaria y equipo comprende lo siguiente: (1) que la máquina bordadora tiene un mantenimiento cada dos meses (US\$29.15); (2) la recta industrial y cortadora se da un mantenimiento cada cinco meses (US\$58.31 c/u); y (3) la máquina de coser semi- industrial cuenta con un mantenimiento de US\$43.73 cada cinco meses, lo que hace un monto anual de US\$466.00. Por último, el mantenimiento de instalaciones de la planta se dará cada cinco meses por un monto de US\$116.62, lo que anualmente da un total de US\$233.00.

\section{Cuadro $\mathbf{N}^{\circ}$ 68:}

Presupuesto de Mantenimiento anual en US\$ - 5 años (2016-2020)

\begin{tabular}{lcccccc}
\hline PRODUCTO & 2016 & 2017 & 2018 & 2019 & 2020 & TOTALES \\
\hline Mantenimiento de Planta: & & & & & & \\
Mantenimiento de Local & $\mathbf{2 6 2}$ & $\mathbf{2 6 2}$ & $\mathbf{2 6 2}$ & $\mathbf{2 6 2}$ & $\mathbf{2 6 2}$ & $\mathbf{1 , 3 1 2}$ \\
Mantenimiento de Máq. y Equipo & $\mathbf{4 6 6}$ & $\mathbf{4 6 6}$ & $\mathbf{4 6 6}$ & $\mathbf{4 6 6}$ & $\mathbf{4 6 6}$ & $\mathbf{2 , 3 3 2}$ \\
Mantenimiento de Instalaciones de Planta & $\mathbf{2 3 3}$ & $\mathbf{2 3 3}$ & $\mathbf{2 3 3}$ & $\mathbf{2 3 3}$ & $\mathbf{2 3 3}$ & $\mathbf{1 , 1 6 6}$ \\
Sub Total & $\mathbf{9 6 2}$ & $\mathbf{9 6 2}$ & $\mathbf{9 6 2}$ & $\mathbf{9 6 2}$ & $\mathbf{9 6 2}$ & $\mathbf{4 , 8 1 0}$ \\
\hline
\end{tabular}

Elaboración Propia 


\subsection{Presupuesto de Gastos de Mano de Obra}

El cuadro $\mathrm{N}^{\circ} 69$ muestra el pago anualizado de aproximadamente US $\$ 3149.00$ que se le hace a cada operario, al cual mensualmente se le paga US\$262.39 (S/.900.00). Este sueldo aumentará un $10 \%$ a partir del 4to y 5 to año.

\section{Cuadro $\mathbf{N}^{\circ}$ 69:}

Presupuesto de MOD en US\$ - 5 años (2016-2020)

\begin{tabular}{|c|c|c|c|c|c|c|c|}
\hline CONCEPTO & & 2016 & 2017 & 2018 & 2019 & 2020 & TOTAL \\
\hline \multicolumn{8}{|c|}{ M. O. Propia - Venta de Servicios: } \\
\hline Operario 1 & & 3,149 & 3,149 & 3,149 & 3,464 & 3,464 & 16,373 \\
\hline Operario 2 & & 3,149 & 3,149 & 3,149 & 3,464 & 3,464 & 16,373 \\
\hline Operario 3 & & 3,149 & 3,149 & 3,149 & 3,464 & 3,464 & 16,373 \\
\hline Sub Total & & 9,446 & 9,446 & 9,446 & 10,391 & 10,391 & 49,120 \\
\hline \multicolumn{8}{|c|}{ Carga Social - Venta de Servicios: } \\
\hline SIS & $4.50 \%$ & 850 & 850 & 850 & 850 & 850 & 4,251 \\
\hline C.T.S & $8.33 \%$ & 1,093 & 1,093 & 1,093 & 1,093 & 1,093 & 5,464 \\
\hline Sub Total & & 787 & 787 & 787 & 787 & 787 & 3,934 \\
\hline Total Mano de obra: & & 11,083 & 11,083 & 11,083 & 12,028 & 12,028 & 57,305 \\
\hline
\end{tabular}

Elaboración Propia

\subsection{Presupuesto de Gastos Indirectos de Fabricación}

Con respecto a los empleados, mostrado en el Cuadro $\mathrm{N}^{\circ} 70$, se hace referencia a que existirá una empleada de limpieza, la cual asistirá cuatro veces por semana y cuya remuneración diaria será de US\$17.70. Esta obrera será contratada de forma externa lo que ocasiona gastos anuales de US\$3360.00. Además, también consideramos a la supervisora de Producción, la cual tiene un salario mensual de US\$437.32 (S/.1500.00) y de forma anual asciende a US\$5248.00. Por otro lado, existirán gastos en los servicios como la energía eléctrica, donde se gastará aproximadamente US\$132.7 y al no saber cuánto variará, de manera anual aproximadamente será de US\$1574.00; de igual manera, el agua tendrá un gasto de US\$700. Por otro lado, se tendrá un teléfono móvil 
de la marca Entel con plan corporativo donde se gastará de forma anual US\$420. El alquiler del local, ya antes mencionado, tendrá un valor mensual de US\$900 y anual de US\$10800. Por último, se tendrán gastos de combustible y lubricantes para una camioneta en la cual se invertirá, lo que asciende a un gasto anual de US\$1399.

\section{Cuadro $\mathbf{N}^{\circ}$ 70:}

Presupuesto de Gastos de Fabricación Anual en US\$ - 5 años (2016-2020)

\begin{tabular}{lrrrrrr}
\hline CONCEPTO & 1 & 2 & 3 & 4 & 5 & \multicolumn{1}{l}{ TOTALES } \\
\hline Supervisora de producción & $\mathbf{5 , 2 4 8}$ & $\mathbf{5 , 2 4 8}$ & $\mathbf{5 , 2 4 8}$ & $\mathbf{5 , 2 4 8}$ & $\mathbf{5 , 2 4 8}$ & $\mathbf{2 6 , 2 3 9}$ \\
Sueldos Empleados & $\mathbf{3 , 3 6 0}$ & $\mathbf{3 , 3 6 0}$ & $\mathbf{3 , 3 6 0}$ & $\mathbf{3 , 3 6 0}$ & $\mathbf{3 , 3 6 0}$ & $\mathbf{1 6 , 8 0 0}$ \\
sub-total & $\mathbf{8 , 6 0 8}$ & $\mathbf{8 , 6 0 8}$ & $\mathbf{8 , 6 0 8}$ & $\mathbf{8 , 6 0 8}$ & $\mathbf{8 , 6 0 8}$ & $\mathbf{4 3 , 0 3 9}$ \\
Servicios: & & & & & & \\
Energía Eléctrica & $\mathbf{1 , 5 7 4}$ & $\mathbf{1 , 5 7 4}$ & $\mathbf{1 , 5 7 4}$ & $\mathbf{1 , 5 7 4}$ & $\mathbf{1 , 5 7 4}$ & $\mathbf{7 , 8 7 2}$ \\
Agua & $\mathbf{7 0 0}$ & $\mathbf{7 0 0}$ & $\mathbf{7 0 0}$ & $\mathbf{7 0 0}$ & $\mathbf{7 0 0}$ & $\mathbf{3 , 4 9 9}$ \\
Comunicaciones: & & & & & & \\
-Telefonía Celular (Entel) & $\mathbf{4 2 0}$ & $\mathbf{4 2 0}$ & $\mathbf{4 2 0}$ & $\mathbf{4 2 0}$ & $\mathbf{4 2 0}$ & $\mathbf{2 , 0 9 9}$ \\
Alquileres: & & & & & & $\mathbf{1 0 0 0}$ \\
Alquiler Maquinaria y Equipo & $\mathbf{1 0 , 8 0 0}$ & $\mathbf{1 0 , 8 0 0}$ & $\mathbf{1 0 , 8 0 0}$ & $\mathbf{1 0 , 8 0 0}$ & $\mathbf{1 0 , 8 0 0}$ & $\mathbf{5 4 , 0 0 0}$ \\
Otros Gastos: & & & & & & $\mathbf{1 , 3 9 9}$ \\
Combustible y Lubricantes & $\mathbf{1 , 3 9 9}$ & $\mathbf{1 , 3 9 9}$ & $\mathbf{1 , 3 9 9}$ & $\mathbf{1 , 3 9 9}$ & $\mathbf{1 , 3 9 9}$ & $\mathbf{6 , 9 9 7}$ \\
Total & $\mathbf{2 3 , 5 0 1}$ & $\mathbf{2 3 , 5 0 1}$ & $\mathbf{2 3 , 5 0 1}$ & $\mathbf{2 3 , 5 0 1}$ & $\mathbf{2 3 , 5 0 1}$ & $\mathbf{1 1 7 , 5 0 6}$ \\
\hline
\end{tabular}

Elaboración Propia

\subsection{Presupuesto de Gastos de Administración}

En el Cuadro $\mathrm{N}^{\circ} 71$ se muestra el presupuesto anual de Gastos Administrativos, donde el principal gasto será la obtención de la Certificación GOTS, la cual tiene un costo de US\$1929 de forma anual y se ve reflejada en el Anexo 5.2. Por otro lado, dentro de los gastos administrativos se encuentra el sueldo de los empleados, el cual será de US\$116.62 (S/.400.00) mensuales, esto es porque será un contador externo, el cual irá sólo para hacer una auditoría de forma anual. Sin embargo, se le dará una remuneración mensual lo que hace un total de US\$1399 anualizado. 
Los gastos de agua y luz serán básicos ya que estos no dependen para la producción. Se contará con un teléfono fijo, tres celulares y un modem de internet los cuales generarán gastos anuales de US\$700, US\$1050 y US\$350 respectivamente. Además, existirán seguros para los trabajadores (vida ley) y un seguro de RIMAC sobre Todo Riesgo para el local, por si ocurren inconvenientes como incendios, robos etc.

\section{Cuadro N 71 :}

Presupuesto de Gastos de Administración Anual en US\$ - 5 años (2016-2020)

\begin{tabular}{|lrrrrrr|r}
\hline CONCEPTO & 2016 & 2017 & 2018 & 2019 & 2020 & TOTALES \\
\hline Sueldos Empleados & $\mathbf{1 , 3 9 9}$ & $\mathbf{1 , 3 9 9}$ & $\mathbf{1 , 3 9 9}$ & $\mathbf{1 , 3 9 9}$ & $\mathbf{1 , 3 9 9}$ & $\mathbf{6 , 9 9 7}$ \\
Sub Total & $\mathbf{1 , 3 9 9}$ & $\mathbf{1 , 3 9 9}$ & $\mathbf{1 , 3 9 9}$ & $\mathbf{1 , 3 9 9}$ & $\mathbf{1 , 3 9 9}$ & $\mathbf{6 , 9 9 7}$ \\
Energía Eléctrica & $\mathbf{2 4 5}$ & $\mathbf{2 4 5}$ & $\mathbf{2 4 5}$ & $\mathbf{2 4 5}$ & $\mathbf{2 4 5}$ & $\mathbf{1 , 2 2 4}$ \\
Agua & $\mathbf{7 0}$ & $\mathbf{7 0}$ & $\mathbf{7 0}$ & $\mathbf{7 0}$ & $\mathbf{7 0}$ & $\mathbf{3 5 0}$ \\
Comunicaciones: & & & & & & \\
-Telefonía Fija & $\mathbf{7 0 0}$ & $\mathbf{7 0 0}$ & $\mathbf{7 0 0}$ & $\mathbf{7 0 0}$ & $\mathbf{7 0 0}$ & $\mathbf{3 , 4 9 9}$ \\
-Telefonía Celular & $\mathbf{1 , 0 5 0}$ & $\mathbf{1 , 0 5 0}$ & $\mathbf{1 , 0 5 0}$ & $\mathbf{1 , 0 5 0}$ & $\mathbf{1 , 0 5 0}$ & $\mathbf{5 , 2 4 8}$ \\
-Internet & $\mathbf{3 5 0}$ & $\mathbf{3 5 0}$ & $\mathbf{3 5 0}$ & $\mathbf{3 5 0}$ & $\mathbf{3 5 0}$ & $\mathbf{1 , 7 4 9}$ \\
Seguros: & & & & & & \\
- Vida Ley & $\mathbf{3 6 4}$ & $\mathbf{3 6 4}$ & $\mathbf{3 6 4}$ & $\mathbf{3 6 4}$ & $\mathbf{3 6 4}$ & $\mathbf{1 , 8 2 0}$ \\
- Todo Riesgo Mueb. y Enseres Ofic. & $\mathbf{1 , 7 4 9}$ & $\mathbf{1 , 7 4 9}$ & $\mathbf{1 , 7 4 9}$ & $\mathbf{1 , 7 4 9}$ & $\mathbf{1 , 7 4 9}$ & $\mathbf{8 , 7 4 6}$ \\
\hline Otros Gastos: & & & & & & $\mathbf{1 0 5 0}$ \\
Útiles de Oficina & $\mathbf{1 , 0 5 0}$ & $\mathbf{1 , 0 5 0}$ & $\mathbf{1 , 0 5 0}$ & $\mathbf{1 , 0 5 0}$ & $\mathbf{1 , 0 5 0}$ & $\mathbf{5 , 2 4 8}$ \\
Certificación GOTS & 1,929 & 1,929 & 1,929 & 1,929 & 1,929 & 9,647 \\
Gastos de Administración: & $\mathbf{6 , 9 7 6}$ & $\mathbf{6 , 9 7 6}$ & $\mathbf{6 , 9 7 6}$ & $\mathbf{6 , 9 7 6}$ & $\mathbf{6 , 9 7 6}$ & $\mathbf{4 4 , 5 2 7}$ \\
\hline
\end{tabular}

Elaboración Propia

\subsection{Presupuesto de Gastos de Ventas}

En el Cuadro $\mathrm{N}^{\circ} 72$ se muestra el presupuesto proyectado a cinco años de Gastos de Ventas los cuales comprenden obsequios a clientes dados en los meses de ventas. Los certificados de origen, gastos logísticos, transporte, agente de aduanas y el terminal handling se pagan por envío de las 1440 prendas en conjunto por mes. El precio de estos es de US\$12.54, US\$29.15, US\$122.45 y US\$52.48 respectivamente. Anualizando todos los gastos de venta, hacen un total de US\$4247. 


\section{Cuadro No72:}

Presupuesto de Gastos de Ventas Anual en US\$ - 5 años (2016-2020)

\begin{tabular}{lrrrrrr}
\hline CONCEPTO & 2016 & 2017 & 2018 & 2019 & 2020 & TOTALES \\
\hline Comisiones Cobranzas & $\mathbf{3 0 8}$ & $\mathbf{3 4 7}$ & $\mathbf{3 9 6}$ & $\mathbf{4 3 6}$ & $\mathbf{4 7 6}$ & $\mathbf{1 , 9 6 3}$ \\
Exterior & & & & & & \\
Obsequios Muestra Clientes & $\mathbf{2 2 5}$ & $\mathbf{2 2 5}$ & $\mathbf{2 8 9}$ & $\mathbf{3 2 1}$ & $\mathbf{3 5 3}$ & $\mathbf{1 , 4 1 4}$ \\
Gastos Viaje al exterior & $\mathbf{1 , 8 9 6}$ & $\mathbf{1 , 8 9 6}$ & $\mathbf{1 , 8 9 6}$ & $\mathbf{1 , 8 9 6}$ & $\mathbf{1 , 8 9 6}$ & $\mathbf{9 , 4 8 0}$ \\
Certificado de origen & $\mathbf{7 6}$ & $\mathbf{7 6}$ & $\mathbf{7 6}$ & $\mathbf{7 6}$ & $\mathbf{7 6}$ & $\mathbf{3 8 2}$ \\
transporte interno logístico & $\mathbf{2 0 4}$ & $\mathbf{2 2 2}$ & $\mathbf{2 8 6}$ & $\mathbf{3 1 8}$ & $\mathbf{3 4 9}$ & $\mathbf{1 , 3 7 9}$ \\
agente de aduanas & $\mathbf{9 3 3}$ & $\mathbf{9 3 3}$ & $\mathbf{1 , 2 0 0}$ & $\mathbf{1 , 3 3 3}$ & $\mathbf{1 , 4 6 7}$ & $\mathbf{5 , 8 6 7}$ \\
terminal handling charge. & $\mathbf{4 0 0}$ & $\mathbf{4 0 0}$ & $\mathbf{5 1 4}$ & $\mathbf{5 7 1}$ & $\mathbf{6 2 9}$ & $\mathbf{2 , 5 1 4}$ \\
Impresos Folletos & $\mathbf{2 0 4}$ & $\mathbf{2 0 4}$ & $\mathbf{2 6 2}$ & $\mathbf{2 9 2}$ & $\mathbf{3 2 1}$ & $\mathbf{1 , 2 8 3}$ \\
Gastos de Venta & $\mathbf{4 , 2 4 7}$ & $\mathbf{4 , 3 0 4}$ & $\mathbf{4 , 9 2 0}$ & $\mathbf{5 , 2 4 3}$ & $\mathbf{5 , 5 6 7}$ & $\mathbf{2 4 , 2 8 1}$ \\
\hline
\end{tabular}

Elaboración Propia

\subsection{Presupuesto de Gastos Financieros}

En el presupuesto de Gastos financieros, el monto a financiar (préstamo) será de US\$9758.01. La tasa de interés será de 1.5\% mensual, el periodo de financiamiento será de tres años y se dará una cuota fija de US\$379.65.

Como se muestra en el Cuadro $\mathrm{N}^{\circ} 73$, el interés que se tendrá en el primer año será de US\$1676.37, el segundo año será de US\$1119.88 y el último por US\$426.18. La amortización que se da por el pago de la cuota menos los intereses, el cual es de US\$2192.54 el primer año, seguido de US\$3435.88 y de US\$4129.59 el tercero. La tasa de préstamo bancario según la SBS es de $20.19 \%$ y la comisión por esta es de $0.05 \%$.

\section{Cuadro No73:}

Presupuesto de Gastos Financieros (2016-2020)

\begin{tabular}{rr}
\hline \multicolumn{2}{c}{ INTERÉS } \\
\hline 1 & $\mathbf{1 , 6 7 6 . 3 7}$ \\
2 & $\mathbf{1 , 1 1 9 . 8 8}$ \\
3 & $\mathbf{4 2 6 . 1 8}$ \\
\hline & AMORTIZACION \\
\hline 1 & $\mathbf{2 , 1 9 2 . 5 4}$ \\
2 & $\mathbf{3 , 4 3 5 . 8 8}$ \\
3 & $\mathbf{4 , 1 2 9 . 5 9}$ \\
\hline
\end{tabular}




\subsection{Presupuesto de Tributos}

La tasa del IGV que se está usando es del $18 \%$ para el Cuadro $\mathrm{N}^{\circ} 74$. Los tributos que se pagarán serán por las compras que se hicieron, por el material de empaque señalado anteriormente, el cual tiene un pago mensual de US\$39 por cada 1440 prendas exportadas, lo que da un total anual de US\$311. Esto se da también con el impuesto por mantenimiento, gastos de fabricación, ventas y administración, según los meses que correspondan.

\section{Cuadro N'74:}

Presupuesto de Tributos en US\$ (2016-2020)

\begin{tabular}{lrrrrrr} 
CONCEPTO & $\mathbf{2 0 1 6}$ & $\mathbf{2 0 1 7}$ & $\mathbf{2 0 1 8}$ & $\mathbf{2 0 1 9}$ & $\mathbf{2 0 2 0}$ & TOTALES \\
\hline & & & & & & \\
I.G.V. Compras Material Empaque & 311 & 350 & 389 & 428 & 467 & 1,944 \\
I.G.V. de Mantenimiento & 236 & 236 & 236 & 236 & 236 & 1,181 \\
I.G.V. de Gastos de Fabricación & 4,230 & 4,230 & 4,230 & 4,230 & 4,230 & 21,151 \\
I.G.V. de Gastos de Administración & 1,256 & 1,256 & 1,256 & 1,256 & 1,256 & 6,279 \\
I.G.V. de Gastos de Ventas & 764 & 775 & 886 & 944 & 1,002 & 4,371 \\
I.G.V. Leasing & 0 & 0 & 0 & 0 & 0 & 0 \\
I.G.V. Activación Leasing & 0 & 0 & 0 & 0 & 0 & 0 \\
Sub Total & $\mathbf{6 , 7 9 8}$ & 6,847 & 6,997 & 7,094 & 7,191 & 34,925 \\
IGV Por Pagar & $\mathbf{- 6 , 7 9 8}$ & $\mathbf{- 6 , 8 4 7}$ & $\mathbf{- 6 , 9 9 7}$ & $\mathbf{- 7 , 0 9 4}$ & $\mathbf{- 7 , 1 9 1}$ & $\mathbf{- 3 4 , 9 2 5}$ \\
\hline
\end{tabular}

Elaboración Propia

\subsection{Flujo de caja económico y financiero proyectado}

En el Cuadro $\mathrm{N}^{\circ} 75$ se presenta el flujo Económico, el cual financia la inversión total de US\$39032.04 con capital propio. Por otro lado, el flujo financiero es cuando se financia el $25 \%$ del total de la inversión por medio de un banco. 


\section{Cuadro $\mathbf{N}^{\circ} 75$ :}

Flujo de Caja económico y financiero en US\$ (2016-2020)

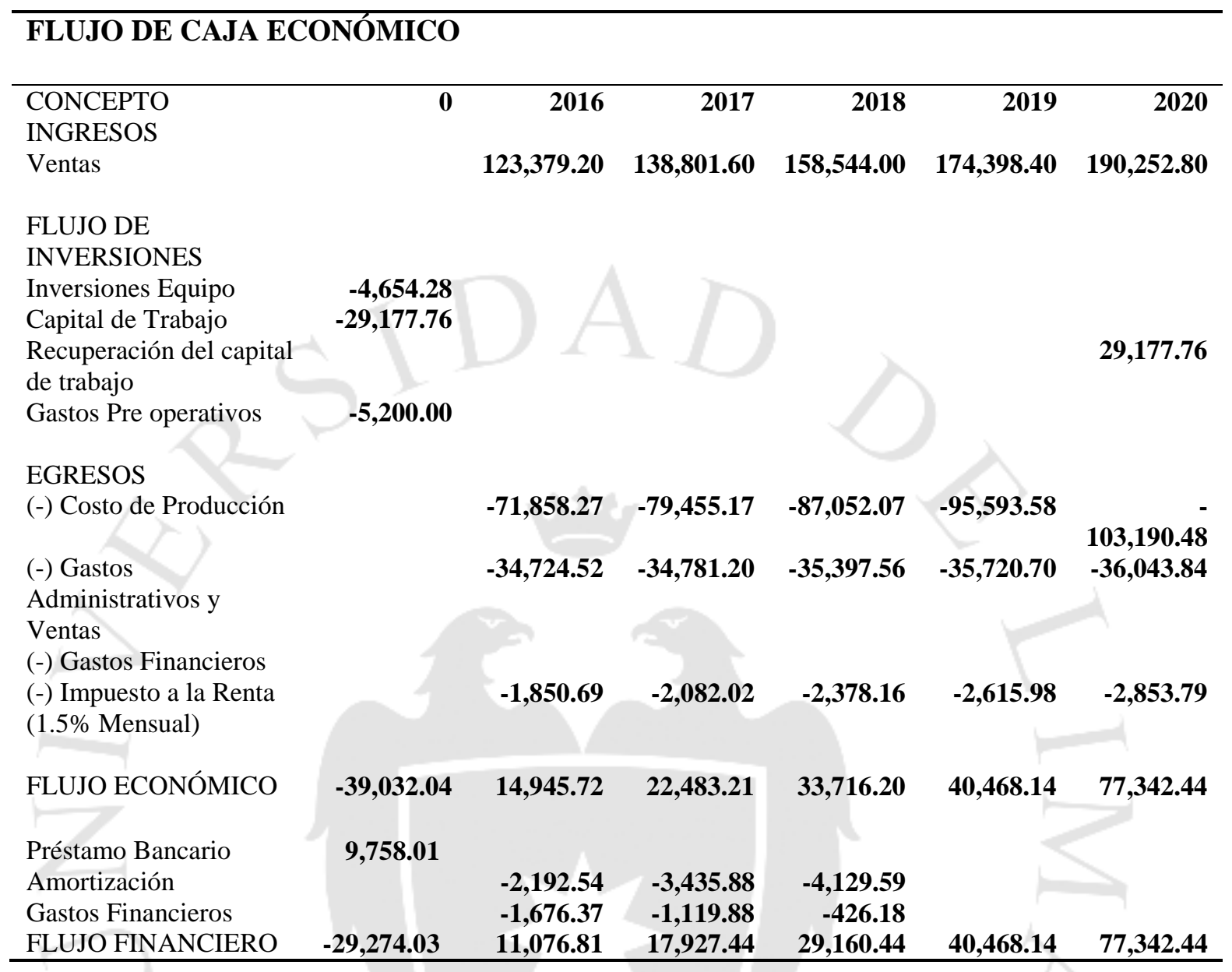

Elaboración Propia

\subsection{Estructura de costos fijos y variables}

Para la producción de prendas orgánicas de vestir hacia el sector bebés se necesitan ciertos costos y gastos como lo son: los sueldos de administración del gerente general, asistente de ventas, alquiler de local, gastos de agua, luz, teléfono, entre otros, los cuales están detallados en el Cuadro $\mathrm{N}^{\circ} 76$. 


\section{Cuadro $\mathbf{N}^{\circ}$ 76:}

Costos Fijos anualizados en US\$ (2016-2020)

\begin{tabular}{lrrrrrr}
\hline & \multicolumn{1}{c}{2016} & \multicolumn{1}{c}{2017} & \multicolumn{1}{c}{2018} & \multicolumn{1}{c}{ TO19 } & \multicolumn{1}{c}{ 2020 } & \multicolumn{1}{c}{ TOTAL } \\
\hline Total Mano de Obra : & $11,083.07$ & $11,083.07$ & $11,083.07$ & $12,027.67$ & $12,027.67$ & $57,304.55$ \\
Operarios & & & & & & \\
Sueldos Empleados & 8,608 & 8,608 & 8,608 & 8,608 & 8,608 & 43,039 \\
Contador & $1,399.42$ & $1,399.42$ & $1,399.42$ & $1,399.42$ & $1,399.42$ & 6,997 \\
Seguro & $1,749.27$ & $1,749.27$ & $1,749.27$ & $1,749.27$ & $1,749.27$ & 8,746 \\
Local & $10,800.00$ & $10,800.00$ & $10,800.00$ & $10,800.00$ & $10,800.00$ & 54,000 \\
\hline
\end{tabular}

Elaboración Propia

Los costos indirectos de fabricación, mostrados en el Cuadro $\mathrm{N}^{\circ} 77$, son la tela de algodón orgánico, la cual tiene un costo de US\$20.70 por kilo. Con este kilo de tela se elaboran cinco prendas, las cuales deben tener un hilado orgánico. Como se apreció en el Cuadro $\mathrm{N}^{\circ} 65$, los materiales de producción tienen un costo de US\$ 5.03. Sin embargo, se le deben añadir las bolsas de yute y las cajas de cartón, lo que da un total de US\$5.08 por prenda.

\section{Cuadro No77:}

Costos Variables en US\$ (2016-2020)

\begin{tabular}{lrr}
\hline INSUMOS & COSTO & \multicolumn{2}{c}{ US\$ por } \\
& US\$ & prenda \\
\hline Tela de algodón Orgánico & $\mathbf{2 0 . 7}$ & $\mathbf{4 . 1 4}$ \\
Merma de la tela $(10 \%)$ & $\mathbf{2 . 0 7}$ & $\mathbf{0 . 4 1}$ \\
Hilo Orgánico & $\mathbf{3 . 4 6}$ & $\mathbf{0 . 3 5}$ \\
Bolsa de Yute & $\mathbf{0 . 0 3}$ & $\mathbf{0 . 0 3}$ \\
Caja de cartón corrugado & $\mathbf{1 . 5}$ & $\mathbf{0 . 0 2}$ \\
Etiqueta & $\mathbf{0 . 1 3}$ & $\mathbf{0 . 1 3}$ \\
Sub total 1 & $\mathbf{2 7 . 8 9}$ & $\mathbf{5 . 0 8}$ \\
\hline
\end{tabular}

Elaboración Propia

Por otro lado, en el Cuadro $\mathrm{N}^{\circ} 78$, se muestran otros costos de fabricación, los cuales son el certificado de origen, transporte interno logístico, Agente de Aduanas y El Terminal Handling Charge. Estos costos se dan por envío. En el Cuadro $\mathrm{N}^{\circ} 79$, se 
muestran los costos totales para la exportación de estas prendas, obteniendo un costo total de producción de US\$6.24 por prenda.

\section{Cuadro No78:}

Gastos de Exportación US\$ (2016-2020)

\begin{tabular}{lr}
\hline ITEM & US\$ X ENVIO \\
\hline Certificado de origen & $\mathbf{1 2 . 5 4}$ \\
transporte interno logístico & $\mathbf{2 9 . 1 5}$ \\
agente de aduanas & $\mathbf{1 2 2 . 4 5}$ \\
Terminal handling charge & $\mathbf{5 2 . 4 8}$ \\
TOTAL & $\mathbf{2 1 6 . 6 2}$ \\
UNITARIO & $\mathbf{0 . 1 5}$ \\
\hline
\end{tabular}

Elaboración Propia

\section{Cuadro No79:}

Costo Total por Prenda a Exportar en US\$ (2016)

\begin{tabular}{llc}
\hline ITEM & UNIDAD & 2016 \\
\hline Insumos & KG & $\mathbf{5 . 0 5}$ \\
Mano de Obra & & $\mathbf{0 . 9 6}$ \\
Pallets & UND & $\mathbf{0 . 0 7}$ \\
COSTO PRODUC. TOTAL (US\$) & & $\mathbf{6 . 0 9}$ \\
GASTOS EXPORTA. (US\$ X KG) & & $\mathbf{0 . 1 5}$ \\
C+ G Variables Unitarios UDS X KG & & $\mathbf{6 . 2 4}$ \\
\hline
\end{tabular}

Elaboración Propia

\subsection{Margen y determinación de precio de venta FOB}

El precio FOB a utilizar para la exportación de cada prenda será de US\$10.71. En este caso, la exportación se dará de forma aérea, lo que genera que el Incoterm será FCA. El costo para la elaboración de la prenda es de US\$6.24, el cual equivale a un $58.24 \%$ del precio, contando así con un margen o una utilidad del $41.76 \%$ mediante el canal minoristas. Por otro lado, el precio CIP será de US $\$ 12.77$ 


\section{Cuadro $\mathbf{N}^{\circ}$ 80:}

Determinación del Precio FCA en US\$ (2016-2019)

\begin{tabular}{lrr}
\hline CONCEPTO & US\$ & \multicolumn{1}{c}{ PART \% } \\
\hline COSTO DE PRODUCCIÓN & $\mathbf{6 . 0 9}$ & $\mathbf{5 6 . 8 4 \%}$ \\
GASTOS EXPORTA. (US\$ X KG) & $\mathbf{0 . 1 5}$ & $\mathbf{1 . 4 0 \%}$ \\
COSTO TOTAL & $\mathbf{6 . 2 4}$ & $\mathbf{5 8 . 2 4 \%}$ \\
U. BRUTA & $\mathbf{4 . 4 7}$ & $\mathbf{4 1 . 7 6 \%}$ \\
PRECIO FCA & $\mathbf{1 0 . 7 1}$ & $\mathbf{1 0 0 . 0 0 \%}$ \\
& \multicolumn{1}{|c}{} \\
Flete Aéreo & $\mathbf{1 . 5 2}$ & \\
Seguro (5\%) & $\mathbf{0 . 5 4}$ & \\
PRECIO CIP & $\mathbf{1 2 . 7 7}$ \\
\hline
\end{tabular}

\subsection{Capital de Trabajo}

Con respecto al capital de trabajo se necesitará invertir un total de US\$29 177.76, lo que contiene costos y gastos tanto fijos como variables. Con respecto a la cantidad mostrada en el Cuadro $\mathrm{N}^{\circ} 81$, se ha considerado el plazo de dos meses por si surgen inconvenientes con el pago de los clientes. Esto se da por si el cliente no paga el primer mes y la empresa no pueda operar.

\section{Cuadro $\mathbf{N}^{\circ}$ 81:}

Capital de Trabajo en US\$ (2016-2020)

\begin{tabular}{lllll}
\hline III. Capital de trabajo & & & & \\
\hline Costos y gastos variables & meses & $\mathbf{2}$ & $8,982.28$ & $17,964.57$ \\
Costos y gastos fijos & meses & $\mathbf{2}$ & $5,606.59$ & $11,213.19$ \\
Sub total 3 & & & & $\mathbf{2 9 , 1 7 7 . 7 6}$ \\
\hline
\end{tabular}

Elaboración Propia 


\subsection{Estructura de la inversión}

La inversión que se requiere es de US\$39 032.04. Según lo mostrado en el Cuadro $\mathrm{N}^{\circ} 82$, se dan conceptos de inversión como la maquinaria y equipos, muebles y enseres, capital de trabajo y los gastos pre operativos.

\section{Cuadro $N^{\circ}$ 82:}

Estructura de Inversión en US\$

\begin{tabular}{|c|c|c|c|c|}
\hline CONCEPTO & U.M. & CANT. & P.UNIT & TOTAL \\
\hline \multicolumn{5}{|l|}{ I. Maquinaria y Equipos } \\
\hline Recta Industrial & ud & 1 & 259.52 & 259.52 \\
\hline Máquina de Coser Semi - industrial & ud & 3 & 217.67 & 653.00 \\
\hline Rellamadora & ud & 1 & 153.98 & 153.98 \\
\hline Cortadora & ud & 1 & 311.42 & 311.42 \\
\hline Computadora & ud & 4 & 484.08 & $1,936.33$ \\
\hline Impresoras & ud & 2 & 96.54 & 193.08 \\
\hline Sub total 1 & & & & 3,507.33 \\
\hline \multicolumn{5}{|l|}{ II. Muebles y Enseres } \\
\hline Escritorio & ud & 4 & 86.51 & 346.02 \\
\hline Sillones & ud & 4 & 34.60 & 138.41 \\
\hline Mesa de producción & ud & 4 & 41.52 & 166.08 \\
\hline Estantes & ud & 3 & 57.06 & 171.18 \\
\hline Útiles de oficina & ud & 1 & 242.21 & 242.21 \\
\hline Extintores & ud & 2 & 41.53 & 83.05 \\
\hline Sub total 2 & & & & $1,146.95$ \\
\hline \multicolumn{5}{|l|}{ III. Capital de trabajo } \\
\hline Costos y gastos variables & meses & 2 & $8,982.28$ & $17,964.57$ \\
\hline Costos y gastos fijos & meses & 2 & $5,606.59$ & $11,213.19$ \\
\hline Sub total 3 & & & & $29,177.76$ \\
\hline \multicolumn{5}{|l|}{ IV. Gastos pre operativos } \\
\hline Plan de negocio, estudios & ud & 1 & $1,000.00$ & $1,000.00$ \\
\hline Alquiler del Local 1 (Garantía) & ud & 3 & 900.00 & $2,700.00$ \\
\hline Licencias y constitución de empresa & ud & 1 & 600.00 & 600.00 \\
\hline Marketing & ud & 1 & 500.00 & 500.00 \\
\hline Remodelación del local administrativo & ud & 1 & 400.00 & 400.00 \\
\hline Sub total 4 & & & & $5,200.00$ \\
\hline TOTAL INVERSIÓN & & & & $39,032.04$ \\
\hline
\end{tabular}

Elaboración Propia 


\subsection{Financiamiento de la inversión}

Como se muestra en el Cuadro $\mathrm{N}^{\circ}$ 83, la inversión total es de US\$39 032.04 y esta se financiará con capital propio en un $75 \%$ y el $25 \%$, el cual equivale a US\$9 758.01 que será financiado con un Banco.

\section{Cuadro N'83:}

Estructura de Inversión (2016-2020)

\begin{tabular}{lrr}
\hline CONCEPTO & US\$ & PART \% \\
\hline Capital Propio & $\mathbf{2 9 , 2 7 4 . 0 3}$ & $\mathbf{7 5 \%}$
\end{tabular}

$\begin{array}{lrr}\text { Financiamiento } & \mathbf{9 , 7 5 8 . 0 1} & \mathbf{2 5 \%} \\ \text { Total Inversión } & \mathbf{3 9 , 0 3 2 . 0 4} & \mathbf{1 0 0 \%}\end{array}$

Elaboración Propia

\subsection{Estado de Pérdidas y Ganancias}

En el cuadro $\mathrm{N}^{\circ} 84$ se muestra el estado de Ganancias y Pérdidas también conocido como Estado de Resultados Integrales. Se aprecia un resultado acumulado en el primer año de US\$12 265.51 con una rentabilidad del 10\%. En el segundo año, esta rentabilidad va en crecimiento con un $15 \%$ hasta el año cinco que llega a $25 \%$. 


\section{Cuadro N'84:}

Estado de Resultados Integrales en US\$ (2016-2020)

\begin{tabular}{|c|c|c|c|c|c|}
\hline CONCEPTO & 2016 & 2017 & 2018 & 2019 & 2020 \\
\hline Ventas & $123,379.20$ & $138,801.60$ & $158,544.00$ & $174,398.40$ & $190,252.80$ \\
\hline (-) Costo de Producción & $71,858.27$ & $79,455.17$ & $87,052.07$ & $95,593.58$ & $103,190.48$ \\
\hline Utilidad Bruta & $51,520.93$ & $59,346.43$ & $71,491.93$ & $78,804.82$ & $87,062.32$ \\
\hline (-) Gastos Administrativos y Ventas & $34,724.52$ & $34,781.20$ & $35,397.56$ & $35,720.70$ & $36,043.84$ \\
\hline EBIDTA & $16,796.41$ & $24,565.23$ & $36,094.36$ & $43,084.12$ & $51,018.48$ \\
\hline (-) Gastos Fi & 1,676 & $\quad 1,120$ & 426 & 0 & 0 \\
\hline (-) Depreciación & $1,003.85$ & $1,003.85$ & $1,003.85$ & $1,003.85$ & $1,003.85$ \\
\hline EBIT & 14,116 & 22,442 & 34,664 & 42,080 & 50,015 \\
\hline $\begin{array}{l}\text { (-) Impuesto a la Renta (1.5\% } \\
\text { Mensual) }\end{array}$ & $1,850.69$ & $2,082.02$ & $2,378.16$ & $2,615.98$ & $2,853.79$ \\
\hline Resultado del Ejercicio & $12,265.51$ & $20,359.48$ & $32,286.18$ & $39,464.30$ & $47,160.84$ \\
\hline Resultado Acumulado & $12,265.51$ & $20,359.48$ & $32,286.18$ & $39,464.30$ & $47,160.84$ \\
\hline$\%$ Rentabilidad & $10 \%$ & $15 \%$ & $20 \%$ & $23 \%$ & $25 \%$ \\
\hline Reserva Legal del Periodo & $1,226.55$ & $2,035.95$ & $3,228.62$ & $3,946.43$ & $4,716.08$ \\
\hline Reserva Legal Acumulada & $1,226.55$ & $3,262.50$ & $6,491.12$ & $10,437.55$ & $15,153.63$ \\
\hline
\end{tabular}

\subsection{Balance General}

En el Estado de Situación Financiera, mostrado en el Cuadro $\mathrm{N}^{\circ} 85$, se aprecia la evolución tanto de los activos como la disminución para los pasivos con respecto a la deuda que tomará la empresa en cuanto al financiamiento del préstamo bancario sobre la inversión de la empresa durante los tres primeros años.

Por otro lado, la Caja - Banco del balance va creciendo favorablemente desde US\$39 032.04 en el año cero hasta el año cinco con US\$215 007.31. Por otro lado, los inventarios se darán con la equivalencia de aproximadamente un mes de venta, lo que 
no afecta a las ganancias. Se aprecia también, la cuenta Capital Social, la cual será de US\$29 274.03 con unas utilidades a lo largo del quinto año por un valor de US\$47 160.84 .

\section{Cuadro N'85:}

Balance General en US\$ (2016-2020)

\begin{tabular}{|c|c|c|c|c|c|c|}
\hline \multicolumn{7}{|c|}{ ESTADO DE SITUACIÓN FINANCIERA } \\
\hline CONCEPTO & $P$ & 2016 & 2017 & 2018 & 2019 & 2020 \\
\hline \multicolumn{7}{|l|}{$\underline{A C T I V O}$} \\
\hline \multicolumn{7}{|l|}{ Activo Corriente } \\
\hline Caja y Bancos & $39,032.04$ & $50,108.85$ & $68,036.29$ & $97,196.73$ & $137,664.87$ & $215,007.31$ \\
\hline Inventarios & $15,422.40$ & $15,422.40$ & $15,422.40$ & $15,422.40$ & $15,422.40$ & $15,422.40$ \\
\hline Total Activo Corriente & $54,454.44$ & $65,531.25$ & $83,458.69$ & $112,619.13$ & $153,087.27$ & 230,429.71 \\
\hline \multicolumn{7}{|l|}{ Activo No Corriente } \\
\hline Inversión Fija Tangible & $4,654.28$ & $4,654.28$ & $3,650.44$ & $2,729.64$ & $1,725.80$ & $2,934.41$ \\
\hline Depreciación & & $1,003.85$ & $1,003.85$ & $1,003.85$ & $1,003.85$ & $1,003.85$ \\
\hline \multicolumn{7}{|l|}{ Inversión Fija Intangible } \\
\hline Total Activo No Corriente & $4,654.28$ & $3,650.44$ & $2,646.59$ & $1,725.80$ & 721.95 & $1,930.57$ \\
\hline Total Activo & $59,108.72$ & $69,181.68$ & $86,105.28$ & $114,344.93$ & $153,809.22$ & $232,360.28$ \\
\hline \multirow{2}{*}{\multicolumn{7}{|c|}{$\frac{P A S I V O}{\text { Pasivo Corriente ( Proveedores) }}$}} \\
\hline & & & & & & \\
\hline Deuda Corriente de Préstamo & 20,077 & 20,077 & 20,077 & 20,160 & 20,160 & $51,550.00$ \\
\hline Total Pasivo Corriente & $20,077.00$ & $20,077.00$ & $20,077.00$ & $20,160.00$ & $20,160.00$ & $51,550.00$ \\
\hline \multicolumn{7}{|l|}{ Pasivo No Corriente } \\
\hline Préstamo & $9,758.01$ & $7,565.47$ & $4,129.59$ & & & \\
\hline Total Pasivo No Corriente & & $7,565.47$ & 4,129.59 & & & \\
\hline Total Pasivo & $29,835.01$ & $27,642.47$ & $24,206.59$ & $20,160.00$ & $20,160.00$ & $51,550.00$ \\
\hline \multicolumn{7}{|l|}{ PATRIMONIO NETO } \\
\hline Capital Social & $29,274.03$ & $29,274.03$ & $29,274.03$ & $29,274.03$ & $29,274.03$ & $29,274.03$ \\
\hline Utilidades del periodo & & $12,265.51$ & $20,359.48$ & $32,286.18$ & $39,464.30$ & $47,160.84$ \\
\hline Utilidades retenidas & & & $12,265.51$ & $32,624.99$ & $64,911.17$ & $104,375.47$ \\
\hline Total Patrimonio Neto & $29,274.03$ & $41,539.53$ & $61,899.01$ & $94,185.20$ & $133,649.49$ & $180,810.33$ \\
\hline Total Pasivo y Patrimonio Neto & $59,109.04$ & $69,182.00$ & $86,105.60$ & $114,345.20$ & $153,809.49$ & $232,360.33$ \\
\hline ACTIVOS - (PASIVO + PATRI) & $\mathbf{0}$ & $\mathbf{0}$ & $\mathbf{0}$ & $\mathbf{0}$ & $\mathbf{0}$ & $\mathbf{0}$ \\
\hline
\end{tabular}

Elaboración Propia 


\subsection{Evaluación Económica y financiera del negocio (TIR, TIRF, VAN Y}

\section{VANF)}

Como se aprecia en el Cuadro $\mathrm{N}^{\circ} 86$, los indicadores financieros que más importancia presenta la empresa son la Tasa de Interés de Retorno (TIR), con un $61.26 \%$, y el Costo de Oportunidad del Inversionista para el rubro textil, con un $20.58 \%$. Este ratio es correcto ya que supera al $20.19 \%$ que es la tasa de préstamo bancario. Además, el Valor Actual Neto económico (VAN) hace referencia a que los flujos de caja neta llevados al presente son positivos, es decir, la empresa sí es rentable.

Con respecto a los ratios financieros, se encuentra nuevamente el TIR, que es un poco más alto que el económico con un valor del 69.34\%. Por otro lado, el Valor Actual Neto Financiero es rentable con un valor de US\$58 350.88 y el COK es mayor al WACC.

\section{Cuadro N 86:}

Ratios Económicos y Financieros (2016-2020)

\begin{tabular}{|c|c|}
\hline \multicolumn{2}{|c|}{ Ratios Económicos } \\
\hline TIR & $61.26 \%$ \\
\hline $\mathrm{COK}$ & $20.58 \%$ \\
\hline VAN & US\$ $57,532.88$ \\
\hline \multicolumn{2}{|c|}{ Ratios Financieros } \\
\hline TIR & $69.34 \%$ \\
\hline WACC & $18.97 \%$ \\
\hline VAN & US\$ $58,350.88$ \\
\hline
\end{tabular}

Elaboración propia 


\section{CAPITULO XIII: EVALUACIÓN Y CONTROL}

\subsection{Balanced Scorecard (Identificación de Indicadores)}

\subsubsection{Finanzas}

El objetivo principal a largo plazo en el área de Finanzas es que la empresa genere valor. El objetivo a corto plazo hacia este, es saber si la empresa se puede adaptar a diversas situaciones a lo largo de su duración. Para esto se tomarán algunos indicadores como:

- Rotación de Capital de Trabajo, donde se mide el número de veces que el Capital de Trabajo rota en función a sus ventas. Las ventas entre el capital de trabajo es de 4.04, esto indica que hay una óptima eficiencia en el uso que se le otorga al Capital.

- Rotación del activo fijo: El ratio resultante es de 3.05 lo que indica que los activos si son suficientes para el nivel de ventas de la empresa.

- Margen Bruto: El margen que queda sobre las ventas es de 35\%. Este porcentaje se utiliza para cubrir cualquier gasto de Teco Caricias S.AC.

- Rentabilidad del Patrimonio: Este es el principal índice ya que las utilidades del ejercicio se relacionan con el patrimonio, el cual es de 3.57 .

\subsubsection{Clientes}

Un objetivo a largo plazo es incrementar la participación de mercado en un $10 \%$ y a corto plazo en un $4 \%$. Para que los clientes puedan confiar en la empresa debemos enfocarnos en el área de marketing y ventas. Uno de los indicadores más importantes es la participación de mercado; aquí el porcentaje de mercado que debe ocupar la marca en 
relación con la competencia debe ser alto para que el posicionamiento esté dado de una manera óptima en la mente del consumidor.

Otro indicador es la cobertura de mercado en Colombia. Los puntos de venta donde se encuentra la marca deben abarcar un $35 \%$ aproximadamente del total de puntos de venta en ese país. Además, la fidelización de los clientes debe ser de un mínimo de $85 \%$. Esto quiere decir que de cada cincuenta clientes que vayan a comprar las prendas, 43 de ellos deberían regresar.

El índice de satisfacción al cliente es el indicador más importante. Es decir, los clientes satisfechos deben ser el $90 \%$ del total.

\subsubsection{Operaciones}

El objetivo a largo plazo es la existencia de la alta rotación de insumos; a corto plazo, es obtener los mismos en tiempos óptimos contando con procesos de forma eficiente.

Los indicadores son el tiempo promedio de abastecimiento, los cuales son la cantidad de materiales abastecidos en un tiempo aproximado de una semana. Además, el tiempo promedio de almacenamiento debe darse de forma diaria con respecto a la cantidad de productos elaborados. Por último, está el indicador de distribución, el cual consiste en el tiempo en el que los productos terminados deben llegar a Colombia sin ningún inconveniente, el cual es de veintiún días. 


\subsubsection{Recursos Humanos}

El objetivo a largo plazo en cuando al indicador de RR.HH es que la remuneración y el ambiente laboral de Teco Caricias S.AC esté posicionada entre las top 10.

Los indicadores más importantes son tres. El primero es el clima laboral, donde indica que el ambiente en el que se desempeñan los trabajadores es confortable; si este tiene un índice alto (se espera que sea un 95\% de trabajadores satisfechos), la productividad de estas personas crece y origina un beneficio para la empresa. En segundo lugar, está el nivel de capacitación dado que en la empresa se realizarán capacitaciones cada medio año en todas las áreas correspondientes para que así los trabajadores tengan mejores conocimientos de la empresa o de las nuevas tecnologías que llegan. Por último, la rotación del personal debe ser mínima, si se puede de 0-10\%, dado que el número de empleados en la empresa debe ser constante y se debe realizar un reclutamiento minucioso para que estos no deseen retirarse.

\section{Cuadro $\mathbf{N}^{\circ}$ 87:}

\section{Matriz CMI}

\begin{tabular}{llll}
\hline Perspectivas & Objetivo & Indicador & Valor/Meta \\
\hline Finanzas & Crecimiento de Valor en & Rotación de Capital de & 4.04 \\
& ventas & Trabajo & \\
& Maximizar ingresos & Rotación Activo Fijo y & 3.05 \\
& Incrementar la rentabilidad & $\begin{array}{l}\text { margen bruto } \\
\text { Rentabilidad de Patrimonio }\end{array}$ & $35 \%$ \\
& & & 3.57 \\
Clientes & Incrementar la participación del & Participación de mercado & $10 \%$ LP \\
& mercado & Cobertura de mercado & $4 \%$ CP \\
& & Fidelización de los clientes & $35 \%$ \\
& & Satisfacción de clientes & $85 \%$ \\
Operaciones & Alta rotación de insumos-LP & Tiempo promedio de & $90 \%$ \\
& Obtener los insumos en & abastecimiento. & 7 días máx. \\
& tiempos óptimos - CP & Tiempo promedio de & Diaria \\
& & almacenamiento & \\
& & Distribución & 21 días \\
RR HH & Remuneración y ambiente & Índice de Clima laboral & $95 \%$ \\
& óptimos & Nivel de capacitación & 2 veces al año-100\% \\
& Top 10 microempresas -LP & Rotación del personal & $0-10 \%$ \\
\hline
\end{tabular}


Por otro lado, como se aprecia en el Cuadro $\mathrm{N}^{\circ} 88$, la matriz EFI tiene un puntaje de 2.90 debido a que los resultados más notorios se aprecian cuando el tiempo de entrega es óptimo, la buena selección del personal para que integre la empresa y porque los precios y servicios serán competitivos. Como ya se explicó en el capítulo 4 sobre el método de análisis de las matrices tanto EFE como EFI, la debilidad que podría perjudicar a la empresa será la inexistencia de nuevo capital para adquirir tecnología de avanzada y la existencia de pocos proveedores de telas orgánicas (cuatro en el Perú)

\section{Cuadro $\mathbf{N}^{\circ}$ 88:}

Matriz EFI

\begin{tabular}{lrrr}
\hline Fortalezas & Peso & Valor & $\begin{array}{l}\text { Puntaje } \\
\text { Ponderado }\end{array}$ \\
\hline Personal profesional y capacitado de forma constante & & 3 & 0.15 \\
Comunicación horizontal & 0.05 & 4 & 0.20 \\
Buena infraestructura & 0.05 & 3 & 0.15 \\
Poseemos una organización funcional y estructural & 0.05 & 3 & 0.15 \\
Se cuenta con capital propio para operar & 0.05 & 4 & 0.2 \\
Precios y Servicios Competitivos & 0.10 & 3 & 0.3 \\
Variedad de colores en las prendas & 0.05 & 3 & 0.15 \\
Buena selección del personal que integrará la empresa. & 0.10 & 4 & 0.4 \\
El tiempo de entrega es óptimo & 0.15 & 4 & 0.6 \\
Almacenamiento espacioso para los productos & 0.05 & 3 & 0.15 \\
Existe control financiero en la empresa & 0.05 & 3 & 0.15 \\
Debilidades & & & 0.05 \\
No se le da un máximo uso a la tecnología ( software) & 0.05 & 1 & 0.1 \\
No existe mucho capital para adquirir nueva tecnología. & 0.05 & 2 & 0.1 \\
Pocos proveedores de telas orgánicas & 0.10 & 1 & 0.05 \\
Baja remuneración hacia el personal porque la empresa es & 0.05 & 1 & \\
nueva. & & & \\
TOTAL & & 0.90 \\
\hline
\end{tabular}

Elaboración Propia 


\section{Conclusiones}

A continuación se detallarán las conclusiones:

- Se fabricarán prendas para bebés de 0-24 meses debido a la tendencia hacia lo natural y al favorecimiento con el medio ambiente que Colombia tiene.

- Se logró tener contacto con la empresa Bergman Rivera S.A.C; la cual será la principal proveedora de la tela orgánica y del hilado.

- Se diseñarán las prendas en colores nativos como el crema, café y verde oliva debido a que son $100 \%$ naturales y para que no existan inconvenientes con las certificaciones.

- Se contará con certificaciones internacionales como GOTS, IMO, entre otras para que no existan problemas en el momento de las exportaciones y estas estén catalogadas como producto estrella.

- Se va a invertir en el sector infantes, de 0-24 meses, por la necesidad de uso sobre lo orgánico, debido a que estos mudan de ropa más rápido que los de edad más avanzada.

- Existirá la factibilidad de inversión en el mercado Colombiano, según los indicadores económicos en el sector textil para bebés, debido a la potencialidad de generar rentabilidad. 
- Existirá una visión favorable para la industria textil orgánica en el Mercado Colombiano debido a la tendencia creciente observada por SUNAT en los próximos cinco años.

- Se logró dar un precio competitivo para el mercado Colombiano de US\$10.71 por prenda para los primeros dos años para luego aumentarla a US\$11.01 de acuerdo a la competencia. Esto generará rentabilidad para la empresa al igual que mayor labor social para los trabajadores del campo.

- De acuerdo a la tendencia del mercado colombiano por los diseños vanguardistas y prendas frescas (que den mayor movilidad a los bebés) se contratará a dos diseñadores (uno Colombiano y otro Peruano) para que las prendas puedan venderse de una manera óptima.

- Se contará con la más alta calidad, con diseños reconocidos de temporada en las prendas debido a que los factores que influyen en la decisión de compra sobre el vestuario son el gusto, la moda y por necesidad.

- Se irá hacia el mercado Colombiano porque según el estudio realizado es una de las economías más sólidas y en crecimiento de toda la región Sudamericana lo que lograría que Teco Caricias S.AC pueda expandirse y tener crecimiento internacional.

- El presente proyecto estará dirigido hacia el sector socioeconómico A y B puesto que la clase media colombiana está en crecimiento para los siguientes 
años y los pertenecientes a esta, tienen disponibilidad para la adquisición de productos de alto rango para sus bebés.

- Se tendrá que ofrecer estrategias de competitividad diferenciadas con los productos Chinos debido a que estos cuentan con menores precios en todo el mercado y serán considerados como productos sustitutos hacia Teco Caricias S.AC.

- La empresa se diferenciará con la competencia por la calidad de productos y servicios, diseños y sobre todo por la lealtad que tendrá el cliente hacia la empresa.

- De acuerdo a la evaluación interna, la organización de la empresa será funcional y estructural para que existan beneficios ante todo el personal debido a la comunicación horizontal.

- La venta a los largo de los cinco primeros años será de 60000 prendas. Donde crecerá de un $3 \%$ a un $5 \%$.

- La fortaleza más importante que se tendrá, será el contacto con empresas internacionales del mismo sector. Por otro lado, el personal que laborará debe ser capacitado de acuerdo a los conocimientos y experiencias de los Gerentes que los liderarán para que la empresa pueda crecer. 
- Con respecto al plan de marketing, las tres fases vistas como el estudio de mercado, lanzamiento de producto y fase de venta se posicionará de forma óptima en el mercado colombiano para que el producto quede marcado en la mente del consumidor.

- Se asignará como envase las bolsas de yute, debido a que estas son orgánicas, cuentan con alta calidad y tienen flexibilidad a la hora de su manipulación y no perjudican la prenda.

- El precio se halló en base al método costing para que exista un doble beneficio, tener un precio más competitivo y ver el margen que conlleva. Este método se actualizará de acuerdo al seguimiento mensual que se tendrá sobre los costos de la competencia.

- Con respecto a los medios de promoción, la empresa se concentrará en la elaboración de la página web, App donde los clientes comprarán on line las prendas. Se ofrecerán volantes y se pondrán paneles publicitarios para incrementar la demanda del producto debido a que la era tecnológica actual está en auge.

- De acuerdo al plan de operaciones, se optimizarán los tiempos de entrega estableciendo un volumen de operaciones de forma mensual mediante diversas herramientas. 
- Mediante este proyecto, se alcanzó una demanda objetivo hacia el mercado colombiano del $0.65 \%$ en el primer año, logrando alcanzar casi el $1 \%$ en el quinto año de producción.

- Se aprecia que las ventas se incrementaron anualmente, llegando a exportar en el primer año ocho pallets y al quinto año doce pallets.

- Mediante una distribución de planta óptima, mostrado en el capítulo 8, se tendrá una mejor utilización de espacio en la empresa para que cumpla con los estándares requeridos por defensa civil y para que exista un buen orden laboral.

- Los principales procesos del proyecto irán desde las cotizaciones del pedido hasta que el producto llegue al cliente final en Colombia. Si todo el proceso es correcto y no ocurren inconvenientes, el cliente estará satisfecho en su totalidad. Mediante el seguimiento mensual se apreciará que los indicadores de la empresa serán óptimos.

- La capacidad instalada se dará mediante la Capacidad de Almacenamiento y de Procesamiento de seis prendas por hora en un turno de ocho horas por tres personas. En los próximos años, si la demanda del mercado crece, se contratará a nuevo personal y se podrá tener hasta 288 prendas diarias.

- Se obtuvo un proceso logístico óptimo, el cual comienza desde la obtención de los insumos (telas, envases, embalaje e hilados) hasta la distribución para 
las empresas minoristas en el mercado colombiano mediante el transporte aéreo.

- Se escogió el transporte aéreo, debido a la cantidad de prendas a exportar (volumen pequeño) a pesar que este medio es caro. Sin embargo, si en algún momento la cantidad es muy elevada se comenzaría a exportar en transporte marítimo con diferentes tipos de contenedores.

- Debido a que existen diversas áreas administrativas se llevará un control sobre las áreas de compras, finanzas y gestión de talento humano mediante un formato de seguimiento (plantillas de Excel) para ver si cumplen con las metas establecidas de cada persona.

- En el flujo financiero mostrado a lo largo del primer hasta el quinto año, las utilidades generadas fueron amplias llegando al quinto año con un valor de US\$ 46916.97.

- La empresa se adaptará a diferentes situaciones financieras para poder así generar rentabilidad mediante un seguimiento con diversos indicadores como rotación de capital de trabajo, activo fijo y el margen bruto. 


\section{Recomendaciones}

A continuación se detallarán las recomendaciones:

- Se debería analizar más el mercado de algodón orgánico colombiano y de los países vecinos para poder ser una empresa con mayor volumen (respecto a las ventas) y competitiva (por el valor agregado que se ofrece: diseño y calidad).

- Durante los primeros años se debería exportar un producto estandarizado. Sin embargo, con el pasar del tiempo y cuando la empresa sea más conocida, se recomendaría comercializar productos complementarios como las gorras, medias, pantaloncitos, politos, entre otras, pero del mismo material orgánico.

- Las prendas ecológicas dirigidas hacia el mercado colombiano cuentan con un precio promedio de US $\$ 10.71$ durante los dos primeros años y los demás por US\$11.01. Sin embargo, es preferible que dependiendo de los diseños que se den y de la época en la que se encuentre (verano/ invierno), el precio sea más elevado o más bajo que el propuesto inicialmente.

- Debido a que los primeros años la empresa se posicionará mediante minoristas en tiendas elegidas en el Centro de Colombia, los próximos años se recomendaría que de acuerdo a las ganancias, se deba establecer una tienda propia y luego una tienda espejo. Todo esto con el fin de que exista más rentabilidad. 
- Se recomienda ir a las ferias más importantes de Colombia en cuanto a textiles y moda como lo son Colombiatex, Baby and Kids, entre otras, con el objetivo de conocer más acerca de las tendencias del país.

- Se recomienda realizar en cada estación del año un focus group hacia el sector de madres gestantes colombianas, para conocer las inquietudes que ellas presentan acerca de las prendas que sus bebes van a vestir.

- Como la empresa textil tiene un panorama futuro de alza hacia un $4 \%$, es recomendable que se dé un seguimiento con respecto a la gestión de inversiones futuras y pueda aprovecharse el resultado que se obtenga en las ganancias y sean distribuidas de manera eficiente.

- Es recomendable buscar otros proveedores de algodón orgánico debido a que existe una alta disponibilidad por parte de Teco Caricias S.AC ante estos insumos. Por otro lado, como se sabe que India y Turquía son los principales productores de algodón orgánico, se deberían de generar visitas para luego tener alguna alianza con ellos y logre existir un back up de emergencia por si se presentan inconvenientes en la obtención de insumos nacionales.

- Puesto que el objetivo del proyecto es que la empresa crezca hasta un 5\%, se recomienda que se comercialice en otros puntos de venta de diferentes ciudades tanto de Colombia como de Perú.

- Debido a que Teco Caricias S.AC se establecerá como una empresa que ofrece calidad y diseños óptimos, es recomendable que esta se mantenga posicionada 
sobre la calidad e innovación en la mente del consumidor mediante spots publicitarios, ya sean por paneles o en la entrega de muestras.

- Se recomienda tener un formato de indicadores actualizados sobre las metas alcanzadas del área de Operaciones y Producción para darle seguimiento mediante comités (reuniones) semanales con los gerentes y los encargados de monitorear los resultados.

- Es recomendable brindar innovación en cuanto al empaque. Es decir, ya que los envíos de prendas son puestos en bolsas de yute para optimizar el espacio en los contenedores, el área de logística podría realizar cotizaciones para la compra de bolsas de cartón reciclado en el mercado colombiano y de esa forma se le pueda brindar a los clientes un nuevo empaque con plus ecológico. Al mismo tiempo, se tendría beneficios sobre el marketing ya que al momento que el cliente compra los productos, estará adquiriendo estas bolsas y el público podrá apreciar la marca e interesarse por su compra.

- Para un mejor reconocimiento en cuanto a la calidad de las prendas, es recomendable adquirir una certificación global. Esta certificación logrará que la empresa sea reconocida y por ende pueda tener mayores ventas en este mercado.

- Se debe tener un personal preparado en la empresa para la elaboración de los textiles. Es recomendable que estos puedan tomar cursos o tener actualizaciones del proceso productivo de las prendas y de las maquinarias. 
- Se debe tener en cuenta que la confianza existente entre los exportadores e importadores es esencial debido al manejo en cuanto a los pagos y en un futuro mejores precios. Por otro lado, la empresa necesita realizar una lista de clientes importantes en el país a comercializar para que pueda ofrecerles muestras de los productos y así logre tener mayor acceso a ellos.

- Mientras se realizaba el presente proyecto, el Embajador de la Cámara Colombiana recomendó, para el mismo, utilizar a futuro un transporte marítimo en vez del aéreo para reducir un poco los costos y así obtener una mayor ganancia. 


\section{REFERENCIAS}

- Dermatológica, S. P. (2015). Evolución y reacciones del recien nacido. Ser Padres.

- Eva, P., \& Rovatti. (17 de 01 de 2016). bebés y más. Obtenido de Salud infantil: http://www.bebesymas.com

- Gonzáles-Oviedo, M. R. (2016). RECIÉN NACIDO: RECOMENDACIONES PARA El CUIDADO DE SU PIEL. ISSN - DERMATOLOGÍA PERUANA, 1-3.

- Paris, E., \& Rovatti, L. (15 de enero de 2016). Bebés y más. Obtenido de Bebés y más: http://www.bebesymas.com

- Salud, O. M. (2014). Cultivo de Algodón orgánico. OMS 2016.

- SUNAT ( 2016), IMPORTACIONES Y EXPORTACIONES DE PRENDAS PERU - COLOMBIA. En:

http://www.siicex.gob.pe/siicex/portal5ES.asp?_page_=172.17100\&_portletid_=sfi chaproductoinit\&scriptdo=cc_fp_init\&pproducto=\%206111200000\%20\&pnompro ducto=\%20PRENDAS\%20Y\%20COMPLEMENTOS\%20DE\%20VESTIR\%20DE \%20PUNTO\%20PARA\%20BEBES,\%20DE\%20ALGODON

- EUROMONITOR(2016), Apparel and Footwer in Colombia, En: http://www.portal.euromonitor.com/portal/analysis/tab

- BANCO MUNDIAL ( 2016), Indicadores de Desarrollo mundial. En: http://datos.bancomundial.org/pais/peru

- Farfán, Heryk. ( 2015). Se aproxima la primera cosecha de algodón orgánico en el Tolima. Recuperado el 04 de enero del 2016. En:

http://www.lasiesta.com/homefiles/img/11_pressepdfs/Pressespiegel/El_nuevo_Dia.pdf

- ORGANIZACIÓN DE LAS NACIONES UNIDASPARA LA ALIMENTACIÓN Y LA AGRICULTURA (2014). El algodón orgánico puede desempeñar un papel vital en la alimentación del mundo. Recuperado el 12 de septiembre del 2015. En: http://www.oia.com.ar/novedades/detalle/211/el-algodon-organico-puededesempenar-un-papel-vital-en-la-alimentacion-del-mundo.

- BANCO CENTRAL DE COLOMBIA ( 2016).Socios Comerciales y Contexto macroeconómico. Recuperado el 3 de enero del 2016. En: http://www.banrep.gov.co/es

- CANCILLERÍA (2016). Asuntos económicos, sociales y ambientales.p3 
- Romero, Carlos. Técnicas de Gestión de Empresas. Cepade Edición. Madrid .pp.45

- Archivo General de la nación. REVISTA PORTAFOLIO: Biodiversidad Colombiana.pp1, 2015.

- VERITRADE(2015), ESTADÍSTICAS : Valores FOB de prendas para el mercado Colombiano.Recuperado el 28 de Diciembre del 2015 En:

http://veritrade.info/productos/2

- THE WORLD FACT BOOK ( 2016). ESTADISTICS : Perú,. Recuperado el 28 de Diciebre del 2015 En: https://www.cia.gov/library/publications/the-worldfactbook/geos/pe.html

- Chávarri, Alfonso. (2012). CONTROL UNION CERTIFICATIONS. Recuperado el 03 de junio del 2015 En:

http://export.promperu.gob.pe/Miercoles/Portal/MME/descargar.aspx?archivo=61D 03D18-92EF-48CF-BFBA-45AB6F02D233.PDF

- SIICEX. (2015). PARTIDAS ARANCELARIAS DEL PRODUCTO. Recuperado el 20 de Enero del 2016 En: http://www.siicex.gob.pe/siicex/portal5ES.asp?_page_=172.17100\&_portletid_=sfi chaproductoinit\&scriptdo=cc_fp_init\&pproducto $=6111200000$

- DANE. (2014). CUENTAS ECONÓMICAS. Recuperado el 3 de Enero del 2016 En: http://www.dane.gov.co/index.php/pib-cuentas-nacionales/cuentas-trimestrales

- DANE. (2012). Censos Población. Recuperado el 02 de setiembre del 2015 En: http://buscador.dane.gov.co/search? $q=$ censo $+2011 \& b t n G \cdot x=0 \& b t n G . y=0 \& c l i e n t=D$ ANE_FrontEnd\&output=xml_no_dtd\&proxystylesheet=DANE_FrontEnd\&proxyre load $=1 \&$ sort $=$ date $\% 3 \mathrm{AD} \% 3 \mathrm{AL} \% 3 \mathrm{Ad} 1 \&$ oe $=\mathrm{UTF}-8 \& \mathrm{ie}=\mathrm{UTF}-$ $8 \&$ ud=1\&exclude_apps $=1 \&$ site $=$ danegovco $\&$ getfields $=* \&$ filter $=0$

- Gaviria, Gaviria y Morales. (2011)¿ Qué tan grande es la clase media en Colombia". Dinero, 2da, p. 6.

- COMUNIDAD ANDINA (2014). Comunidad Andina de Naciones Colombia Perú. Recuperado el 10 de setiembre del 2014 En: http://tvcan.comunidadandina.org/index.aspx

- BANCO POPULAR (2014). Recuperado de Remesa Documentaria, el 20 de mayo del 2015, En: http://www.bancopopular.es/popular-web/empresas/gestion-comercioexterior/gestion-tesoreria-internacional/remesa-documentaria 
- WIKISPACES (2012). "Medios de Pago". Recuperado el 25 de abril del 2015, En: http://mediosdepago.wikispaces.com/Remesa+documentaria+(David)

- OFICINA COMERCIAL DE LA EMBAJADA DE ESPAÑA EN COLOMBIA. Comercio y Distribución en Colombia. Recuperado el 15 de octubre del 2014, En: http://www.fenalco.com.co/sites/default/files/blog/COMERCIO\%20Y\%20DISTRI BUCI\%C3\%93N\%20en\%20Colombia.pdf

- Ministry of Foreign Affairs. (2012). Estructura y Canales de comercio para la ropa de bebés. Recuperado el 05 de octubre del 2014, de CBI. En:

http://www.cbi.eu/system/files/marketintel/Estructura_y_canales_de_comercio_para _la_ropa_de_bebes.pdf

- INEXMODA (2014). Colombiatex de las Américas. Recuperado el 05 de octubre del 2014 En: :http://www.nferias.com/colombiatex-americas/

- REPÚBLICA DEL PERÚ (2014) Superintendencia de Banco y Seguros y AFP: Tipo de Cambio y Tasa de Interés. Recuperado el 07 de Mayo del 2015, En: http://www.sbs.gob.pe/

- Asociación Naturland. (2000). Producción Orgánica de Algodón. Asociación Naturland, I edición, 16.

- OLX (2014). Departamentos en Alquiler. Recuperado el 01 de julio del 2015 , En : http://lima-lima.olx.com.pe/alquilo-local-comercial-en-los-olivos-av-proceres-dehuandoy-iid-725856013\#galleryContainer

- Ortiz, Sandra (2014), “El consumidor Colombiano”. Recuperado el 06 de junio del 2015. En: http://www.globalpyme.org/memorias/el-consumidor-colombiano.pdf 


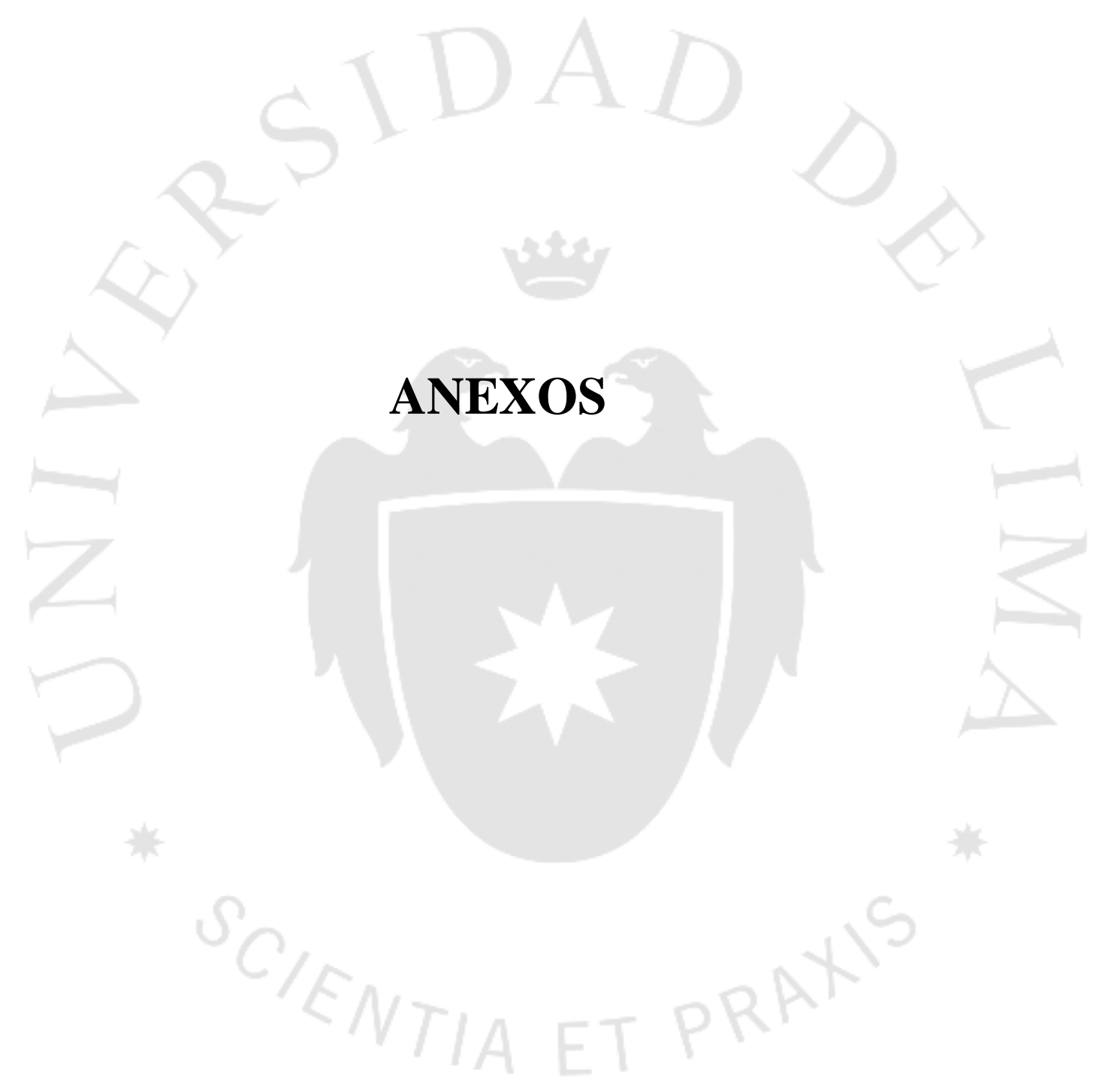




\section{Bergman/Rivera}

\section{TELAS MERCADO LOCAL PIMA 2015}

\begin{tabular}{|l|c|c|c|cc|}
\hline & & & \multicolumn{3}{|c|}{ Produccion } \\
Tipo de Tela & Peso (gms) & Ancho (mts) & Metros $\times$ Kg & Blco/Nat & Color \\
\hline & & & & & \\
JERSEYS & & & & & \\
Jersey 20/1 & $190-210$ & 0.90 & $2.7-2.8$ & $\$ 15.40$ & $\$ 17.40$ \\
Jersey 24/1 & $170-190$ & 0.90 & $3.1-3.4$ & $\$ 15.70$ & $\$ 17.70$ \\
Jersey 30/1 & $140-160$ & 0.80 & $3.7-3.9$ & $\$ 15.90$ & $\$ 17.99$ \\
Jersey 40/1 & $110-130$ & 1.60 & $4.9-5.0$ & $\$ 16.85$ & $\$ 18.85$ \\
Jersey 50/1 & $90-110$ & 1.50 & $6.5-6.6$ & $\$ 17.75$ & $\$ 19.75$ \\
Jersey 60/1 & $70-100$ & 1.40 & $8.2-8.4$ & $\$ 18.80$ & $\$ 20.80$ \\
RuBS & & & & & \\
Rib 20/1 & $250-290$ & 0.80 & $1.9-2.2$ & $\$ 14.80$ & $\$ 16.80$ \\
Rib 24/1 & $220-260$ & 0.80 & $2.4-2.8$ & $\$ 15.20$ & $\$ 17.20$ \\
Rib 30/1 & $180-220$ & 0.70 & $3.2-3.9$ & $\$ 15.50$ & $\$ 17.50$ \\
Rib 40/1 & $150-180$ & 0.65 & $4.2-5.0$ & $\$ 16.20$ & $\$ 18.20$ \\
Rib 50/1 & $115-145$ & 0.65 & $5.2-6.6$ & $\$ 17.20$ & $\$ 19.20$ \\
Rib 60/1 & $100-130$ & 0.60 & $6.3-8.2$ & $\$ 18.35$ & $\$ 20.35$ \\
INTERLOCKS & & & & & \\
Interlock 24/1 & $260-300$ & 0.80 & $1.8-2.1$ & $\$ 15.70$ & $\$ 17.70$ \\
Interlock 30/1 & $220-250$ & 0.85 & $2.2-2.5$ & $\$ 16.15$ & $\$ 18.15$ \\
Interlock 40/1 & $180-210$ & 0.85 & $2.7-3.2$ & $\$ 16.85$ & $\$ 18.85$ \\
Interlock 50/1 & $155-195$ & 0.75 & $3.1-3.9$ & $\$ 17.75$ & $\$ 19.75$ \\
& & & & & \\
\hline
\end{tabular}

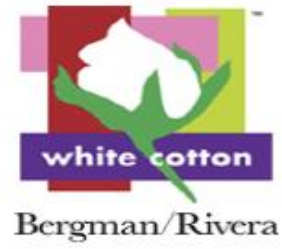




\section{Bergman/Rivera}

TELAS MERCADO LOCAL TANGUIS 2015

\begin{tabular}{|c|c|c|c|c|c|}
\hline \multirow[b]{2}{*}{ Tipo de Tela } & \multirow[b]{2}{*}{ Peso (gms) } & \multirow[b]{2}{*}{ Ancho (mts) } & \multirow[b]{2}{*}{ Metros $\mathrm{x} \mathrm{Kg}$} & \multicolumn{2}{|c|}{ Produccion } \\
\hline & & & & Blco/Nat & Color \\
\hline JERSEYS & & & & & \\
\hline Jersey 20/1 & $190-210$ & 0.90 & $2.7-2.8$ & $\$ 11.55$ & $\$ 13.55$ \\
\hline Jersey 24/1 & $170-190$ & 0.90 & $3.1-3.4$ & $\$ 11.80$ & $\$ 13.80$ \\
\hline Jersey 30/1 & $140-160$ & 0.80 & $3.7-4.2$ & $\$ 12.25$ & $\$ 14.25$ \\
\hline Jersey $40 / 1$ & $110-130$ & 1.60 & $4.7-5.6$ & $\$ 13.40$ & $\$ 15.40$ \\
\hline RIBS & & & & & \\
\hline Rib 20/1 & $250-290$ & 0.80 & $1.9-2.2$ & $\$ 11.00$ & $\$ 13.00$ \\
\hline Rib 24/1 & $220-260$ & 0.80 & $2.4-2.8$ & $\$ 11.50$ & $\$ 13.50$ \\
\hline Rib 30/1 & $180-220$ & 0.70 & $3.2-3.8$ & $\$ 11.75$ & $\$ 13.75$ \\
\hline $\begin{array}{l}\text { Rib 40/1 } \\
\text { INTFRI OCKS }\end{array}$ & $150-180$ & 0.65 & $4.2-5.0$ & $\$ 12.50$ & $\$ 14.50$ \\
\hline INTERLOCKS & & & & & \\
\hline Interlock 24/1 & $260-300$ & 0.80 & $1.8-2.1$ & $\$ 12.00$ & $\$ 14.00$ \\
\hline Interlock 30/1 & $220-250$ & 0.85 & $2.2-2.5$ & $\$ 12.35$ & $\$ 14.35$ \\
\hline Interlock 40/1 & $180-210$ & 0.85 & $2.7-3.2$ & $\$ 13.05$ & $\$ 15.05$ \\
\hline $\begin{array}{l}\text { OTRAS TELAS } \\
\text { Jersey } 30 / 195 \% \text { Algodón } 5 \% \text { Lycra* }\end{array}$ & & & & $\$ 13,90$ & $\$ 16.20$ \\
\hline French terry & & & & $\$ 12.95$ & $\$ 15.25$ \\
\hline Fleece & & & & $\$ 12.45$ & $\$ 14.45$ \\
\hline
\end{tabular}

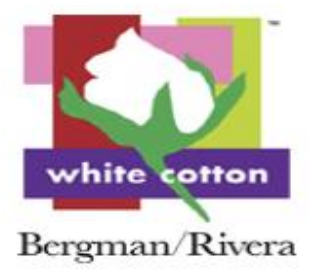




\begin{tabular}{|c|c|c|c|c|c|}
\hline Tela /Fabric & Color & Fibra/Fiber & Peso/Weight & Stock & Precio/Price \\
\hline Rib 20/1 & Natural & Pima & $235 \mathrm{gr} / \mathrm{mt} 2$ & $7 \mathrm{kgs}$ & US\$20.00/kg \\
\hline Interlock 30/1 & Listado Marron & Nativo/Pima & $210 \mathrm{gr} / \mathrm{mt} 2$ & $147 \mathrm{kgs}$ & US\$22.00/kg \\
\hline Interlock 30/1 & Natural & Pima & $210 \mathrm{gr} / \mathrm{mt} 2$ & $5 \mathrm{kgs}$ & US\$22.00/kg \\
\hline Mini Jacquard & Blanco & Tanguis & $230 \mathrm{gr} / \mathrm{mt} 2$ & $42 \mathrm{kgs}$ & US\$30.80/kg \\
\hline Interlock 40/1 & Azul Heather & Pima & $190 \mathrm{gr} / \mathrm{mt} 2$ & $56 \mathrm{kgs}$ & US\$24.85/kg \\
\hline Interlock 40/1 & Gris Heather & Pima & $190 \mathrm{gr} / \mathrm{mt} 2$ & $25 \mathrm{kgs}$ & US\$22.75/kg \\
\hline Interlock 40/1 & Oatmeal Heather & Pima & $190 \mathrm{gr} / \mathrm{mt} 2$ & $46 \mathrm{kgs}$ & US\$21.80/kgs \\
\hline Interlock 40/1 & Natural & Pima & $190 \mathrm{gr} / \mathrm{mt} 2$ & $201 \mathrm{kgs}$ & US\$21.85/kg \\
\hline Interlock 40/1 & Eco White & Pima & $190 \mathrm{gr} / \mathrm{mt} 2$ & $147 \mathrm{kgs}$ & US\$21.85/kg \\
\hline Interlock 40/1 & Marron & Nativo & $190 \mathrm{gr} / \mathrm{mt} 2$ & $127 \mathrm{kgs}$ & US\$23.90/kg \\
\hline Interlock 40/1 & Acero/Eco White & Pima & $190 \mathrm{gr} / \mathrm{mt} 2$ & $26 \mathrm{kgs}$ & US\$28.00/kg \\
\hline Interlock 40/1 & Lila/Eco White & Pima & $190 \mathrm{gr} / \mathrm{mt} 2$ & $32 \mathrm{kgs}$ & US\$28.00/kg \\
\hline Interlock 40/1 & Gris /Eco White & Pima & $190 \mathrm{gr} / \mathrm{mt} 2$ & $12 \mathrm{kgs}$ & US\$28.00/kg \\
\hline Interlock 40/1 & Listado Marron & Nativo/Pima & $190 \mathrm{gr} / \mathrm{mt} 2$ & $93 \mathrm{kgs}$ & US\$22.00/kg \\
\hline Interlock 50/1 & Natural & Pima & $170 \mathrm{gr} / \mathrm{mt} 2$ & $6 \mathrm{kgs}$ & US\$22.75/kg \\
\hline Interlock 50/1 & Ecowhite & Pima & $170 \mathrm{gr} / \mathrm{mt} 2$ & $102 \mathrm{kgs}$ & US\$22.75/kg \\
\hline Interlock 50/1 & Negro & Pima & $170 \mathrm{gr} / \mathrm{mt} 2$ & $149 \mathrm{kgs}$ & US\$24.50/kg \\
\hline Interlock 50/1 & Celeste & Pima & $170 \mathrm{gr} / \mathrm{mt} 2$ & $109 \mathrm{kgs}$ & US\$24.50/kg \\
\hline Interlock 50/1 & Rosado & Pima & $170 \mathrm{gr} / \mathrm{mt} 2$ & $8 \mathrm{kgs}$ & US\$24.50/kg \\
\hline Interlock 50/1 & Rosado Claro & Pima & $170 \mathrm{gr} / \mathrm{mt} 2$ & $127 \mathrm{kgs}$ & US\$24.50/kg \\
\hline Interlock 50/1 & Mint & Pima & $170 \mathrm{gr} / \mathrm{mt} 2$ & $138 \mathrm{~kg}$ & US\$24.50/kg \\
\hline Interlock 50/1 & Pebble & Pima & $170 \mathrm{gr} / \mathrm{mt} 2$ & $68 \mathrm{kgs}$ & US\$24.50/kg \\
\hline Interlock 50/1 & Mauve Mist/Lila Oscuro & Pima & $170 \mathrm{gr} / \mathrm{mt} 2$ & $50 \mathrm{kgs}$ & US\$24.50/kg \\
\hline Jersey 24/1 & Marron & Marron Nativo & $180 \mathrm{gr} / \mathrm{mt} 2$ & $69 \mathrm{kgs}$ & US\$18.50/kg \\
\hline Jersey $24 / 1$ & Rosado & Tanguis & $180 \mathrm{gr} / \mathrm{mt} 2$ & $37 \mathrm{kgs}$ & US\$18.10/kg \\
\hline Jersey $24 / 1$ & Naranja & Tanguis & $180 \mathrm{gr} / \mathrm{mt} 2$ & $12 \mathrm{kgs}$ & US\$18.10/kg \\
\hline Rib $24 / 1$ & Rosado & Tanguis & $240 \mathrm{gr} / \mathrm{mt} 2$ & $11 \mathrm{kgs}$ & US\$18.35/kg \\
\hline Jersey 30/1 Acanalado Con Lycra & Negro & Tanguis & $195 \mathrm{mt} / \mathrm{mt} 2$ & $49 \mathrm{kgs}$ & US\$27.15/kg \\
\hline Jersey $30 / 1$ & Marron & Nativo & $155 \mathrm{gr} / \mathrm{mt} 2$ & $102 \mathrm{kgs}$ & US\$20.10/kg \\
\hline Jersey 30/1 & Marron/Natural & Nativo/Pima & $155 \mathrm{gr} / \mathrm{mt} 2$ & $109 \mathrm{kgs}$ & US\$20.85/kg \\
\hline Jersey $30 / 1$ & Natural/Marron & Pima/Nativo & $155 \mathrm{gr} / \mathrm{mt} 2$ & $120 \mathrm{kgs}$ & US\$20.85/kg \\
\hline Jersey $30 / 1$ & Ecowhite & Pima & $155 \mathrm{gr} / \mathrm{mt} 2$ & $143 \mathrm{kgs}$ & US\$20.85/kg \\
\hline Jersey $36 / 1$ Con Lycra & Rojo & Pima & $170 \mathrm{gr} / \mathrm{mt} 2$ & $7 \mathrm{kgs}$ & US\$19.50/kg \\
\hline Jersey $36 / 1$ Con Lycra & Verde & Pima & $170 \mathrm{gr} / \mathrm{mt} 2$ & $19 \mathrm{kgs}$ & US\$19.50/kg \\
\hline Jersey $36 / 1$ Con Lycra & Azul & Pima & $170 \mathrm{gr} / \mathrm{mt} 2$ & $18 \mathrm{kgs}$ & US\$19.50/kg \\
\hline Jersey $40 / 1$ Con Lycra & Negro & Pima & $155 \mathrm{gr} / \mathrm{mt} 2$ & $50 \mathrm{kgs}$ & US\$27.50/kg \\
\hline Jersey $40 / 1$ Con Lycra & Gris Oscuro Heather & Pima & $155 \mathrm{gr} / \mathrm{mt} 2$ & $45 \mathrm{kgs}$ & US\$27.50/kg \\
\hline Jersey $40 / 1$ & Marron & Nativo & $120 \mathrm{gr} / \mathrm{mt} 2$ & $44 \mathrm{kgs}$ & US\$23.90/kg \\
\hline Jersey 40/1 & Gris Oscuro Heather & Pima & $120 \mathrm{gr} / \mathrm{mt} 2$ & $95 \mathrm{kgs}$ & US\$24.75/kg \\
\hline Jersey 40/1 & Oatmeal Heather & Pima & $120 \mathrm{gr} / \mathrm{mt} 2$ & $92 \mathrm{kgs}$ & US\$22.80/kg \\
\hline Jersey $40 / 1$ & Azul Heather & Pima & $120 \mathrm{gr} / \mathrm{mt} 2$ & $32 \mathrm{kgs}$ & US\$25.85/kg \\
\hline Jersey $40 / 1$ & Gris Heather & Pima & $120 \mathrm{gr} / \mathrm{mt} 2$ & $7 \mathrm{kgs}$ & US\$23.75/kg \\
\hline Jersey $40 / 1$ & Ecowhite & Pima & $120 \mathrm{gr} / \mathrm{mt} 2$ & $112 \mathrm{kgs}$ & US\$22.85/kg \\
\hline Jersey 40/1 & Dusk & Pima & $120 \mathrm{gr} / \mathrm{mt} 2$ & $5 \mathrm{kgs}$ & US\$24.80/kg \\
\hline Jersey $40 / 1$ & Pebble & Pima & $120 \mathrm{gr} / \mathrm{mt} 2$ & $51 \mathrm{kgs}$ & US\$24.80/kg \\
\hline Jersey $40 / 1$ & Mist/Lila Oscuro & Pima & $120 \mathrm{gr} / \mathrm{mt} 2$ & $43 \mathrm{kgs}$ & US\$24.80/kg \\
\hline Jersey 40/1 & Powder/Rosado Claro & Pima & $120 \mathrm{gr} / \mathrm{mt} 2$ & $46 \mathrm{kgs}$ & US\$24.80/kg \\
\hline Jersey 50/1 & Eco White & Pima & $100 \mathrm{gr} / \mathrm{mt} 2$ & $61 \mathrm{kgs}$ & US\$23.35/kg \\
\hline Jersey 50/1 & Negro & Pima & $100 \mathrm{gr} / \mathrm{mt} 2$ & $72 \mathrm{kgs}$ & US\$25.45/kg \\
\hline Rib $50 / 1$ & Natural & Pima & $130 \mathrm{gr} / \mathrm{mt} 2$ & $24 \mathrm{kgs}$ & US\$23.35/kg \\
\hline Rib 50/1 Con Lycra & Natural & Pima & $200 \mathrm{gr} / \mathrm{mt} 2$ & $10 \mathrm{kgs}$ & US\$23.35/kg \\
\hline Jersey $60 / 1$ & Ecowhite & Pima & $80 \mathrm{gr} / \mathrm{mt} 2$ & $136 \mathrm{kgs}$ & US\$23.80/kg \\
\hline Jersey 60/1 & Gris Claro/Paloma & Pima & $80 \mathrm{gr} / \mathrm{mt} 2$ & $5 \mathrm{kgs}$ & US\$26.45/kg \\
\hline Plush & Eco White & Tanguis & $220 \mathrm{gr} / \mathrm{mt} 2$ & $87 \mathrm{kgs}$ & US\$25.00/kg \\
\hline French Terry Con Lycra & Negro & Tanguis & $220 \mathrm{gr} / \mathrm{mt} 2$ & $56 \mathrm{kgs}$ & US\$22.10/kg \\
\hline Franela & Acero & Tanguis & $270 \mathrm{gr} / \mathrm{mt} 2$ & $49 \mathrm{kgs}$ & US\$21.00/kg \\
\hline Franela & Negro & Tanguis & $270 \mathrm{gr} / \mathrm{mt} 2$ & $6 \mathrm{kgs}$ & US\$21.00/kg \\
\hline Franela & Marron & Nativo & $270 \mathrm{gr} / \mathrm{mt} 2$ & $21 \mathrm{kgs}$ & US\$24.50/kg \\
\hline Franela & Heather Gris Oscuro & Pima & $270 \mathrm{gr} / \mathrm{mt} 2$ & $58 \mathrm{~kg}$ & US\$ $34.60 / \mathrm{kg}$ \\
\hline Franela & Naranja Estampada & Tanguis & $270 \mathrm{gr} / \mathrm{mt} 2$ & $79 \mathrm{kgs}$ & US\$15.00/kg \\
\hline Franela & Verde Estampada & Tanguis & $270 \mathrm{gr} / \mathrm{mt} 2$ & $108 \mathrm{kgs}$ & US\$15.00/kg \\
\hline Art 2176 & Natural & Tanguis & $200 \mathrm{gr} / \mathrm{mt} 2$ & $241 \mathrm{mts}$ & US\$6.00/mt \\
\hline Art 2236 & Natural & Tanguis & $125 \mathrm{gr} / \mathrm{mt} 2$ & $820 \mathrm{mts}$ & US\$3.70/mt \\
\hline Art 2176 & Negro & Tanguis & $200 \mathrm{gr} / \mathrm{mt} 2$ & $60 \mathrm{mts}$ & US\$8.00/mt \\
\hline Oxford & Celeste & Pima & & $4 \mathrm{mts}$ & US\$8.00/mt \\
\hline Oxford & Blanco & Pima & & $4 \mathrm{mts}$ & US\$8.00/mt \\
\hline
\end{tabular}




\section{ANEXO N ${ }^{\circ}$ 2: CLASE MEDIA Y ALTA EN}

\section{COLOMBIA}

\section{¿Qué tan grande es la clase media en Colombia?}

Con la misma metodologia usada por el Banco Mundial, un estudio realizado por Angulo, Gaviria y Morales (2012) $)^{9}$ para la Misión de Equidad y Movilidad Social del DNP, encuentran que la clase media en Colombia ha ido en aumento en la última década pasando de un $16.3 \%$ en 2002 a $26.5 \%$ en 2011. Por su parte, la pobreza disminuyó de un $49.9 \%$ en el 2002 a un $34.4 \%$ en 2011. Es bueno también observar que la población Vulnerable, también definida como clase media emergente, pasó de representar un $32.2 \%$ a un $36.8 \%$ entre iguales periodos.

\section{En Colombia la pobreza disminuye y la clase media}

\section{aumenta.}

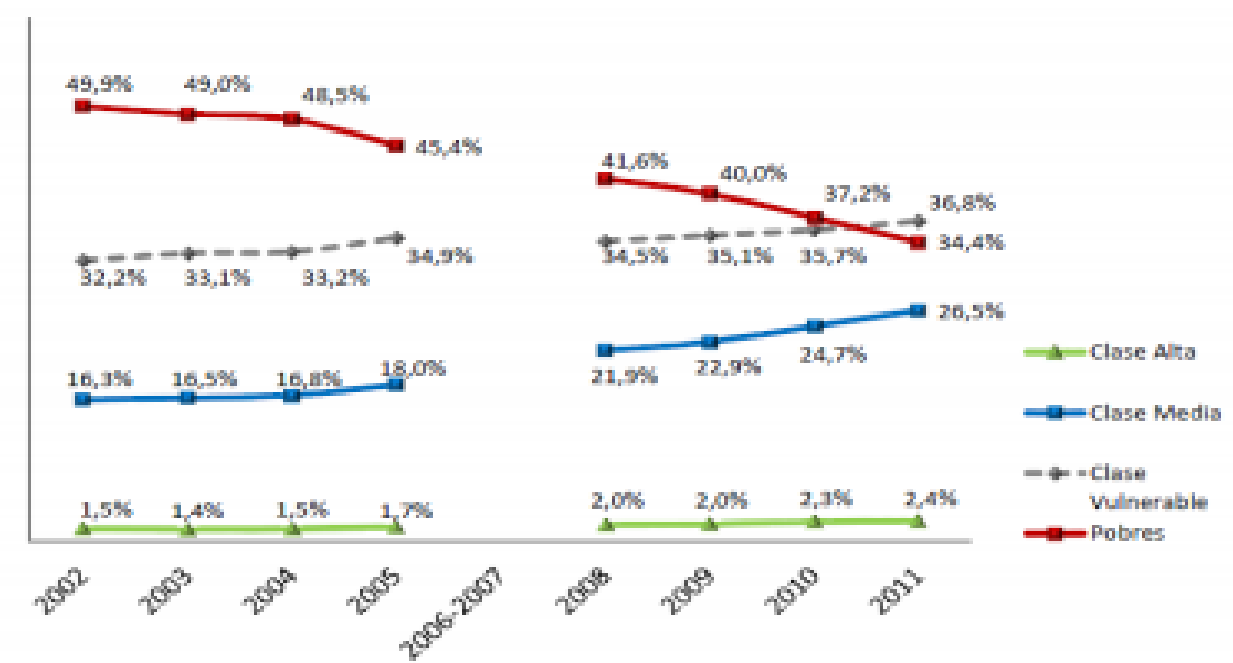

Fuente: Clase media en Colombia. Más allá del umbral de la pobreza, Informe de la Misión de Equidad y Movilidad Social del DNP. 2012.

Con respecto a la pobreza, es importante anotar que una cosa es la medición que se hace con la metodología del Banco Mundial y la otra la tasa de pobreza que calcula anualmente el DANE. Sin bien, ambas series presentan la misma tendencia para Colombia y las diferencias son pequeñas, la metodología Banco Mundial trabaja con el umbral de ingresos per cápita inferiores a los US\$4 diarios PPA. Para el DANE por su parte, el umbral de pobreza es el costo per cápita mínimo necesario para adquirir una canasta de bienes (alimentario y no alimentarios) que permiten un nivel de vida adecuado en un pais determinado.

\footnotetext{
${ }^{9}$ Angulo, Gaviria, Morales. 2012. Clase media en Colombia, Más allá del umbral de la pobreza. Informe de la Misión de Equidad y Movilidad Social. DNP.
} 


\section{ANEXO N³: DESARROLLO DE MATRICES}

En el presente anexo se detallará a fondo los tipos de matrices y cómo funcionan:

\subsection{Matriz Interna y Externa ( IE)}

Esta matriz, tiene 9 estrategias planteadas con números romanos. Los números I, II y IV hacen referencia a que la estrategia a utilizar deberá de ser Intensiva o de integración, a estos cuadrantes se les conoce como "Crecer y construir". Los cuadrantes que tienen número III, V y VII hacen referencia a la estrategia de Penetración de mercados y Desarrollo de productos, conocidos como "Retener y mantener". La estrategia Defensiva es llamada para esta matriz "Cosechar o desinvertir", las cuales hacen referencia a los cuadrantes VI, VIII y IX.

Esta matriz se realiza de acuerdo a las Matrices EFE (mostrado en el capítulo 4 - Cuadro $\mathrm{N}^{\circ} 29$ ) y a la Matriz EFI (mostrado en el capítulo 13- Cuadro $\mathrm{N}^{\circ}$ 87). La puntuación horizontal de esta matriz va de 1 a 4. Donde de 1 a 1.99 significa Débil y se ubica en el lado derecho; la puntuación de 2 a 2.99 significa Promedio y va ubicada en el medio. Por último, la puntuación obtenida en la matriz EFI de 3 a 4 significa que tienen un promedio fuerte, los cuales van pegadas al eje izquierdo.

Con respecto a la puntuación del eje vertical, son las puntuaciones obtenidas de la matriz EFE, las cuales en la parte de abajo son de 1 a 1.99, en la parte media de 2 a 2.99 y de 3 a 1 en la parte alta. Su significado es que los totales ponderados de esta matriz van de bajo hacia alto.

\subsection{Matriz de la Gran Estrategia ( GE)}

Esta matriz se da para que pueda existir más de una estrategia a escoger por la empresa. Las variantes son 4. La variante superior se da para un rápido crecimiento del mercado, estas pueden ser tanto el cuadrante I como el II. La variante de los cuadrantes inferiores (el III y el IV) se dan por un lento crecimiento del mercado. La parte derecha de esta matriz se da por una posición competitiva fuerte, la cual 
corresponde a la posición I o VI. Por último los cuadrantes de la parte izquierda se dan cuando la empresa tiene una posición competitiva débil.

Cada cuadrante tiene diversas estrategias a escoger, como lo son Desarrollos de mercado, Penetración en el mercado, desarrollo de productos, integración hacia adelante, atrás, horizontal, concéntrica, entre otros.

\subsection{Matriz de Igor:}

Esta matriz, se divide en cuatro cuadrantes. Los dos cuadrantes horizontales se refieren a si los productos son actuales, es decir ya existen en el mercado (parte izquierda) y los productos que son nuevos (ubicados en la parte derecha). Los cuadrantes del eje vertical se refieren al mercado. Si el mercado es el elegido será posicionado como Actual (parte superior) y si se va un mercado nuevo va en la parte inferior.

El cruce de estos cuadrantes genera que se escoja una estrategia específica como penetración de mercado, desarrollo de productos o mercados y diversificación. Todo esto se da con el objetivo para que la empresa pueda conocer en dónde puede ubicarse la empresa (mercado) y las mejoras que pudiera tener el producto.

\subsection{Matriz de Decisión:}

Esta última matriz, engloba todas las mencionadas anteriormente. Se realiza un pequeño análisis del resultado de cada una de la matriz con su estrategia escogida. En el eje vertical se pondrá el nombre de las matrices y en el eje horizontal las estrategias que se escogieron.

Las estrategias que se mencionan de tres a más veces en diferentes matrices se deben de tomar. En este caso la matriz de penetración se menciona 4 veces. Por ende, esta estrategia será la principal para que la empresa pueda surgir. 
ANEXO N ${ }^{\circ}$ : TIPO DE CAMBIO

\begin{tabular}{|c|c|c|c|}
\hline PAIS & MONEDA & $\begin{array}{l}\text { TIPO DE } \\
\text { CAMBIO } \\
\text { (En S/.) }\end{array}$ & $\begin{array}{l}\text { TIPO DE } \\
\text { CAMBIO } \\
\text { ( En US\$) }\end{array}$ \\
\hline Colombia & Peso Colombiano & 0.001425 & 0.000489 \\
\hline
\end{tabular}

Según la feria de Colombiatex, el costo de esta es de 200,000 pesos Colombianos. A continuación se realizará la conversión de pesos colombianos a US\$ y $\mathrm{S} /$.

\section{De Pesos Colombianos a Nuevos Soles:}

Tipo de Cambio

$\mathrm{US} \$ / \mathrm{COP}=0,0014300$

Resultado:

$200,000 \mathrm{COP}=286 \mathrm{PEN}$

\section{De Pesos Colombianos a US\$:}

Tipo de Cambio

$\mathrm{US} \$ / \mathrm{COP}=0,00049000$

Resultado:

$200,000 \mathrm{COP}=\mathrm{US} \$ 98$

Con respecto al TC para poder realizar la parte financiera, se tomaron datos promedios por parte de MEF, BCR y SUNAT:

\begin{tabular}{ll}
\hline Año & TC \\
\hline 2015 & 3.189 \\
2016 & 3.63 \\
2017 & 3.524 \\
2018 & 3.429 \\
2019 & 3.38 \\
\hline
\end{tabular}




\section{ANEXO N 5: CORREOS}

\subsection{Tintes aprobados por GOTS}

\section{Andrea Gabriela Ovalle Velazco (HAY-LIM)}

Para:

andrea Ovalle

Asunto:

RE: cotizaciones

FYI

-----Mensaje original-----

De: andrea Ovalle [mailto:andy_0156@hotmail.com] Enviado el: viernes, 27 de mayo de 2016 12:05 p.m.

Para: roselyne.thibault@bergmanrivera.com

Asunto: RE: cotizaciones

Muchas gracias por el apoyo.

> From: roselyne.thibault@bergmanrivera.com

> To: andy_0156@hotmail.com

$>$ Subject: RE: cotizaciones

> Date: Fri, 27 May 2016 11:50:59 -0500

> Buenos días Andrea,

$>$ Los tintes que utilizamos son tintes químicos de bajo impacto

$>$ aprobados por las normas GOTS.

> Saludos,

$>$ Roselyne Thibault

$>$ Asistente Comercial

$>$ Tel. (511) 242-3021

$>$ RPC. (511) 9810-86078

$>$ www.bergmanrivera.com

$>$

-----Mensaje original-----

> De: andrea Ovalle [mailto:andy_0156@hotmail.com] Enviado el: jueves,

$>26$ de mayo de 2016 05:16 p.m.

> Para: Roselyne Thibault <roselyne.thibault@bergmanrivera.com>

$>$ Asunto: RE: cotizaciones

$>$ Estimada Roselyne,

$>$ Gracias por la cotización,

$>$ En cuestión de los colores de las telas quería saber si utilizan

$>$ tintes químicos $\mathrm{o}$ animales y plantas o son tintes aprobados por GOTS

$>$ Esto es debido que al exportar hacia el mercado de Colombia se debe

> saber su composición para ver si existe algún requerimiento para

$>$ certificar el contenido de sustancias peligrosas como es el contenido

$>$ de plomo en los tintes y colorantes

$>$

> slds,

$>$ Andrea Ovalle

> From: roselyne.thibault@bergmanrivera.com

> To: andy_0156@hotmail.com; mariela.calderon@bergmanrivera.com 
> Subject: RE: cotizaciones

> Date: Wed, 25 May 2016 17:30:52 -0500

> Buenas tardes Andrea,

> Te enviamos en adjunto listas de precios de nuestras telas. Estos

> precios aplican a pedidos de 120 kgs o más. El tiempo de entrega es

$\gg$ de

> 60 días después de recibido el $50 \%$ de adelanto y aprobados los lab

$>$ dips

$>$ (10-15dias).

> También te enviamos en adjunto la lista de las telas que tenemos en

> stock y nuestros colores. El pedido mínimo de tela de punto es de

> 2 kgs por tela y por color. Para tela plana el pedido mínimo es de

> $15 \mathrm{mts}$. El pago de la telas de stock se hace al contado.

> Los precios no incluyen IGV.

$>$ Saludos,

> Roselyne Thibault

> Asistente Comercial

> Tel. (511) 242-3021

> RPC. (511) 9810-86078

> www.bergmanrivera.com

----Mensaje original-----

> De: andrea Ovalle [mailto:andy_0156@hotmail.com] Enviado el:

> miércoles, 25 de mayo de 2016 12:27 p.m.

> Para: Mariela Calderon Ariz <mariela.calderon@bergmanrivera.com>

> CC: roselyne.thibault@bergmanrivera.com

> Asunto: RE: cotizaciones

> Estimada,

> De acuerdo a lo conversado vía telefónica, Por favor antes de mandar

> a realizar una cotización para la compra de Telas. Me han pedido

> realizar un pequeño estudio hacia ustedes, los cuales serían el

> proveedor principal de mi obtención de telas. Necesitaría saber

> cuales son los requerimientos y mínimos de compra que se realizarían.

> Slds,

> Andrea Ovalle Velazco

>> <mariela.calderon@bergmanrivera.com<mailto:mariela.calderon@bergmanri

$>$ vera.com $>$

$<$ mailto:mariela.calderon@bergmanrivera.co<mailto:mariela.calderon@bergmanriver.com>

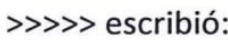

$\gg \gg \gg$

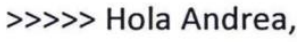

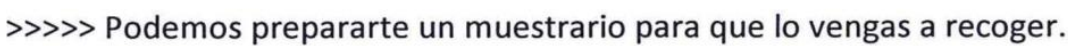

$\gg \gg>$ Gloria quien esta en copia de este correo te puede confirmar

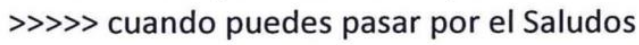

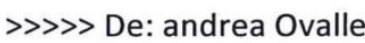

>> [mailto:andy_0156@hotmail.com<mailto:andy_0156@hotmail.com>] 


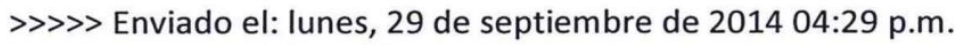

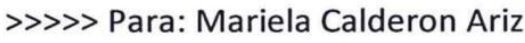

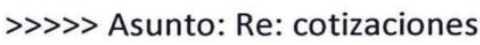

\> > Deseo adquirir sólo muestras para ir al mercado colombiano y que

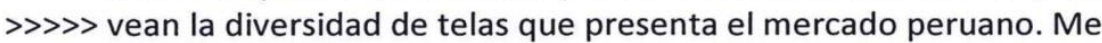

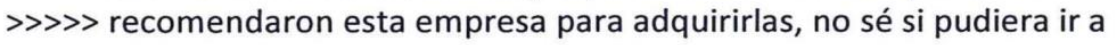

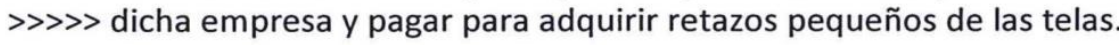
$\gg \gg \gg$ Espero una pronta respuesta

$\gg \gg>$ Andrea Ovalle

$\gg \gg>$ Enviado desde mi iPhone

$\gg \gg \gg$

〉> > El 29/09/2014, a las 03:58 p.m., "Mariela Calderon Ariz"

>> <mariela.calderon@bergmanrivera.com<mailto:mariela.calderon@bergmanri

$>$ vera.com>

$<$ mailto:mariela.calderon@bergmanrivera.co<mailto:mariela.calderon@bergmanriver.com> 〉>> escribió:

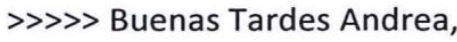

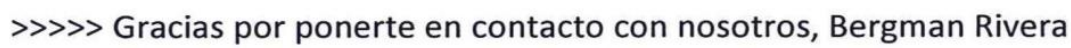

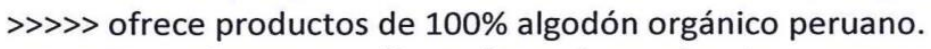

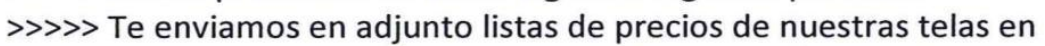

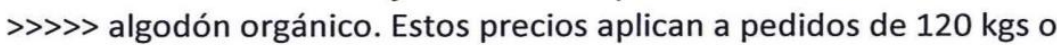

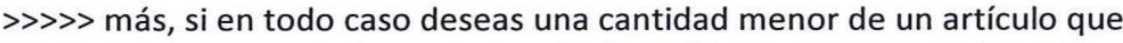

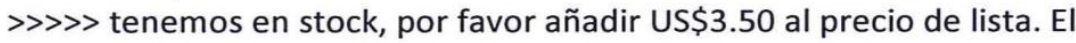

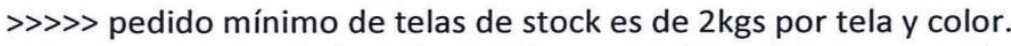

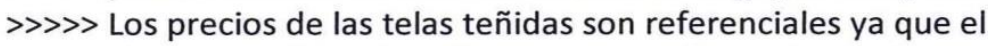

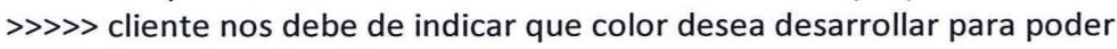

$\gg \gg>$ hacer la cotización.

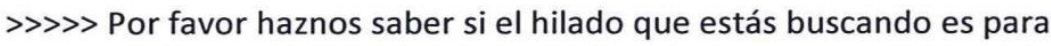

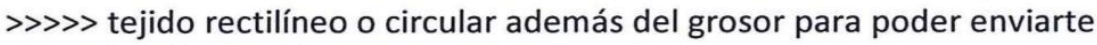

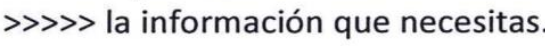

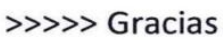

$\gg \gg>$ Saludos

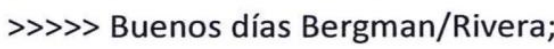

$\gg \gg \gg$

$\gg \gg \gg$ Soy una exportadora de prendas de vestir de bebé ( De Perú a Colombia).

$\gg \gg \gg$

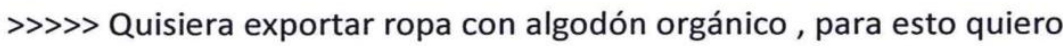

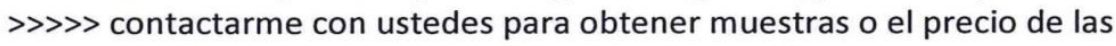

$\gg \gg \gg$ telas de punto y del hilo para poder comprarlo.

$\gg \gg \gg$

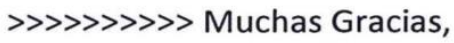

$\gg \gg \gg$

$\gg \gg>$ atte.

$\gg \gg \gg \gg \gg \gg>$ Andrea Ovalle

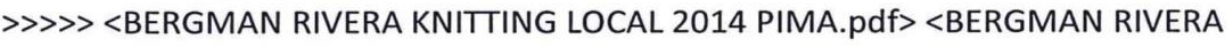

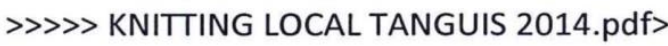




\subsection{Cotización de certificación GOTS}

\section{CONTROL UNION PERU SAC}

Av. RIVERA NAVARRETE 762 PISO 15 - SAN ISIDRO

LIMA - PERU

TELEFONOS 51-(01)-7190400-7190123

FAX 51-(01)-421-7573

EMAIL comercial.peru@controlunion.com

EC-000-2016

\begin{tabular}{|c|c|c|}
\hline CLIENTE & \multicolumn{2}{|l|}{ TECO CARICIAS S.A.C. } \\
\hline \multicolumn{3}{|l|}{ CODIGO } \\
\hline DIRECCION & \multicolumn{2}{|l|}{ ESTEBAN BENTARELLO 121 - SAN BORJA } \\
\hline PAIS & \multicolumn{2}{|l|}{ PERU } \\
\hline \multicolumn{3}{|l|}{ RUC } \\
\hline \multicolumn{3}{|c|}{$\begin{array}{l}\text { ESTADO DE COBRANZA } \\
\text { FACTURACION } 2016\end{array}$} \\
\hline & & US\$ \\
\hline \multicolumn{2}{|c|}{ INSPECCION Y CERTIFICACION GOTS 2016} & $1,450.00$ \\
\hline FEE GOTS & & 180.00 \\
\hline & & \\
\hline COURIER & & 5.00 \\
\hline $\begin{array}{l}\text { SUB - TOTAL } \\
\text { IGV }\end{array}$ & & $\begin{array}{r}1,635.00 \\
294.30\end{array}$ \\
\hline $\begin{array}{l}\text { IGV } \\
\text { TOTAL }\end{array}$ & & $\begin{array}{r}294.30 \\
1,929.30\end{array}$ \\
\hline
\end{tabular}

POR FAVOR, PARA HACER EFECTIVO EL PAGO ADJUNTAR VOUCHER O NÚMERO DE OPERACIÓN A:

facturacion.peru@controlunion.com Y comercial.peru@controlunion.com

Puede efectuar su pago en cualquiera de nuestras dos cuentas (Control Unión Perú SAC):

CONTROL UNION PERU SAC

BANK ACCOUNT US\$ : 7000014784

SOLES : 7000095059

SWIFT CODE : BIFSPEPL

BANK : BANCO INTERAMERICANO DE FINANZAS

ADDRESS : AV. Rivera Navarrete 600, Lima 27, PERU

CONTROL UNION PERU SAC

BANK ACCOUNT US\$ : 193 - $1733437-1-73$

SOLES : $193-1704576-0-38$

SWIFT CODE : BCPL-PEPL

BANK : BANCO DE CREDITO DEL PERU

ADDRESS : Jr. Lampa 499 ; Lima 01 - Peru 
From: "Oscar Mestanza Mesta"

To: "andrea Ovalle"

CC: "Yemil Zarzar"

Date: viernes, 27 de mayo de 2016 06:02:53 p.m.

Subject: Control Union Peru SAC: CERTIFICACION GOTS

Srta. Andrea

Es correcto, el precio se mantiene cada año, salvo que su proyecto agregue unidades o tenga cambios.

Saludos cordiales.

Oscar Antonio Mestanza Mesta - Asistente Comercial

$\mathrm{T}+5117190400$ • M +51 989275040 • Skype omesta94

Control Union Perú SAC - Inspecciones y Certificaciones

OFICINA Av. Petit Thouars No. 4653 Piso 6 - Miraflores • Lima

- Perú

WWW. cuperu.com

WWW. controlunion. com

----Mensaje original--.--

De: andrea Ovalle [mailto:andy_0156@hotmail.com]

Enviado el: viernes, 27 de mayo de 2016 05:52 p.m.

Para: Oscar Mestanza Mesta

Asunto: Re: Control Union Peru SAC: CERTIFICACION GOTS

Estimado,

El pago es de Aprox 1900 anual y cuando es renovación el valor es el mismo?

Slds

Enviado desde mi iPhone

El 27 may. 2016, a las 5:32 p.m., Oscar Mestanza Mesta escribió:

Estimada Srta. Andrea

Debe pasarse una auditoría por año, es decir,

la certificación es anual.

$>$

$>$ A la espera de sus comentarios.

$>$ Saludos cordiales.

Oscar Antonio Mestanza Mesta . Asistente Comercial

$\mathrm{T}+5117190400$. M +51 989275040 . Skype omesta94

$>$ Control Union Perú SAC . Inspecciones y Certificaciones

OFICINA Av. Petit Thouars No. 4653 Piso 6 - Miraflores . Lima

Perú

WWW.cuperu.com

WWW.controlunion.com 


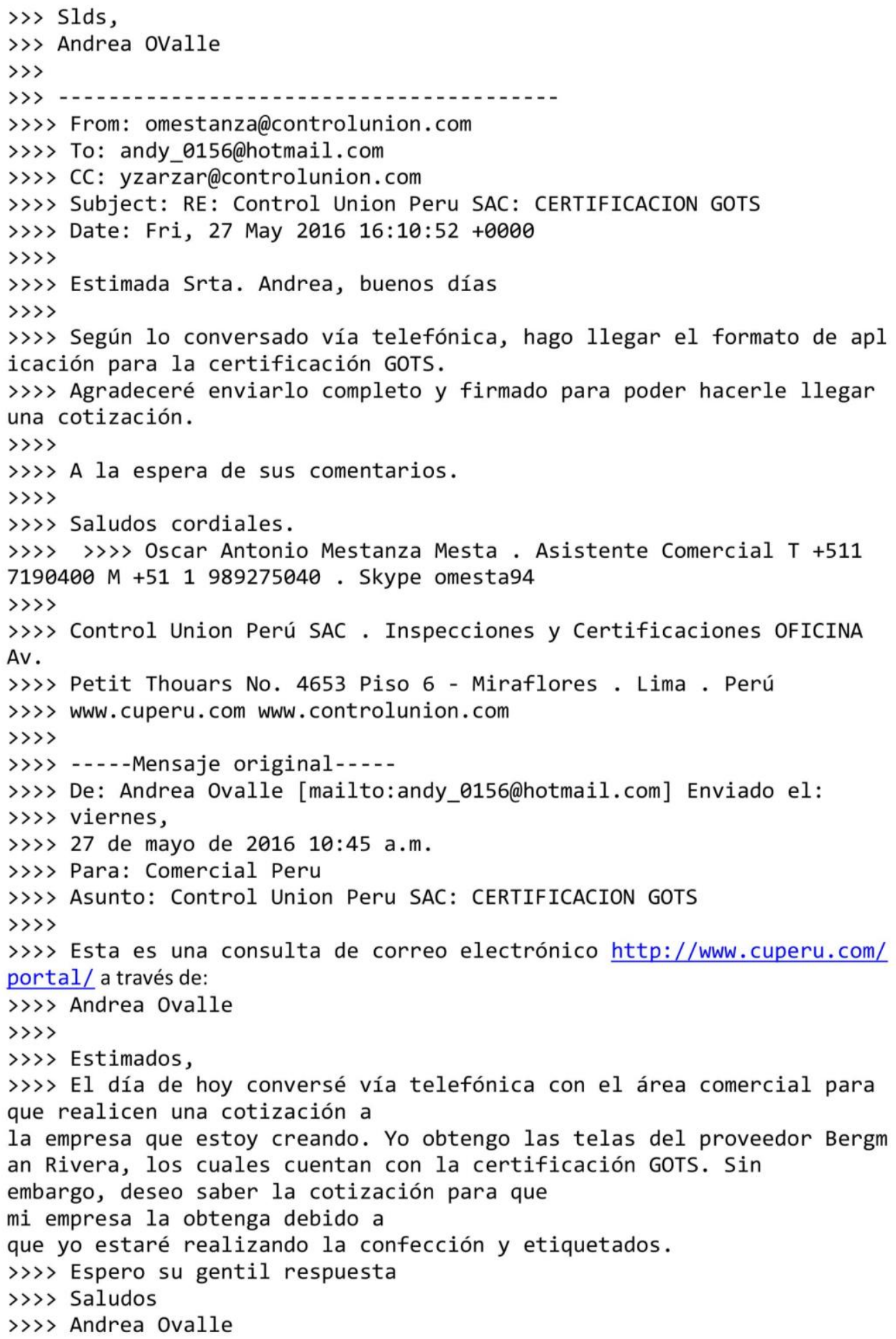

\> Envio lo requerido.

〉> Deseaba hacerle hincapié que la empresa aún está en proceso de 〉> creación por ende no figura. Sin embargo, deseo ir cotizando o tener 〉> un aproximado de cuánto saldría con ustedes dicha certificación $\gg>$ 


\subsection{Proveedor de Envases}

\section{Andrea Gabriela Ovalle Velazco (HAY-LIM)}

Fy

De: Andrea Gabriela Ovalle Velazco (HAY-LIM)

Enviado el: lunes, 30 de mayo de 2016 09:14 a.m.

Para: 'cover@gzcover.com'; 'bag@gzcover.com'

CC: andy 0156@hotmail.com

Asunto: cotice you products

\section{Dear Mr. Liu}

PLease tell me know if your bags have GOTS certification or any certifications that certifies that your company help to the enviroment like your page tell us

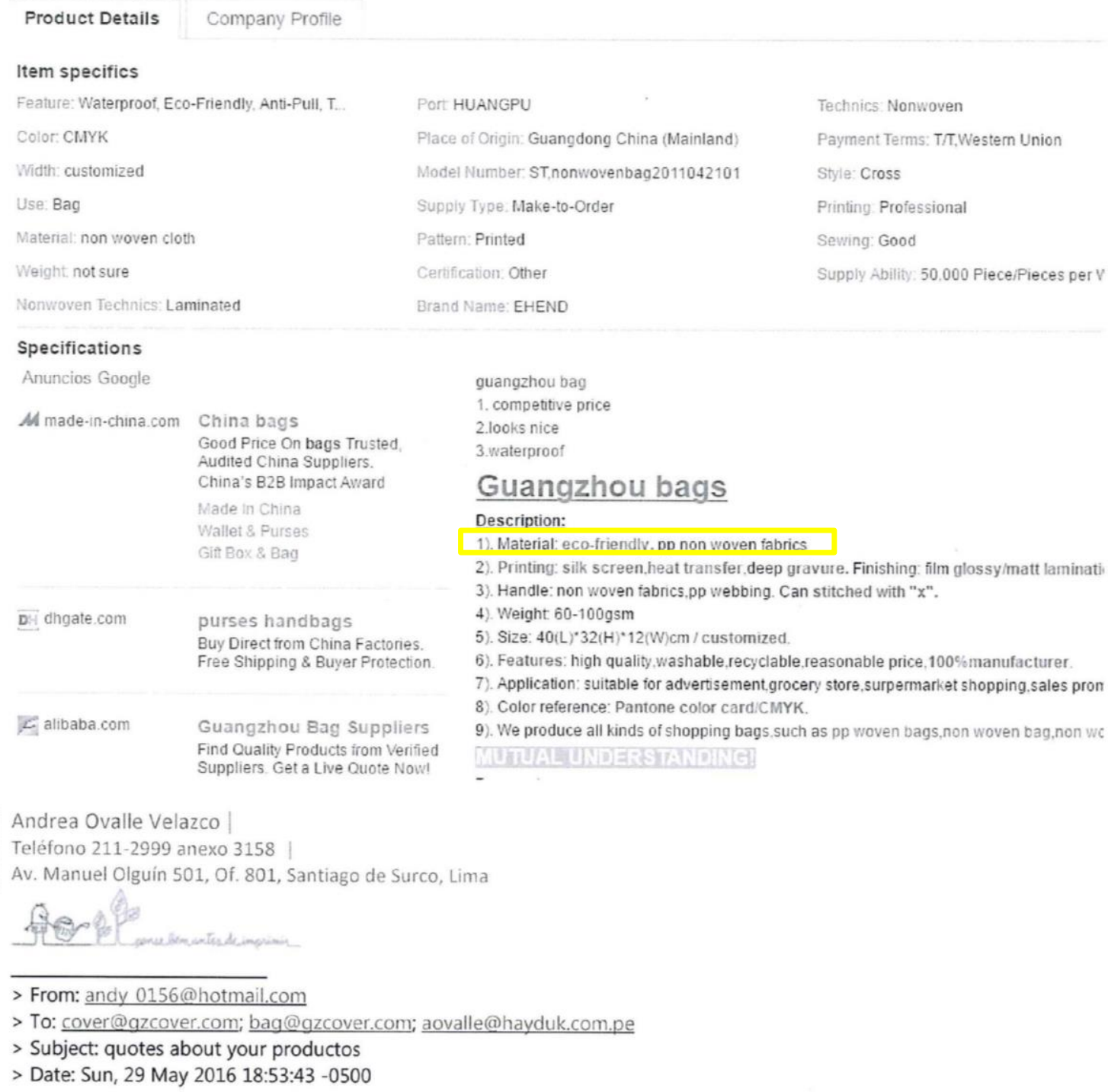

Port HUANGPU

Place of Origin: Guangdong China (Mainland)

Model Number ST nonwovenbag2011042101

Supply Type. Make-to-Order

Pattern: Printed

Certification: Other

Brand Name: EHEND

guangzhou bag

1. competitive price

$2.100 \mathrm{ks}$ nice

3.waterproof

\section{Guangzhou bags}

Description:

Wade in China

Wallet \& Purses

Gitt Box \& Bag

D. dhgate.com purses handbags

Buy Direct from China Factories.

Buy Direct trom China Factories.

1). Material: eco-friendlv. DD non woven fabrics

2). Printing: silk screen.heat transfer deep gravure. Finishing: film glossy/matt laminat

3). Handle: non woven fabrics.pp webbing. Can stitched with " $x$ ".

4). Weight $60-100 \mathrm{gsm}$

5). Size: $40(\mathrm{~L}) * 32(\mathrm{H}) * 12(\mathrm{~W}) \mathrm{cm} /$ customized

6). Features: high quality, washable,recyclable,reasonable price, $100 \%$ manufacturer

7). Application: suitable for advertisement,grocery store,surpermarket shopping, sales pron 8. Color reference: Pantone color card.CMYK.

F alibaba.com Guangzhou Bag Suppliers Find Quality Products from Verified Suppliers. Get a Live Quote Now!

Technics Nonwoven

Payment Terms: TrT,Western Union

Style: Cross

Printing Professional

Sewing: Good

Supply Ability: 50.000 Piece/Pieces per V

9). We produce all kinds of shopping bags,such as pp woven bags,non woven bag,non we

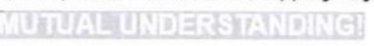

Andrea Ovalle Velazco

Teléfono 211-2999 anexo 3158 |

Av. Manuel Olguín 501, Of. 801, Santiago de Surco, Lima

> From: andy 0156@hotmail.com

> To: cover@gzcover.com; bag@gzcover.com; aovalle@hayduk.com.pe

> Subject: quotes about your productos

> Date: Sun, 29 May 2016 18:53:43 -0500 
$>$ Dr. Mr Liu

$>$ I am an exporter of organic clothes in Perú. By Alibaba page I

$>$ contacted your company for the listing of this type of packaging. He

$>$ wanted to know whether all the products you have are recycled, ie has

$>$ no toxic which could damage my clothes .

$>$ Thank you

$>$ best regards

$>$ Andrea Ovalle

Andrea Ovalle Velazco |

Teléfono 211-2999 anexo 3158

Av. Manuel Olguín 501, Of. 801, Santiago de Surco, Lima

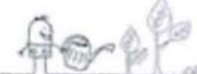

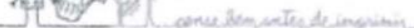

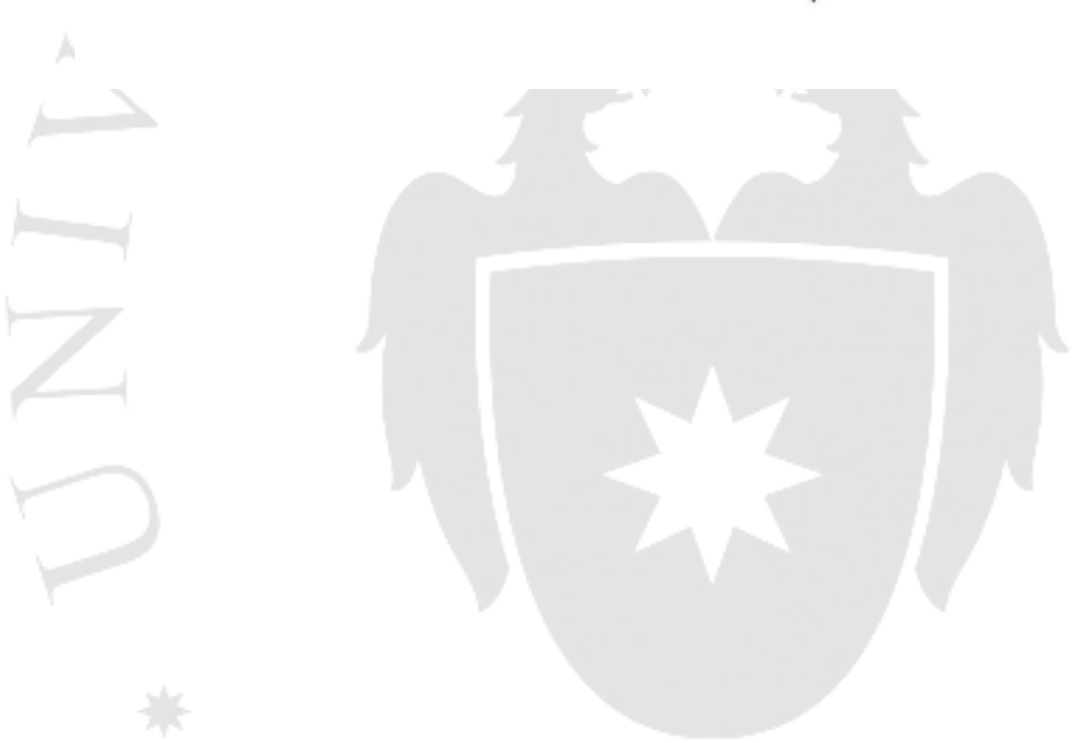




\subsection{Proveedor de Embalaje}

\section{Global Companies}

Welcome Guest, Join Free / Sign In

www.companiess.com

\section{Shenzhen Zhongtaijia Trading Co., Ltd.}

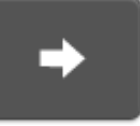

\section{Company Description}

Shenzhen Zhongtaijia Trading Co., Ltd. is a professional manufacturer and exporter that is concerned with the design, development and production of printing products. Shenzhen Zhongtaijia Trading Co., Ltd. located in Shenzhen, with convenient transportation access. All of our products comply with international quality standards and are greatly appreciated in a variety of markets around the world.

We are currently exporting $80 \%$ of our products worldwide. Our well-equipped facilities and excellent quality control throughout all stages of production enable us to guarantee total customer satisfaction.

If you are interested in any of our products or would like to discuss a custom order, please feel free to contact us. We are looking forward to forming successful business relationships with new clients around the world in the near future.

\section{Company Information}

Contact Person:Ms. Tina Zou

Job Title:Sales Manager

Mobile Phone:13510100045

Zip: 518112

City:Shenzhen

\author{
Department:Sales \\ Telephone:86-0755-89511557 \\ Fax:86-0755-28754815 \\ Province/State:Guangdong
}

Operational Address:Floor 3, Building A, Gaoxin

\section{Product}

- small cosmetic box Eco Friendly Stayflat Utility Mailers

- CMYK printed mailer Kraftboard Mailers No Bend Mailers - White Self Seal No Bend Booklet Mailers

- White Self Seal No Bend Catalog Mailers - chipboard mailer kraft mailer for Screen protection film

- Tough rigid envelopes mailing envelopes

- Shipping utility envelope, paper Courier envelopes

- High quality best selling utility envelopes - recyclable colorful utility envelope best price hot selling

- recyclable colorful paper utility envelope best price hot selling 
$\begin{array}{ll}\text { Para: } & \text { andrea Ovalle } \\ \text { Asunto: } & \text { RE: cotice your products }\end{array}$

FYI

> From: andv0156@hotmail.com

$>$ To: $\underline{\text { sales1@zti-cn.com }}$

$>$ Subject: RE: cotice your products

> Date: Mon, 30 May 2016 09:05:40 -0500

$>$

$>$ Mr Jayson,

$>$ Thanks for your answer. I need to know if you have cardboard boxes for put my organic clothes to export to Colombia.

$>$ Please tell me know if your materials have any chemicals because we are in the process of acquiring GOTS certification.

$>$

$>$ Best regards,

$>$

$>$ Adrea Ovalle

$>$

> Date: Mon, 30 May 2016 09:18:07 +0800

> From: sales1@zti-cn.com

> To: andy0156@hotmail.com

> Subject: Re: cotice your products

$>>$

$\gg$ Hi Andrea,

$>$

$\gg$ Thanks fo your inquiry,

$\gg$

$\gg$ But sorry, I can't see what list of the packaging you need?

$\gg$ All the products the we have in our company are recycling with high

$\gg$ quality standards Thanks, Jayson

$\gg$ Sales Manager | SZZTJ

$>$

> From: andrea Ovalle<mailto:andy 0156@hotmail.com>

> Date: 2016-05-30 08:00

> To: allen@zti-cn.com<mailto:allen@zti-cn.com>

> Subject: cotice your products

$\gg$ Dr. Mr Jayson Wong

$>>$

$\gg$ I am an exporter of organic clothes in Perú. By Alibaba page I

$\gg$ contacted your company for the listing of this type of packaging. He

$\gg$ wanted to know whether all the products you have are recycled, or

> has no toxic which could damage my clothes, because $\mathrm{i}$ am going to

$\gg$ take GOTS certification.

$>$

$\gg$ Thank you

> best regards

$>>$

> Andrea Ovalle 


\section{ANEXO N6: REGLAMENTO DE CONFECCIONES}
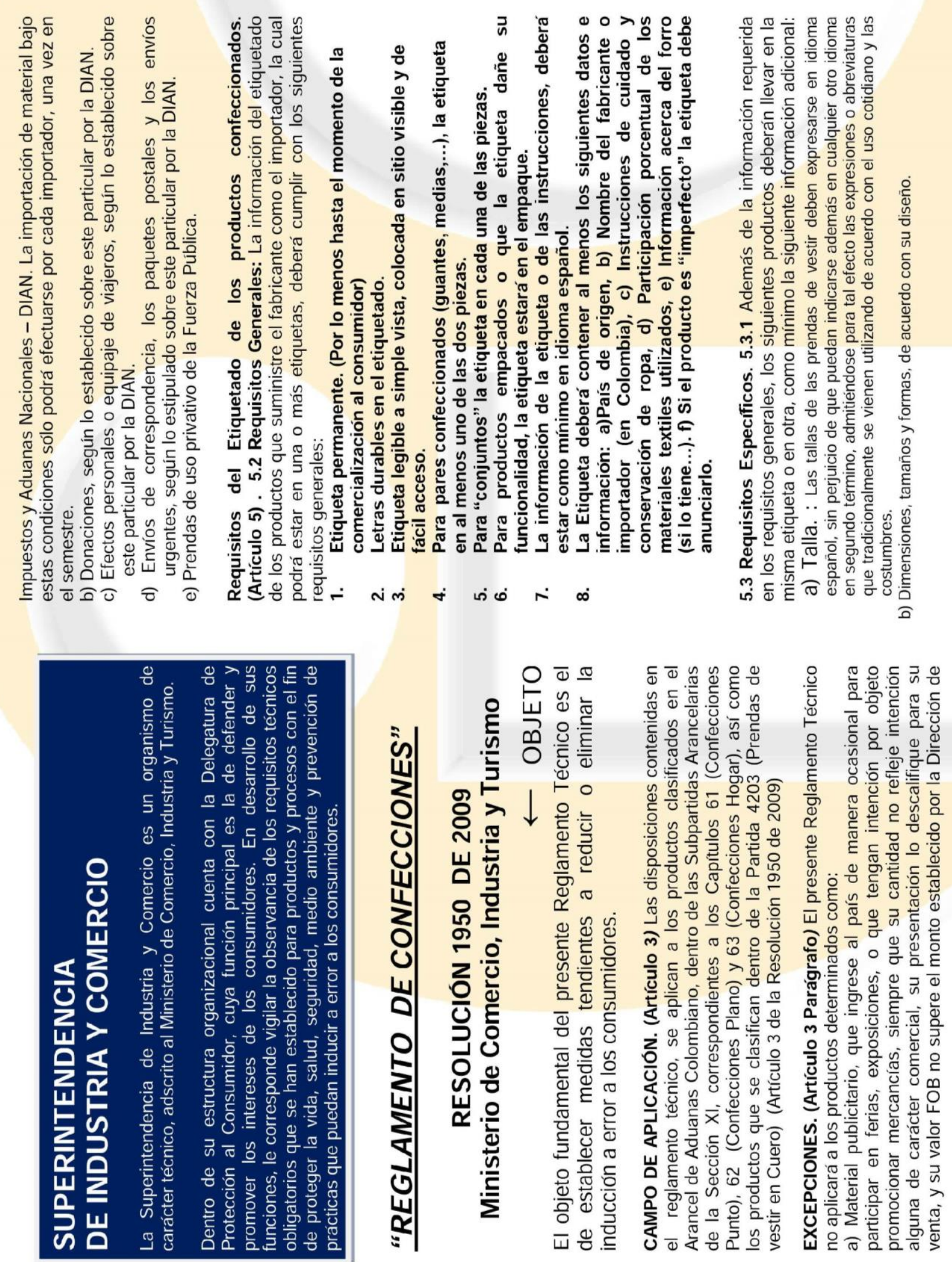

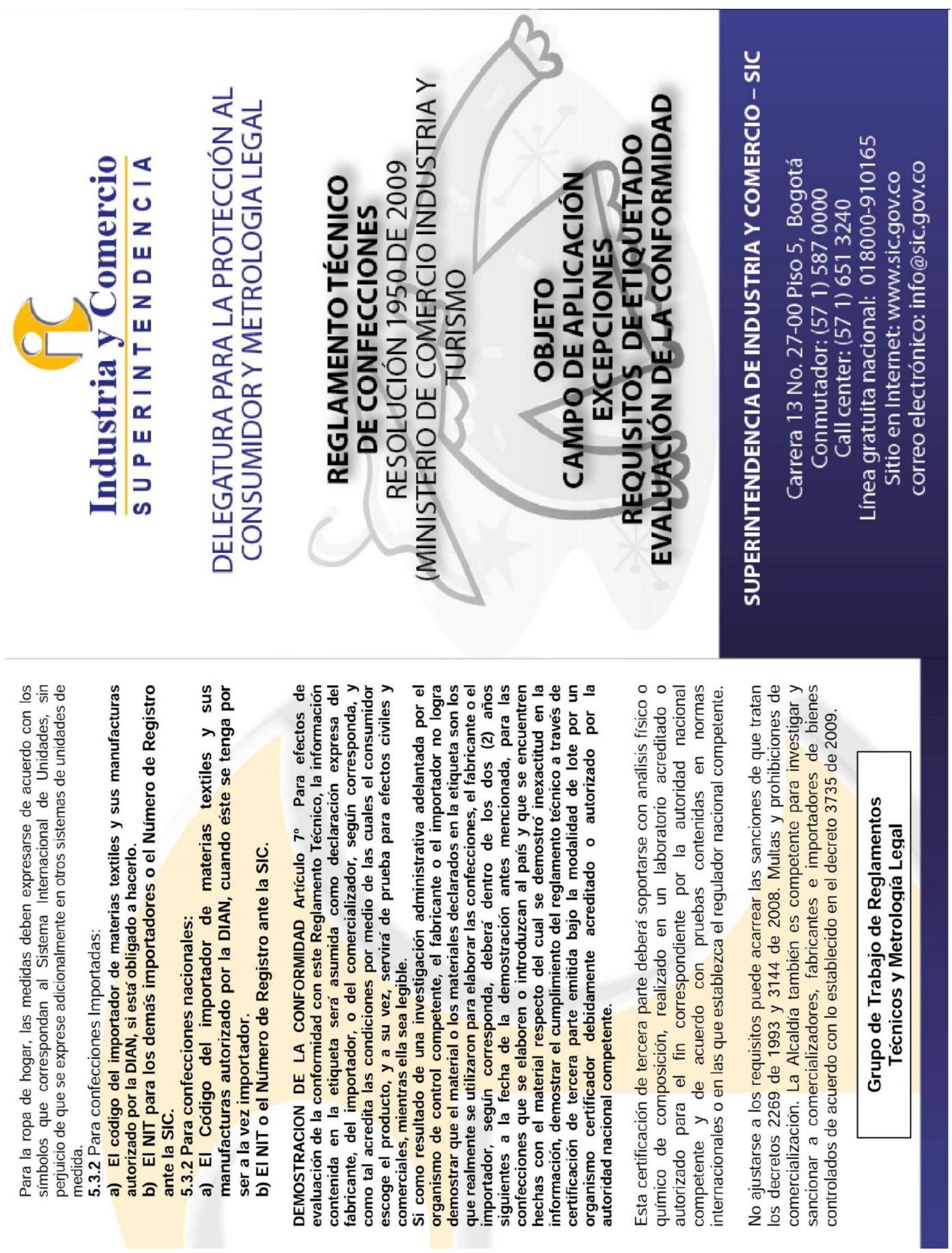